\title{
1st Amazon
}

STEM ACADEM

CONFERENCE

\section{1}

Tecnologia, Inovação e Sustentabilidade na Educação em Engenharia

\section{ORGANIZADORES}

Jucimar Maia da Silva

Francis Wagner Silva Correia

Maria Olívia de Albuquerque Ribeiro Simão

Adan Sady de Medeiros Silva

José Renato Sátiro Santiago Júnior

Kelly Christiane Silva de Souza

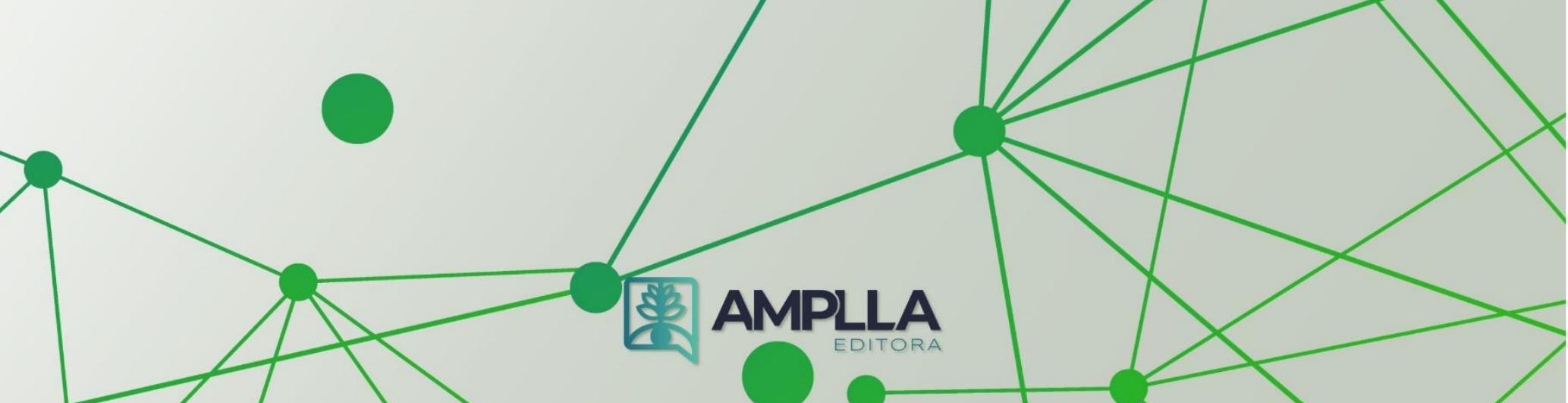


1st Amazon

STEM ACADEMY

CONFERENCE

ASAC21

ORGANIZAÇÃO

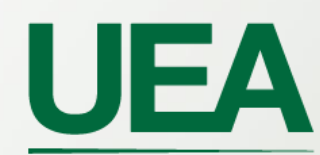

UNIVERSIDADE

DO ESTADO DO

ACADEMIA

AMAZONAS

stem

PRODUÇÃO

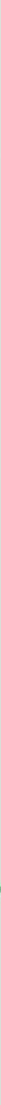




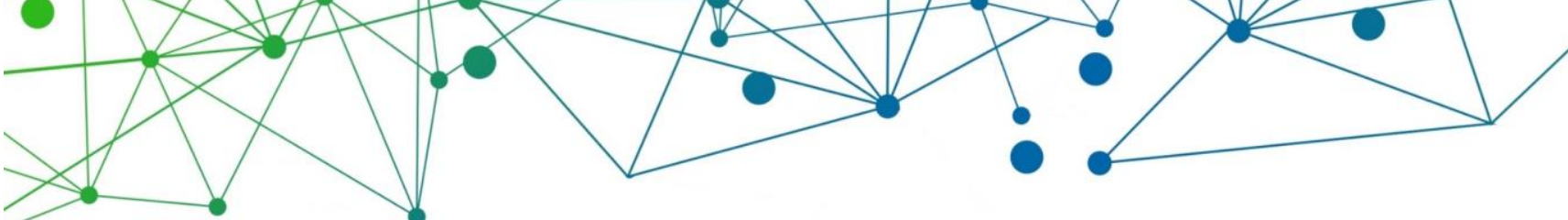

\section{CONSELHO EDITORIAL - EDITORA AMPLLA}

Andréa Cátia Leal Badaró - Universidade Tecnológica Federal do Paraná Andréia Monique Lermen - Universidade Federal do Rio Grande do Sul Antoniele Silvana de Melo Souza - Universidade Estadual do Ceará Bergson Rodrigo Siqueira de Melo - Universidade Estadual do Ceará Bruna Beatriz da Rocha - Instituto Federal do Sudeste de Minas Gerais Caio César Costa Santos - Universidade Federal de Sergipe Carina Alexandra Rondini - Universidade Estadual Paulista Carla Caroline Alves Carvalho - Universidade Federal de Campina Grande Carlos Augusto Trojaner - Prefeitura de Venâncio Aires Carolina Carbonell Demori - Universidade Federal de Pelotas Cícero Batista do Nascimento Filho - Universidade Federal do Ceará Clécio Danilo Dias da Silva - Universidade Federal do Rio Grande do Norte Daniela de Freitas Lima - Universidade Federal de Campina Grande Denise Barguil Nepomuceno - Universidade Federal de Minas Gerais Dylan Ávila Alves - Instituto Federal Goiano Edson Lourenço da Silva - Instituto Federal de Educação, Ciência e Tecnologia do Piaú Elane da Silva Barbosa - Universidade Estadual do Ceará Érica Rios de Carvalho - Universidade Católica do Salvador Gilberto de Melo Junior - Instituto Federal do Pará Higor Costa de Brito - Universidade Federal de Campina Grande Italan Carneiro Bezerra - Instituto Federal da Paraíba Ivo Batista Conde - Universidade Estadual do Ceará Jaqueline Rocha Borges dos Santos - Universidade Federal Rural do Rio de Janeiro Jessica Wanderley Souza do Nascimento - Instituto de Especialização do Amazonas João Henriques de Sousa Júnior - Universidade Federal de Santa Catarina João Manoel Da Silva - Universidade Federal de Alagoas João Vitor Andrade - Universidade de São Paulo Joilson Silva de Sousa - Instituto Federal do Rio Grande do Norte José Cândido Rodrigues Neto - Universidade Estadual da Paraíba Jose Henrique de Lacerda Furtado - Instituto Federal do Rio de Janeiro Josenita Luiz da Silva - Faculdade Frassinetti do Recife Josiney Farias de Araújo - Universidade Federal do Pará Karina de Araújo Dias - SME/Prefeitura Municipal de Florianópolis Laíze Lantyer Luz - Universidade Católica do Salvador Lindon Johnson Pontes Portela - Universidade Federal do Oeste do Pará Lucas Capita Quarto - Universidade Federal do Oeste do Pará Lúcia Magnólia Albuquerque Soares de Camargo - Unifacisa Centro Universitário Luciana de Jesus Botelho Sodré dos Santos - Universidade Estadual do Maranhão Luís Paulo Souza e Souza - Universidade Federal do Amazonas Luiza Catarina Sobreira de Souza - Faculdade de Ciências Humanas do Sertão Central Manoel Mariano Neto da Silva - Universidade Federal de Campina Grande Marcelo Alves Pereira Eufrasio - Centro Universitário Unifacisa Marcelo Williams Oliveira de Souza - Universidade Federal do Pará Marcos Pereira dos Santos - Faculdade Rachel de Queiroz Marcus Vinicius Peralva Santos - Universidade Federal da Bahia Marina Magalhães de Morais - Universidade Federal de Campina Grande Nadja Maria Mourão - Universidade do Estado de Minas Gerais Natan Galves Santana - Universidade Paranaense Nathalia Bezerra da Silva Ferreira - Universidade do Estado do Rio Grande do Norte Neide Kazue Sakugawa Shinohara - Universidade Federal Rural de Pernambuco Neudson Johnson Martinho - Faculdade de Medicina da Universidade Federal de Mato Grosso Patrícia Appelt - Universidade Tecnológica Federal do Paraná Paulo Henrique Matos de Jesus - Universidade Federal do Maranhão Rafael Rodrigues Gomides - Faculdade de Quatro Marcos

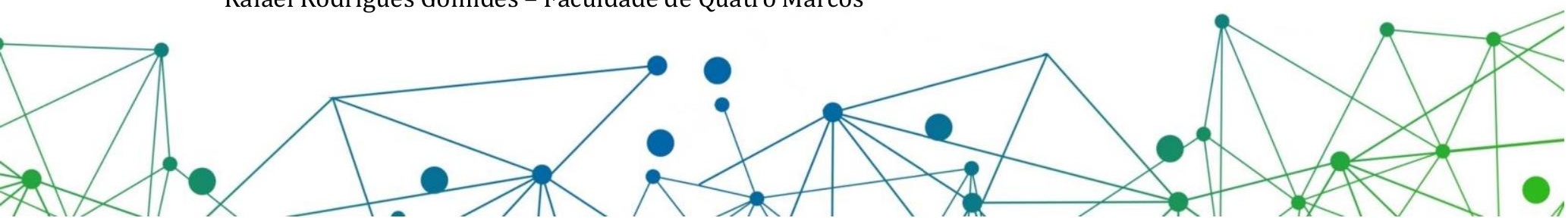




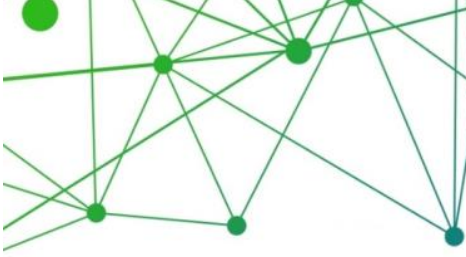

Reângela Cíntia Rodrigues de Oliveira Lima - Universidade Federal do Ceará Rebeca Freitas Ivanicska - Universidade Federal de Lavras Renan Monteiro do Nascimento - Universidade de Brasília Ricardo Leoni Gonçalves Bastos - Universidade Federal do Ceará Rodrigo da Rosa Pereira - Universidade Federal do Rio Grande Sabrynna Brito Oliveira - Universidade Federal de Minas Gerais Samuel Miranda Mattos - Universidade Estadual do Ceará Shirley Santos Nascimento - Universidade Estadual Do Sudoeste Da Bahia Silvana Carloto Andres - Universidade Federal de Santa Maria Silvio de Almeida Junior - Universidade de Franca Tatiana Paschoalette Rodrigues Bachur - Universidade Estadual do Ceará Telma Regina Stroparo - Universidade Estadual do Centro-Oeste Thayla Amorim Santino - Universidade Federal do Rio Grande do Norte Virgínia Maia de Araújo Oliveira - Instituto Federal da Paraíba Virginia Tomaz Machado - Faculdade Santa Maria de Cajazeiras Walmir Fernandes Pereira - Miami University of Science and Technology Wanessa Dunga de Assis - Universidade Federal de Campina Grande Wellington Alves Silva - Universidade Estadual de Roraima Yáscara Maia Araújo de Brito - Universidade Federal de Campina Grande Yasmin da Silva Santos - Fundação Oswaldo Cruz Yuciara Barbosa Costa Ferreira - Universidade Federal de Campina Grande

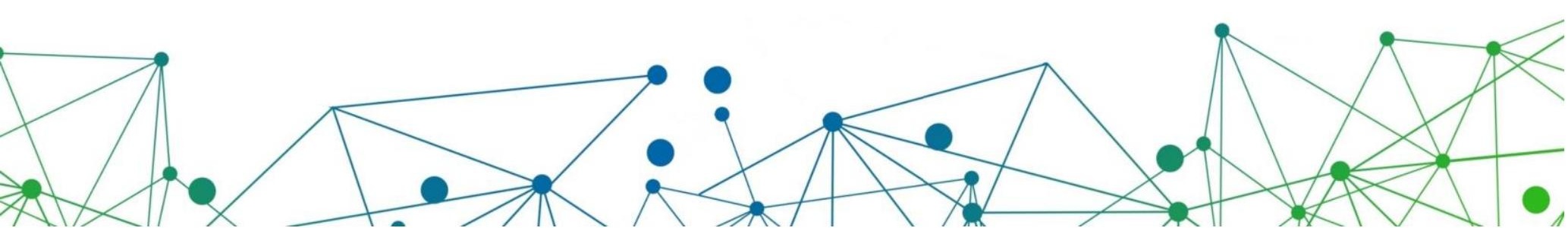




\section{APRESENTAÇÃO}

A 1st Amazon Stem Academy Conference - ASAC21 foi realizada de forma virtual e gratuita no período de 07 a 10 de outubro de 2021. A Conferência faz parte das atividades do Projeto Academia STEM, fruto da parceria da Universidade do Estado do Amazonas (UEA) com a Samsung Eletrônica da Amazonia.

A 1st ASAC21 teve por tema: "Tecnologia, Inovação e Desenvolvimento Sustentável na Educação" como forma de destacar a oportunidade de convergência entre a formação de engenheiros e a promoção da sustentabilidade. Por estarmos na Amazônia, temos especial capacidade de aliar desenvolvimento tecnológico e inovação à conservação do Bioma. Foram muito importantes as discussões estabelecidas a partir desta perspectiva!!

04 diferentes keynotes nas áreas de Engenharia Elétrica, Eletrônica, Controle e Automação, Produção e Computação foram o ponto central do evento. Além disso, tivemos: 05 palestras, 13 trilhas, 02 mesas redondas e 01 roda de conversa abordando temas referentes ao estado da arte em Tecnologia, Inovação, Sustentabilidade, Eficiência Energética, Industria 4.0, Tecnologias Digitais e Inteligência Artificial.

Um espaço especial na 1st ASAC21 foi dedicado as apresentações dos resultados de 46 projetos Científicos, Tecnológicos, de Inovação e Sustentabilidade desenvolvidos por alunos e professores dos cursos de engenharia ao longo do primeiro ano da Academia STEM.

Neste Anais apresentamos uma coletânea de conhecimentos, os resumos expandidos dos trabalhos científicos apresentados durante o evento com o link de acesso no YouTube para assistir aos vídeos de apresentação desses trabalhos durante o evento.

Leia e confira o que foi apresentado e discutido no ASAC 21!

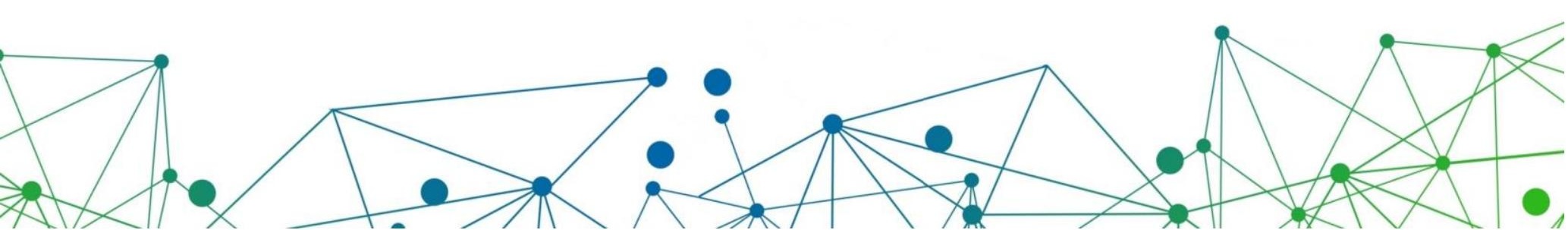




\section{SUMÁRIO}

CAPÍTULO I - TRANSFORMADAS DE LAPLACE ASSOCIADAS EM CIRCUITOS ELÉTRICOS.

CAPÍTULO II - ANÁLISE DAS CARACTERÍSTICAS CONSTRUTIVAS PARA DIMENSIONAR AS LINHAS DE TRANSMISSÃO DE ENERGIA

CAPÍTULO III - PREVISÃO DA DEMANDA DE ENERGIA CONTRATADA USANDO REDES NEURAIS RECORRENTES DO TIPO LSTM ...23

CAPÍTULO IV - FUNDAMENTOS MATEMÁTICOS PRESENTES NO PROCESSAMENTO DIGITAL DE IMAGENS- PDI.. 29

CAPÍTULO V - UTILIZAÇÃO DE FONTES RENOVÁVEIS PARA ELETRIFICAÇÃO DOS SISTEMAS ISOLADOS DA AMAZÔNIA ............... 36

CAPÍTULO VI - SIMULAÇÃO DO SISTEMA ELÉTRICO DE POTÊNCIA DO MUNICÍPIO DE ANAMÃ -AM . .41

CAPÍTULO VII - ESTUDO SOBRE AS PRINCIPAIS DISTORCÕES PRESENTES NO FORNECIMENTO DE ENERGIA ELÉTRICA. . .47

CAPÍTULO VIII - ENSAIOS E EXPERIÊNCIAS PRÁTICAS PARA O LABORATÓRIO DA DISCIPLINA DE MÁQUINAS ELÉTRICAS. 53

CAPÍTULO IX - PANORAMA NACIONAL DE FONTES RENOVÁVEIS PARA GERAÇÃO DE ELETRICIDADE COMPARADA AO CENÁRIO DO ESTADO DO AMAZONAS. 58

CAPÍTULO X - OS IMPACTOS DA CRISE HÍDRICA NO SETOR ELÉTRICO BRASILEIRO 64

CAPÍTULO XI - SIMULAÇÃO DE PERTURBAÇÕES DAS LINHAS DE TRANSMISSÃO DE ENERGIA USANDO ATPDRAW. . .70

CAPÍTULO XII - DETECTOR DE DIFERENÇA DE FASE EM SINAIS SENOIDAIS . .77

CAPÍTULO XIII - SISTEMA INTELIGENTE DE SOCORRO IMEDIATO AO MOTOCICLISTA . .82

CAPÍTULO XIV - FUNDAMENTOS MATEMÁTICOS DE FILTROS LINEARES EM PROCESSAMENTO DIGITAL DE IMAGENS - PDI....... 88

CAPÍTULO XV - SIMULAÇÃO DE UM PAINEL FOTOVOLTAICO MONOCRISTALINO DE 12V / 6OW: MODELOS MATEMÁTICOS........ 94

CAPÍTULO XVI - CONHECIMENTO E AVALIAÇ̃̃O DAS EMISSÕES DE RADIAÇÃO ELETROMAGNÉtICA NÃO IONIZANTE (RNI) ORIUNDAS DE ESTAÇ̃̃ES RÁDIO BASE (ERB) NA CIDADE DE MANAUS . 99

CAPÍTULO XVII - DESENVOLVIMENTO DE HARDWARE PARA MONITORAMENTO DE PARÂMETROSELÉTRICOS DE MOTORES.....104

CAPÍTULO XVIII - DESENVOLVIMENTO DE FIRMWARE E SOFTWARE PARA MONITORAMENTO DE MOTORES DE INDUÇ̧̃O TRIFÁSICOS

CAPÍTULO XIX - UM HISTÓRICO DAS PRINCIPAIS ENERGIAS RENOVÁVEIS E APLICAÇÕES DE FERRAMENTAS DA INDÚSTRIA 4.0 .116

CAPÍTULO XX - ALGORITMOS BARE METAL PARA CONTROLE E USO DE PERIFÉRICOS DE PLATAFORMAS EMBARCADAS MICROCONTROLADAS.

CAPÍTULO XXI - PESQUISA BIBLIOGRÁFICA E IMPLEMENTAÇÃO DE PROGRAMAS EM LINGUAGEM PYTHON PARA MEDIDAS DE INFORMAÇÃO E CODIFICAÇÃO PARA COMPRESSÃO DE DADOS .129

CAPÍTULO XXII - APLICAÇÕES ELÉTRICAS EM FONTES RENOVÁVEIS DE ENERGIA — INDÚSTRIA 4.0...............................136

CAPÍTULO XXIII - CONSTRUÇÃO DE APLICATIVOS EM FÍSICA .143

CAPÍTULO XXIV - DESENVOLVIMENTO DE UMA PLATAFORMA WEB PARA DISPONIBILIZAÇÃO DE DADOS HIDROCLIMÁTICOS .. 147 CAPÍTULO XXV - ASPECTOS ERGONÔMICOS DO TELE ESTUDO DURANTE A PANDEMIA DO COVID-19 .154

CAPÍTULO XXVI - FERRAMENTAS DE ACESSIBILIDADE E FLUXO DE COMUNICAÇÃO PARA PESSOAS COM DEFICIÊNCIA VISUAL162 


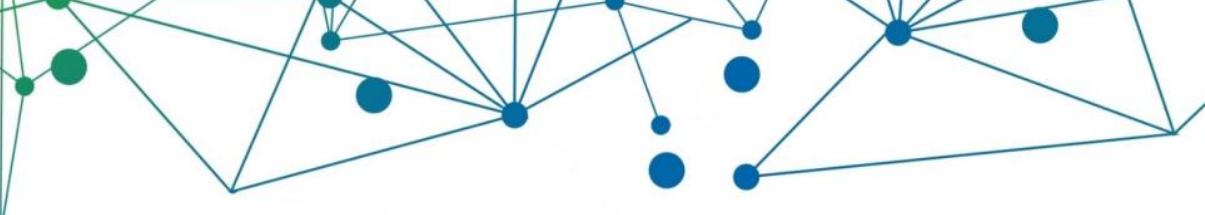

CAPÍTULO XXVII - LOGÍSTICA DO TRANSPORTE FLUVIAL DE ENCOMENDAS PARA O INTERIOR DO ESTADO DO AMAZONAS .....168 CAPÍTULO XXVIII - ENSINANDO DE PROGRAMAÇÃO USANDO PYTHON E JOGOS ELETRÔNICOS .174

CAPÍTULO XXIX - LOGÍSTICA DE VENDAS DE PRODUTOS DE SUPERMERCADO EM MANAUS (AM). .179

CAPÍTULO XXX - E-COMMERCE - DESAFIOS NO CENÁRIO MANAUARA. .184

CAPÍTULO XXXI - PLATAFORMA DE E-COMMERCE: MEUCLOSET. 191

CAPÍTULO XXXII - PROGRAMAÇÃO COMPETITIVA. .197

CAPÍTULO XXXIII - DISPOSITIVOS MÉDICOS INTELIGENTES. .202

CAPÍTULO XXXIV - ESTUDO E APLICAÇÃO DAS NOVAS FERRAMENTAS DA QUALIDADE 206

CAPÍTULO XXXV - DIAGNÓSTICO DA RECICLAGEM NA CIDADE DE MANAUS (AM) 211

CAPÍTULO XXXVI - TESTE DE INTRUSÃO INDEPENDENCE. .217

CAPÍTULO XXXVII - ANÁLISE DA APLICAÇÃO DO ROBÔ HUMANOIDE NAO COMO AGENTE DE COMUNICAÇÃO, INCENTIVO E PERMANÊNCIA PARA OS ALUNOS DOS CURSOS DE ENGENHARIA DO PROJETO STEM. .222

CAPÍTULO XXXVIII - CADEIRA DE RODAS DE PROPULSÃO MOTORIZADA. . .228

CAPÍTULO XXIX - MODELAGEM DE FÍSICA EM PYTHON: GRAVITAÇ̃̃O E DILATAÇÃO TÉRMICA. .234

CAPÍTULO XL - SMART PRODUCTS .242

CAPÍTULO XLI - ANÁLISE DE PUBLICAÇÕES NACIONAIS E INTERNACIONAIS COM FOCO DO ROBÔ HUMANOIDE NAO PARA APLICAÇÕES EM INTELIGÊNCIA ARTIFICIAL. 249

CAPÍTULO XLII - DESENVOLVIMENTO DE FIRMWARE PARA NAVEGAÇÃO INDOOR COM ROBÔS MÓVEIS .255

CAPÍTULO XLIII - DESENVOLVIMENTO DE COREOGRAFIAS PARA O ROBÔ HUMANOIDE NAO .261

CAPÍTULO XLIV - ESTUDO DO SISTEMA DE PROPULSÃO MANUAL DE CADEIRA DE RODAS .266

CAPÍTULO XLV - ANTI WIND-UP. COMPENSAÇ̃̃O DE UM FENÔMENO REAL .271

CAPÍTULO XLVI - DESENVOLVIMENTO DE UMA METODOLOGIA DE ENSINO DE LINGUAGEM DE PROGRAMAÇÃO APLICADA À AUTOMAÇÃO. .279

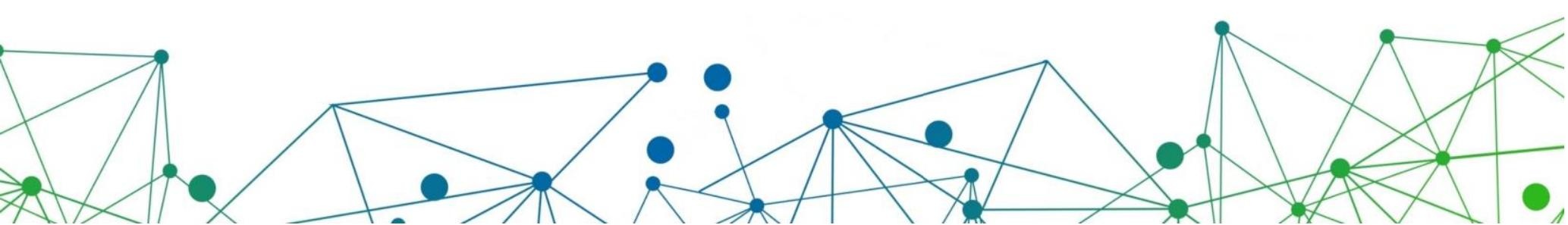




\section{TRANSFORMADAS DE LAPLACE ASSOCIADAS EM CIRCUITOS ELÉTRICOS}

Augusto Rafael da Silva Santos'

Caio Marcos da Silva Freitas'

Eduardo Araújo de Dliveira'

Elainne Ladislau Ferreira Pereira'

${ }^{1}$ Escola Superior de Tecnologia (EST) - Universidade do Estado do Amazonas (UEA) CEP 69050-020 - Manaus - AM - Brasil arss.eng17@uea.edu.br, cmdsf.eng20@uea.edu.br, eado.eng20@uea.edu.br, elpereira@uea.edu.br

\section{INTRODUÇÃO}

Muitos problemas na Engenharia são diretamente relacionados com a Matemática, mais especificamente com Problemas de Valores Iniciais (PVI), as quais são resolvidas por meio das Equações Diferenciais Ordinárias (EDO's). Em particular na Engenharia Elétrica quando se trabalha com Circuitos Elétricos contendo Resistores (R), Capacitores (C) e Indutores (L) na qual resulta em uma Equação Diferencial de $1^{\mathrm{a}}$ ordem, onde temos somente R-L, e numa Equação Diferencial de $2^{\underline{a}}$ Ordem quando se tem C. Neste trabalho enfatizaremos o uso das Transformadas de Laplace para a resolução de tais EDO's utilizando o software Matlab.

\section{OBJETIVOS}

O objetivo deste trabalho é elucidar fatos matemáticos aplicados diretamente à Engenharia Elétrica, mais especificamente ligados à Circuitos Elétricos, trazendo toda as informações para que se entenda do que são formados tais circuitos, como a resolução na sua forma analítica, seu mecanismo em cada instante temporal. Bem como mostrar as principais ferramentas do software Matlab/Simulink utilizadas para a construção de tal circuito e sua resolução por meio de técnicas provenientes de EDO por meio das Transformadas de Laplace. 


\section{MATERIAIS E MÉTODOS}

Este trabalho resulta do projeto Stem com o curso de Engenharia Elétrica da Universidade do Estado do Amazonas, onde foi proposto o Projeto de Extensão Stem Transformada de Laplace associadas em Circuitos Elétricos. Consiste em caracterizar os circuitos elétricos e quais seus principais componentes, bem como equacionados por meio de PVI e solucionados por meio dos métodos de EDO e também por Transformadas de Laplace.

Com a realização de estudos dirigidos e bibliográficos, os discentes puderam realizar seminários e destacar suas principais dúvidas. Assim como os encontros quinzenais e mini-cursos foram realizados de forma virtual pelo Google Meet. 0 material foi disponibilizado pelo Google Classroom e pela plataforma YouTube. Para as técnicas de resolução e processamento com Circuitos RL e RCL foi utilizado o Matlab versão App para androides.

\section{RESULTADOS}

O estudo de EDO's nos últimos séculos foi alvo de curiosidade por muitos matemáticos. Ora como sendo o foco a modelagem de algum sistema ora a sua análise puramente matemática. É muito difícil falar de equações diferenciais sem associá-las a um problema.

Um dos responsáveis pelo estudo das resoluções de Equações Diferenciais Ordinárias foi o alemão Gottfried Wilhelm Leibniz (1646 - 1716). Entre 1691 e 1694, Leibniz desenvolveu o método da separação de variáveis e o método de resolução de equações lineares de primeira ordem, além da notação matemática de derivada e integral.

Para modelarmos o problema, iremos inicialmente entender o que é um circuito elétrico e quais os seus principais componentes.

\subsection{CIRCUITOS ELÉTRICOS}

Alguns dos principais componentes dos circuitos elétricos são:

Fonte Geradora; É um dispositivo que consegue converter diferentes formas de energia, como energia mecânica, química e solar, em energia elétrica. (figura 1)

Resistor: Funciona como um supressor de passagem de corrente elétrica. Também usa o efeito Joule para dissipar energia em forma de calor. (figura 2) 
Capacitor: Geralmente é usado para estabilizar a tensão em um circuito. Tem a função de armazenar carga elétrica e a converter em um campo elétrico. (figura 3)

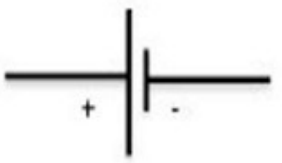

Figura 1. Representação simbólica de gerador elétrico no modelo de circuito.
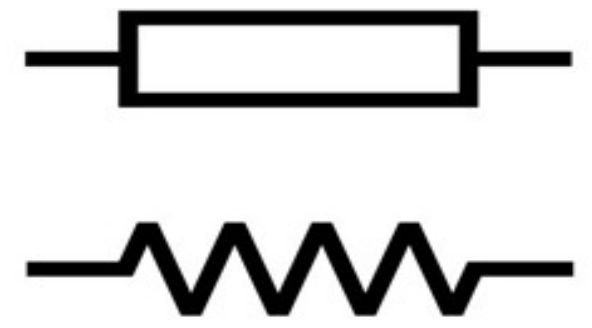

Figura 2. Simbologia de resistor.

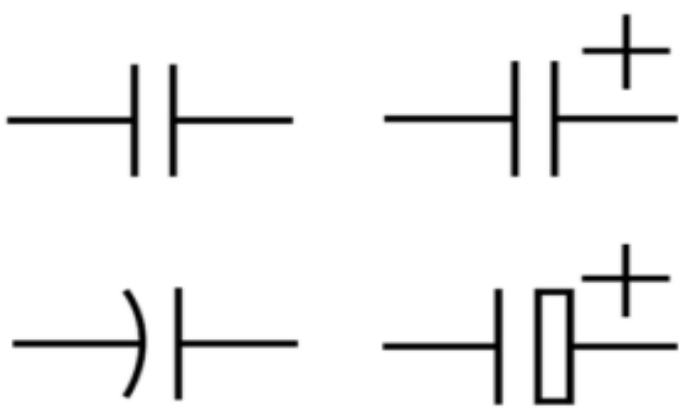

Figura 3. Simbologia do capacitor.

Nos circuitos, os componentes podem ser organizados em série, onde se organizam um após o outro, ou em paralelo, no qual ficam um ao lado do outro.

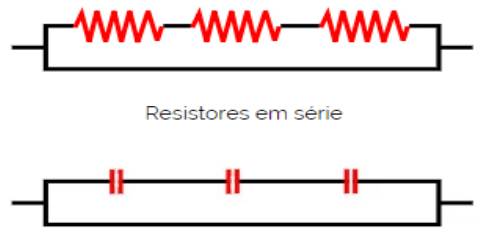

Capacitores em serie

Figura 4. Componentes em série 


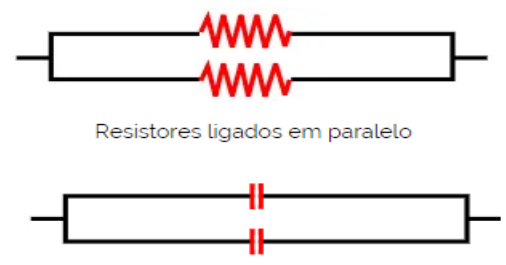

Capacitores em paralelo

Figura 5. Componentes em paralelo

\section{2. $E D O ' S$}

Em termos matemáticos podemos expressar uma Equação Diferencial como uma equação cujas incógnitas são derivadas de funções, as quais são classificadas pela ordem, i.e, dentre as derivadas existentes na equação, à de maior ordem será dada a ordem da EDO, e quanto ao grau, que neste caso será explicitado ao expoente que está associado à derivada de maior ordem.

\subsection{MODELAGEM MATEMÁTICA}

Compreenda que cada componente dentro do Circuito ocasiona um acréscimo ou queda de corrente dentro do Circuito. Pela $1^{\circ}$ Lei de Kirchhoff, diz que a soma de todas as correntes de um no do circuito deve ser igual à soma de todas as correntes que deixam esse mesmo nó. Essa é uma consequência do princípio de conservação da carga elétrica.

A equacionalização é baseada pelo Sistema Linear (E=L.di/dt+i.C) que contem os componentes L (instância) C (capacitância) I (corrente elétrica).

Vejamos um exemplo:

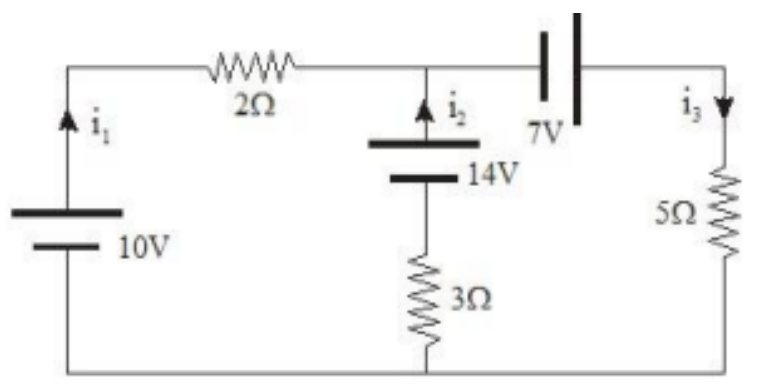

Figura 5. Circuito elétrico.

$$
\begin{gathered}
10+2 \mathrm{i} 1+14-3 \mathrm{i} 2=-4 \\
-14-7+5 \mathrm{i} 3+3 \mathrm{i} 2=0 \\
\mathrm{i} 3=\mathrm{i} 1+\mathrm{i} 2 \\
\\
2 \mathrm{i} 1-3 \mathrm{i} 2+0 \mathrm{i} 3=-4 \\
0 \mathrm{i} 1+3 \mathrm{i} 2+5 \mathrm{i} 3=21 \\
1 \mathrm{i} 1+1 \mathrm{i} 2-1 \mathrm{i} 3=0 \\
\mathrm{i} 1=1 \mathrm{~A}, \mathrm{i} 2=2 \mathrm{~A} \text { e } 3=3 \mathrm{~A} .
\end{gathered}
$$




\subsection{COMANDOS PARA RESOLUÇÃO DE TRANSFORMADA DE LAPLACE NO MATLAB}

Podemos resolver as TL de duas formas, manualmente, ou usando software como o MatLab

Tabela 1: Principais comandos utilizados no Software Matlab

\begin{tabular}{cc}
\hline Comando & Descrição \\
\hline Input (“ “) & Entrada \\
Disp (“") & Saída \\
Laplace () & Soluciona uma equação usando Laplace \\
Ilaplace ( ) & Soluciona a Inversa da Transformada de Laplace \\
Simplify () & Simplifica uma equação já resolvida \\
\hline
\end{tabular}

\subsection{RESOLUÇÃO DE TRANSFORMADAS DE LAPLACE}

Resolução manual:

$$
\begin{aligned}
\mathcal{L}[u(t)] & =\int_{0}^{\infty} u(t) e^{-s t} d t=\lim _{M \rightarrow \infty} \int_{0}^{M} e^{-s t} d t \\
& =\lim _{M \rightarrow \infty}\left[\frac{e^{-s t}}{-s}\right]_{0}^{M}=\lim _{M \rightarrow \infty}\left[\frac{e^{-s M}}{-s}-\frac{1}{-s}\right]=\frac{1}{s}
\end{aligned}
$$

Figura 6. Resolução manual de Transformada de Laplace

Resolução com MatLab:

» syms t s;

$\gg \mathrm{f}=1$;

$\gg$ laplace $(\mathrm{f}, \mathrm{t}, \mathrm{s})$

ans $=1 / 2$

\begin{tabular}{|c|c|c|c|c|c|c|}
\hline $\mathrm{N}$ & função & $\mathcal{L}[f]$ & $\mathrm{N}$ & função & $\mathcal{L}[f]$ & Condição \\
\hline 01 & $u(t) \equiv 1$ & $1 / s$ & 02 & $t$ & $1 / s^{2}$ & $s>0$ \\
\hline 03 & $t^{2}$ & $2 / s^{3}$ & 04 & $t^{n}$ & $n ! / s^{n+1}$ & $s>0$ \\
\hline 05 & $e^{a t}, a \in \mathbb{R}$ & $\frac{1}{s-a}$ & 06 & $e^{a t}, a \in \mathbb{C}$ & $\frac{1}{z-a}$ & $\operatorname{Re}(z-a)>0$ \\
\hline 07 & $\cos (a t)$ & $\frac{s}{s^{2}+a^{2}}$ & 08 & $\sin (a t)$ & $\frac{a}{s^{2}+a^{2}}$ & $s>0$ \\
\hline 09 & $e^{a t} \cos (b t)$ & $\frac{s-a}{(s-a)^{2}+b^{2}}$ & 10 & $e^{a t} \sin (b t)$ & $\frac{b}{(s-a)^{2}+b^{2}}$ & $s>a$ \\
\hline 11 & $\cosh (a t)$ & $\frac{s}{s^{2}-a^{2}}$ & 12 & $\sinh (a t)$ & $\frac{a}{s^{2}-a^{2}}$ & $s>a$ \\
\hline 13 & $t \cos (a t)$ & $\frac{s^{2}-a^{2}}{\left(s^{2}+a^{2}\right)^{2}}$ & 14 & $t \sin (a t)$ & $\frac{2 a s}{\left(s^{2}+a^{2}\right)^{2}}$ & $s>0$ \\
\hline
\end{tabular}

\subsection{TABELA COM AS PRINCIPAIS TRANSFORMADAS}

Figura 8. Tabela de transformadas . 


\section{CONCLUSÃO}

Aos discentes de Engenharia Elétrica envolvidos no Projeto estando estes nos períodos iniciais da Graduação é muito interessante já se ter um contato com uma aplicação direta do curso, além da apresentação do software Matlab para a resolução dos problemas utilizando Transformadas de Laplace. Muitas das perguntas dos graduandos é detectar a usabilidade da Ciência Matemática em seus cursos e estes estão sendo de uma certa forma privilegiados com essa abordagem teórica e prática, ampliando as possibilidades de escritas em Congressos com artigos na área de Elétrica.

\section{REFERÊNCIAS BIBLIOGRÁFICAS}

Programa de Educação Tutorial de Engenharia Elétrica. "Introdução ao Matlab". Universidade Federal de Santa Maria. The Math Works Inc. 2010.

STEWART, J., “Cálculo”. Volume II. 8 ed. São Paulo: CENGAGE Learning, 2017.

Wylie. C. R; Barrett, K, C. "Advanced Engineering Mathmatics". Fifth Edition. McGraw-Hill International Editions. 1982. 


\section{ANÁLISE DAS CARACTERÍSTICAS CONSTRUTIVAS PARA DIMENSIONAR AS LINHAS DE TRANSMISSÃO DE ENERGIA}

Fabrício Falcão de Suuza Dliveira'

Israel Gondres Torné

Edry Antonio Garcia Cisneros'

1Escola Superior de Tecnologia (EST) - Universidade do Estado do Amazonas (UEA) CEP 69050-020 - Manaus - AM - Brasil ffso.eng18@uea.edu.br, itorne@uea.edu.br, ecisneros@uea.edu.br

\section{INTRODUÇÃO}

Devido as grandes distâncias das usinas de geração de energia elétrica até os centros de consumo, linhas de transmissão de alta tensão são criadas para fazer o transporte de energia de forma técnica e economicamente viável. Além do transporte de energia aos centros de carga, estas construções oferecem diversas possibilidades de emprego direto nos canteiros de obra, nas empresas transmissoras de energia e, indiretamente, nas indústrias e empresas fornecedoras de materiais, equipamentos e serviços.

O desenvolvimento social e econômico de uma nação tem uma forte relação com a expansão do setor elétrico, o que torna a energia elétrica e suas diversas aplicações indispensáveis à sociedade moderna. Menezes (2015). De acordo com Menezes (2015) com o intuito de unificar redes que até então eram independentes, devido aos dois níveis de frequência que existiam (50 Hz e $60 \mathrm{~Hz}$ ) no Brasil, a Eletrobras promoveu um plano que padronizou a frequência de transmissão nacional como $60 \mathrm{~Hz}$. Com isso, em 1973, o país foi dividido em quatro regiões geoelétricas: Nordeste; Sudeste, Distrito Federal e parte dos estados de Goiás e Mato Grosso; Sul e Norte, viabilizando-se, portanto, a otimização do processo de transmissão de energia elétrica no país.

As tensões usuais de transmissão adotadas no Brasil, em corrente alternada, podem variar de $138 \mathrm{kV}$ até $765 \mathrm{kV}$ incluindo neste intervalo as tensões de $230 \mathrm{kV}$, $345 \mathrm{kV}, 440 \mathrm{kV}$ e $500 \mathrm{kV}$. Ainda há no país a operação em corrente contínua, com níveis de tensão de $600 \mathrm{kV}$ C.C. e $800 \mathrm{kV}$ C.C. As redes com tensões nominais iguais 
ou superiores a $230 \mathrm{kV}$ são denominadas de Redes em extra alta tensão e no Brasil formam a chamada Rede Básica de transmissão. Santos (2020). 0 estudo da criação de linhas de transmissão requer primeiramente de forma detalhada fazer um levantamento de campo, a fim de conhecer os aspectos físicos, meteorológicos, geotécnicos e até históricos da região. Dessa forma, com a utilização crescente do sistema de transmissão interligado no Brasil é necessário ampliar a rede de transmissão de energia, seja para interligar áreas ainda não conectadas ao sistema ou para elevar a sua confiabilidade.

\section{OBJETIVOS}

Com isso, o presente trabalho tem como objetivo verificar a formação do atual cenário, no que diz respeito ao setor de energia elétrica, identificando áreas que carecem de um serviço adequado que consiga suprir a demanda de sua população e por fim, apresenta os aspectos geográficos dessa região e calcula-se os parâmetros mecânicos referentes ao condutor para uma linha de transmissão nessas localidades.

\section{MATERIAIS E MÉTODOS}

A pesquisa para a realização do trabalho desenvolvido foi feita através da plataforma digital Google Acadêmico, onde por meio da análise e leitura de diversos artigos, buscou-se em um primeiro momento, entender a constituição do setor elétrico brasileiro, bem como as suas características e seus avanços até os dias atuais. Posteriormente, feito o estudo introdutório do assunto, abordou-se como tema de pesquisa as regiões caracterizadas como Sistemas Isolados, que se fazem presente, praticamente, em sua totalidade na região Amazônica. Em seguida, discorreu-se a respeito dos principais componentes que constituem as linhas de transmissão, afim de apresentar suas funções na estrutura, utilizando-se para esta explanação o livro referência indicado para a leitura pelo orientador. Além disso, dissertou-se, com base em monografias sobre alguns aspectos geográficos, que se fazem presentes na região Amazônica com o intuito de identificar possíveis fatores que pudessem interferir nos parâmetros adotados para a futura realização de cálculos referentes a linha de transmissão. Por fim, possuindo como bibliografia um trabalho relacionado aos cálculos dos parâmetros mecânicos indicado pelo 
coorientador, desenvolveram-se os resultados das forças que atuam no condutor fixado entre dois suportes de uma linha de transmissão, considerando-se que esta linha se faz presente na Amazônia.

\section{RESULTADOS}

Para a realização dos cálculos mecânicos, primeiramente, será vista a equação da catenária, que servirá para descrever a equação dos dois suportes que mantém o cabo ancorado, no caso, estas fórmulas apresentam as alturas do ponto onde o cabo está fixo até uma determinada posição no solo. Por fim, são calculadas as respectivas posições no solo dos suportes, o comprimento do cabo, as tensões tangencias nos pontos em que o cabo é ancorado em cada suporte, a flecha máxima, a posição no solo do ponto mais baixo da curva da catenária e o valor da tensão média equivalente. Para os respectivos cálculos adotou-se uma região plana (Amazônia), com um vão de 350 metros e a utilização do cabo condutor do tipo ACSR de codinome Rail.

A condição aderida para os cálculos é a condição EDS, na qual é desconsiderado o efeito do vento sobre os condutores e a temperatura utilizada como referência é a temperatura média. Desta maneira, como o estudo apresentado é voltado para a região Amazônica, considerou-se um terreno plano (nos cálculos realizados o desnível (D) é igual a 0 , sendo o vão nivelado) e uma temperatura média de $26^{\circ}$.

Na figura a seguir são apresentadas as equações utilizadas para a realização dos cálculos dos parâmetros mecânicos, no que diz respeito ao cabo presente na linha de transmissão. 


$$
\begin{aligned}
& \begin{array}{c}
\text { Equação da catenária } \\
y=\frac{H}{W}\left(\cosh \frac{W x}{H}-1\right) \\
y_{1}=\frac{H}{W}\left(\cosh \frac{W x_{1}}{H}-1\right) \quad y_{2}=\frac{H}{W}\left(\cosh \frac{W x_{2}}{H}-1\right)
\end{array} \\
& \text { Equações das posições no solo dos suportes A e B } \\
& x_{1}=\frac{S}{2}+\frac{H}{W} \cdot \ln \left[\frac{W D}{2 H \operatorname{senh} \frac{W S}{2 H}}+\sqrt{\left(\frac{W D}{2 H \operatorname{senh} \frac{W S}{2 H}}\right)^{2}+1}\right] x_{2}=-\frac{S}{2}+\frac{H}{W} \cdot \ln \left[\frac{W D}{2 H \operatorname{senh} \frac{W S}{2 H}}+\sqrt{\left(\frac{W D}{2 H \operatorname{senh} \frac{W S}{2 H}}\right)^{2}+1}\right] \\
& \text { Equação da posição no solo do ponto mais baixo da catenária }
\end{aligned}
$$

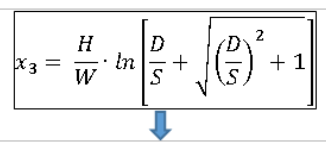

$$
\begin{aligned}
& \text { Equação do comprimento } \\
& \text { do cabo } \\
& \text { quações das tensões nos suportes } \mathrm{A} \text { e B Equação da flecha máxima } \\
& L=\frac{H}{W}\left[\operatorname{senh} \frac{W x_{1}}{H}-\operatorname{senh} \frac{W x_{2}}{H}\right] \\
& T_{A}=H \cosh \frac{W x_{2}}{H} T_{B}=H \cosh \frac{W x_{1}}{H} \\
& \text { Equação da tensão média equivalente } \\
& T_{e}=\frac{H}{4} \cdot \frac{\operatorname{senh} \frac{2 W x_{1}}{H}-\operatorname{senh} \frac{2 W x_{2}}{H}+\frac{2 W S}{H}}{\operatorname{senh} \frac{2 W x_{1}}{H}-\operatorname{senh} \frac{2 W x_{2}}{H}} \\
& F=\frac{H}{W}\left(\cosh \frac{S W}{2 H}-1\right)
\end{aligned}
$$

Figura 1. Equações utilizadas para o cálculo dos parâmetros mecânicos.

Para este estudo, adotou-se um vão (S) de tamanho igual a 350 metros e o cabo ACSR de codinome Rail (que segundo Bezerra (2010), deve possuir uma tensão horizontal máxima $(\mathrm{H})$ na faixa de $18 \%$ a $23 \%$ da sua carga de ruptura que possui em valor de $11740 \mathrm{kgf}$ ). Sendo assim, escolheu-se uma tensão horizontal máxima com $21 \%$ da carga de ruptura do respectivo cabo. Logo, $H=0,21 \cdot 11740 \cong$ $2465 \mathrm{kgf}$. Além disso, de acordo com Bezerra (2010) verifica-se também que o cabo ACSR de codinome Rail possui um peso por unidade de comprimento (W) igual a $1600,2 \mathrm{kgf} / \mathrm{km}$. Com essas informações e por meio das equações apresentadas anteriormente, calcularam-se os parâmetros mecânicos e organizaram-se os mesmos na tabela seguinte.

Tabela 1. Resultados dos cálculos referentes aos parâmetros mecânicos

\begin{tabular}{|c|c|}
\hline \multicolumn{2}{|c|}{ Parâmetros Mecânicos } \\
\hline D & 0 \\
\hline S & $350 \mathrm{~m}$ \\
\hline H & $2465 \mathrm{kgf}$ \\
\hline W & $1600,2 \mathrm{kgf} / \mathrm{km} \mathrm{ou} 1,6 \mathrm{kgf} / \mathrm{m}$ \\
\hline $\mathrm{X} 1$ & $175 \mathrm{~m}$ \\
\hline
\end{tabular}




\begin{tabular}{|c|c|}
\hline \multicolumn{2}{|c|}{ Parâmetros Mecânicos } \\
\hline $\mathrm{X}_{2}$ & $-175 \mathrm{~m}$ \\
\hline $\mathrm{x}_{3}$ & 0 \\
\hline $\mathrm{y}_{1}$ & $9,9498 \mathrm{~m}$ \\
\hline $\mathrm{y}_{2}$ & $9,9498 \mathrm{~m}$ \\
\hline $\mathrm{L}$ & $350,7531 \mathrm{~m}$ \\
\hline $\mathrm{T}_{\mathrm{A}}$ & $2480,9197 \mathrm{kgf}$ \\
\hline $\mathrm{T}_{\mathrm{B}}$ & $2480,9197 \mathrm{kgf}$ \\
\hline $\mathrm{F}$ & $9,9498 \mathrm{~m}$ \\
\hline $\mathrm{T}_{\mathrm{e}}$ & $1227,2309 \mathrm{kgf}$ \\
\hline
\end{tabular}

Os resultados obtidos e organizados na tabela acima foram calculados, por meio da ferramenta Symbolab (2021). Assim, após a coleta e análise dos mesmos, constatou-se que as maiores tensões obtidas no cabo foram as tangenciais nos pontos A e B com um valor de 2480,9197 kgf que corresponde a aproximadamente ao percentual de $21 \%$ da carga de ruptura do cabo escolhido, no caso, o mesmo percentual adotado para a tensão horizontal $(\mathrm{H})$, como foi visto anteriormente.

Desta forma, os parâmetros referentes as tensões no cabo encontram-se dentro da faixa de sua carga de ruptura (18\% a 23\%), estando os cálculos adequados e os valores coerentes com o que foi apresentado.

\section{CONCLUSÃO}

O conhecimento do funcionamento e da construção desta tecnologia se faz necessário para dimensionar de forma correta e adequada, buscando transmitir de maneira eficaz, evitando, o máximo de perdas possível, acidentes e promovendo uma menor interferência nos aspectos naturais onde a mesma é implantada.

Assim, o estudo buscou complementar e reforçar a importância de interligar as áreas conhecidas como Sistemas Isolados que se fazem presentes na Amazônia, afim de suprir a demanda da população oriunda dessas localidades que compõem a região e elevar a qualidade do serviço de energia elétrica ofertado pela concessionária.

Os parâmetros mecânicos referentes ao cabo condutor para uma potencial implementação de estrutura de linha de transmissão foram obtidos através do 
cálculo das forças atuantes no condutor, a posição dos suportes e suas alturas para um vão da linha de transmissão, considerando-se as características da região Amazônica.

\section{REFERÊNCIAS BIBLIOGRÁFICAS}

Amaral, C. T., Moret, A. d., \& Marta, J. M. (Agosto de 2018). "Luz para Todos" na Amazônia: Uma Reflexão Acerca da Contribuição do Programa para Fomentar o Desenvolvimento Sustentável em Rondônia. Goiânia, Goiás, Brasil.

Amaral, R. C. (2015). Dimensionamento de Fundações para Torres Metálicas de Linha de Transmissão de Energia Elétrica. Florianópolis, Santa Catarina, Brasil.

Bessa, D. d. (2019). Ciclo do Carbono na Floresta Amazônica: Percepções Ambientais de Moradores da Reserva Extrativista do Baixo Juruá, Amazônia Ocidental, Brasil. Manaus, Amazonas, Brasil.

Bezerra, F. V. (Novembro de 2010). Projeto Eletromecânico de Linhas Aéreas de Transmissão de Extra Alta Tensão. Rio de Janeiro, Rio de Janeiro, Brasil.

Burin, F. d. (1 de Julho de 2010). Modelagem do Comportamento Mecânico de Cabos Suspensos Através de Métodos Analíticos e Numéricos. Porto Alegre, Rio Grande do Sul, Brasil.

Carvalho, J. W., \& Carvalho, S. S. (2021). Consequências Jurídicas do Apagão Elétrico no Amapá. Maringá, Paraná, Brasil.

Cataia, M. (Maio de 2019). Macrossistema Elétrico Brasileiro: Integração Nacional e Centralização do Poder. Campinas, São Paulo, Brasil.

Ferreira, G. A., \& Assed, C. (2020). A Regulação da Energia Elétrica no Brasil e a Teoria dos Leilões. Ribeirão Preto, São Paulo, Brasil.

Menezes, V. P. (Agosto de 2015). Linhas de Transmissão de Energia Elétrica Aspectos Técnicos, Orçamentários e Construtivos. Rio de Janeiro, Rio de Janeiro, Brasil.

Moura, A. P., Moura, A. A., \& Rocha, E. P. (2019). Engenharia de Sistemas de Potência: Transmissão de Energia Elétrica em Corrente Alternada. Fortaleza: Edições UFC.

ONS. (2021). Fonte: ONS: http://www.ons.org.br/

Pedraça, D. d., Silva, R. R., Araújo, L. F., Santos, J. F., \& Lima, G. d. (Junho de 2020). Analise das Problemáticas e Soluções de Energia Elétrica na Zona Rural do Município de Tefé-AM. Tefé, Amazonas, Brasil. 
Reimann, M. A. (2020). Geopolítica da Amazônia: Proposta para a Defesa e Integração. Rio de Janeiro, Rio de Janeiro, Brasil.

Santana, D. P. (2018). Crescimento Econômico e Desenvolvimento Sustentável - 0 Caso do Linhão de Tucuruí no Trecho Amazonas - Roraima. Boa Vista, Roraima, Brasil.

Santos, T. F. (2020). Otimização Multiobjetivo para Controle de Tensão em Tempo Real. Niterói, Rio de Janeiro, Brasil.

Symbolab. (2021). Fonte: Symbolab: https://pt.symbolab.com/

Zuza, A. F. (2019). O Abastecimento Energético em Cidades da Linha do Gasoduto Urucu-Coari- Manaus. Manaus, Amazonas, Brasil. 


\section{PREVISÃO DA DEMANDA DE ENERGIA CONTRATADA USANDO REDES NEURAIS RECORRENTES DO TIPO LSTM}

Bruno Jardanilson Pantoja da Silva

Kaio Alexandre Silva Lima

Wagner Dos Santos Farah Junior

Israel Gondres Torné

Raimunda Cláudio Souza Gomes

Escola Superior de Tecnologia (EST) - Universidade do Estado do Amazonas (UEA) CEP 69050-020 - Manaus - AM - Brasil bjpds.eng19@uea.edu.br kasl.eng19@uea.edu.br wdsfj.eng19@uea.edu.br itorne@uea.edu.br rclaudio.gomes@gmail.com

\section{INTRODUÇÃO}

É nítido que o crescimento populacional é diretamente proporcional ao consumo de energia elétrica tanto em residências quanto em empresas, isso acaba gerando um problema quanto ao fornecimento de energia elétrica (Morante, 2004). Uma desvantagem na utilização da corrente alternada é que não existe uma maneira de armazená-la, nesse caso a energia gerada nas usinas devem ser consumidas quase que instantaneamente (Defilippo, 2008). Sendo assim, a problemática principal é: quanto de energia deve ser gerada? Essa pergunta pode ser facilmente respondida no caso de uma residência, onde pode-se padronizar seu comportamento através de um histórico de consumo e fornecer a energia necessária, porém, se for levado em consideração todas as residências, empresas e comércios de uma cidade, mesmo que seja pequena, a previsão de demanda de energia se torna mais complexa (Defilippo, 2008).

Caso a energia elétrica gerada pelas usinas esteja abaixo da demanda de um determinado local, é certo que em algum momento irá ocorrer um "apagão" (Alves, 2004). Como não é economicamente e ambientalmente viável produzir energia elétrica em excesso, as concessionárias exigem que consumidores de altas potências contratem uma determinada quantidade de energia elétrica e é gerada uma multa 
em cima do valor excedido caso o consumidor ultrapasse a demanda contratada ANEEL, 2012).

\section{OBJETIVOS}

Este artigo tem como objetivo prever a demanda de energia elétrica de uma Unidade Acadêmica utilizando Inteligência Artificial (IA), fazendo o uso do método das Redes Neurais Artificiais (RNA's) do tipo LSTM e avaliar se sua aplicação nessa área é válida.

\section{MATERIAIS E MÉTODOS}

As redes neurais artificiais são estruturas matemáticas que buscam simular o funcionamento do sistema neural biológico de forma a processar uma quantidade de dados grande e de forma não linear, se assemelha ao cérebro humano por ser capaz de armazenar conhecimento com a experiência e por atribuir pesos sinápticos para a experiência adquirida (Haykin, S.1998). 0 modelo trabalhado será o LSTM que é um dos tipos de redes neurais recorrentes e o seu diferencial é trabalhar com a memória de curto-longo prazo, a retroalimentação de informações, superar o processo de atrasos de tempos, além de resolver tarefas complexas e artificiais de atraso de tempo que nunca foram resolvidas por algoritmos de rede recorrentes anteriores (S. Hochreiter, J. Schmidhuber, 1997). Por esses motivos, o modelo de previsão que será usado será o de redes neurais artificiais recorrentes do tipo LSTM, juntamente com o Keras, que é uma Application Programming Interface (API) utilizada para compilar códigos de rede neural e que roda em cima do TensorFlow que é uma biblioteca de aprendizado de máquina, sendo assim, o Keras é uma API do TensorFlow utilizada com foco em Deep Learning, cuja suas estruturas mais utilizadas são os modelos e as camadas, sendo tipo mais simples de modelo o sequential, que são várias camadas em uma pilha linear com a variação de neurônios em cada uma (Keras, 2020).

\section{RESULTADOS}

Sabendo que as redes neurais não possuem uma metodologia específica com relação às quantidades de camadas e neurônios que devem ser utilizadas, as primeiras previsões feitas foram usando pequenas quantidades e a seguir serão 
apresentadas algumas configurações até que um padrão de precisão e exatidão seja alcançado analisando o erro por meio da métrica de Mean Absolute Percentage Error (MAPE).

Tabela 1. Medidas de comparação das melhores configurações.

\begin{tabular}{c|c|c|c|c}
\hline \multicolumn{2}{c}{ 5 CAMADAS - 150 EPOCHS } & \multicolumn{2}{c}{ 9 CAMADAS - 1000 EPOCHS } \\
\hline & MAPE TESTE & MAPE TREINO & MAPE TESTE & MAPE TREINO \\
\hline TESTE 1 & $6,71 \%$ & $10,65 \%$ & $7,10 \%$ & $9,88 \%$ \\
\hline TESTE 2 & $5,40 \%$ & $10,17 \%$ & $6,40 \%$ & $9,97 \%$ \\
\hline TESTE 3 & $7,63 \%$ & $9,96 \%$ & $5,98 \%$ & $9,97 \%$ \\
\hline TESTE 4 & $6,38 \%$ & $10,41 \%$ & $10,33 \%$ & $10,18 \%$ \\
\hline TESTE 5 & $4,73 \%$ & $10,18 \%$ & $11,33 \%$ & $10,02 \%$ \\
\hline TESTE 6 & $5,40 \%$ & $10,14 \%$ & $7,98 \%$ & $9,93 \%$ \\
\hline TESTE 7 & $5,85 \%$ & $10,07 \%$ & $5,26 \%$ & $10,88 \%$ \\
\hline TESTE 8 & $8,71 \%$ & $10,16 \%$ & $4,62 \%$ & $10,01 \%$ \\
\hline TESTE 9 & $6,33 \%$ & $10,79 \%$ & $6,34 \%$ & $10,12 \%$ \\
\hline TESTE 10 & $6,29 \%$ & $10,37 \%$ & $5,65 \%$ & $10,67 \%$ \\
\hline
\end{tabular}

Tabela 2. Médias para os dados da configuração - 9 camadas 1000 epochs.

Médias para os Erros MAPE

\begin{tabular}{c|c}
\hline MAPE TREINO 9 CAM & $10,16 \%$ \\
\hline MAPE TESTE 9 CAM & $7,10 \%$ \\
\hline
\end{tabular}

A partir disso, a configuração de camadas que melhor representou os dados de output foi para um modelo com 9 camadas com a configuração 120;100;130;100;110;130;100;90;1. Com o modelo preparado, foi usado a tática de separar os dados em partes, sendo a maior parte destinada ao treinamento do código, que é a parte responsável pela aprendizagem, e os demais dados foram usados para a validação do modelo já treinado. 


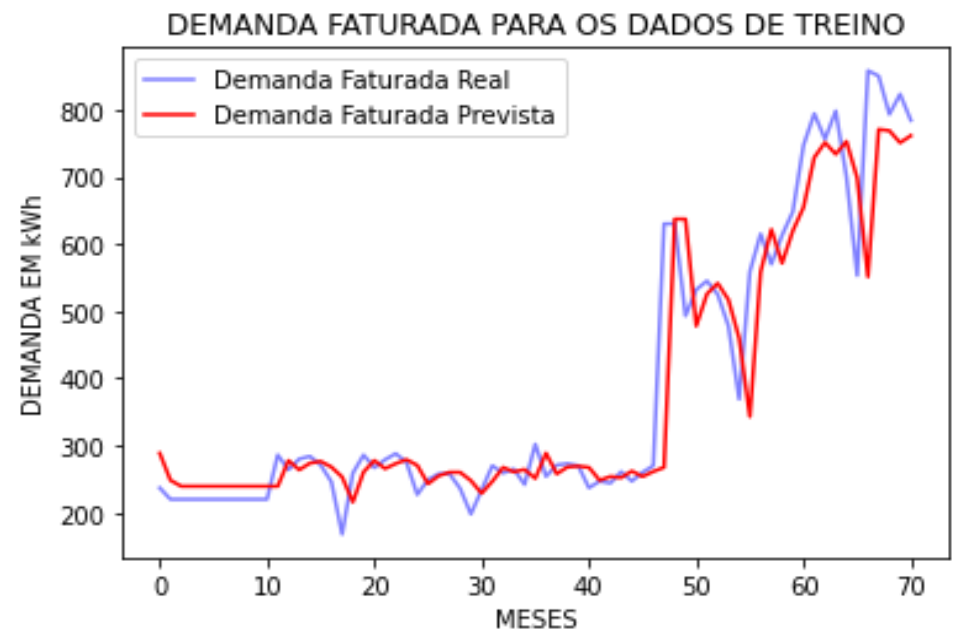

Figura 1. Outputs obtidos para os dados de treino.

Fonte: Autoria Própria.

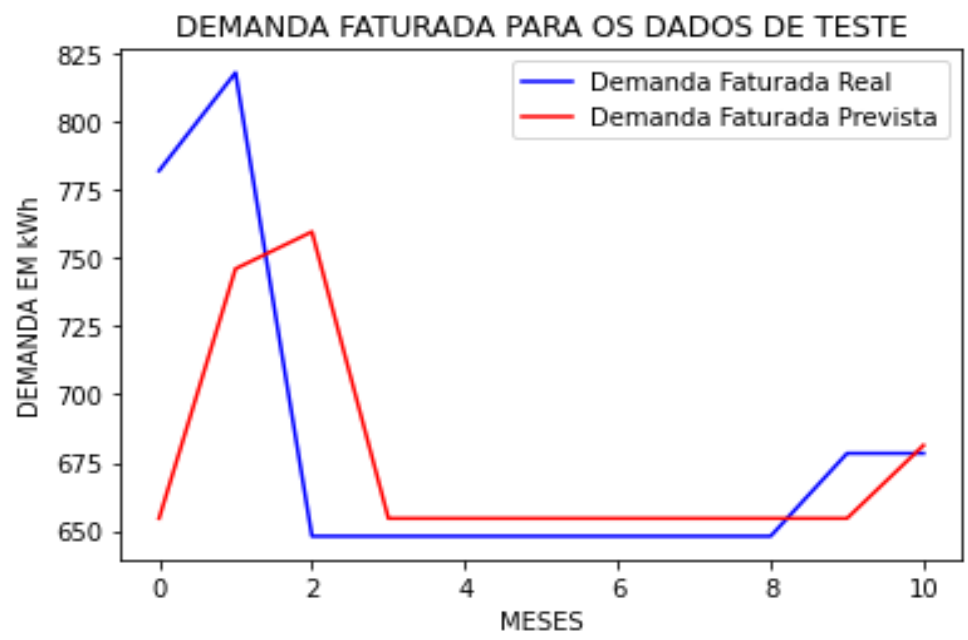

Figura 2. Outputs obtidos para os dados de teste.

Fonte: Autoria Própria.

É perceptível que os dados sofreram uma alteração inicial e ficaram um pouco distantes do que aconteceu na demanda real, mas podemos perceber também que apesar de ter ocorrido uma grande variação, o modelo ainda conseguiu acompanhar o gráfico no seu sentido de pico, queda e em seguida um esboço de uma ascensão. Analisando o erro que os dados apresentam, foi constatado que o erro MAPE foi de 10,28\% para os dados de treino e 4,76\% para os dados de teste. 


\section{CONCLUSÃO}

Sabendo que os dados utilizados para a previsão possuem valores atípicos, considerando o ano de 2020, conseguimos obter um modelo com uma precisão adequada, dado erros de MAPE baixos. Logo, foi observado que o modelo acompanhou bem as flutuações que as medidas apresentaram e conseguiu fazer as previsões dos valores futuros das demandas que a unidade iria necessitar nos meses seguintes, isso faz com que a análise por meio de modelos preditivos, como o apresentado nesse artigo, seja viável para fazer o levantamento de dados do crescimento de consumo da unidade em questão e assim saber a tendência que os dados podem a apresentar.

Mesmo com uma quantidade relativamente pequena de dados foi possível obter bons resultados em comparação com dados aritméticos que não analisam as variações que os dados podem apresentar. Isso indica que em oportunidades futuras, com uma maior base de dados desse parâmetro, acompanhamento contínuo por uma equipe de gestão de energia para gerenciar perdas e buscar equipamentos de Internet of Things (IoT) para melhor operação e registro dos dados, além de ter uma equipe para a operação e atualização dos modelos, as previsões aqui apresentadas podem diminuir ainda mais os erros e assim fazer predições cada vez melhores que já podem ser aplicadas na prática da contratação da demanda de energia.

\section{REFERÊNCIAS BIBLIOGRÁFICAS}

S. Hochreiter and J. Schmidhuber, "Long Short-Term Memory," in Neural Computation, vol. 9, no. 8, pp. 1735-1780, 15 Nov. 1997, doi: 10.1162/neco.1997.9.8.1735.

Bayer, D. M., Castro, N. D. R., \& Bayer, F. M. (2012). Modelagem e previsão de vazões médias mensais do rio Potiribu utilizando modelos de séries temporais. Revista brasileira de recursos hídricos, 17(2), 229-239.

Graves A. (2012) Long Short-Term Memory. In: Supervised Sequence Labeling with Recurrent Neural Networks. Studies in Computational Intelligence, vol 385. Springer, Berlin, Heidelberg. https://doi.org/10.1007/978-3-642-24797-2_

COSSI, Antonio Marcos. Planejamento de redes de distribuição de energia elétrica de média e baixa tensão. 2008. 
Kagan, N., De Oliveira, C. C. B., \& Robba, E. J. (2005). Introdução aos sistemas de distribuição de energia elétrica. Editora Blucher.

IBM. (24 de julho de 2017). A neural networks deep dive. Fonte: IBM corporation: https://developer.ibm.com/articles/cc-cognitive-neural-networks-deepdive/?mhsrc=ibmsearch_a\&mhq=neural\%20network\%3F

IBM cloud education. (17 de agosto de 2020). Neural Networks. Fonte: IBM corporation: https://www.ibm.com/cloud/learn/neuralnetworks?mhsrc=ibmsearch_a\&mhq=neural\%20network

Keras. (12 de abril de 2020). Keras. Fonte: Keras: https://keras.io/

Superintendência de Gestão Tarifária. (16 de 09 de 2020). Perdas de Energia. Fonte: ANEEL: https://www.aneel.gov.br/metodologia-distribuicao//asset_publisher/e2INtBH4EC4e/content/perdas/654800?inheritRedirect $=$ false

Superintendência de Regulação dos Serviços de Distribuição. (06 de 09 de 2018). Regulação dos Serviços de Distribuição. Fonte: ANEEL: https://www.aneel.gov.br/regulacao-da-distribuicao/ /asset_publisher/nHNpDfkNeRpN/content/regulacao-dos-servicos-dedistribuicao/656827? inheritRedirect=false\&redirect=https $\% 3 \mathrm{~A} \% 2 \mathrm{~F} \% 2 \mathrm{Fw}$ ww.aneel.gov.br\%2Fregulacao-dadistribuicao\%3Fp_p_id\%3D101_INSTANCE_nHNpD 


\title{
FUINDAMENTOS MATEMÁTICOS PRESENTES NO
} PROCESSAMENTO DIGITAL DE IMAGENS- PDI

\author{
Jefferson Tiago Santos de Dliveira' \\ Lauro Benício Gambizs Brizidio' \\ Elainne Ladislau Ferreira Pereiral
}

${ }^{1}$ Escola Superior de Tecnologia (EST) - Universidade do Estado do Amazonas (UEA) CEP 69050-020 - Manaus - AM - Brasil jtso.ele16@uea.edu.br,lbgb.ele18@uea.edu.br, elpereira@uea.edu.br

\section{INTRODUÇÃO}

É sempre importante frisar a importância da Ciência Matemática nos Cursos de Engenharias, em particular na Engenharia Eletrônica, um curso que atualmente está em crescente auge devido à grande procura por tecnologias com o uso da Internet. E diante desse novo destaque não podemos deixar de enfatizar o uso da matemática para tais serviços de automação, principalmente ligados ao processamento digital de imagens. Conceitos tão simples da Álgebra Linear como o uso de matrizes para a representação de imagens processadas até Cálculo diferencial como identificação da função intensidade de luminosidade na representação de objetos.

\section{OBJETIVOS}

O objetivo geral deste trabalho consiste em descrever alguns principais temas de Processamento digital de imagens trabalhados com os bolsistas do projeto STEM que envolvem temas das disciplinas de Cálculo Diferencial e Integral e Álgebra Linear. Um fato importante a citar é que esse é o primeiro contato dos discentes com um estudo cientifico e com isso, os resultados são bem iniciais a fim de que eles consigam ir acompanhando juntamente com as disciplinas cursadas no período.

\section{MATERIAIS E MÉTODOS}

Este trabalho resulta do projeto STEM com o curso de Engenharia Eletrônica da Universidade do Estado do Amazonas, no qual foi proposto o Projeto de Extensão 
STEM Fundamentos matemáticos presentes em Processamento Digital de Imagens, e consiste em abordar alguns temas de PDI que estão ligados com as disciplinas de Cálculo Diferencial e Integral e Álgebra Linear I.

Com a realização de estudos dirigidos e bibliográficos, uma vez que estamos na pandemia devido ao COVID 19, os discentes puderam realizar seminários e destacar suas principais dúvidas. Assim como os encontros quinzenais e minicursos foram realizados de forma virtual pelo Google Meet. 0 material foi disponibilizado através do Google Classroom e plataforma YouTube. Para as técnicas de processamento com imagens foi utilizado o App MATLAB, compatíveis com celulares e com versão gratuita.

\section{RESULTADOS}

A pergunta inicial ao se deparar com o processo digital de imagens é: Como é feita a leitura de uma imagem pelo computador, ou seja, pelo software MATLAB. E a resposta decorre de um fato importante e inicial da Álgebra Linear, que a imagem nada mais é do que associada a uma matriz, cuja ordem é exatamente igual ao tamanho da imagem.

Para exemplificação iremos fazer a leitura de um pequeno pedaço de uma imagem, ilustrada na Figura 1, a qual podemos verificar sua representação matricial no workspace (uma das principais janelas do software), onde cada entrada representa uma tonalidade variando no intervalo de 0 a 255.

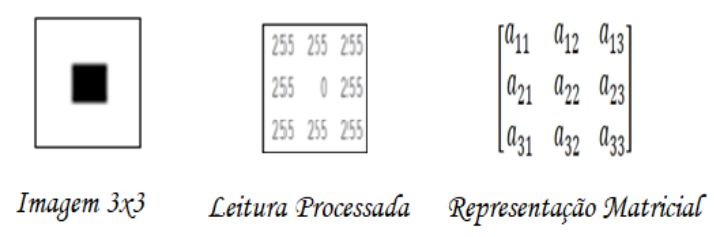

Figura 1. À esquerda figura Bolat.png que constitui um zoom de uma figura em escala de cinza contendo 9 pixels. No meio a leitura após o processamento (Ver Tabela 1), onde o 0 indica o preto e 255 indica branco. À direita a matriz que representa matematicamente a figura no software MATLAB.

Para entender como se associou o valor numérico às entradas da matriz, faremos um pequeno resumo proveniente da Física o que nos leva para a próxima pergunta: 
Como será que o computador "enxerga" uma imagem colorida?

A cor é definida como uma sensação na percepção humana. Mais especificamente, do ponto de vista da Física, a cor é o resultado da incidência de uma onda eletromagnética na retina. Esta tem um comprimento de onda entre 400 a 700nm. (Figura 2).

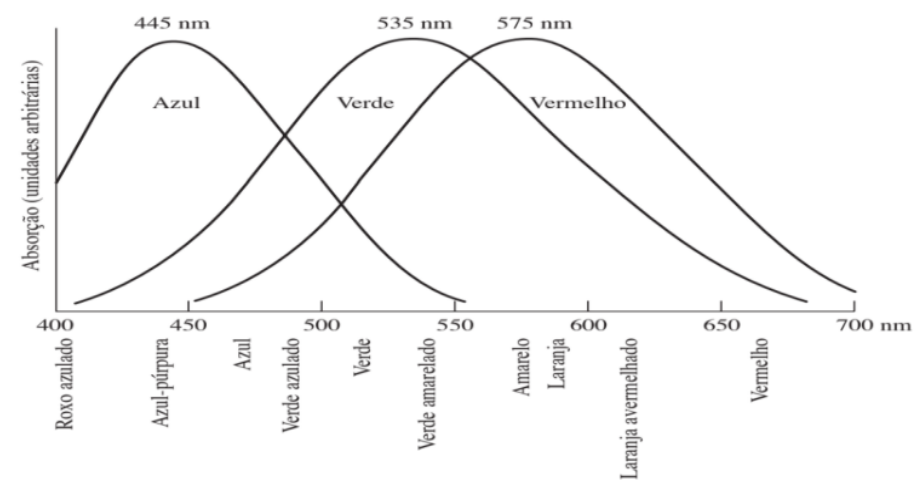

Figura 2. Absorção da luz pelos cones: vermelho, verde e azul no olho humano como uma função do comprimento de onda. (Gozalez, R. C; Woods, R. E, pg 261)

Então a resposta da pergunta acima é que a imagem colorida é uma superposição de matrizes com mesma ordem, igual ao tamanho da imagem original.

No caso do software Matlab se tivermos uma imagem colorida 20x40, então no workspace aparecerá a nomeação da imagem indicando sua dimensão $(20,40,3)$.

Esta última numeração se refere a quantidade de matrizes que neste caso são exatamente três matrizes, onde uma representa a tonalidade Vermelho (Red), uma Verde (Green) e outra Azul (Blue). A partir de tal afirmação foi - se definido o sistema de cores RGB de 24 bits. Assim os números que aparecem em cada elemento da matriz variam numericamente de 0 a 255, onde 0 representa preto e 255 representa branco. Em algumas situações, para reduzir o custo de processamento é preciso converter a imagem para tons de cinza (Gray Scale), processo o qual pode obtido a partir de uma média aritmética em cada pixel da imagem fazendo $\frac{R+G+B}{3}$, ou através da recomendação ITU-RC207 que define determinadas distribuições de luminosidade entre as cores de forma que pareçam mais perceptíveis aos olhos humanos, que obtemos a partir da seguinte equação: $0,299 R+0,587 G+0,114 B$. (Ver Figura 3). 

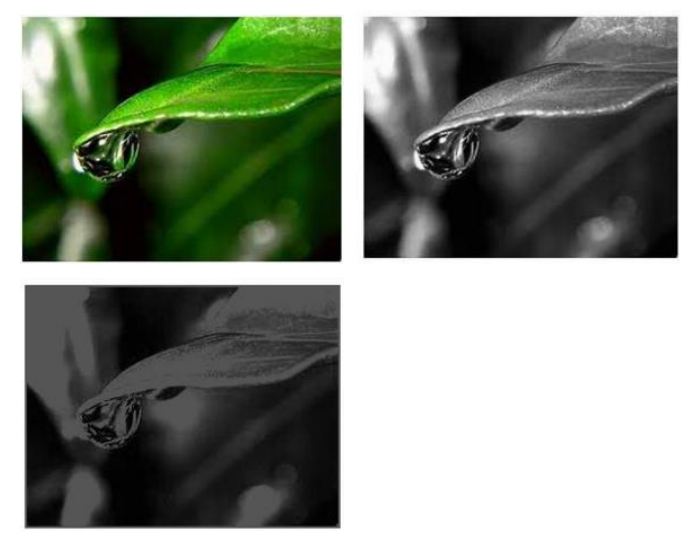

Figura 3. Superior esquerda, imagem original, Superior Direita, Imagem em escala de cinza padrão ITU RC207, e Inferior, Imagem em escala de cinza por média aritmética simples.

A seguir encontra-se os scripts utilizados para cada uma das operações utilizadas acima.

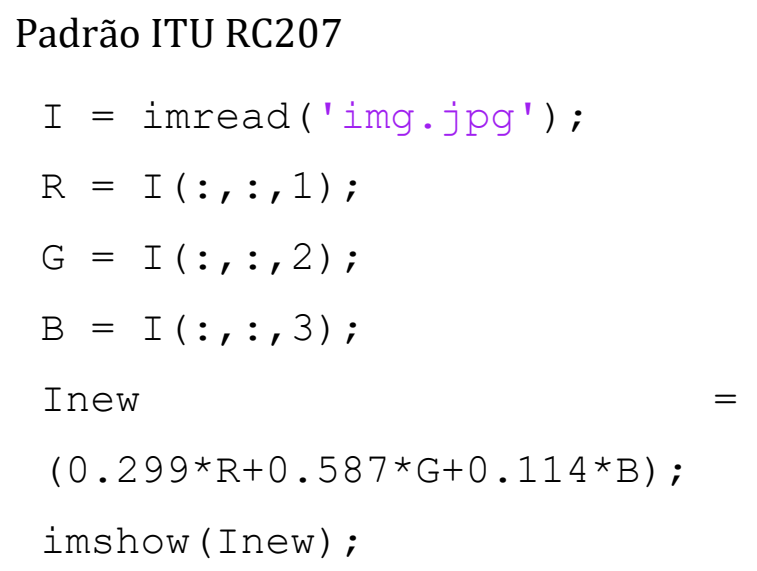

\section{Padrão Média Arimética Simples}

$$
\begin{aligned}
& \mathrm{I}=\mathrm{imread}(' \mathrm{img} \cdot j \mathrm{pg} ') ; \\
& \mathrm{R}=\mathrm{I}(:,:, 1) ; \\
& \mathrm{G}=\mathrm{I}(:,:, 2) ; \\
& \mathrm{B}=\mathrm{I}(:,:, 3) ; \\
& \text { Inew }=(\mathrm{R}+\mathrm{G}+\mathrm{B}) / 3 ; \\
& \text { imshow }(\text { Inew }) ;
\end{aligned}
$$

As funções e comandos utilizados do software Matlab utilizado para o processamento digital estão dispostos na Tabela 1. 
Tabela 1: Principais comandos utilizados no Software Matlab

\begin{tabular}{cc}
\hline Comando & Descrição \\
\hline imread('Nome.Ext') & Lê a imagem \\
imshow('Nome.Ext') & Mostra a imagem \\
rgb2gray(...) & Converte a imagem colorida (RGB) para escalas de cinza \\
histogram(...) & Mostra o gráfico de distribuição de Frequências \\
\hline
\end{tabular}

Para alguns tipos de processamentos com imagens utilizamos o Histograma, que nada mais é do que um gráfico de distribuição das frequências, onde o eixo das abscissas contém a numeração ou uma faixa em tonalidades de cinza e no eixo das ordenadas a quantidade de pixels que tem essa tonalidade dentro da matriz analisada. Um exemplo de obtenção do histograma no MATLAB é usando o comando histogram()(Comando utilizado na Tabela 1), passando como parâmetro a imagem a ser obtida a distribuição das frequências da tonalidade desejada, lembrando que o histograma é obtido a partir da análise de frequência de um conjunto de dados, ou seja, pode ser uma coleção de dados de uma amostra de imagem em tons de cinza, ou em cada uma das tonalidades RGB, como será demostrado a seguir:
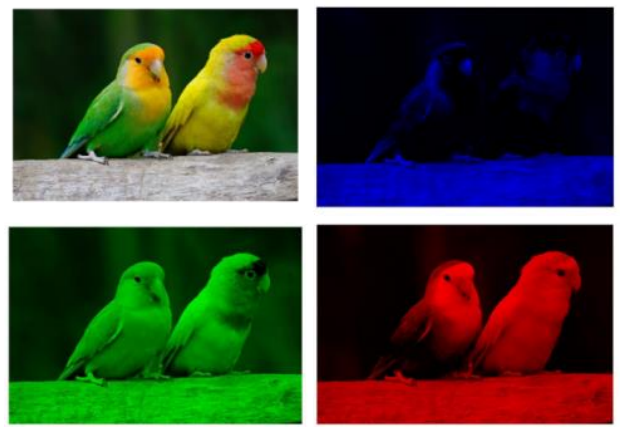

Figura 4. Imagem original, no canto superior esquerdo. Imagem em tons de azul, no canto superior direito. Imagem em tons de verde, no canto inferior esquerdo. Imagem em tons de vermelho, no canto inferior direito.

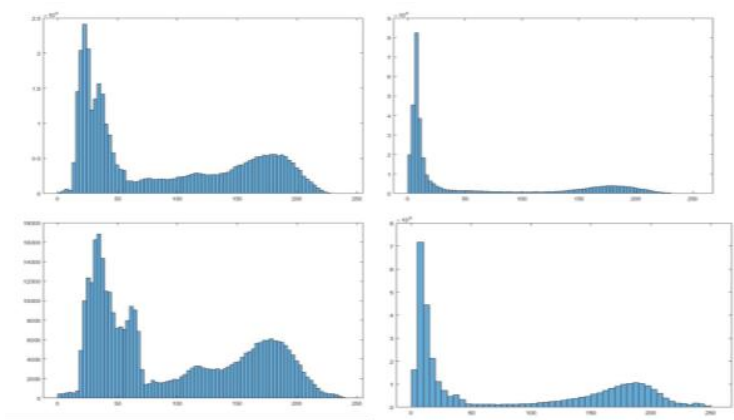

Figura 5. Histograma da Escala de Cinza respectivo as posições das imagens da Figura 4. 
Os histogramas, conforme observado, permitem-nos ver de forma mais concreta, a distribuição dos níveis de tonalidade da imagem, vê-se que há uma concentração de preto muito maior na imagem de tons azuis do que na imagem em tons de verde, e isso é claramente observado no histograma, visto que se mostra uma frequência muito maior próximo a abscissa 0 , que representa a cor preta. Abaixo segue o script para obter o histograma da imagem em escala de cinza.

Script de obtenção do histograma de uma imagem no MATLAB.

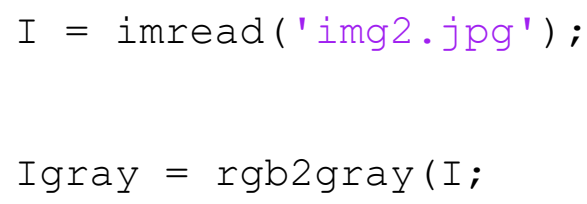

\section{CONCLUSÃO}

É notório o enriquecimento no ensino-aprendizagem dos discentes de Engenharia quando associamos de alguma forma a Matemática ao restante do curso, e, o projeto STEM fez com que muitos deles pudessem perceber essa ênfase logo no início, o que abre uma certa vantagem em relação aos que não tiveram esse preparo inicial. Neste caso, até a utilização do software MATLAB já traz uma grande compreensão do uso das disciplinas iniciais cursadas, como o próprio nome MATLAB já diz é um Laboratório de Matrizes. Esta associação da Imagem com uma matriz já vem com uma grande bagagem das operações triviais. Além disso temos que sempre levar em consideração as diversas aplicações que esses estudos sobre esse assunto podem trazer, desde investimentos fabris para identificação de falhas em inserção de componentes que já estão na casa de nanômetros até a utilização desses filtros para identificar possíveis problemas dentro da agricultura e começar o tratamento para melhorar a produção, também pode ser usado em VANTs para sobrevoar áreas que tenham sofrido alguma catástrofe natural ou não natural e ajudar a identificar pessoas para que as equipes de busca ajam com mais eficiência e as mais diversificadas situações, por isso é muito importante a introdução desses conceitos nas faculdades de engenharias e o investimento em pesquisas ativas.

\section{REFERÊNCIAS BIBLIOGRÁFICAS}

Edson C. Neto; Pedro P. R. F. “Técnicas de PDI e inteligência artificial aplicadas ao reconhecimento de placas de carro nos padrões brasileiro", IFCE-CE. 
Eric V. C. M. "Estudo de técnicas computacionais para suavização de imagem radiográfica", UFMS-MS

Gonzalez, R. C; Woods, R. E. "Processamento Digital de Imagens”. 3a Edição. São Paulo. Person. 2010. 


\section{CAPÍTULO V}

\section{UTILIZAÇÃO DE FONTES RENOVÁVEIS PARA ELETRIFICAÇÃO DOS SISTEMAS ISOLADOS DA AMAZÔNIA}

Eduarda Elias Nunes'

Aldir Ferreira dos Santos Neto'

Thiago Araújo Gonçalo'

Israel Gondres Torné

Raimunda Cláudio Souza Gomes'

1Escola Superior de Tecnologia (EST) - Universidade do Estado do Amazonas (UEA) CEP 69050-020 - Manaus - AM - Brasil een.eng17@uea.edu.br, afsn.eng18@uea.edu.br,tag.eng18@uea.edu.br, itorne@uea.edu.br, rsgomes@uea.edu.br

\section{INTRODUÇÃO}

O setor elétrico da Amazônia necessita de diversificação das fontes de suprimento de combustíveis fósseis, assim como fomenta o uso de fontes renováveis de energia, portanto o projeto realizou um estudo crítico das fontes de geração de energia e sua utilização para garantir o fornecimento de eletricidade de maneira ambientalmente sustentável para a eletrificação dos sistemas isolados na Amazônia. A partir disso foi realizado um estudo da arte sobre as principais fontes de energias renováveis utilizadas do Brasil e na Amazônia, caracterizando os custos atuais de geração de eletricidade nessas comunidades isoladas, com isso ficou evidente que para esses sistemas as fontes de geração de energia renováveis mais viáveis de acordo com a análise de custos realizada neste trabalho são a solar fotovoltaica, biomassa e os sistemas híbridos.

\section{OBJETIVOS}

\subsection{GERAL:}

Estudo das alternativas energéticas baseadas em fontes de geração renováveis para a eletrificação nos sistemas isolados na Amazônia.

\subsection{ESPECIFICOS:}

1. Fazer um estudo da arte sobre as fontes de geração de energia renováveis.

2. Caracterizar os sistemas isolados de geração de energia no Amazonas. 
3. Caracterizar o custo atual da geração de energia nas comunidades isoladas.

\section{MATERIAIS E MÉTODOS}

0 projeto de pesquisa caracteriza-se pela realização de um estado da arte sobre geração de energia para eletrificação dos sistemas isolados da Amazônia, bem como consiste na execução de análises das alternativas energéticas que poderão ser utilizadas para suprir as necessidades dessas comunidades. 0 local de análise foram os sistemas isolados da Amazônia, caracterizados por comunidades ribeirinhas, áreas indígenas e comunidades quilombolas, além de unidades de conservação que não são atendidas pelo Sistema Interligado Nacional (SIN).

Foram realizadas pesquisas bibliográficas em livros, artigos, monografias, teses, manuais, catálogos e revistas publicadas nos últimos cinco anos e que possuam relevância para o aprofundamento no assunto em estudo e levantamento dos dados e informações relevantes para o trabalho.

A partir dessas pesquisas bibliográficas, foi feita a identificação e o mapeamento dos sistemas isolados da Amazônia. Caracterizando suas atuais formas de geração de energia elétrica. Elaborou-se com esse mapeamento um estudo do potencial desses sistemas isolados para determinar qual fonte de energia renovável mais apropriada para suprir as demandas energéticas dessas regiões. Determinouse que as energias renováveis que mais se encaixavam para essas regiões eram as Energias Fotovoltaicas e Biomassa, com isso foi executado um levantamento dos custos de implantação dessas fontes renováveis nos sistemas isolados identificados. Por fim foi realizado um estudo dos impactos ambientais e socioeconômicos, após a eletrificação nessas comunidades.

\section{RESULTADOS}

Com base nos resultados obtidos com as pesquisas, chegou-se à criação de duas tabelas referentes ao custeamento de tais energias nessas regiões isoladas: 
Tabela 1. Referente aos custos de um sistema de Biomassa para um gaseificador de $1 \mathrm{~kW}$.

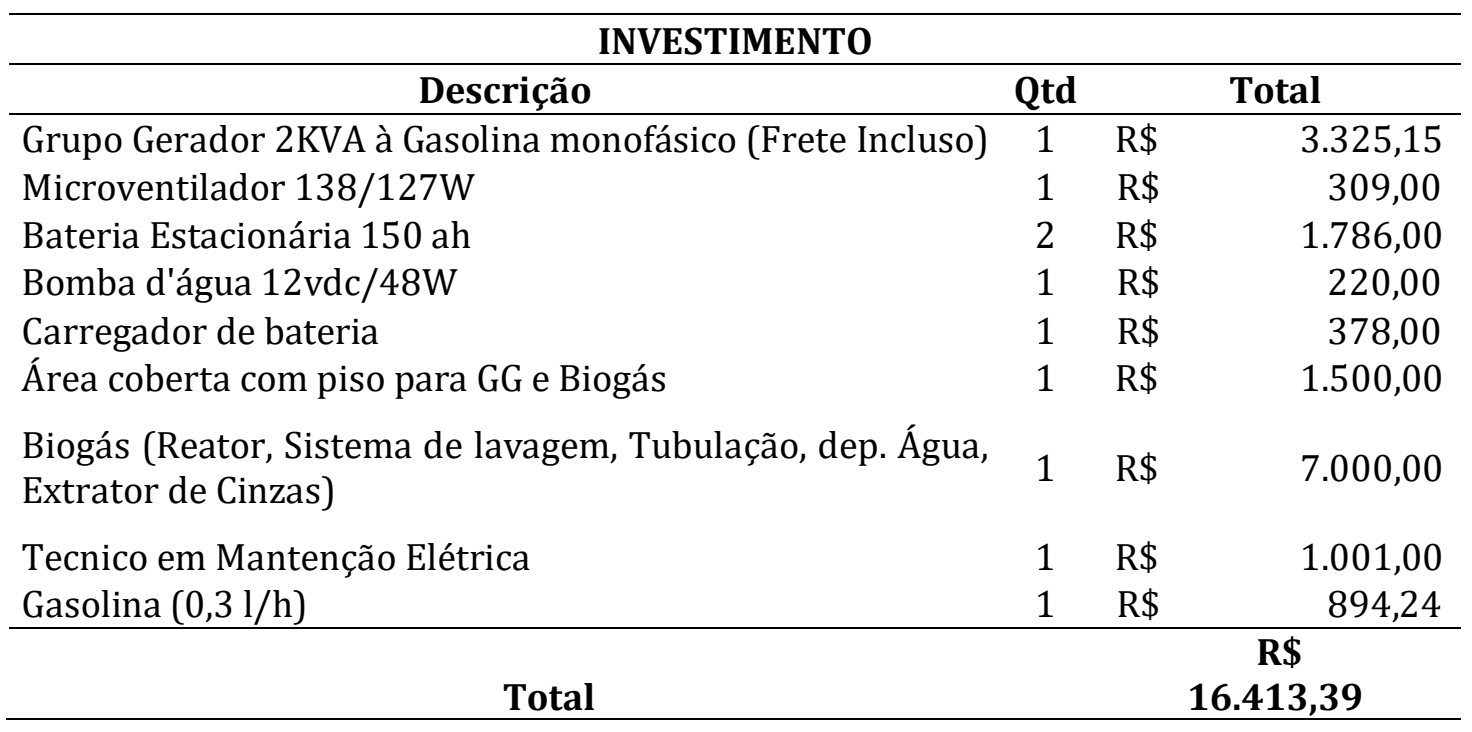

Fonte: BRASILEIRO, 2017.

Tabela 2. Referente aos custos de um sistema Fotovoltaico de $275 \mathrm{Wp}$.

\begin{tabular}{lcrrrrr}
\hline \multicolumn{1}{c}{ INVESTIMENTO } & & & \\
\hline \multicolumn{1}{c}{ Descrição } & Qtd & & \multicolumn{2}{c}{ Preço } & \multicolumn{2}{c}{ Total } \\
\hline Módulo FV Yingli 275Wp & 2 & $\mathrm{R} \$$ & 759,00 & $\mathrm{R} \$$ & $1.518,00$ \\
Controlador MPPT Epsolar 20 A 12/24V & 1 & $\mathrm{R} \$$ & 589,00 & $\mathrm{R} \$$ & 589,00 \\
Inversor Xander Xpower 1500W & 1 & $\mathrm{R} \$$ & $1.399,00$ & $\mathrm{R} \$$ & $1.399,00$ \\
Baterias de 220 Ah & 6 & $\mathrm{R} \$$ & $1.289,00$ & $\mathrm{R} \$$ & $7.734,00$ \\
Estrutura de Fixação/p2 módulos & 1 & $\mathrm{R} \$$ & 500,00 & $\mathrm{R} \$$ & 500,00 \\
marerial Elétrico & 1 & $\mathrm{R} \$$ & 400,00 & $\mathrm{R} \$$ & 400,00 \\
Projeto & 1 & $\mathrm{R} \$$ & 400,00 & $\mathrm{R} \$$ & 400,00 \\
Instalação & 1 & $\mathrm{R} \$$ & $1.600,00$ & $\mathrm{R} \$$ & $1.600,00$ \\
Frete para Baterias & - & $\mathrm{R} \$$ & $1.600,00$ & $\mathrm{R} \$$ & $1.600,00$ \\
Frete para Módulos, Controlador e Inversor & - & $\mathrm{R} \$$ & 800,00 & $\mathrm{R} \$$ & 800,00 \\
Tecnico em Mantenção Elétrica & 2 & $\mathrm{R} \$$ & 250,00 & $\mathrm{R} \$$ & 500,00 \\
\hline \multicolumn{1}{c}{ Total } & & $\mathbf{R} \$$ & $\mathbf{9 . 5 8 6 , 0 0}$ & $\mathbf{R} \$$ & $\mathbf{1 7 . 0 4 0 , 0 0}$ \\
\hline
\end{tabular}

Fonte: BRASILEIRO, 2017

\section{CONCLUSÃO}

De acordo com as pesquisas realizadas pode-se concluir que as alternativas mais viáveis para eletrificação dos sistemas isolados da Amazônia são a energia solar fotovoltaica fonte limpa com disponibilidade de radiação solar o dia todo e boa eficiência, assim como a biomassa, que é uma fonte renovável que pode ser gerada através de atividades agrícolas da própria comunidade e não causa grandes 
impactos ambientais, além dos sistemas híbridos que são mais seguros e estáveis visto que não dependem da sazonalidade e clima local.

A eletrificação dos sistemas isolados da Amazônia através de fontes renováveis é de extrema importância pois gera mais oportunidades de emprego e renda, melhoria na educação e saúde, além de proporcionar uma vida mais digna à população dessas comunidades.

Essas fontes de energia não agridem fortemente o meio ambiente e geram sustentabilidade visto que os moradores dessas regiões podem utilizar os resíduos de suas produções agrícolas para gerar energia por exemplo.

\section{REFERÊNCIAS BIBLIOGRÁFICAS}

BRASILEIRO, B. C. Análise de um modelo energético baseado no uso de biomassa residual local em comunidades isoladas no entorno da UHE de Tucuruí, PA. 2017. Dissertação (Pós-Graduação em Engenharia Elétrica) - Universidade Federal do Pará- Belém, 2017.

FREITAS, L. B. C; SANTOS, M. C; CASTRO, A. O. ENERGY EFFICIENCY IN THE AMAZONAS: THE SOLAR ALTERNATIVE. Journal of Engineering and Technology for Industrial Applications. Manaus, Amazonas, v. 5, n.19, p.151155. sept. 2019. DOI: https://dx.doi.org/10.5935/2447-0228.20190063 . Disponível em:https://www.itegam-jetia.org. Acesso em: 12 jun. 2021;

FREITAS, Josenildo. S; FREITAS, Josimar. S. MATRIZ ENERGÉTICA AMAZÔNICA: CONVENCIONAL OU RENOVÁVEL? Revista Observatorio de la Economía Latinoamericana, Blumenau, Santa Catarina, p. 1-6. dez. 2018;

INSTITUTO DE ENERGIA E MEIO AMBIENTE-IEMA. Acesso aos serviços de energia elétrica nas comunidades isoladas da Amazônia: mapeamento jurídicoinstitucional, São Paulo, jun. 2018; <https://www.energiaecomunidades.com.br/index.php/2021/02/24/ama zonia-legal-quem-esta-sem-energia-eletrica/>. Acesso em: 22 de ago. de 2021.

NASCIMENTO, B. Z et al. Avaliação da Viabilidade de Implementação de Sistemas Híbridos Renováveis para o Acesso de Energia na Região Amazônica. Revista Sociedade e Desenvolvimento, Vitória, Espírito Santo, p. 1-16. ago. 2019. DOI: http://dx.doi.org/10.33448/rsd-v8i10.1415;

MATIELLO, Sabrina et al.Energia e desenvolvimento: alternativas energéticas para comunidades isoladas da Amazônia. Revista Presença geográfica, Viçosa, Minas Gerais, v. 5-7, n.01, p.11-20. jul.2018. DOI: 10.36026/rpgeo.v5i1.2723 . Disponível em: https://www.researchgate.net/publication/335161648. Acesso em: 15 mar. 2021; 
DASSIE, Adriana Maria. Programa Luz para Todos: avaliação da cobertura com os dados disponíveis. ABEP, 2016. Disponível em: http://www.abep.org.br/publicacoes/index.php/anais/article/viewFile/27 18/2620. Acesso em: 20 jul. 2021;

RODRIGUES, Arlete Moysés. BRASIL. O programa luz para todos. alteração na produção do espaço e na reprodução da vida cotidiana. Universitat de Barcelona, 2019. Disponível em: http://www.ub.edu/geocrit/Electricidad-ytransformacion-de-la-vida-urbana/ArleteRodrigues.pdf. Acesso em 19 jul. 2021; 


\title{
SIMULAÇÃO DO SISTEMA ELÉTRICO DE POTÊNCIA DO MUNICÍPIO DE ANAMÃ -AM
}

\author{
Clemiltan Furtada' \\ Felipe Ferreira' \\ Felipe Jaime ${ }^{1}$ \\ Vinícius Barroso' \\ Fabriane Moreira de Dliveiral \\ Weverson Cirino ${ }^{2}$
}

1,2Escola Superior de Tecnologia (EST) - Universidade do Estado do Amazonas (UEA) CEP 69050-020 - Manaus - AM - Brasil cbdsf.eng20@uea.edu.br,ffr.eng20@uea.edu.br, fjfp.eng20@uea.edu.br, veb.eng20@uea.edu.br, fmdo.eng19@uea.edu.br,wdsantos@uea.edu.br

\section{INTRODUÇÃO}

A cidade de Anamã está localizada no interior do estado do Amazonas, a oeste de Manaus e cerca de $165 \mathrm{~km}$ da capital amazonense. Sua área é de aproximadamente $2453,934 \mathrm{~km}^{2}$ e de acordo com a estimativa feita pelo IBGE em 2020, possuía cerca de 13.956 habitantes. 0 município faz limite ao norte e a oeste com Anori, ao sul com Beruri e a leste com Manacapuru. A economia é baseada na agricultura e pesca.

O sistema elétrico de potência da cidade de Anamã proposto neste trabalho é formado por um parque gerador composto por seis geradores a gás natural que geram individualmente $433 \mathrm{~kW}$ de potência ativa efetiva e $250 \mathrm{kVAR}$ de potência reativa efetiva, sendo dois geradores de reserva.[1] A tensão produzida por cada gerador é de $3,45 \mathrm{kV}$ sendo que todos estão ligados em paralelo a um barramento conectado na Subestação Elevadora (SE1), que possui um transformador de distribuição T1 com relação de transformação 1:100, elevando a tensão para 34,5 kV e enviando para a Linha de Transmissão Principal (LTP) que conduz até a Subestação Abaixadora (SE2) localizada próximo a cidade. A SE2 possui um transformador de distribuição com relação de transformação 100:1, ou seja, ele abaixa a tensão de $34,5 \mathrm{kV}$ para 3,45 kV. Após ter a tensão abaixada na SE2, a energia elétrica pode ser distribuída na cidade por meio de quatro linhas de transmissão que 
possuem ao todo oito barramentos de distribuição secundária. Vale lembrar que este SEP proposto foi estimado, não possuindo valores idênticos ao Sistema Elétrico de Potência (SEP) original da cidade de Anamã, porém alguns dados são verídicos. [2]

Para realizar a simulação deste SEP foi utilizado o software Powerworld que é um simulador que possibilita fazer estudos, análises e simulações para fluxo de carga em sistemas elétricos de potência. A versão utilizada para a construção da simulação foi a Demo, que pode ser utilizada para pequenos sistemas, limitando o uso de no máximo treze barramentos e podendo ser adquirida gratuitamente no site www.powerworld.com.

\section{OBJETIVOS}

Utilizando os conhecimentos adquiridos no decorrer do desenvolvimento do Projeto STEM - Fluxo de Potência, o qual tem como professor orientador o Prof. Eng. Me. Weverson Cirino, este trabalho tem como objetivo apresentar a simulação do Sistema elétrico de Potência da cidade de Anamã no software Powerworld, versão Demo, utilizando dados estimados, depois definir ações corretivas em casos de contingências que podem ocorrer durante o funcionamento deste sistema elétrico de potência.

\section{MATERIAIS E MÉTODOS}

Os materiais foram gerados a partir de um cenário base proposto pelo professor orientador que retrata o sistema elétrico de potência da cidade de Anamã. "Este cenário não é o verídico, mas a partir de dados coletados do verdadeiro sistema elétrico de potência é possível construir o estudo de caso", assim diz o professor Weverson Cirino. [2] Dentre os principais materiais estão: os geradores, os barramentos elétricos, as linhas de transmissão e os transformadores.

O método utilizado foi uma análise do comportamento das tensões dos barramentos elétricos e das linhas de transmissão quando as cargas são distribuídas no sistema Powerworld sendo estabelecido uma tensão base de 0,95 a 1,05 pu. [3] Posteriormente, com o sistema montado foram feitas contingências, ou seja, o surgimento e a solução de um problema ou um mal funcionamento em alguma parte 
do sistema no intuito de checar como o sistema se comportaria e quais as melhores maneiras para sanar tais complicações sem prejudicar o bem estar e a economia da população de Anamã.

\section{RESULTADOS}

Ao buscarmos o material didático de construção dentro do Software PowerWorld, e analisar o template de criação podemos chegar ao seguinte resultado para o caso base, tendo isso como o material de estudo para simulação de contingências que podemos encontrar no dia a dia. É importante salientar que o resultado do caso base da distribuição de Anamã é simulado e não oficial, apesar de utilizar alguns valores reais que atuam na geração e distribuição de energia do local.

Sucintamente, após análise da imagem do Google maps proposta pelo professor, podemos transformar no seguinte dado do software. O caso base é composto por um parque gerador de 4 geradores principais e 2 reservas, nas quais são a Gás Natural SFGLD 440 Guascor Power de potência ativa efetiva de $433 \mathrm{~kW}$ e potência reativa efetiva de $250 \mathrm{kVAR}$. Eles estão interligados por uma subestação elevadora, devido a perdas na hora de levar essa energia para a cidade. Para distribuir a energia para a população, é necessário passar por uma outra subestação, dessa vez, abaixadora, que vai regular essa tensão novamente, para os parâmetros iniciais do parque gerador. Da subestação elevadora para a abaixadora, foram passados por 4 barramentos, entre o barramento principal (interligado com o gerador principal) e o seu posterior barramento, está conectado um transformador, cujos os dados serão indicados por tabela. Ele tem a função de elevar a potência e tensão, porque logo em seguida irá ser transmitido por uma longa linha de transmissão, resultará em perdas, mas não haverá prejuízo. 0 mesmo ocorre quando está próximo da cidade, irá passar por outros 2 barramentos que fazem parte da subestação 2 para abaixar e regular essa potência e tensão. Após a energia finalmente chegar até a cidade, estará pronto para a distribuição, que foram feitas em 4 LT's principais, cada LT tem um número específico de barramento e, consequentemente, números específicos de linhas de transmissão e seu tipo. Os dados também são explicados por tabela, cada barramento de LT também terá uma carga. De acordo com o tipo de linha de transmissão associado a LT, terá dados diferentes, de por exemplo, susceptância. Mas ainda não será o suficiente para o 
melhor funcionamento, devido a alguns barramentos estiverem fora do padrão de segurança $(0,95 \rightarrow 1,05)$, então serão feitos alguns incrementos para sua estabilidade.

Para fazer o ajuste foi necessário adicionar 3 linhas de transmissão, após isso as LT's estão interligadas por essas linhas de transmissão, foi possível obter, o barramento da LT 4, foi adicionado uma linha transmissão para o primeiro barramento da LT 1, e desse barramento foi adicionado outra linha de transmissão para o segundo barramento da LT2. Adicionamos também uma linha de transmissão que vai do primeiro barramento da LT2 para o segundo barramento da LT3, assim o caso base ficou estabilizado. Lembramos que ao adicionar as linhas de transmissão, o caso base que era fracamente malhado, se tornou também radial.

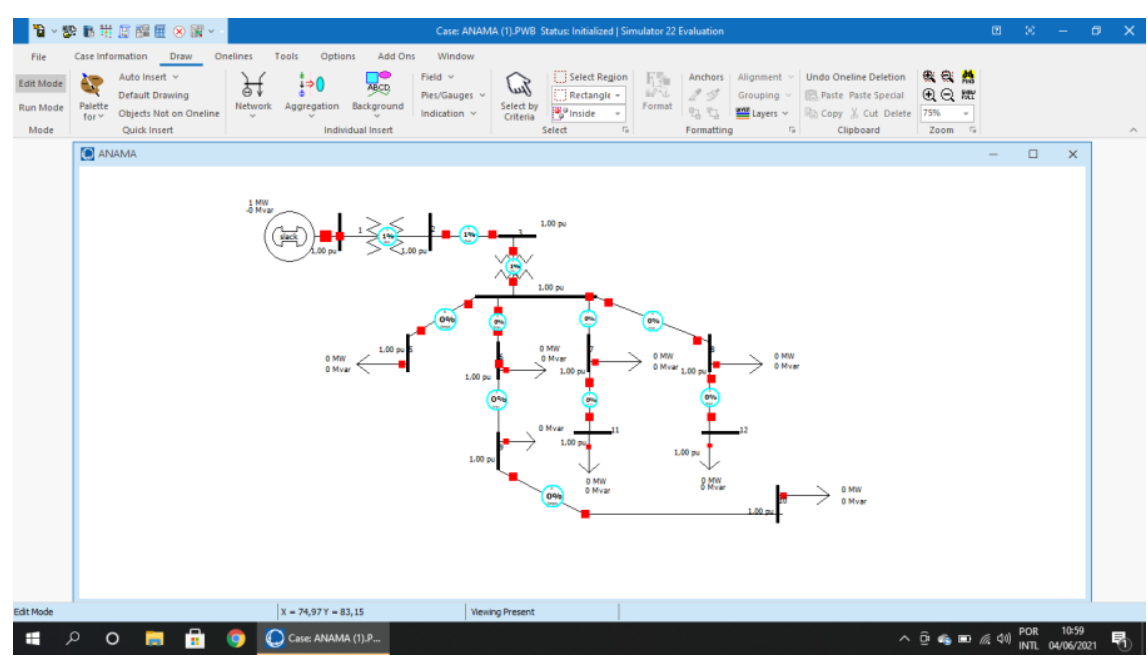

Figura 1. Caso Base do Sistema Elétrico de Potência criado no Powerworld. Fonte: 0 próprio autor.

Algumas contingências foram estudadas:

4.1) Perda da carga no segundo barramento da LT02: Foi proposto para a primeira simulação de defeito na distribuição de energia a perda da carga, neste caso, foi concluído que apesar de ter um aumento no PU dos barramentos, não foi realizado nenhum desligamento de disjuntor, pois o caso ainda esteve estabilizado apesar dessa falta, só será necessário, assim que possível, um eletricista resolver o problema.

4.2) Diminuição de $50 \%$ da geração no parque gerador: Nesta segunda Contingência o nosso case base teve uma queda na geração de $50 \%$, podemos considerar o apoio dos nossos dois geradores reservas e, apesar da redução no PU, 
ainda teve ótimos resultados para continuar funcionando sem grandes problemas, o PU permaneceu na faixa apropriada e segura.

4.3) Perda simultânea das LT3 e LT4: Perdemos duas linhas importantes para o funcionamento e estabilidade do caso base, com isso houve um prejuízo alarmante, pois uns barramentos passaram do seu limite possível. Dessa vez foi necessário verificar algumas cargas para o desligamento, a carga da LT3 no primeiro barramento foi desligada, também tivemos que dividir a carga da LT2 segundo barramento e LT3 segundo barramento, assim adicionamos duas cargas de menor valor que ao somarmos daria sua equivalência, fizemos isso porque esse trabalha com potência reativa, ou seja, é um edifício que trabalha com motores e equipamentos que precisam funcionar, um exemplo é que poderia ser um hospital, com um frigorífico guardando doação de sangue. Necessitamos ter uma atenção especial para propriedades que trabalham com potência reativa, pois são equipamentos que realmente precisam ter seu funcionamento priorizado.

4.4) Perda do transformador T2: 0 transformador da subestação abaixadora acabou de dar defeito no seu funcionamento, neste caso, após pesquisas relacionadas aos defeitos de partes primordiais na distribuição de energia elétrica, foi proposto um transformador reserva, visto que precisa ter em casos como este, onde uma cidade inteira poderia ficar sem energia (inclui até pontos importantes que precisam ter energia elétrica), este transformador reserva está localizado a $1 \mathrm{~km}$ do transformador T2 e deve ter o mesmo tamanho e parâmetros específicos.

Todas as Contingências foram casos proposto de defeitos no funcionamento da distribuição de energia elétrica que um município pode passar, as resoluções para os casos foram devidamente pesquisadas e estudadas de soluções que são realizadas nestes casos. As Contingências foram atribuídas para expandir o conhecimento sobre a área de utilização do software e, ao mesmo tempo, ter a consciência de problemas reais que podemos enfrentar.

\section{CONCLUSÃO}

Portanto, com esse experimento foi concluído que a análise do fluxo de potencias é fundamental para o abastecimento de energia da cidade de Anamã pois com ela podemos medir e controlar os geradores, as cargas, as linhas de transmissão e toda a sua distribuição. Com o uso do PowerWorld fica mais simples e nítido 
enxergarmos quaisquer problemas e principalmente resolve-los sem que afete a população e sem que ajam gastos desnecessários.

\section{REFERÊNCIAS BIBLIOGRÁFICAS}

[1] Cummins Brasil ltda. Soluções de Energia Grupos Geradores e Sistemas de Energia que se integram às suas necessidades. Guarulhos - SP. 2015, 18pgs.

[2] Notas das aulas sobre Introdução aos Sistemas Elétricos de Potência. Projeto STEM, Turma 1o Edital 2020/2021. Prof. Weverson dos Santos Cirino. Pilar Permanência. Escola Superior de Tecnologia - EST/UEA.

[3] CIRINO, Weverson dos Santos. Noções Básicas sobre o software PowerWorld. Apostila de sala de aula. Análise de Sispemas de Potênca. (Professor Weverson dos Santos Cirino). Universidade do Estado do Amazonas. Nov. de 2016. Impresso. 
ESTUDO SOBRE AS PRINCIPAIS DISTORÇÕES PRESENTES NO FORNECIMENTO DE ENERGIA ELÉTRICA

Felipe Seong Jae Won ${ }^{\prime}$

Lumma Cristina de Dliveira Maia'

Weverson dos Santos Cirino'

1Escola Superior de Tecnologia (EST) - Universidade do Estado do Amazonas (UEA) CEP 69050-020 - Manaus - AM - Brasil fsjw.eng18@uea.edu.br, lcdom.eng20@uea.edu.brwdsantos@uea.edu.br

\section{INTRODUÇÃO}

Diante de um sistema elétrico de potência, podemos entender que a geração, transmissão e distribuição da energia elétrica é de extrema importância, entretanto, um outro ponto de relevância é na utilização dessa energia elétrica dentro das unidades consumidoras, quer seja residenciais, comerciais ou industriais. Muitas cargas, ou seja, equipamentos elétricos-eletrônicos de diversos tipos e tamanhos possuem em seus manuais de especificação de funcionamento uma faixa de tensão adequada, a qual devem trabalhar. Isso também acontece com a frequência, outra grandeza elétrica importantíssima em uma rede de energia elétrica. Existem equipamentos sensíveis e que não funcionam quando acontece alguma flutuação ou achatamento do nível de tensão elétrica distribuído. Enfim, existem distorções que podem acontecer durante o fornecimento de energia elétrica aos consumidores e distorções causadas pelos consumidores, as quais afetam a qualidade da energia elétrica há outros consumidores.

Até hoje os benefícios da energia elétrica estão estampados e fazem parte do nosso dia-a-dia, tanto de pessoas como de empresas, fábricas e lojas. A partir dessa premissa é natural que se pense na Qualidade da Energia Elétrica. Logo de cara, ou seja, de forma explicita, o primeiro aspecto a se analisar é a continuidade do serviço, já que não podemos admitir qualquer interrupção do fornecimento, pois isso implicaria em transtornos em todas as esferas. De forma implícita, está a questão sobre a Qualidade da Energia Elétrica como um produto comercial, mesmo que não 
ocorram interrupções. Isso é possível de se perceber devido a falhas no funcionamento em alguns equipamentos.

O Procedimento de Distribuição de Energia Elétrica no Sistema Elétrico Nacional, em seu Módulo 08 [1] relaciona diversos aspectos que permite a avaliação da qualidade do fornecimento de energia elétrica, tais como: continuidade do fornecimento, nível de tensão, oscilações de tensão, desequilíbrios, distorções harmônicas de tensão e interferência em sistemas de comunicações. Dentro dos distúrbios referentes às oscilações de tensão, tem-se os distúrbios tipo impulso, oscilações transitórias, variações no valor eficaz (de curta ou longa duração), desequilíbrio de tensão e distorção harmônica, as quais provocam mudanças na forma de onda consumida, em relação a onda teórica puramente senoidal. Este trabalho descreve, como assim diz o título, estudar as principais distorções presentes no fornecimento de Energia Elétrica que influenciam diretamente na Qualidade da Energia Elétrica.

\section{OBJETIVOS}

Este trabalho tem como objetivos, apresentar as principais distorções presentes no fornecimento de energia elétrica, no caso, distorção harmônica, flutuação da tensão e variações de tensão de curta duração, bem como introduzir as formulas que quantificam essas distorções.

\section{MATERIAIS E MÉTODOS}

A metodologia aplicada neste trabalho foi baseada em etapas. Na $1^{\text {a }}$ etapa, iniciou-se com a Pesquisa Exploratória buscando literatura sobre todas as distorções que podem ser encontradas no fornecimento de energia elétrica provocadas por qualquer entidades que compõem a rede de distribuição de energia elétrica. Essa pesquisa foi realizada em sites de busca como o Google, Bing e Wolframalpha com palavras-chaves tais como: qualidade da energia elétrica, distorções no fornecimento de energia elétrica, onde várias fontes de pesquisas, tais como: artigos, dissertações, projetos, livros e apostilas foram listados, sendo que as principais constam neste trabalho como referências bibliográficas. A $2^{\underline{a}}$ etapa da metodologia foi uma Pesquisa Explicativa, a qual estabelece uma explicação sobre 
as distorções mais presentes no fornecimento de energia elétrica e que provocam distúrbios na forma de onda senoidal pura. As distorções selecionadas foram: a distorção harmônica, flutuação da tensão e variações de tensão de curta duração. Com base na literatura técnica pesquisada foram estabelecidas definições e formulação de equações para quantificar cada uma dessas distorções selecionadas. Os resultados foram colhidos

\section{RESULTADOS}

As principais distorções presentes no fornecimento de energia elétrica que serão apresentadas neste trabalho, são:

1. Distorção Harmônica: são fenômenos contínuos e não devem ser confundidos com fenômenos de curta duração, os quais duram apenas alguns ciclos. Estas perturbações no sistema podem normalmente ser eliminadas com a aplicação de filtros de linha, capacitor para correção do fator de potência combinado em série com um reator. Tecnicamente, um harmônico é um componente de uma onda periódica, cuja frequência é um múltiplo inteiro da frequência fundamental, no caso da energia elétrica, de $60 \mathrm{~Hz}$.

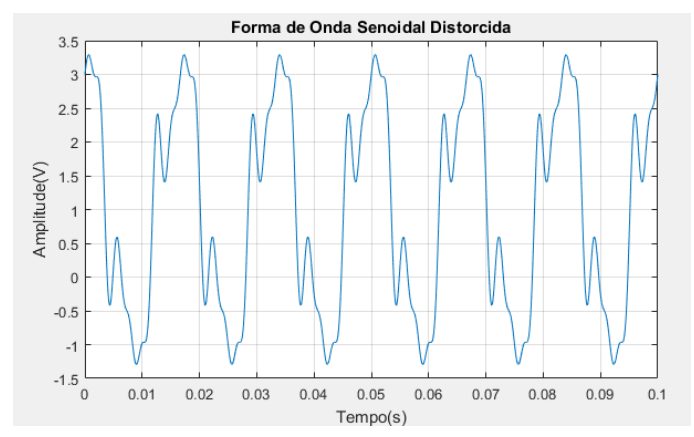

Figura 1. Exemplo de uma forma de onda com distorção harmônica. Fonte: o próprio autor.

O cálculo da Distorção Harmônica Total (DHT) da forma de onda senoidal distorcida, neste caso, de tensão, é dada pela equação (1): [1]

$$
D H T_{V}=\frac{\sqrt{\sum_{h=2}^{h \text { máx. }} V_{h}^{2}}}{V_{1}} x 100 \%
$$

2. Flutuação de Tensão (Flicher): este fenômeno é caracterizado pela variação aleatória, repetitiva ou esporádica do valor eficaz ou de pico da tensão instantânea. 
A determinação da qualidade da tensão do sistema de distribuição quanto à flutuação de tensão tem por objetivo avaliar o incômodo provocado pelo efeito da cintilação luminosa no consumidor, que tenha em sua unidade consumidora pontos de iluminação alimentados em baixa tensão. Os resultados da flutuação são obtidos mediante tratamento estatístico dos valores registrados nos índices Pst - Coeficiente de Segurança em Curta Duração (Pst) Coeficiente de Segurança em Curta Duração (Pst)Coeficiente de Segurança em Longa Duração (Plt) (Figura 2).

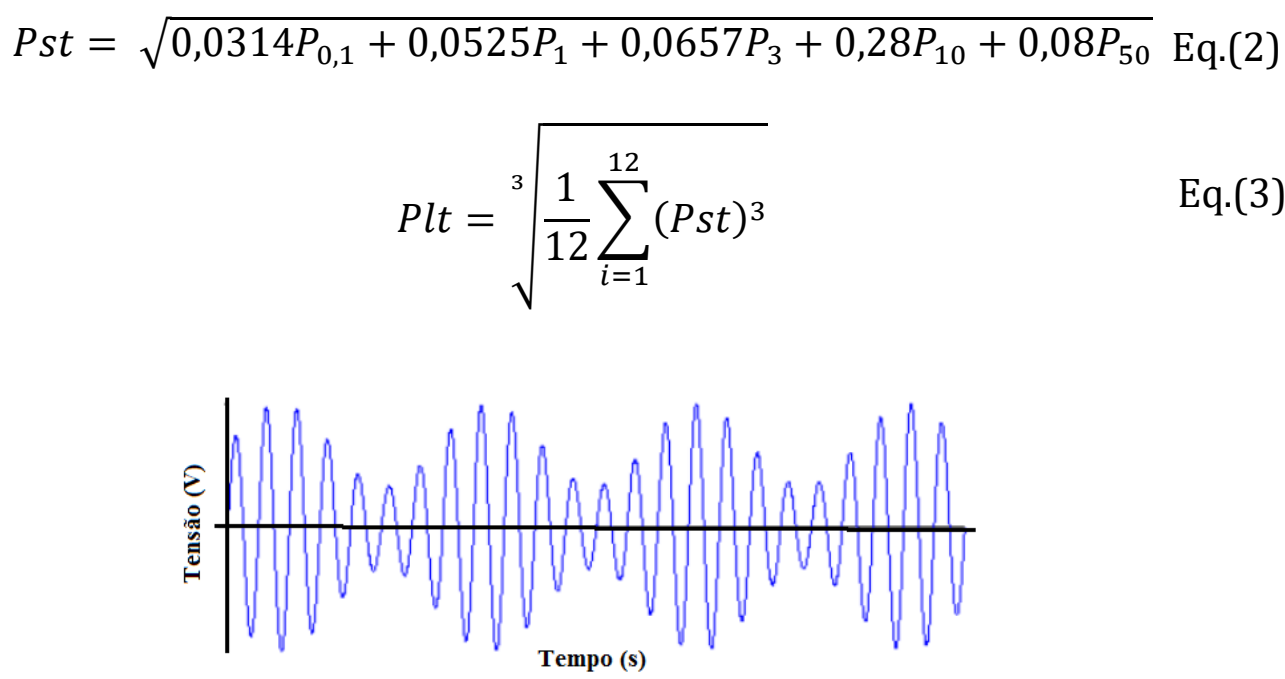

Figura 2. Forma de onda senoidal contendo flutuação de tensão.

Fonte: (VITORINO et al, 2006) [2].

3. Variações de Tensão de Curta Duração (VTCD): são desvios significativos na amplitude do valor eficaz da tensão durante um intervalo de tempo inferior a três minutos. As variações de tensão de curta duração são geralmente causadas por condições de faltas no sistema elétrico e pela energização de grandes blocos de carga que requerem elevadas correntes de partida. Dependendo da localização da falta e das condições operacionais do sistema, a falta pode causar uma elevação de tensão (swell), uma depressão de tensão (sag) ou, ainda, a perda completa da tensão (interrupção). 0 método de cálculo dos indicadores associados com as variações de tensão de curta duração são os seguintes: [3]

$$
V_{e}=\frac{V_{\text {res }}}{V_{\text {ref }}} * 100
$$

onde $V_{e}$ é a amplitude do evento de VTCD (em \%), $V_{\text {res }}$ a tensão residual do evento de VTCD (em Volt), e $V_{\text {ref }}$ a tensão de referência (em Volt) (Figura 3). 


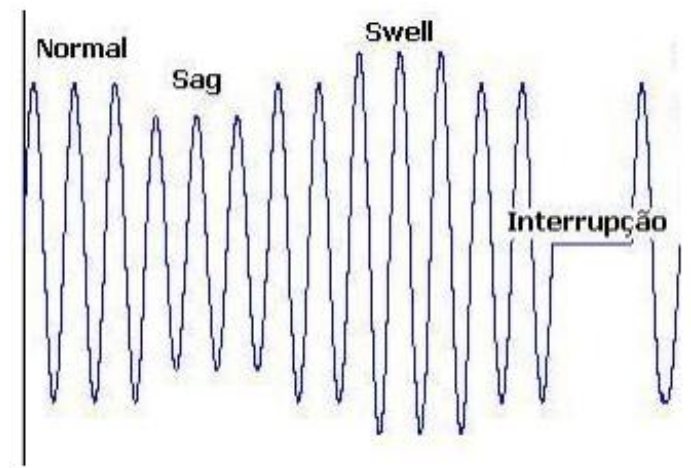

Figura 3. Forma de onda exemplificando todas as variações de tensão de curta duração. (da esquerda para direita: onda normal, Sag, Swell e interrupção).

Fonte: adaptado de [4].

$$
\Delta t_{e}=t_{f}-t_{i}
$$

onde: $\Delta t_{e}$ duração do evento de VTCD (em milissegundos), $t_{f}$ instante final do evento de VTCD, e $t_{i}$ instante inicial do evento de VTCD.

$$
f_{e}=n
$$

onde: $f_{e}$ é a frequência de ocorrência de eventos de VTCD, e $n$ é a quantidade de eventos de VTCD registrados.

O Fator de Impacto, para caracterização da severidade da incidência de eventos de VTCD, é calculado conforme a seguinte expressão:

$$
F I=\frac{\sum_{i=A}^{I}\left(f_{e i} * f_{P i}\right)}{F I_{\text {Base }}}
$$

Onde: $f_{e i}$ é a frequência de ocorrência de eventos de VTCD, apuradas por meio de medição apropriada, em um período de 30 dias consecutivos, para cada região de sensibilidade $i$, sendo $\mathrm{i}=\mathrm{A}, \mathrm{B}, \mathrm{C}, \mathrm{D}, \mathrm{E}, \mathrm{F}, \mathrm{G}, \mathrm{H}$ e I; $f_{p i}$ é o fator de ponderação para cada região de sensibilidade i, estabelecido de acordo com a relevância do evento, correlacionando sua amplitude e duração, e; $F I_{\text {Base }}$ é o fator de Impacto base, obtido do somatório dos produtos dos fatores de ponderação pelas frequências máximas de ocorrência em um período de 30 (trinta) dias de VTCD para cada região de sensibilidade.

A detecção e a caracterização dos eventos de VTCD deverão ser realizadas por meio de instrumentos de medição que considerem como parâmetro de 
referência uma tensão fixa ou uma tensão média deslizante, de acordo com a seguinte expressão:

$$
V_{s r(n)}=0,9967 * V_{s r(n-1)}+0,033 * V_{12 R M S}
$$

onde: $V_{s r(n)}$ é o valor calculado da tensão de referência; $V_{s r(n-1)}$ é o valor prévio da tensão de referência; e $V_{12 R M S}$ é o valor da tensão eficaz média de 12 (doze) ciclos mais recentes.

\section{CONCLUSÃO}

Este trabalho apresentou os tipos de distúrbios elétricos conhecido por Distorção Harmônica, Flutuação de Tensão (flicker) e Variações de Tensão de Curta Duração, no caso, o Sag, Swell e a Interrupção, os quais podem ocorrer no fornecimento de energia elétrica e distorcer a forma de onda senoidal produzida pela geração, caso os projetos dos equipamentos elétricos-eletrônicos não possuírem circuitos para detectar, eliminar ou mitigar essas distorções, como por exemplo, a utilização de filtros harmônicos. Também foi possível destacar que essas distorções, presente na rede de distribuição de energia elétrica, podem causar prejuízos, não só a rede como também a outros consumidores.

Além disso, neste trabalho foram apresentadas, de forma básica e rápida, as definições de cada distorções estudadas, bem como, foi possível apresentar o método de como elas podem ser quantificadas. Para trabalho futuro é importante estudar o que as normas brasileiras e internacionais definem como faixa ou limites aceitáveis para cada uma dessas distorções estudada neste trabalho.

\section{REFERÊNCIAS BIBLIOGRÁFICAS}

[1] Agência Nacional de Energia Elétrica. Procedimentos de Distribuição de Energia Elétrica no Sistema Elétrico Nacional - PRODIST. Módulo 8: Qualidade da Energia Elétrica. ANEEL.

[2] M. A. Vitorino, G. R. P. Almeida, L. V. Hartmann, M. B. R. Corrêa, and A. M. N. Lima. Nova técnica de busca do ponto de máxima potência para sistemas fotovoltaicos baseada na curva imax-vmax do gerador fotovoltaico. XVI CBA, 2006.

[3] Notas das aulas sobre Qualidade de Energia Elétrica. Projeto STEM, Turma 1o Edital 2020/2021. Prof. Weverson dos Santos Cirino. Pilar Permanência. Escola Superior de Tecnologia - EST/UEA.

[4] MARTINHO, Edson. Distúrbios da rede elétrica. 3 ed. rev. São Paulo: Erica, 2013. 
ENSAIOS E EXPERIÊNCIAS PRÁTICAS PARA O LABORATÓRIO DA DISCIPLINA DE MÁQUINAS ELÉTRICAS

Leandro Henrique de Souza Carrascosa

Nicolly Mharessa Sares de Souza

Wicttory Leônidas Pontes Da Silva

Pierre Macedo

Israel Gondres Torné

Escola Superior de Tecnologia (EST) - Universidade do Estado do Amazonas (UEA) CEP 69050-020 - Manaus - AM - Brasil lhdsc.eng20@uea.edu.br; nmsds.eng20@uea.edu.br,vpds.eng20@uea.edu.br,itorne@uea.edu.br; pmacedo@uea.edu.br.

\section{INTRODUÇÃO}

A grande evolução na área da Engenharia Elétrica é do conhecimento de toda a sociedade, especificamente no uso final da energia. Além da radical transformação que foi gerada em nossa vida diária, ela também provocou transformações profundas de conteúdo e forma no ensino das disciplinas que abrangem o curso de graduação de Engenharia Elétrica, assim como as expectativas do mercado de trabalho quanto ao profissional em formação. Devido ao seu caráter formativo, e à grande quantidade de alunos envolvida, é de fundamental importância que os laboratórios que atendem diferentes disciplinas sejam bem planejados e bem equipados, para garantir o elevado nível de ensino a que se propõe a UEA. Afirmando este fato de uma outra forma: Nada pode substituir uma experiência realizada em laboratório ou substituir a experiência prática ou pessoas tecnicamente preparadas e treinadas em laboratório para conectar, testar, inspecionar, dispositivos relacionados a máquinas elétricas.

\section{OBJETIVOS}

Elaborar práticas para laboratório relacionada as disciplinas de máquinas elétricas, nos tópicos: transformador elétrico, paralelismo de transformadores, montagem de banco trifásico, máquina de corrente contínua, máquina de indução trifásica, e gerador síncrono. Cada prática contendo, materiais e equipamentos, 
esquemas elétricos, orientações teóricas, e procedimentos práticos. Seguem-se também uma lista de equipamentos de medição e um manual de segurança. 0 manual de segurança contém regras de comportamento, vestimenta, cuidados com o equipamento e procedimentos de segurança. Para maior precisão nos cálculo e suporte gráfico apresentamos o MATLAB, Octave, ou Freemat.

\section{MATERIAIS E MÉTODOS}

0 trabalho foi desenvolvido consultando as principais referências bibliográficas e literatura que trata do estudo do processo de conversão eletromecânica de energia.

\section{RESULTADOS}

Apresentamos a seguir a relação de práticas e scripts produzidos (Figura 1), (Figura 2), (Figura 3) e (Figura 4).

Prática 1: Ensaio de polaridade em transformador

Prática 2: Montagem de dois transformadores em paralelo

Prática 3: Medição Resistencia CC

Prática 4: Ensaio do transformador em vazio

Prática 5: Ensaio do transformador em curto circuito

Prática 6: Montagem do banco trifásico em estrela

Prática 7: Montagem do banco trifásico em delta

Prática 8: Montagem do banco trifásico em delta aberto

Prática 9: Montagem do banco trifásico em delta zig-zag

Prática 10: Montagem do transformador como autotransformador

Prática 11: Ensaio da curva de magnetização da máquina CC

Prática 12: Controle de velocidade da máquina CC com excitação

independente

Prática 13: Controle de velocidade da máquina CC com excitação em paralelo

Prática 14: Ensaio de MIT em vazio

Prática 15: Ensaio de MIT com rotor bloqueado

Prática 16: Medição da resistência CC do MIT

Prática 17: Curva de magnetização do transformador

Prática 18: Ensaio do MIT de rotor bobinado como transformador

Prática 19: Determinação dos parâmetros elétricos da máquina síncrona

Prática 20: Curva de regulação do gerador síncrono

Prática 21: Ensaio em vazio com MIT de rotor bobinado

Prática 22: Partida MIT com chave soft-starter

Prática 23: Partida MIT com inversor de frequência

Script 1: Plotagem da indutância em um circuito magnético em função da permeabilidade magnética do material.

Script 2: Cálculo corrente e ângulo de fase. 
Script 3: Cálculo da corrente em um circuito.

Script 4: Gráfico da força eletromagnética em um solenoide.

Script 5: Gráfico regulação de tensão em um gerador síncrono.

Script 6: Gráfico potência de saída em um gerador síncrono.

Script 7: Gráfico da corrente de carga em um gerador síncrono.

Script 8: Uso da função spline.

Script 9: Gráfico ângulo de potência em uma máquina síncrona.

Script 10: Gráfico do conjugado em máquina síncrona de polos salientes.

Script 11: Gráfico da curva do torque eletromagnético para uma máquina de indução trifásica.

Script 12: Potencia disponível no eixo de uma máquina de indução trifásica.

Script 13: Gráfico da curva característica da potência para uma máquina CC com excitação série.

Script 14: Gráfico da curva característica da potência para uma máquina CC com excitação em paralelo;

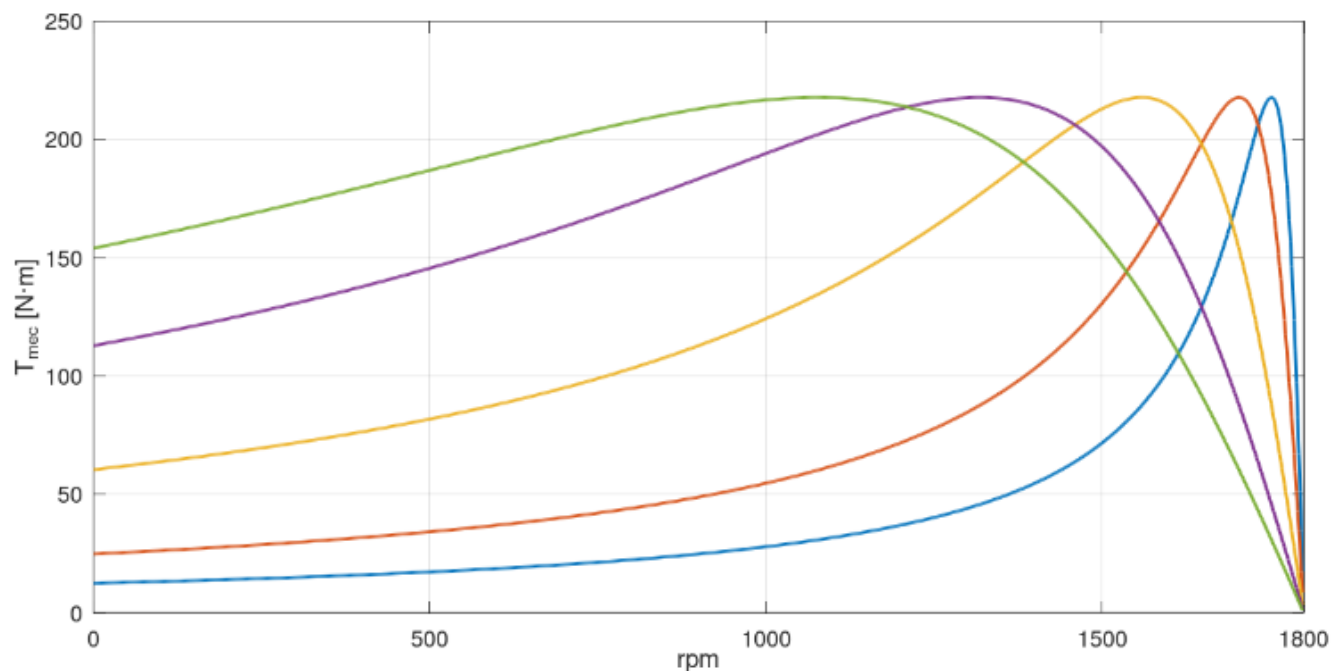

Figura 1. Gráfico da curva do torque eletromagnético para uma máquina de indução trifásica, para várias resistências do rotor, usando softwares: Octave, Matlab, ou Feemat.

Fonte: Autoria Própria.

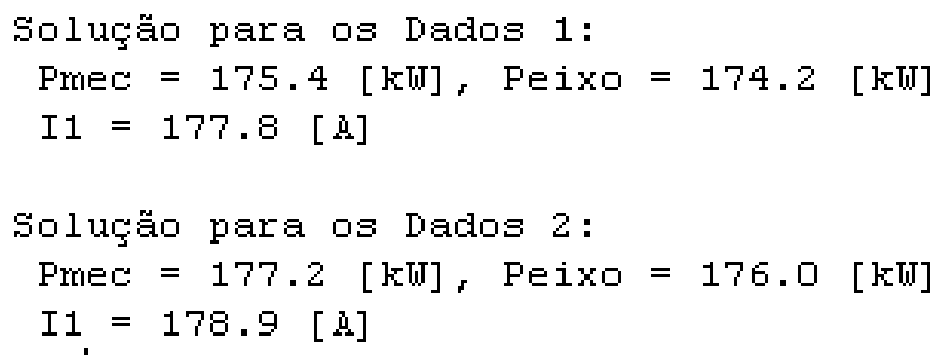

Figura 2. Potência mecânica da saída para MIT a partir dos parâmetros elétricos.

Fonte: Autoria Própria. 


\section{MANUAL DE SEGURANÇA E BOAS PRÁTICAS DO LABORATORIO DE MAQUINAS ELETRICAS}

O manual tem como finalidade especificar as regras e procedimentos a serem aderidas durante a realizações dos ensaios no laboratório de maquinas elétricas, o mesmo visa a prevenção de acidentes, e redução de riscos dos usuários ao laboratório.

\section{Sumário}

1. Introdução

2. Regras de comportamento

3. Regras de vestimenta

4. Cuidados com equipamentos e maquinas do laboratório

5. Procedimento de segurança

5.1. Em caso de acidentes

5.2. Em caso de Incêndio

Figura 3. Manual de segurança.

Fonte: Autoria Própria.

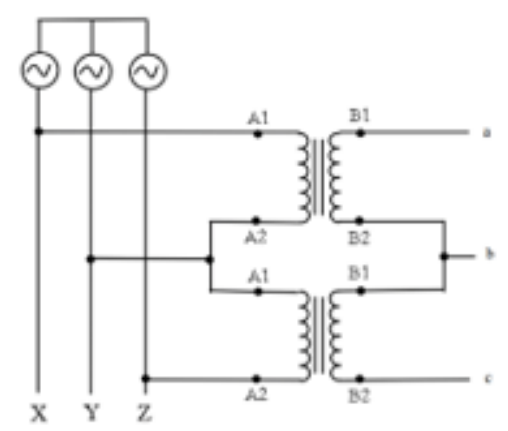

Figura 4. Esquema de ensaio do banco delta aberto.

Fonte: Autoria Própria.

\section{CONCLUSÃO}

Foram elaboradas 23 práticas para o laboratório de Máquinas Elétricas e 14 scripts para o tópico máquinas elétricas, além de orientações de segurança na forma de manual, guia passo a passo de cada experiência, com uma pesquisa das normas 
da ABNT relativa a cada ensaio. Adicionamos uma lista de equipamentos necessários a cada experimento.

Verificamos a escassez de literaturas associadas a estas práticas. Devido ao isolamento social por medidas de segurança não foi possível realizar as práticas elaboradas, sendo uma sugestão para novos trabalhos a realização das mesmas e eventuais adequações dos equipamentos especificados.

\section{REFERÊNCIAS BIBLIOGRÁFICAS}

Associação Brasileira de Normas Técnicas (2018). Máquinas Elétricas Girantes Parte 3: Motores de Indução Trifásicos - Métodos de Ensaio.

Chapman, S. J. (2013) Fundamentos de Máquinas Elétricas, AMGH Editora Ltda., 5aㅗ Edição, Porto Alegre.

Richardson, D. V. (1997). Laboratory operation for rotating electric machinery and transformer. Prentice Hall.

Umans, S. D.(2014) Máquinas Elétricas de Fitzgerald e Kingsley, AMGH Editora Ltda., 7a Edição, Porto Alegre. 
PANORAMA NACIONAL DE FONTES RENOVÁVEIS PARA GERAÇÃO DE ELETRICIDADE COMPARADA AO CENÁRIO DO ESTADO DO AMAZONAS

\author{
Marcus Vinicius Bezerra da Cunha' \\ Lorena Brandão de Souza' \\ Victor Hugo Kroeff Araujo' \\ Israel Gondres Torné
}

1Escola Superior de Tecnologia (EST) - Universidade do Estado do Amazonas (UEA) CEP 69050-020 - Manaus - AM - Brasil mvbc.eng17@uea.edu.br, lbds.eng20@uea.edu.br, vhka.eng19@uea.edu.br, itorne@uea.edu.br

\title{
1. INTRODUÇÃO
}

O Brasil possui uma matriz energética diversificada. No entanto, é necessário aumentar a participação dessas fontes estudadas a fim de reduzir o impacto das crises hídricas, e ainda, diminuir a dependência do país sobre combustíveis fósseis [LIMA et al., 2020]. O Estado do Amazonas, região de estudo deste trabalho, possui enorme potencial para produção de energia elétrica a partir de fontes solar fotovoltaica, biomassa e seus derivados. A subseções seguintes apresentam os principais resultados a respeito.

\section{OBJETIVOS}

O presente trabalho possui por objetivo apresentar a matriz de geração de energia elétrica nacional, com foco em energias renováveis. E comparar esse panorama com o cenário do Estado do Amazonas (Brasil), ressaltando as recentes expansões da fonte solar fotovoltaica.

\section{MATERIAIS E MÉTODOS}

Com base em diversos trabalhos publicados na área de fontes de energia renováveis, mitigação da emissão de gases de efeito estufa e consequente redução do consumo de combustíveis fósseis, decidiu-se pesquisar as fontes de energia solar fotovoltaica e biomassa. Visto a enorme quantidade de localidades remotas da 
Floresta Amazônica as quais não possuem acesso regular a energia elétrica, por não estarem conectadas ao Sistema Interligado Nacional (SIN), escolheu-se limitar os dados relacionados à geração de eletricidade para o Estado do Amazonas.

Os dados foram extraídos das publicações fornecidas publicamente pela Empresa de Pesquisa Energética, entre elas Anuário Estatístico de Energia 2021, Balanço Energético Nacional 2021 e ferramentas interativas. O Histórico de Operação, disponibilizado pelo Operador Nacional do Sistema Elétrico (ONS), também foi utilizado. Procurou-se manter as informações coletadas delimitadas entre os anos de 2016 a 2020, totalizando cinco anos. A pesquisadora Lorena Brandão realizou visita técnica em campo de fazenda solar.

\section{RESULTADOS}

Conforme verifica-se no Balanço Energético Nacional [BEN 50 anos], publicado pela Empresa de Pesquisa Energética (EPE), as fontes de energia renováveis forneceram até $83 \%$ da Oferta Interna de Energia Elétrica (OIEE) em 2019. Este índice varia bastante com a sazonalidade durante o ano, pois isso afeta diretamente a produção de energia elétrica nas usinas hidrelétricas (UHE), cuja hidráulica é a principal fonte renovável no Brasil, com produção de 47,198 MWmed (71,3\% da geração total), entre 2016 e 2020 [CUNHA et al., 2021].

Também, a energia eólica vem-se destacando como fonte de geração de energia elétrica promissora. No último ano (2020) a produção de energia elétrica por fonte eólica alcançou 57,051 GWh, somente o subsistema Nordeste foi responsável pela produção de $85,7 \%$ dessa energia, seguido pelo subsistema Sul $(11,4 \%)$ e demais subsistemas (2,9\%) [EPE, 2021; ONS, 2021].

Com advento da Resolução Normativa (REN) n 687, publicado pela Agência Nacional de Energia Elétrica (ANEEL) em 2015, a qual revisou a REN no 482/2012 e a seção 3.7 dos Procedimentos de Distribuição de Energia Elétrica no Sistema Elétrico Nacional (PRODIST), houve diversas melhorias no custo e tempo para a conexão de micro e minigeração distribuída, além do incentivo à geração distribuída trazido pelo Sistema de Compensação de Energia Elétrica. Assim, a produção de energia elétrica através de fonte solar fotovoltaica começou a crescer a partir de 2016 (Figura 1), culminando na produção de 10,717 GWh em 2020 [EPE, 2021]. 


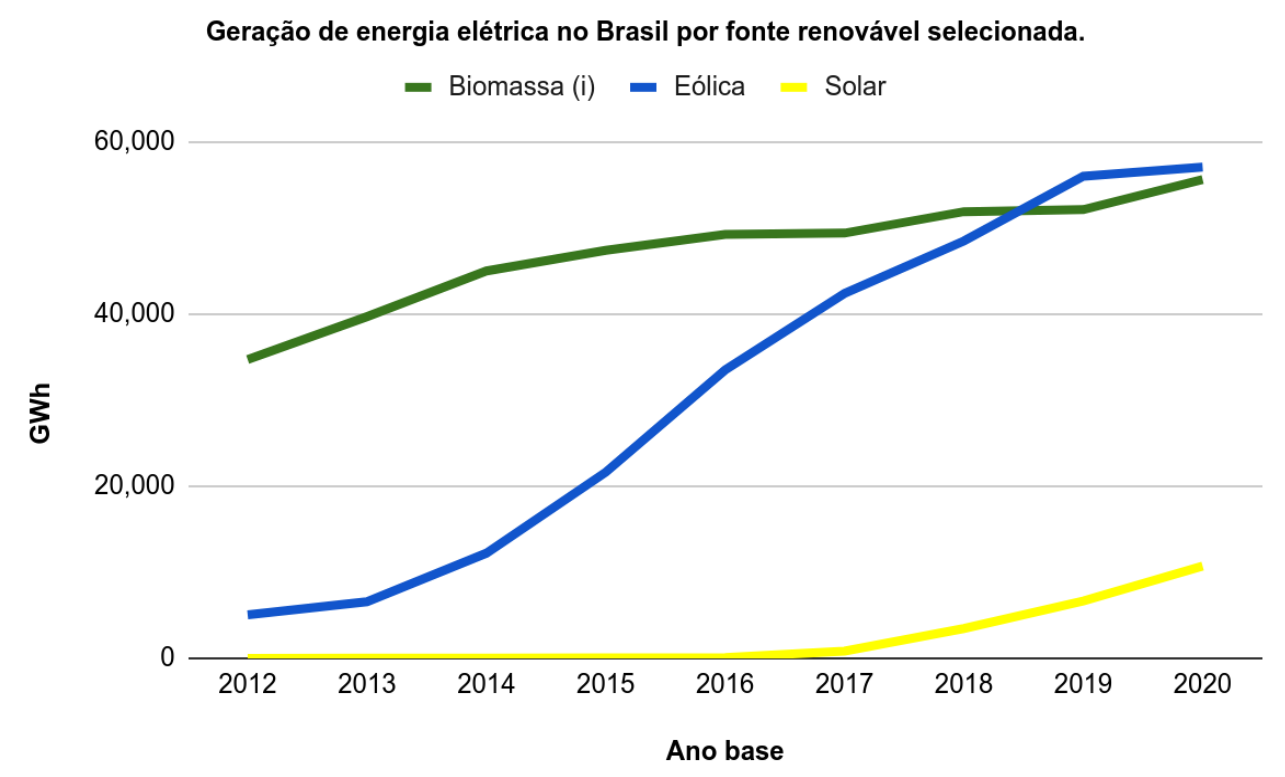

Figura 1. Geração de energia elétrica por fonte renovável selecionada durante os anos de 2012 a 2020. Fonte: Anuário Estatístico de Energia Elétrica 2021, EPE. (i) Biomassa: Lenha, bagaço de cana-de-açúcar e lixívia.

No Brasil, a cana-de-açúcar e a lixívia (resíduo líquido escuro obtido após o processo de cozimento da madeira) são os recursos mais utilizados para a produção de bioeletricidade, com $76,8 \%$ e $17,5 \%$ da capacidade instalada respectivamente [Oliveira et al., 2020]. A maior produção de bioeletricidade por cana-de-açúcar encontra-se na região Sudeste, enquanto a produção de bioeletricidade a partir de lixívia encontra-se nas regiões Nordeste, Sul e Centro-Oeste brasileiro, onde ocorrem os polos da indústria de celulose e papel [Oliveira et al., 2020].

Por fim, os biocombustíveis também são uma fonte renovável e podem ser utilizados para produção de eletricidade a partir de geradores a óleo diesel. A produção de biodiesel (B100) no Brasil foi de 5,3 Mtep em 2020, com acréscimo de 8,6\% em relação ao ano de 2019 [EPE, 2021].

Os principais insumos para a produção do biodiesel (B100) no Brasil são óleo de soja, metanol e outros materiais graxos (EPE, 2021). Com o percentual de biodiesel adicionado no diesel fóssil chegando a 11\% (B11), os Sistemas Isolados (SISOL), dentre os quais $94,6 \%$ são atendidos por termelétricas a óleo diesel [CUNHA et al., 2021], também se tornam mais sustentáveis e energeticamente diversificados. 
O Estado do Amazonas possui 95 unidades isoladas do SIN, correspondendo a cerca de 45,5\% de todo o SISOL [CUNHA et al., 2021], muitos desses atendidos por geradoras a óleo diesel. À parte da geração de eletricidade pela usina hidrelétrica de Balbina (UHE), o estado todo é alimentado por termelétricas, sendo gás, gás natural e petróleo os principais combustíveis utilizados (Figura 2).

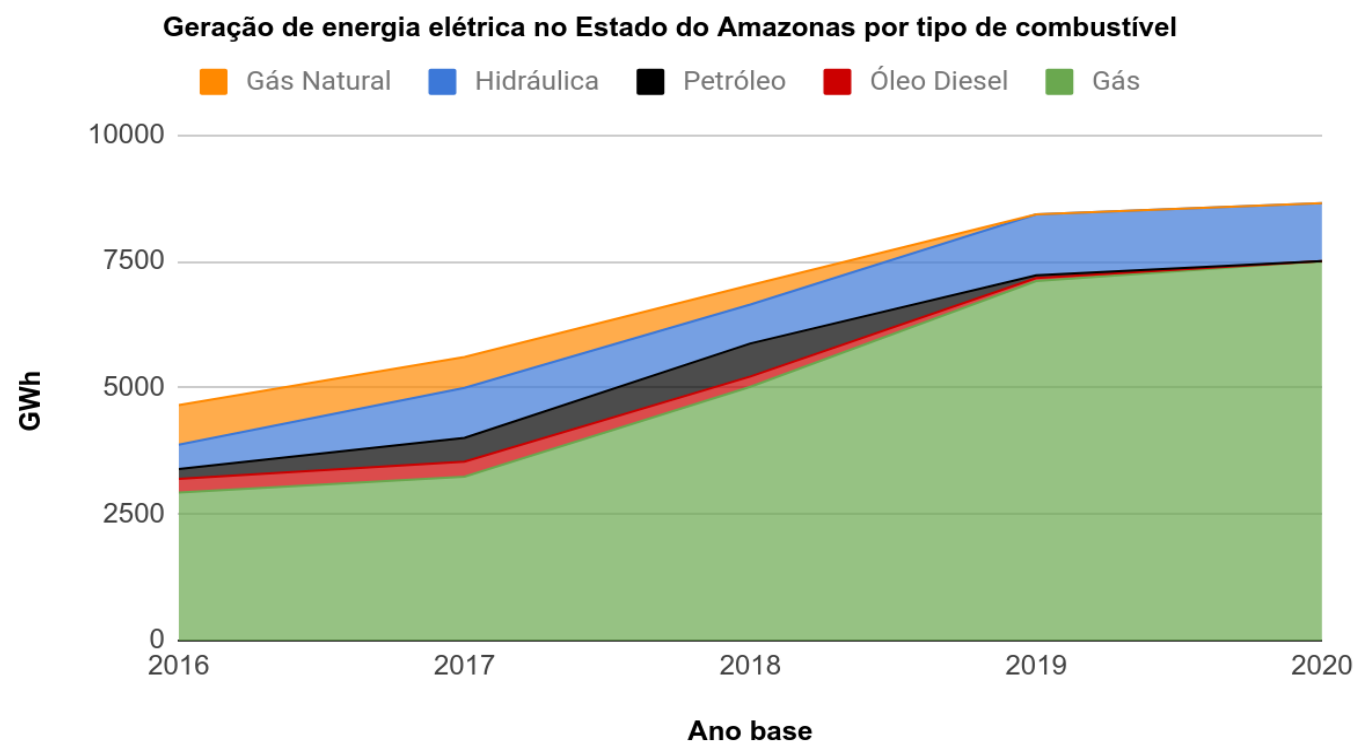

Figura 2. Geração de energia elétrica no Estado do Amazonas por tipo de combustível durante os anos de 2016 a 2020. Fonte: Histórico de Operação, ONS.

Seguindo a tendência de crescimento de micro e minigeração distribuída (GD) vista no cenário nacional, o Estado do Amazonas passou a produzir energia a GD significativa a partir de 2017, com produção total de 17 GWh em 2020, tanto para autoconsumo quanto para injeção na rede (Figura 3-i),. Um dos investimentos ganhando notoriedade é a fazenda solar localizada na AM-010 km 23. Fruto da parceria com a Bemol Solar, a fazenda possui carga instalada de $30 \mathrm{MWp}$ e atualmente está em fase de finalização e teste (Figura 3-ii). 


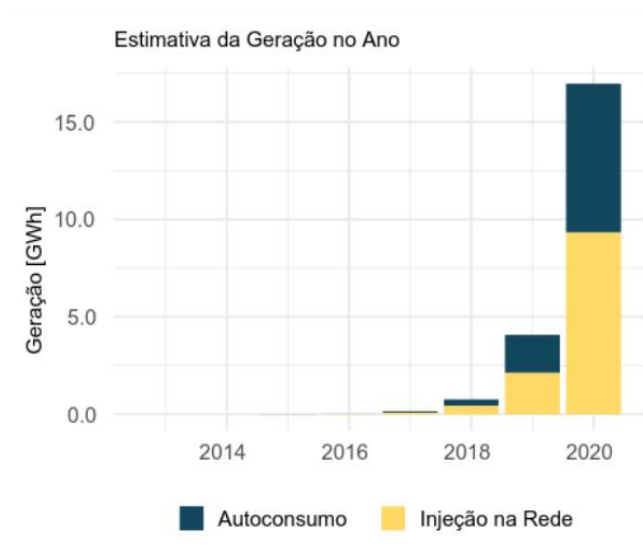

(i)

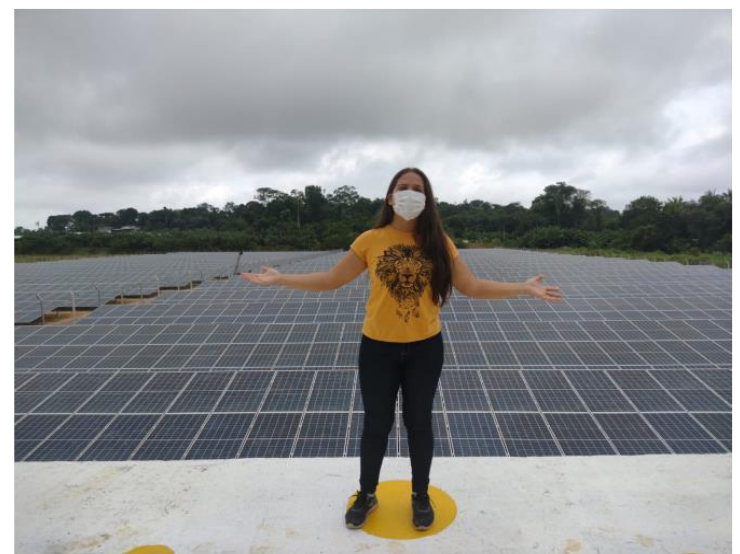

(ii)

Figura 3. (i) Produção elétrica por mini e microgeração distribuída no Estado do Amazonas. Fonte: PDGD, EPE. (ii) Pesquisadora Lorena Brandão na fazenda solar com capacidade de $30 \mathrm{MWp}$. Fonte: própria.

\section{CONCLUSÃO}

0 presente trabalho identificou e ressaltou como o Brasil é um país com matriz elétrica diversificada, e assim como sugerido por diferentes autores o país necessita de maior participação das fontes solar fotovoltaica, biomassa e seus derivados, de modo a reduzir o consumo de combustíveis fósseis e diminuir a dependência do sistema nas usinas hidrelétricas.

Verificou-se que o Estado do Amazonas é alimentado quase inteiramente por usinas termelétricas, as quais usam gás, gás natural e petróleo como principais combustíveis. A contribuição de micro e minigeração distribuída cresce bastante nos setores residenciais e comerciais, com uso de fonte solar fotovoltaica.

A biomassa também deve ser utilizada em breve, já que os recursos florestais presentes na Floresta Amazônica são abundantes.

\section{REFERÊNCIAS BIBLIOGRÁFICAS}

AGÊNCIA NACIONAL DE ENERGIA ELÉTRICA - ANEEL. Micro e minigeração distribuída: sistema de compensação de energia elétrica. 2. ed. Brasília: ANEEL. 2016.

CUNHA, M. V. B., SOUZA, L. B., ARAUJO, V. H. K., TORNÉ, I. G. Análise da carga e geração de energia elétrica do subsistema Norte com inclusão dos sistemas isolados. 1st Brazilian Congress of Engineneering. 2021.

Empresa de Pesquisa Energética- EPE. Balanço Energético Nacional: Relatório Síntese 2021, Ano base 2020. 
Empresa de Pesquisa Energética- EPE. Painel de Dados de Micro e Minigeração Distribuída (PDGD). Disponível em: http://shinyepe.brazilsouth.cloudapp.azure.com:3838/pdgd/. Acesso em: 10 set. 2021.

Empresa de Pesquisa Energética. Anuário Estatístico de Energia Elétrica 2021: ano base 2020. Brasília, 2021.

LIMA, M.A., MENDES, L.F.R., MOTHÉ, G.A., LINHARES, F.G., CASTRO, M.P.P. de, SILVA, M.G. da, STHEL, M.S. Renewable energy in reducing greenhouse gas emissions: Reaching the goals of the Paris agreement in Brazil. Environmental Development, v. 33, 2020.

OLIVEIRA, L. L., KERDAN, I. G., RIBEIRO, C. O., NASCIMENTO, C. A. O., REGO, E. E., GIAROLA, S., Hawkes, A. Modelling the technical potential of bioelectricity production under land use constraints: A multi-region Brazil case study. Renewable and Sustainable Energy Reviews, v. 123. 2020.

OPERADOR NACIONAL DO SISTEMA ELÉTRICO - ONS. Histórico de operação. Disponível em: http://www.ons.org.br/paginas/resultados-daoperacao/historico-da-operacao. Acesso em: 10 set. 2021. 


\title{
OS IMPACTOS DA CRISE HÍDRICA NO SETOR ELÉTRICO BRASILEIRO
}

\author{
Sterfany da Silva Dliveira' \\ Victoria dos Santos Andrade' \\ Daniel Guzmán del Rio' \\ Daniel Sousa da Silva'
}

${ }^{1}$ Escola Superior de Tecnologia (EST) - Universidade do Estado do Amazonas (UEA) CEP 69050-020 - Manaus - AM - Brasil sdso.ele19@uea.edu.br, vdsa.ele20@uea.edu.br, drio@uea.edu.br, dass.eng@uea.edu.br

\section{INTRODUÇÃO}

O Brasil é abastecido por um sistema hidro-termo-eólico de grande porte. Esse sistema é chamado de Sistema Interligado Nacional (SIN) que compreende as regiões sudeste, centro-oeste, sul, nordeste e norte, com exceção de alguns estados brasileiros (ESFERA ENERGIA, 2021).

Em 2001, ocorreu um grande racionamento de energia, onde cerca de 89,3\% de toda a energia no Brasil era gerada em hidrelétricas. E atualmente, em 2021, o Brasil registrou a pior crise hidrológica em 91 anos. Segundo Macário (2021), as consequências do baixo volume de chuvas atravessam vários setores (da agricultura à oferta de água para grandes cidades) e impactam diretamente a geração de energia.

Diante dessa dependência por recursos limitados, os investimentos para o desenvolvimento tecnológico, direcionados ao setor de energia, são cada vez mais necessários, além da execução de um plano estratégico que incentive a participação de fontes renováveis, diversificando o SIN e contribuindo para o desenvolvimento sustentável do país, conforme Pinheiro (2020).

\section{OBJETIVOS}

O objetivo deste trabalho foi desenvolver uma pesquisa referente as crises hídricas sofridas pelo país em 2001 e 2021, relatando sobre os motivos que a levaram para tal situação e reunindo propostas para conter e/ou evitar que futuros 
cenários de escassez hídrica afetem criticamente o abastecimento de energia elétrica.

\section{MATERIAIS E MÉTODOS}

O estudo foi realizado através de uma revisão de literatura baseada no estado da arte, em que foi aplicado um critério de tempo entre 2000 e 2004 a respeito do assunto de racionamento de energia ocorrido em 2001-2002. Outro critério considerado foi entre os meses de maio a setembro de 2021 para o problema da atual crise hídrica.

Além disso, também foram levados em consideração alguns artigos, dissertações e sites entre os anos 2018 a 2021 que abordam informações relevantes para melhor entendimento e desenvolvimento do assunto.

\section{RESULTADOS}

O Brasil já passou por algumas crises no setor elétrico, porém a mais severa ocorreu entre junho de 2001 e fevereiro de 2002 quando houve um período de racionamento de energia elétrica. Essa crise se estabeleceu por diversos fatores e um deles foi que na época a matriz energética brasileira era em sua maior parte, mais de 90\%, composta por hidrelétricas.

Com isso, regiões como sudeste e centro-oeste passaram por uma forte estiagem que já vinha apresentando sinais desde 1998 e foi questão de tempo para que culminasse em reservatórios com níveis baixíssimos.

Além disso, também houve falhas na gestão, de tal forma que o país apresentou um déficit entre geração e consumo onde o consumo anual acabou se tornando maior que a capacidade instalada. Segundo Oliveira (2021), problemas como falta ou o atraso de obras de transmissão e geração de energia contribuíram para o agravamento da crise conforme o relatório realizado pela Comissão de Análise do Sistema Hidrotérmico de Energia Elétrica.

Na tentativa de resolver o problema, o governo de Fernando Henrique Cardoso optou pela implementação de uma nova fonte de energia, as termelétricas, que usaria como combustível o gás natural. No entanto, o plano acabou fracassando por falta de investidores. 
Vinte anos após a tenebrosa crise hídrica, o Brasil preocupa-se novamente. Isto por que o país enfrenta a pior crise hidrológica dos últimos 91 anos nas regiões centro-oeste e sul. Um levantamento realizado pelo Operador Nacional do Sistema Elétrico (ONS) mostrou que, nos últimos sete anos, os reservatórios das hidrelétricas, ainda responsáveis pela maior parte da energia gerada, agora cerca de $60 \%$, receberam um volume de água inferior à média histórica, estando apenas com um percentual de $23 \%$ de água nos reservatórios.

Apesar dos níveis recordes mencionados, a matriz elétrica brasileira nos últimos 20 anos passou por algumas modificações. Segundo a Empresa de Pesquisa Energética (EPE), a matriz elétrica no ano de 2020 se encontrava conforme gráfico da figura 1B. Devido a essa diversificação ainda não estamos vivenciando um racionamento elétrico (Figura 1 ).

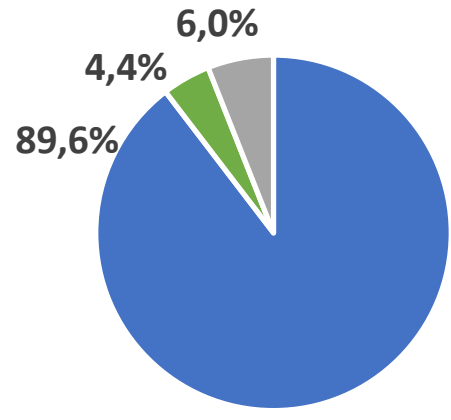

- HIDRELÉTRICA - NUCLEAR - TÉRMICA

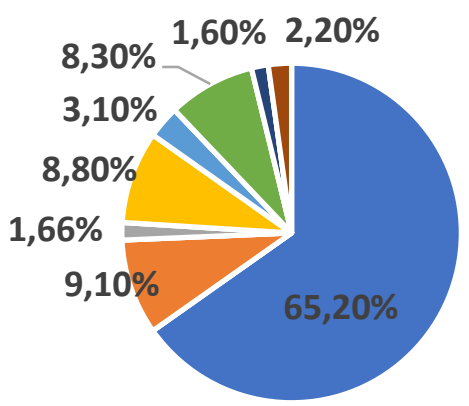

- HIDRELÉTRICA

SOLAR

- CARVÃO E DERIVADOS

- DERIVADOS DE PETRÓLEO

- BIOMASSA

- EÓLICA

- GÁS NATURAL

- NUCLEAR

Figura 1. [A] Matriz elétrica brasileira de 2001. [B] matriz elétrica brasileira de 2021, com ano base 2020.

Fontes: [A] Adaptado de ONS. [B] Adaptado de EPE, BEN2021.

Após analisar os dados coletados através do mapeamento realizado pelo MapBiomas - um projeto de mapeamento anual do uso e cobertura da terra no Brasil - entre os anos de 1985 e 2020, pesquisadores puderam constatar que o território brasileiro está perdendo superfície de água desde o início dos anos 90, isso significa que todos os biomas que compõem o território sofreram redução hídrica.

Outro fator que contribui para o agravamento da escassez hídrica é o desmatamento na região Amazônica, visto que a floresta funciona como uma bomba 
que suga a umidade do oceano Atlântico ocasionando as chuvas, contribuindo para o equilíbrio do ciclo hidrológico. Desta forma, a umidade gerada é direcionada para diferentes regiões.

Diversos estudos demonstram que o aumento de desmatamento altera essa fonte de umidade. Segundo o monitoramento Sistema de Detecção do Desmatamento em Tempo Real (DETER) do Instituto Nacional de Pesquisas Espaciais (INPE), o desmatamento da Amazônia Legal alcançou uma área de 2547,7 $\mathrm{km}^{2}$, alta de $25 \%$ em relação a igual período do ano passado.

O sistema de abastecimento de energia brasileiro se destaca por uma gestão integrada das usinas, conhecido como Sistema Interligado Nacional (SIN), onde as regiões com maior capacidade de geração contribuem no abastecimento de outras áreas.

Esta condição aumenta a dependência das usinas localizadas em outros subsistemas, principalmente das hidrelétricas com grande capacidade de geração em períodos chuvosos, como é o caso da usina de Belo Monte, que conta com 18 turbinas e é umas das maiores do Brasil, segundo o Canal Energia (2021).

Durante a atual crise, a usina classificada como fio d'água, ou seja, não possui reservatório, está operando com apenas 1 das 18 turbinas existentes pela baixa vazão do Rio Xingu. Segundo a ONS, em 08 de setembro foram gerados apenas 244 MW. Gráfico do ONS mostra que a mesma atingiu o pico de geração, em 2021, no dia 27 de fevereiro, durante o período chuvoso. Nesse dia, a usina distribuiu para o sistema 11,1 GW. Desde 24 de maio, a geração teve trajetória decrescente (Figura 2).

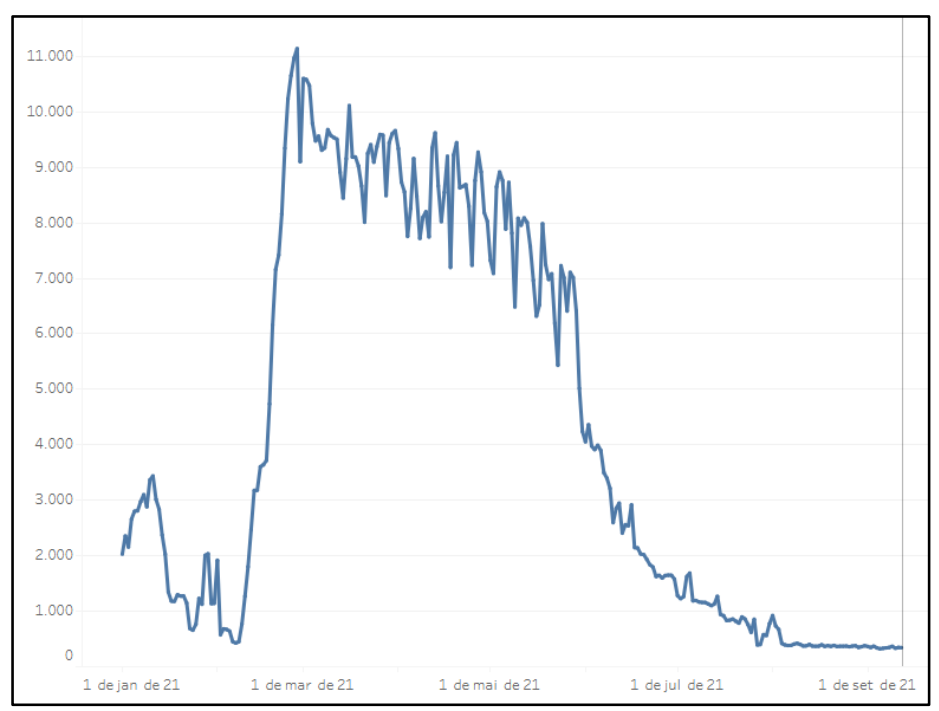


Figura 2. Gráfico da Geração de Energia da Usina de Belo Monte Fonte: ONS

Na ausência dessa geração, o país é obrigado a recorrer às termelétricas, que geram energia a um custo elevado. Esta medida gerou sucessivos reajustes de aumento tarifário aos consumidores. Desta forma, a seca impulsiona a inflação, e como resultado, o Brasil mais que dobrou o volume de energia elétrica importada em agosto (UOL, 2021).

Visando adotar medidas para mitigar os efeitos gerados pelas atividades humanas, no Brasil, a EPE realizou estudos e elaborou o Plano Nacional de Energia 2050 (PNE 2050), que tem como objetivo traçar soluções para desafios no setor elétrico em longo prazo. Dentre as medidas propostas, os impactos das mudanças climáticas sobre o setor elétrico são usados como parâmetro de incentivo para investimento no crescimento de fontes renováveis.

\section{CONCLUSÃO}

Ao se iniciar este trabalho de pesquisa constatou-se a influência do desempenho das hidrelétricas diante dos períodos de estiagem, por essa razão é considerável analisar os efeitos gerados em um cenário de crise. Diante disso, a pesquisa teve como objetivo geral identificar as razões que desencadeiam os períodos de secas históricas. Assim sendo, examinou-se a existência de diversas variáveis que potencializam períodos de escassez hídrica severas.

\section{REFERÊNCIAS BIBLIOGRÁFICAS}

ANEEL. Agência Nacional de Energia Elétrica. Disponível em: https://www.aneel.gov.br/

BARDELIN, C. E. A. Os efeitos do Racionamento de Energia Elétrica ocorrido no Brasil em 2001 e 2002 com ênfase no Consumo de Energia Elétrica. 2004. Dissertação (Mestrado) - Escola Politécnica, Universidade de São Paulo, São Paulo, 2004.

EPE. Empresa de Pesquisa Energética. Disponível em: https://www.epe.gov.br/pt MAPBIOMAS. Superfície de água no Brasil reduz $15 \%$ desde o início dos anos 90 , 2021. Disponível em: https://mapbiomas.org/superficie-de-agua-no-brasilreduz-15-desde-o-inicio-dos-anos-90.

OLIVEIRA, C. Dados apontam para crise hídrica no Brasil, intensificada pelo desmatamento amazônico, 2021. Disponível em: 
https://www.brasildefato.com.br/2021/05/14/dados-apontam-para-crisehidrica-no-brasil-intensificada-pelo-desmatamento-amazonico

OLIVEIRA, I. O que foi o Apagão de 2001? A conta de luz subiu? Pode acontecer de novo? Economia UOL, 2021. Disponível em: https://economia.uol.com.br/faq/o-que-foi-o-apagao-de-2001-riscoracionamento-energia-eletrica.htm

ONS. Operador do Sistema Elétrico. Disponível em: http://www.ons.org.br PINHEIRO, M.B.C. Previsão da produção de fontes renováveis e não renováveis selecionadas da matriz energética brasileira. 2020. 78 f. Dissertação (Mestrado em Economia Rural) - Centro de Ciências Agrárias, Universidade Federal do Ceará, Fortaleza, 2020.

Pior seca em quase um século aprofunda crise energética no Brasil. Economia UOL, 2021.

Disponível

em: https://economia.uol.com.br/noticias/afp/2021/09/01/pior-seca-emquase-um-seculo-aprofunda-crise-energetica-no-brasil.htm

SALES, C. J. D; MONTEIRO, E. M; UHLIG, A. Belo Monte e as comportas do diálogo. Instituto Acende Brasil, 2021. Disponível: https://acendebrasil.com.br/wpcontent/uploads/2021/03/20210331_CanalEnergia_Belo-Monte-e-ascomportas-do-dialogo.pdf

TOLMASQUIM, M. As origens da crise energética brasileira. Scielo Brasil, jun. 2000. Disponível em: https://doi.org/10.1590/S1414-753X2000000100012.

VIECELI, L; PAMPLONA, N. Desmatamento e mudança climática agravam crise hídrica, $2021 . \quad$ Disponível em: https://amazonasatual.com.br/desmatamento-e-mudanca-climaticaagravam-crise-hidrica-dizem-especialistas. 
SIMULAÇÃO DE PERTURBAÇÕES DAS LINHAS DE TRANSMISSÃO DE ENERGIA USANDO ATPDRAW

\author{
Carlos Rodrigo Santos da Silva' \\ Herbert Lucas Corrêa Fonseca' \\ Sinara Arcanjo de Souza' \\ Israel Gondres Tornél
}

1Escola Superior de Tecnologia (EST) - Universidade do Estado do Amazonas (UEA) CEP 69050-020 - Manaus - AM - Brasil crsds.eng20@uea.edu.br, hlcf.eng20@uea.edu.br, sads.eng19@uea.edu.br, itorne@uea.edu.br,

\title{
1. INTRODUÇÃO
}

As linhas de transmissão de energia (LT) precisam atravessar diferentes regiões transitando tanto por áreas rurais quanto urbanas, logo uma análise prévia deve ser feita sobre os possíveis problemas que variam de acordo com o tipo de ambiente, gerando inúmeros impactos negativos nas áreas urbanas e rurais. Para Karine (2015), esses impactos negativos ocorrem muitas vezes ou são agravados por conta do crescimento acelerado das cidades. E tais construções de linhas de transmissão devem ter um planejamento e uma estratégia bem elaborada analisando diversos aspectos ambientais para coibir situações de risco, pois existem torres ou postes com ocupação irregular e isso pode afetar drasticamente as pessoas que moram próximo e também a concessionária que é responsável pela manutenção, chegando até a impossibilitar de a manutenção ser realizada. Deve-se acrescentar também a importância na análise do solo e seu papel no desempenho das linhas de transmissão, por isso Leandro (2010, P. 14) recorda que o valor da resistividade do solo dentro de certas condições, possui uma relação quase linear com o valor da impedância impulsiva de aterramento.

\section{OBJETIVOS}

O objetivo principal é analisar a incidência das principais perturbações nas linhas de transmissão através da simulação no ATPDraw (ATP) para diminuir as perdas de energia durante o fornecimento aos consumidores finais. 


\section{MATERIAIS E MÉTODOS}

E há certas regiões que devem ter um adendo maior na hora do planejamento para as construções das linhas de transmissão, pois certas regiões com bastante vegetação e períodos de seca sofrem bastante com queimadas tanto artificiais e naturais, e as queimadas junta com as descargas atmosféricas são as principais perturbações nas linhas de transmissão.

Segundo o Relatório de Análise da Agência Nacional de Energia Elétrica (ANEEL) do ano de 2016, um dos modos de tentar conter esses desligamentos forçados por queimadas é realizar uma análise das instalações susceptíveis a queimadas, mapeando as linhas vulneráveis e verificando a situação dessas quanto à permissão de limpeza de faixa de servidão. As principais causas de perturbações em linhas de transmissão em 2020, que podem ser observadas com bastante clareza no gráfico de barras abaixo (figura 1).

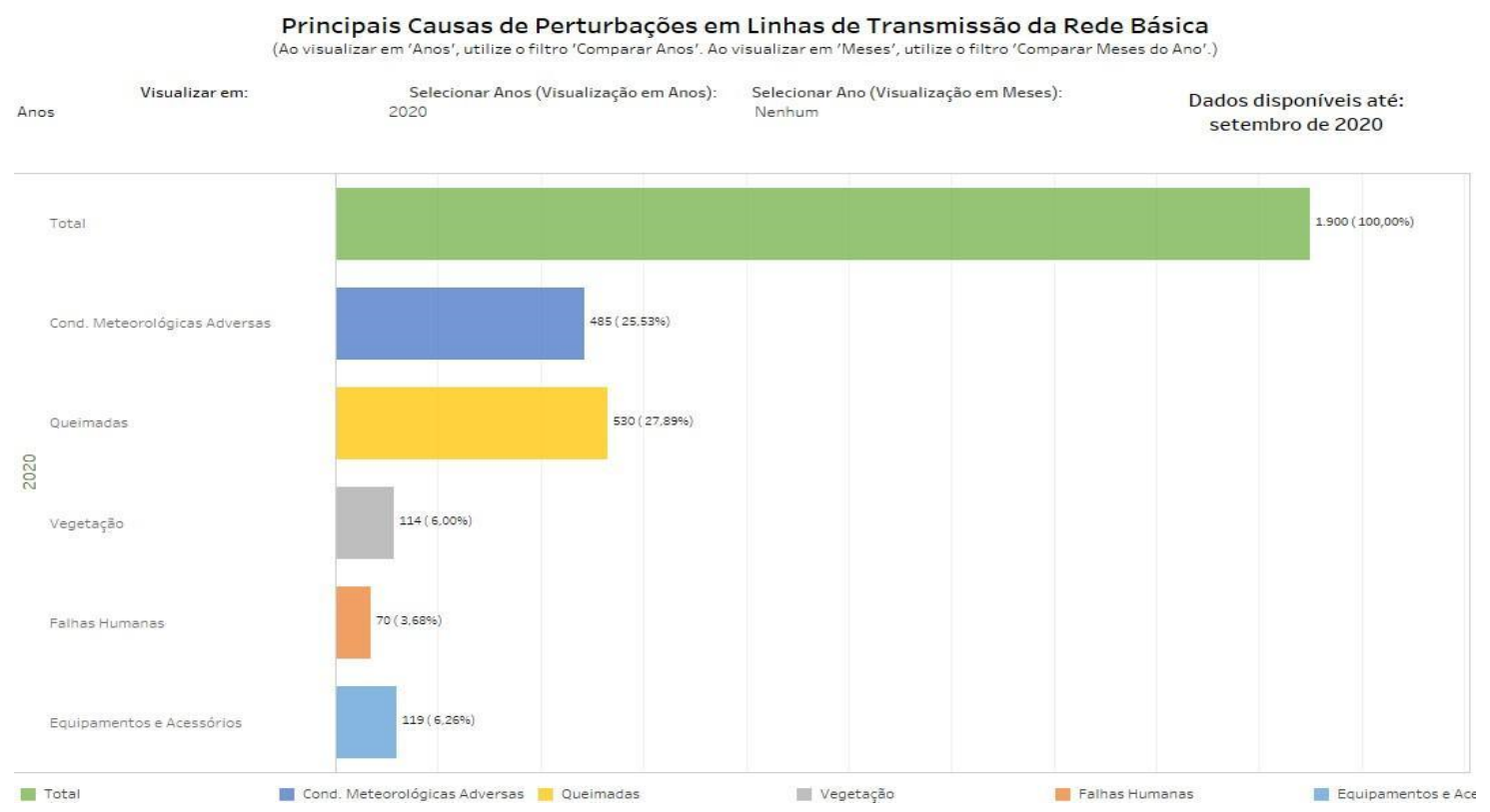

Figura 1. Principais causas de perturbações em linhas de transmissão da Rede básica em 2020. Fonte: ONS

Os problemas elétricos ocasionados por descargas atmosféricas são induzidos por inúmeras características de projeto e ambientais, como por exemplo: altura das torres, distância entre os cabos, aterramento, solo (resistividade), relevo, etc. Sabe-se que ainda não existe uma forma precisa de analisar o sistema dinâmico 
atmosférico para descobrir onde e quantas serão as descargas elétricas atmosféricas que afetarão a rede.

Segundo o Operador Nacional do Sistema Elétrico (NOS), os problemas causados por Descargas Atmosféricas possuem seu pico nos $1^{\mathrm{o}}$ e $4^{\mathrm{o}}$ trimestres do ano (período úmido das regiões Sudeste/Centro-Oeste, Nordeste e Norte), assim como ocorre o aumento de queimadas no $3^{\mathrm{o}}$ e no início do $4^{\mathrm{o}}$ trimestre do ano. Aumento que pode ser observado com bastante clareza no gráfico abaixo (figura 2), que mostra o aumento de casos durante o ano de 2020 e a comparação com a média dos últimos 5 anos (excluindo o atual).

O sistema de proteção contra descargas atmosféricas que nas LTs são constituídas de: aterramento (impedâncias instaladas e cabos de contrapesos) e cabos de guarda (ou para-raios). Segundo Menezes (2015), esta composição do aterramento (impedâncias instaladas e cabos de contrapesos) são fundamentais para proteção contra descargas atmosféricas, rompimento do cabo condutor, indução de correntes de LTs, etc. Menezes ainda acrescenta mais adiante que a utilização de dois cabos de guarda feitos de aço está sendo modificado para um cabo de aço e outro cabo óptico, pois o cabo óptico permite o envio, o recebimento de muitos parâmetros detalhados e informações do funcionamento do sistema de transmissão.

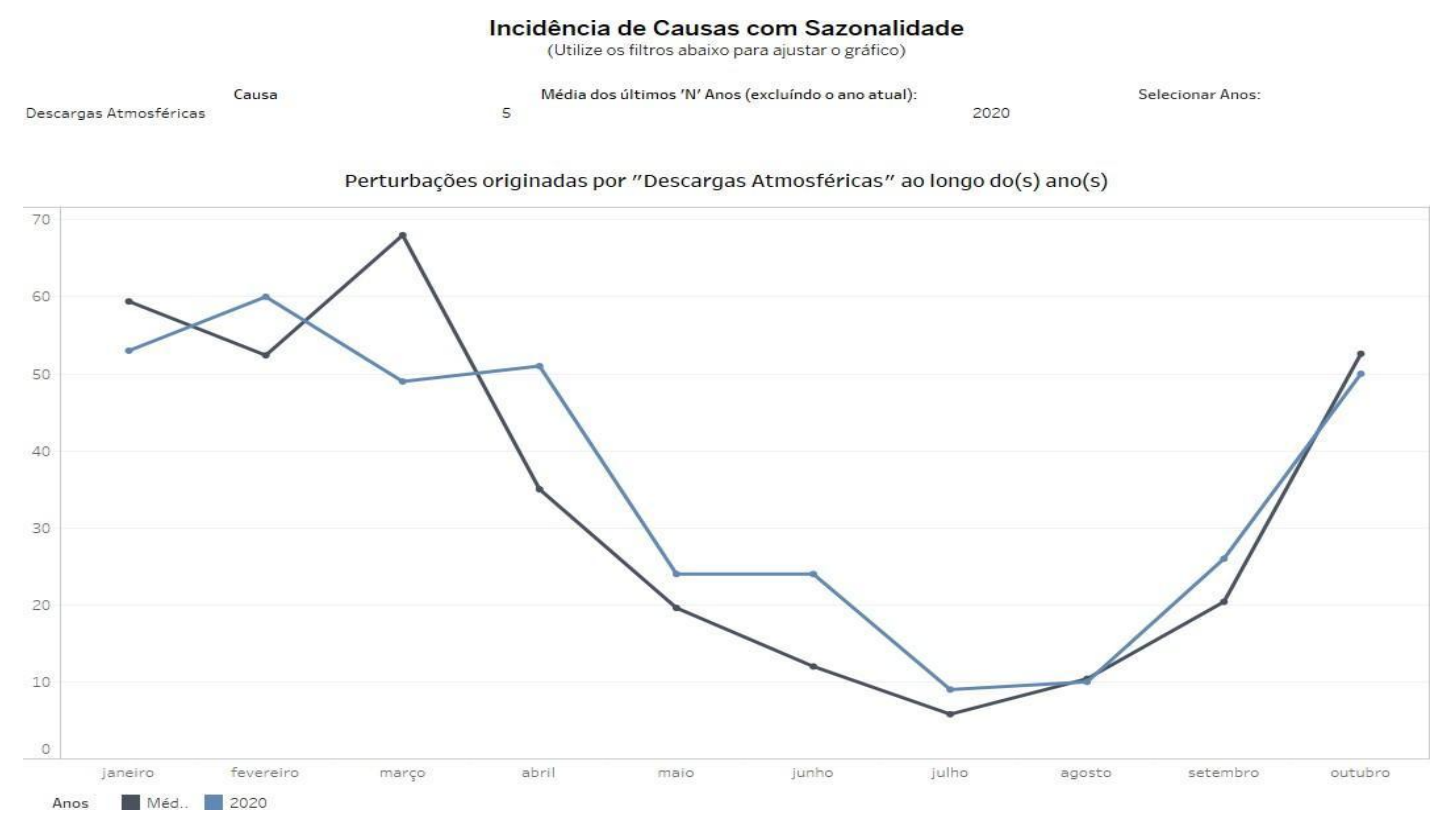

Figura 2. Perturbações originadas por Descargas Atmosféricas em 2020. Fonte: NOS 
O software escolhido para executar as simulações foi o ATPDraw (Alternative Transient Program), o mesmo é um pré-processador gráfico dirigido por mouse para a versão ATP do Programa de Transientes Eletromagnéticos (EMTP) programa este que começou a ser desenvolvido a partir da década de 60 e ao passar dos anos foi sofrendo melhorias em seu sistema de desenvolvimento na plataforma MSWindows. A justificativa para temos optado pelo ATPDRAW é o seu ótimo recurso pra realizar simulações de sistemas elétricos, sendo possível modelar o mais parecido possível com uma configuração de um sistema elétrico real.

Os elementos básicos para simulação de circuitos elétricos no ATPDraw são mostrados na figura 3, as respectivas figuras são obtidas pressionando-se a tecla direita do mouse na tela do ATPdraw.
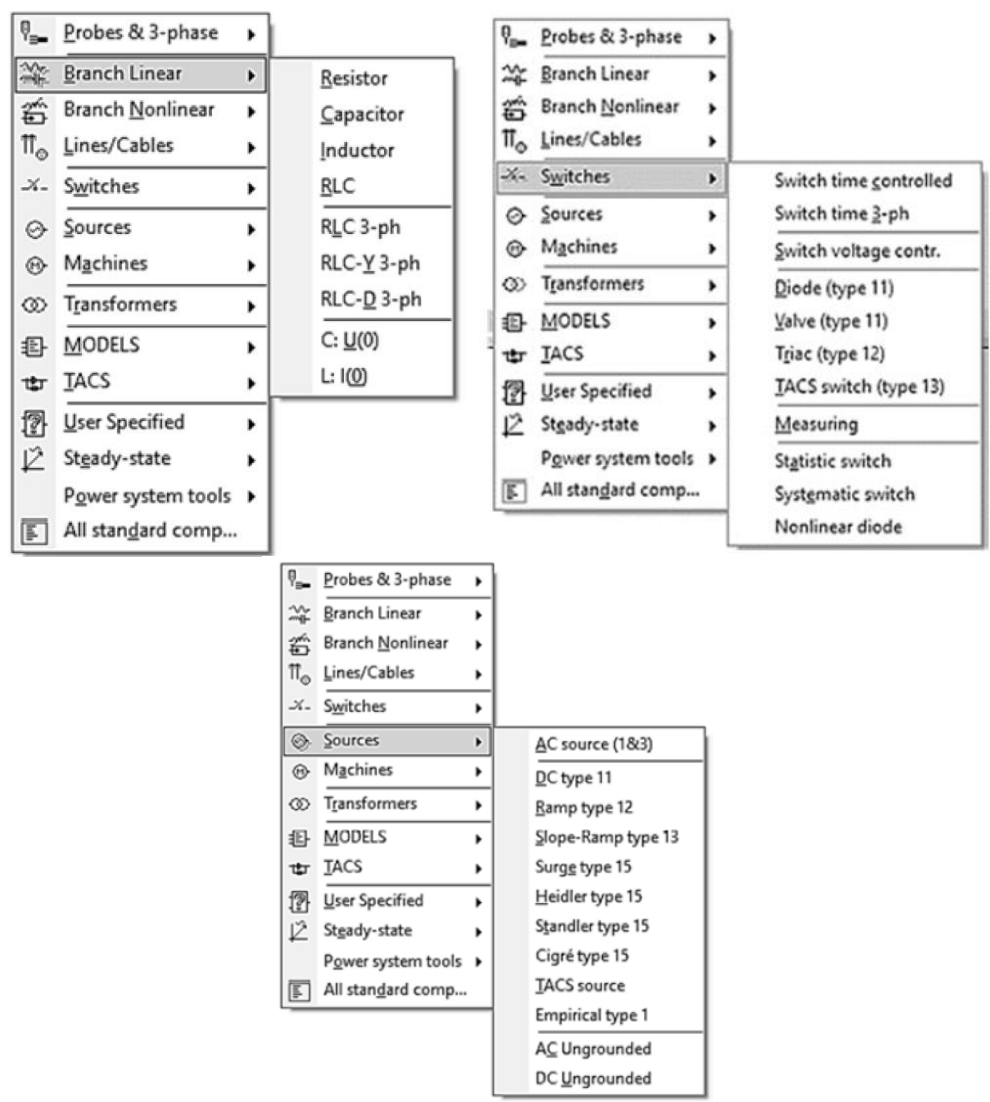

Figura 3. Principais elementos para simulação de circuitos elétricos.

Fonte: Moura, 2019.

\section{RESULTADOS}

Foi feita uma análise do comportamento transitório eletromagnético de uma linha de transmissão frente as manobras que podem ocorrer em um sistema de 
transmissão, buscando diminuir ou evitar o risco aos equipamentos e ao restante do sistema interligado quando submetidos a situações anormais durante a manobras definidas nos procedimentos de rede do ONS (figuras 4 e 5).

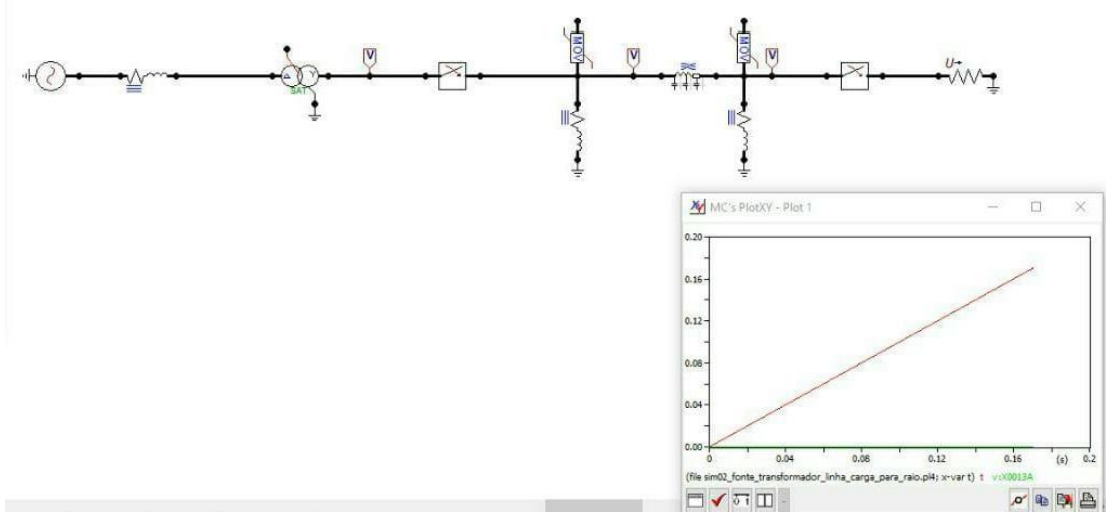

Figura 4. Análise do comportamento transitório eletromagnético A.

Fonte: Autoria Própria.

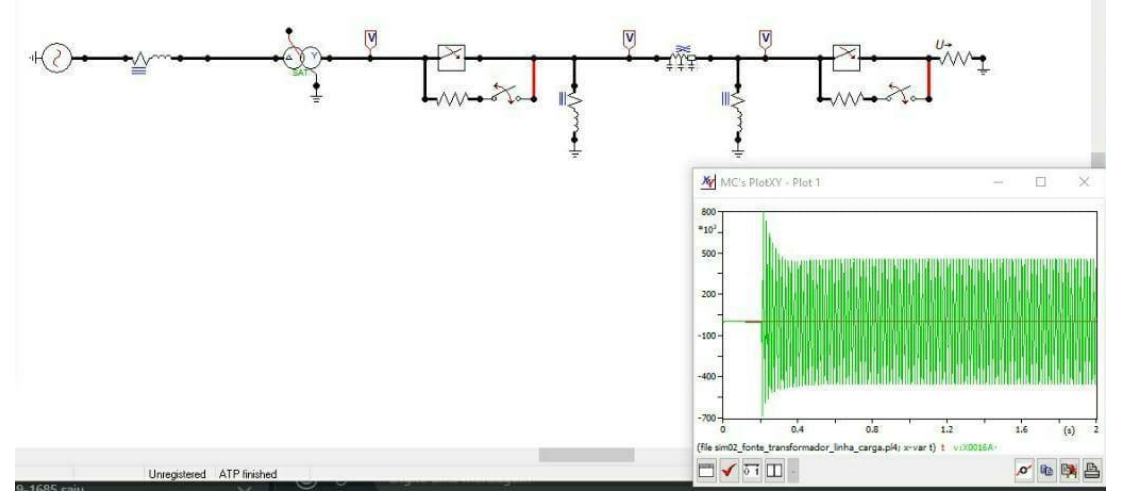

Figura 5. Análise do comportamento transitório eletromagnético B.

Fonte: Autoria Própria.

Realizadas as implementações necessárias de manobras de religamentos simuladas no software ATPDraw, constatou-se que em regime transitório, o linhão quando energizado, e visando a menor sobretensão, se mostrou mais eficiente adotando a manobra de chaveamento através de resistores de pré-inserção com para-raios. Esta adequa-se melhor a realidade da região já que nesse tipo de religamento, há uma diminuição significativa de sobretensões ao acionar os disjuntores do sistema; enquanto que para chaveamento direto torna-se insustentável sua implementação, pois após a energização da linha, ao fechar as 
chaves, o pico de tensão em regime transitório é bastante elevado, podendo danificar equipamentos.

\section{CONCLUSÃO}

O ATPDraw é um software de simulação de transitórios bem conceituado na área da indústria e pesquisa, tanto no Brasil quanto no exterior. Por intermédio das muitas de suas ferramentas, é capaz de calcular desde circuitos simples até os mais complexos.

A linha de transmissão quando energizada, e visando a menor sobretensão, se mostrou mais eficiente adotando a manobra de chaveamento através de resistores de pré-inserção com para-raios.

O chaveamento sincronizado não é muito adequado quando se trata do campo prático, pois é necessário ter informações que são de difícil acesso, como o instante onde a tensão da rede elétrica é zero.

\section{REFERÊNCIAS BIBLIOGRÁFICAS}

CARVALHO, J.; VIVEKANANDA, R.; LUZ, M.; SCIAMMARELLA, S. Desenvolvimento de dispositivo de telemonitoração de pontos críticos de LT's. II CITENEL, 2004.

CONINCH PERIN, A. C., \& COUTO, V. F. (2015). Uso Do Software ATPdraw No Estudo De Transitórios Eletromagnéticos. Unoesc \&Amp; Ciência - ACET, 6(2), 245250.

GLOVER, J. D.; SARMA, M. S. Sistemas de Potência. Cengage Learning Editores, 2003. 9706862919.

MELO, M. V. E. S. d. Linhas de transmissão e descargas atmosféricas: análise de avarias, perdas técnico-financeiras e sistemas de proteção, 2016.

MENEZES, Victor Prangiel de. Linhas de transmissão de energia elétrica-aspectos técnicos, orçamentários e construtivos. Rio de Janeiro, 2015.

MOURA, Ailson P. Engenharia de sistemas de potência: transmissão de energia elétrica em corrente alternada/ Ailson P. de Moura, Adriano Aron F. de Moura, Ednardo P. da Rocha. - Fortaleza: Edições UFC, 2019.

ROSSI, J.; SARAIVA, C. P.; FARIA, P. E.; ROMANO, R. B. et al. Sistema de Transmissão de Dados para Monitoramento de Linhas de Transmissão da Eletronorte. Projeto de Pesquisa e Desenvolvimento. ANEEL, p. 0372-0040, 2003.

www.ons.org.br/Paginas/resultados-da-operacao/qualidade-do-suprimentopaineis.aspx. 


\section{DETECTOR DE DIFERENÇA DE FASE EM SINAIS SENOIDAIS}

Ana Beatriz Pimentel Soares

Gabriel Augusto Tavares Dibo

Paulo Henrique Costa Marque

Angilberto Muniz Ferreira Sobrinho

1Escola Superior de Tecnologia (EST) - Universidade do Estado do Amazonas (UEA) CEP 69050-020 - Manaus - AM - Brasil abps.ele20@uea.edu.br, gatd.ele20@uea.edu.br, phcm.ele20@uea.edu.br, asobrinho@uea.edu.br

\section{INTRODUÇÃO}

Subsistema, em linguagem Python, para detectar e medir a diferença de fase existente entre dois sinais senoidais, baseado no simulador, de código livre, GNU Radio. A estimação desses sinais tem aplicação em diversas áreas da engenharia elétrica, como radiocomunicações e sistemas de medição e controle. Em sistemas de comunicações, os circuitos de correção de frequência baseiam-se em medir a diferença de fase entre um sinal de referência e um sinal recebido e usar essa diferença para indiretamente corrigir a frequência de um oscilador de controle. Assim, investiga-se alguns métodos para estimar e quantizar a diferença de fase entre dois sinais utilizando uma ferramenta de código aberto utilizada para simulações de radiocomunicações.

\section{OBJETIVOS}

Geral: Desenvolver um módulo, em linguagem Python, capaz de estimar a diferença de fase entre dois sinais e, eventualmente, usar o resultado desse módulo para corrigir a fase de um oscilador.

Específico: Conhecer o simulador de comunicações GNU Radio e sua estrutura de interfaceamento com funções definidas pelo usuário, investigar os algoritmos matemáticos existentes para a estimação de fase, escolher e implementar um algoritmo, em linguagem Python, e integra-lo à ferramenta GNU Radio. 


\section{MATERIAIS E MÉTODOS}

Primeiramente, foi realizada uma revisão de conceitos matemáticos, em relação aos sinais senoidais e suas formas de representação, bem como, pesquisas acerca das aplicações, assim como exemplos destes tipos de sinais no cotidiano da engenharia e da eletrônica. Esta revisão tomou parte pois a análise de sinais é algo extremamente necessário para a extração da fase e compreensão dos métodos matemáticos para então implementação em um software definido por rádio (SDR).

Após isso, estabeleceu-se uma base sobre o objeto de estudo, o que possibilitou a inclusão de uma nova ferramenta: GNU-Octave, para analisar analiticamente, as representações gráficas dos sinais senoidais. Visto que, os mesmos podem ter uma componente real e outra componente imaginária, ou seja, complexa. Desse modo, utilizando os conceitos aprendidos pôde-se compreender o papel do GNU-Octave no processo de representação dos sinais senoidais.

Dessa forma, utilizou-se a ferramenta, de código aberto, GNU-Radio, comumente usada para simulação de sistemas de comunicação, eventualmente combinada com a ferramenta computacional GNU-Octave, compatível com Matlab. Os métodos matemáticos existentes serão investigados, simulados e comparados entre si. Um desses métodos será implementado em linguagem Python na forma de uma função que será integrada à plataforma GNU-Radio.

\subsection{GNU-OCTAVE}

GNU Octave é uma linguagem computacional, desenvolvida para computação matemática. Possui uma interface em linha de comando para a solução de problemas numéricos, lineares e não-lineares, também é usada em experimentos numéricos. Além disso, faz parte do GNU (sistema operacional tipo Unix). Este programa foi utilizado no projeto para fazer as análises matemáticas das expressões do período, tempo, frequência e características gerais dos sinais senoidais e suas representações seja em forma trigonométrica ou exponencial-complexa.

\subsection{GNU RADIO}

O GNU Radio é um kit de ferramentas de desenvolvimento de software gratuito que fornece blocos de processamento de sinal para implementar rádios e sistemas de processamento de sinal definidos por software. Nesse sentido, o GNU 
Radio consolidou de forma prática o objetivo do projeto: desenvolver em linguagem python um sistema detector de diferença de fase entre dois sinais senoidais.

\section{RESULTADOS}

Com o GNU Radio, criou-se primeiro o simulador de fase, no qual foi possível gerar dois sinais senoidais, através de blocos em comando python, com a característica e o formato de uma senoide exponencial complexa. Logo, com os sinais gerados, a próxima etapa foi a de disponibilizá-los em um osciloscópio virtual $(Q T$ GUI Time Sink) e simular a criação entre uma diferença de fase entre dois sinais senoidais, via Time Sink e o slider chamdo de Phase Shift. Após a simulação da fase no osciloscópio, criou-se o detector de fase, através do bloco Embedded Python, no qual foi feito o cálculo do conjugado complexo a fim de retirar a diferença de fase existente entre o sinal multiplicado pela constante, e o sinal original que não havia nenhuma modificação. 0 bloco Embedded Python foi configurado por meio de um editor de texto, neste caso, pelo Notepad++ e programado através da linguagem python, dentro do próprio GNU Radio. Nesse sentido, o bloco alterou a saída para float (real) e realizou as operações de multiplicação de conjugado e complex to arg, a qual originalmente era usada para extrair o argumento da função.

Por fim, foi possível visualizar todas as informações do programa em uma tela gerada ao compilar o arquivo dentro do GNU Radio (Figura 1), (Figura 2) e (Figura 3).

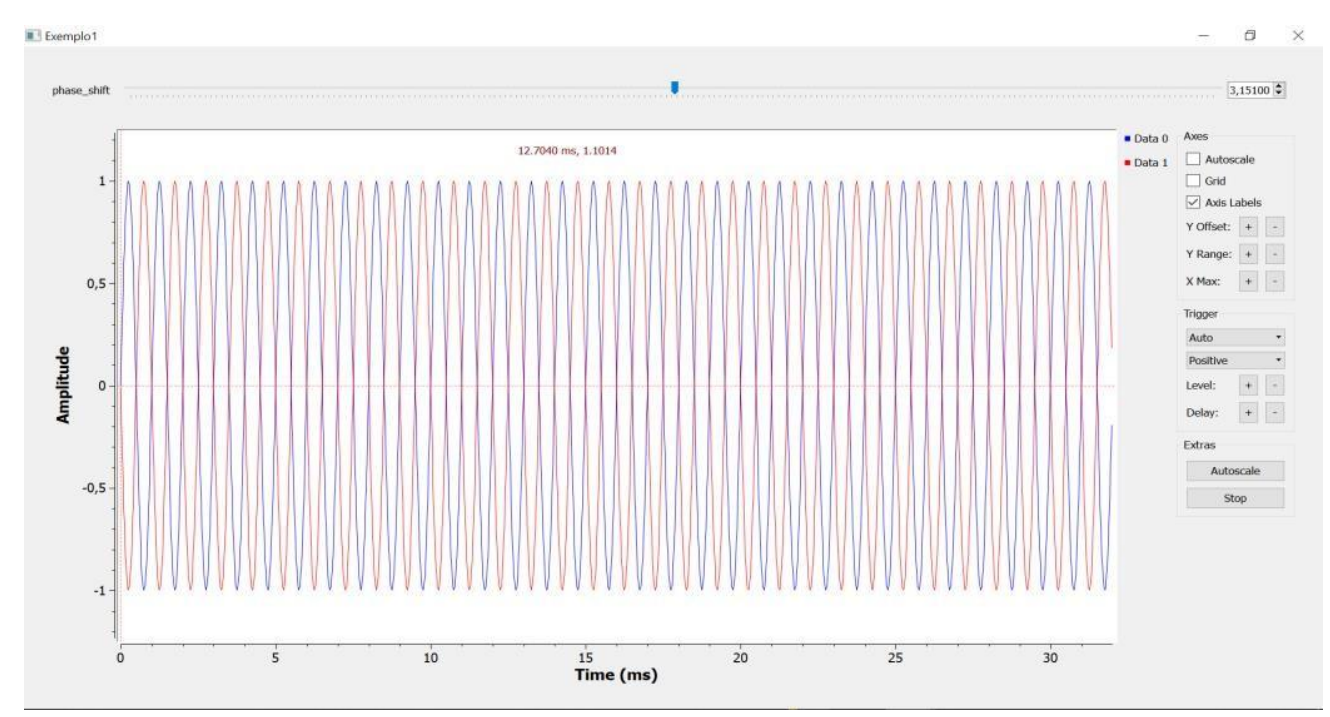

Figura 1. Versão Final do Subsistema, em Python, no GNU Radio. 


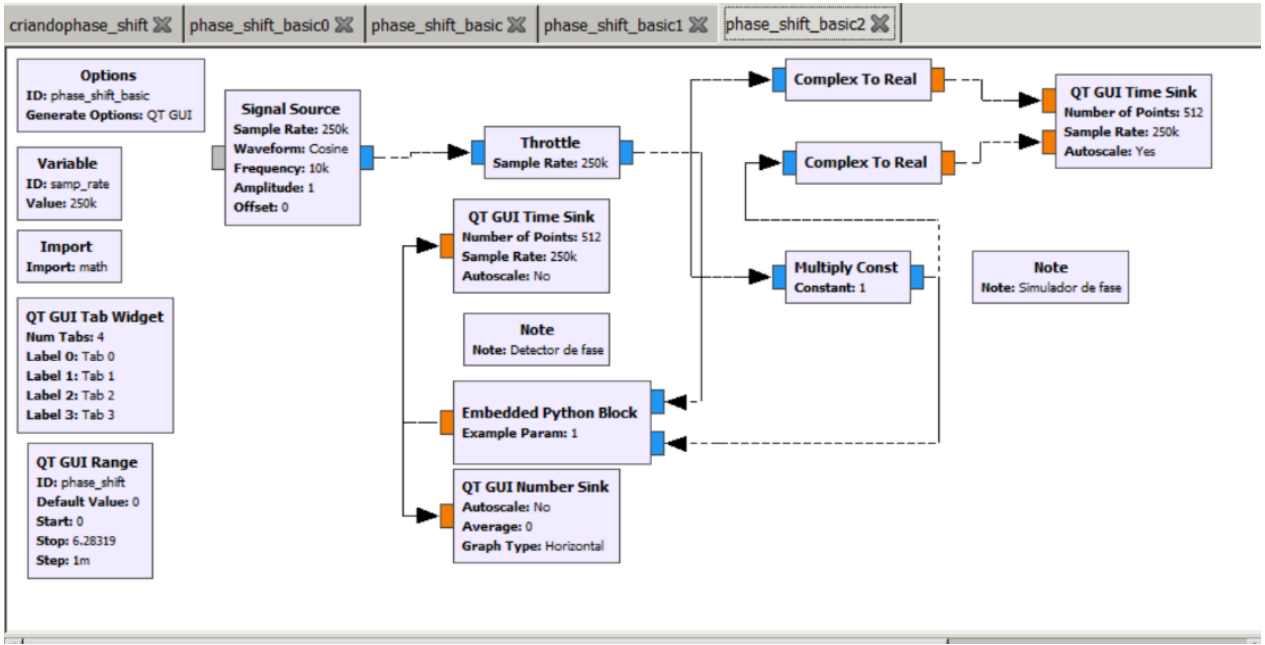

Figura 2. Versão Final do Subsistema, em Python, no GNU Radio.

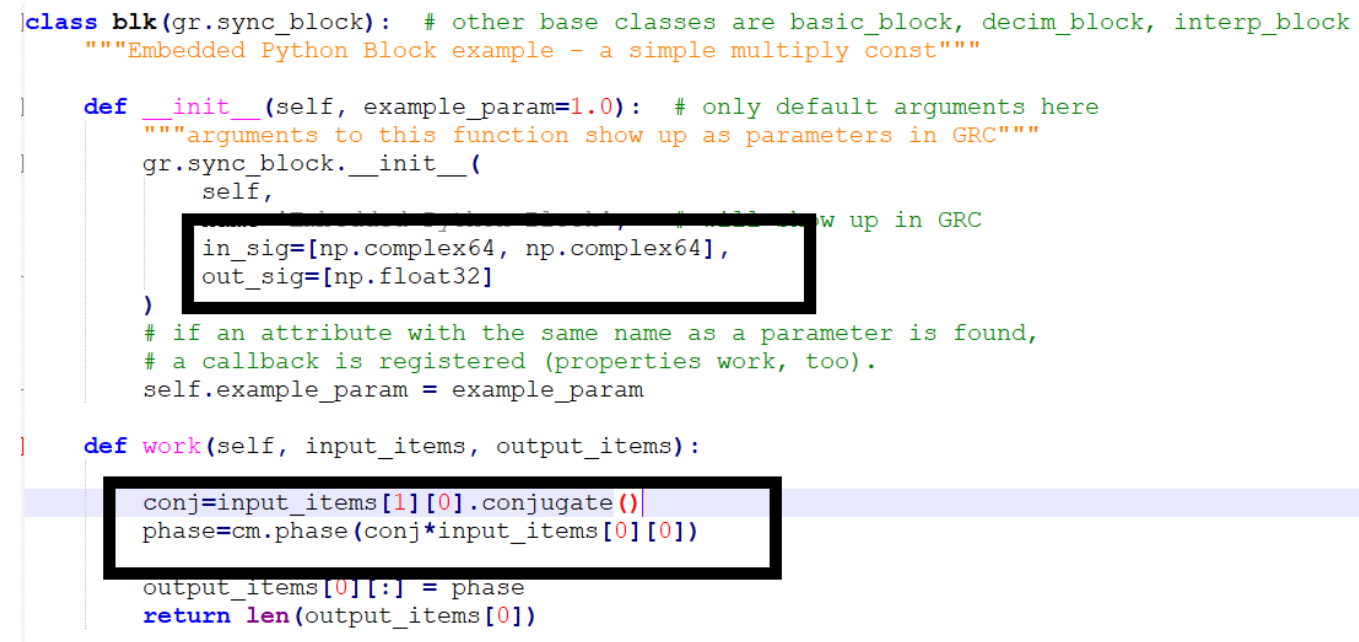

Figura 3. Versão Final do Subsistema, em Python, no GNU Radio.

\section{CONCLUSÃO}

A conclusão do projeto adveio das pesquisas realizadas de acordo com as orientações do professor orientador e do empenho coletivo com os alunos integrantes. Os materiais fornecidos pelo mesmo foram pontuais nas definições programáticas. A partir disso, foi possível obter conhecimento ideal para a realização das simulações feitas nos programas Matlab, GNU Octave e GNU Radio. A proposta oferecida no projeto trouxe a possibilidade de integrar um programa de custo acessível que através das leituras em blocos fornecesse detalhes matemáticos, técnicos e eletrônicos das ondas de sinais senoidais representando-os utilizando notação complexa e conveniente em aplicações que tem por objetivo investigar a relação de fase entre esses sinais. Portanto, compreende-se a visibilidade que 
sistemas de medição como este possuem ao quantizar a diferença entre sinais senoidais a fim de referenciar circuitos de correção em aparelhos de comunicação e radiocomunicação. Dentre as suas finalidades, indiretamente pode-se destacar a praticidade em acessibilidade a conhecimentos na telecomunicação como forma educativa em jovens iniciantes na área de engenharia.

\section{REFERÊNCIAS BIBLIOGRÁFICAS}

A. Sobrinho, E. Gurjão e J. Rocha Neto, Beamforming distribuído baseado em inversão remota de fase: Uma prova de conceito em GNU-Radio/USRP, XXXVIII SIMPÓSIO BRASILEIRO DE TELECOMUNICAÇÕES E PROCESSAMENTO DE SINAIS - SBrT 2020, 2020.

B.

Dušan Ponikvar, "Metal Detector using a PC Computer and a Sound card", Faculty of Mathematics and Physics, Jadranska 19, Ljubljana, Slovenia, 2017.

George Godby, "Using GNU Radio for Signal Phase Measurements". Disponível em: https://www.egr.msu.edu/classes/ece480/capstone/spring14/group02/d ocs/Application\%20Note\%20-

\%20Phase\%20George\%20Godby\%20Team\%202.pdf. Acesso em 9 de junho de 2021.

Greaves, Eduardo \& Rodríguez, An Michel \& Ruiz-Camacho, J., "A one-way speed of Hrishikesh Kulkarni, "Electronic Distance Measurement", EE318 Electronic Design Lab Project Report, EE Dept, IIT Bombay, April 2007.

light experiment". American Journal of Physics - AMER J PHYS, 2009.

Omar A. Yeste-Ojeda and René Landry, Jr. , "Software Defined Radio Approach to Distance Measuring Equipment", École de technologie supérieure Montreal, Canada , 2014.

RISI, Daniel. Oficina de Usabilidade. UX, UI e Usabilidade, Usuário vs. Sistema, 10 heurísticas de usabilidade. In: Cursos Ocean Samsung, 2019, Anais Eletrônicos, São Paulo. 


\title{
SISTEMA INTELIGENTE DE SOCORRO IMEDIATO AO MOTOCICLISTA
}

\author{
Ana Beatriz de Souza Maciel' \\ Felipe Correa da Silva' \\ Israel Gondres Tornél \\ Fábio de Sousa Cardoso'
}

${ }^{1}$ Escola Superior de Tecnologia (EST) - Universidade do Estado do Amazonas (UEA) CEP 69050-020 - Manaus - AM - Brasil abdsm.eng20@uea.edu.br, fcs.eng17@uea.edu.br, itorne@uea.edu.br,fcardoso@uea.edu.br

\section{INTRODUÇÃO}

Com o aumento da mobilidade urbana no Brasil, a motocicleta vem protagonizando esse cenário com um número crescente de veículos por habitantes. De acordo com dados disponibilizados pela Associação Brasileira dos Fabricantes de Motocicletas, Ciclomotores, Motonetas, Bicicletas e Similares, de 2010 a 2020, enquanto a população brasileira teve crescimento de $11 \%$, a frota de motocicletas e similares teve um aumento de 76\%. Com esse aumento, o número de acidentes envolvendo esses veículos, consequentemente, também aumentaram, com frequência cada vez maior de atendimento por órgãos da saúde. Em 2011, de acordo com dados da Associação Brasileira de Medicina de Tráfego disponibilizados a revista Em Discussão do Senado Federal, ocorreram 72,4 mil internações de vítimas de acidentes de trânsito, das quais quase 50\% foram vítimas de acidentes de moto. Nessas situações, o resgate imediato é indispensável. Diante desse cenário de aumento na frota de motocicletas, os números de furtos e roubos também têm apresentado um crescimento alarmante, principalmente em regiões metropolitanas e nas capitais. Por conseguinte, esses dados evidenciam a importância de sistemas antifurtos em motos.

\section{OBJETIVOS}

O objetivo principal é a criação de um sistema que, em caso de acidentes graves com motociclistas, acionasse de imediato o Serviço de Atendimento Móvel de Urgência (SAMU), e assim por meio de sensores identificar a ocorrência de acidentes 
e coletar os dados necessários para chamar o socorro. Além disso, teve foco no desenvolvimento de mais três sistemas: sistema antifurto com uso da biometria e desenvolvimento de dois aplicativos: um aplicativo mobile para o motociclista, no qual o objetivo é acompanhar esses dados, adicionar biometrias e servir de alternativa para liberar a ignição e um aplicativo web para o atendente, no qual os atendentes do SAMU receberão os chamados de socorro e terão acesso as informações dos acidentes.

\section{MATERIAIS E MÉTODOS}

Para atingir os objetivos propostos, foi necessário seguir algumas etapas para melhor organização e desenvolvimento do projeto. Na primeira fase, houve pesquisas e levantamento de requisitos para o projeto, a fim de coletar as informações necessárias para o desenvolvimento dos sistemas. Na segunda fase, houve as pesquisas de requisitos, estudos de funcionalidades e capacitações, visando melhor preparação dos bolsistas. Por fim, foi possível iniciar a produção dos aplicativos e protótipo de sistema antifurto e de identificação de acidentes.

\subsection{LEVANTAMENTO DE REQUISITOS E TECNOLOGIAS APLICÁVEIS}

De início, foi realizado o levantamento de requisitos aplicáveis, ao passo que foi possível compreender e explorar as necessidades dos motociclistas.

Para o sistema de identificação de acidentes e sistema antifurto, foi necessário o desenvolvimento das arquiteturas básicas, definição dos requisitos funcionais de hardware (microcontrolador Esp 32, relés de acionamento, módulo de leitura biométrica, sensores e módulos de comunicação), de software (IDE Arduino) e mecânicos (capsula para o circuito com o microcontrolador, sistema de acoplamento para cápsulas e suporte para sensores).

Quanto aos aplicativos, foi realizado também a arquitetura básica, ou mockup, e o levantamento de requisitos funcionais de hardware: autenticação do usuário, preenchimento de dados, opções de análise de dados e cadastro de biometria e liberação de ignição da moto especificamente para o aplicativo do motociclista. Também foi feito o levantamento de tecnologias aplicáveis, na qual foi necessária a escolha um ambiente de desenvolvimento de aplicativos. 


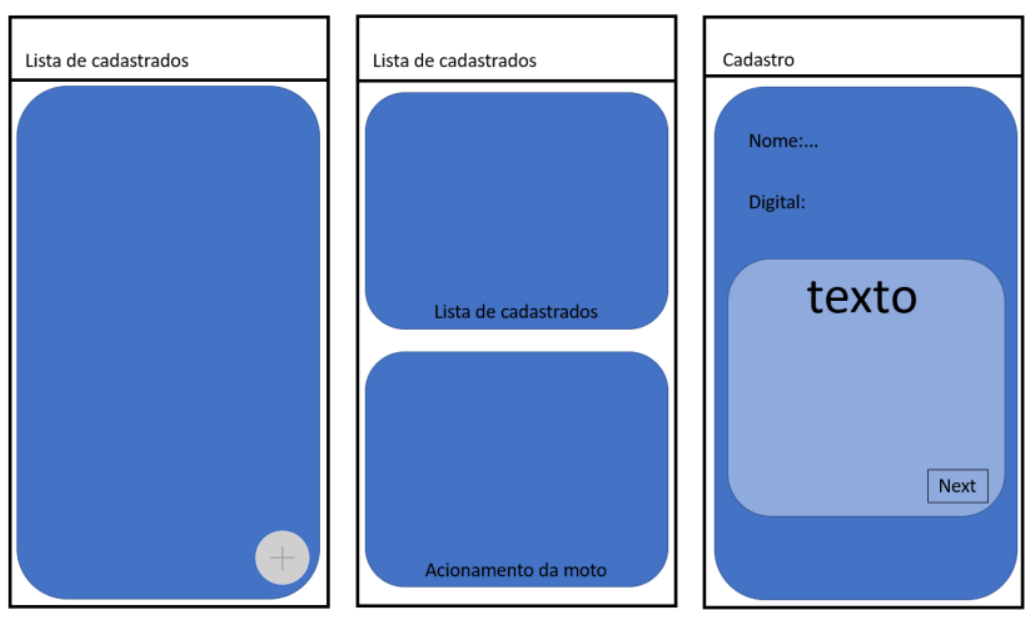

Figura 1. Mockup do aplicativo.

\subsection{ESTUDOS, PESQUISAS E CAPACITAÇÕES}

Nessa fase, foi necessário o estudo de tecnologias e suas aplicações, com mais detalhes para dar início a parte manufaturada do protótipo do projeto e criação dos aplicativos.

A pesquisa de módulos e sensores foi essencial nessa etapa. A priori, foram realizadas pesquisas de sensores e suas funcionalidades, procurando os mais adequados ao projeto. Os principais módulos estudados foram: leitor biométrico (para o sistema antifurto), GPS (localização), GSM (responsável por se comunicar com o atendimento de urgência pré-hospitalar) e módulo Esp 32 (microcontrolador). Além disso, foi preciso o estudo de sensores, tais como: sensores de pressão, ultrassônico, giroscópio e acelerômetro. Para tanto, além da pesquisa de funcionalidades e uso, foi feito uma pesquisa de preços no mercado.

Ademais, foram realizadas capacitações para o desenvolvimento do aplicativo em plataformas como: Bubble, Adalo e Kodular. Outrossim, houve capacitação para o uso de API's externas, necessárias para a comunicação dos dados da moto e do aplicativo, bem como a capacitação para manipulação de bancos de dados.

\subsection{DESENVOLVIMENTO DOS SISTEMAS}

Após as capacitações, foram realizados testes de funcionamento de sensores e criação de diagramas para a pré-visualização dos sistemas, tais como o circuito de ignição da moto, do leitor de sinais vitais, de alimentação e de parada de alimentação dos sistemas integrados a moto, bem como o desenho em 3D pelo AutoCad do 
encapsulamento dos circuitos. Em seguida, foi possível dar prosseguimento ao projeto com a montagens dos circuitos e encapsulamento.

Nessa etapa, foi iniciado o desenvolvimento do aplicativo mobile Android do motociclista pela plataforma Kodular, na qual a programação é feita por linguagem em blocos. Para o aplicativo web do atendente, foi utilizada a plataforma Bubble com o auxílio de uma API externa do google para o acesso dos dados dos sistemas integrados a moto, necessários para se ter as informações do acidente. Além disso, em ambos os aplicativos foi criado a função de verificação dos dados de pessoas cadastras e sistema de resgate de senha.

Com o estudo de sensores e módulos para o sistema de identificação de acidentes, foi observado nos dispositivos móveis todos os sensores desejáveis ao projeto. Portanto, viabilizou-se a aplicação da programação da lógica de acidentes nos celulares, por meio do aplicativo do motociclista, no qual foram realizados testes com ajuste de sensibilidade do giroscópio e acelerômetro para as simulações de acidentes que, posteriormente, foram ajustados para a detecção de um acidente em escala real.

Para o sistema de liberação de ignição da moto (antifurto), o microcontrolador utilizado foi o Esp 32, portanto, foi feito a configuração da lógica em linguagem c na IDE Arduino combinando o microcontrolador - responsável por receber as informações lógicas de comparação de usuários cadastrados para liberação da ignição - com o módulo relé. Para tanto, foi necessário a localização da conexão da ignição da moto para acrescentar o relé e a elaboração do circuito com o microcontrolador, seguido da criação do código de programação.

\section{RESULTADOS}

Após a programação dos aplicativos, foi possível se obter as funcionalidades desejadas no aplicativo mobile do motociclista: tela de cadastro do usuário, tela com a lista de cadastrados com biometria, ou seja, pessoas autorizadas a usar a moto, opção de adicionar biometrias e tela de configurações com informações do usuário. Nesse mesmo aplicativo, foi integrado a lógica de identificação de acidentes com alerta visual na tela e envios de dados para o aplicativo do atendente. 

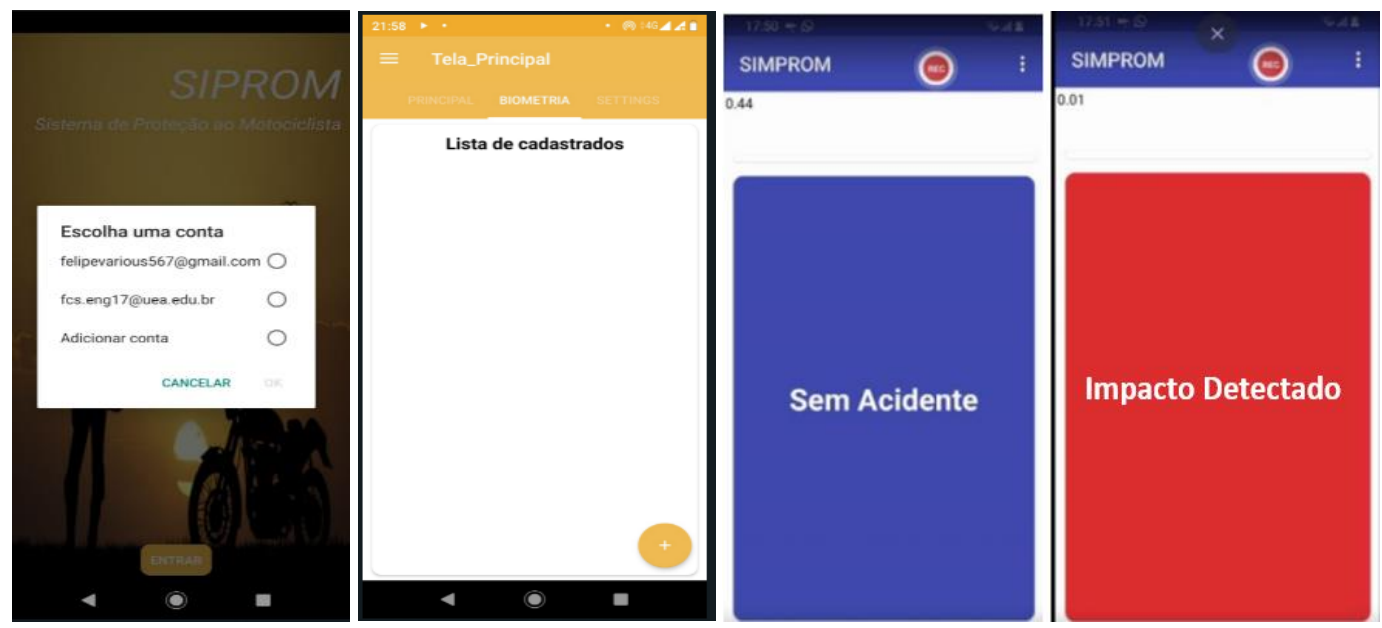

Figura 1. Aplicativo mobile do motociclista.

No aplicativo web do atendente, foi programada a tela de cadastro, seguida da tela principal, na qual com o auxílio da API externa, as solicitações de socorro com identificação de acidente foram obtidas instantaneamente, com a visualização das informações do motociclista e localização.

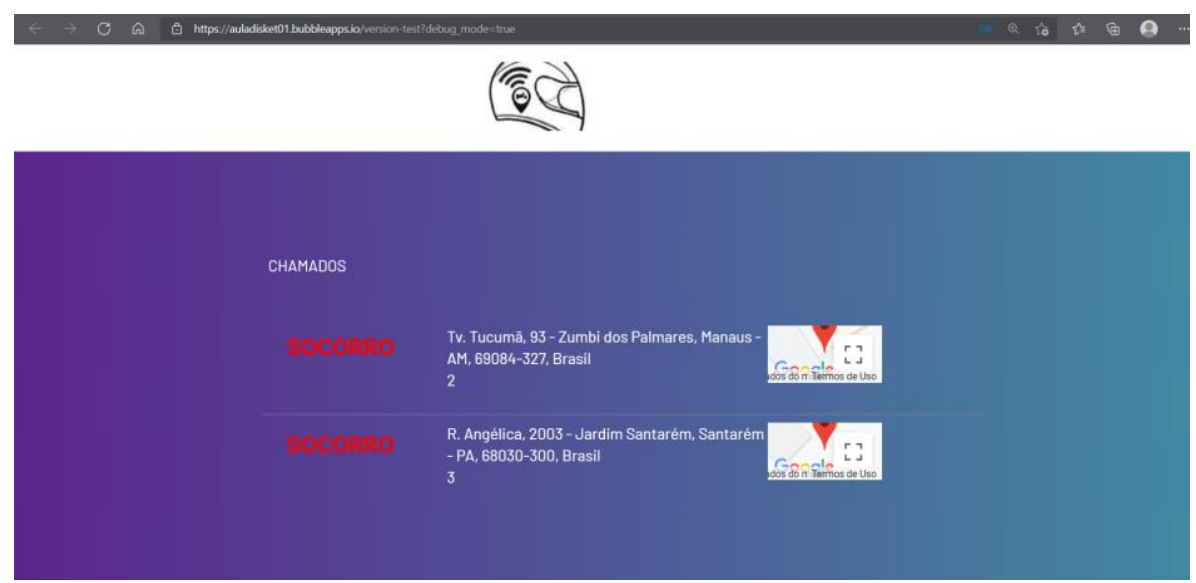

Figura 2. Aplicativo web do atendente.

No sistema antifurto, após os testes de identificação de biometria de cadastrados, obteve-se sucesso no sistema. Quando identificado a biometria de uma pessoa cadastrada no sistema, é dada a partida na moto, com a emitido um aviso sonoro cumprimentando o usuário. É importante ressaltar que o aplicativo do motociclista também foi configurado como alternativa para liberação da ignição, portanto, também pode ser utilizado para essa finalidade. 


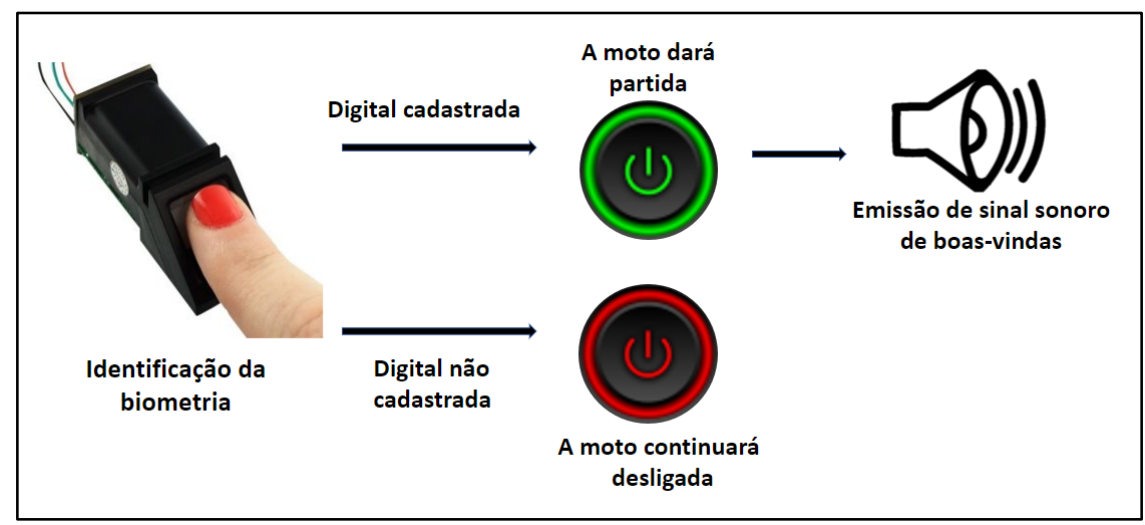

Figura 3. Esquemático do funcionamento do sistema antifurto.

\section{CONCLUSÃO}

Portanto, foi possível concluir que com o sistema de liberação da ignição da moto, além de evitar furtos, proporciona agilidade ao motociclista, uma vez que é possível dar partida na moto por meio dele.

Já por meio do aplicativo do motociclista, foi possível verificar a lógica de acidentes e adicionar dados e biometria de usuários da motocicleta.

Enquanto no aplicativo do atendente, é oferecido a possibilidade de visualização instantânea dos dados e localização do acidentado, proporcionando maior agilidade no envio do resgate do SAMU.

\section{REFERÊNCIAS BIBLIOGRÁFICAS}

Sotero, Paulo. Dados do setor duas rodas 2020. 74p. Associação Brasileira dos Fabricantes de Motocicletas, Ciclomotores, Motonetas, Bicicletas e Similares, São Paulo, 2020.

Souza, Silane. A cada 57 minutos uma moto é roubada em Manaus, segundo levantamento da SSP. Disponível em: http://www.acritica.com. Acesso em: 10 de setembro de 2021.

"Estudos e dados estatísticos apontam aumento do número de vítimas fatais de acidentes com motos no trânsito[...]". Em discursão, Revista de audiências públicas do Senado Federal. Brasília, n. 13, p.17-21, nov.12.

Kodular,

"Sensores".

Disponível em:<https://docs.kodular.io/components/sensors/>, Acesso em 10 de julho de 2021.

Bubble, “Data API". Disponível em:< https://manual.bubble.io/coreresources/api/data-api>, Acesso em 15 de julho de 2021. 
FUNDAMENTOS MATEMÁTICOS DE FILTROS LINEARES EM PROCESSAMENTO DIGITAL DE IMAGENS - PDI

Jefferson Tiago Santos de Dliveira'

Lauro Benício Gambizs Brizidio'

Elainne Ladislau Ferreira Pereira'

${ }^{1}$ Escola Superior de Tecnologia (EST) - Universidade do Estado do Amazonas (UEA) CEP 69050-020 - Manaus - AM - Brasil jtso.ele16@uea.edu.br, lbgb.ele18@uea.edu.br,elpereira@uea.edu.br

\section{INTRODUÇÃO}

A importância do processamento digital de imagens durante os últimos vinte anos tem aumentado consideravelmente, e o uso das ferramentas relacionadas a esse tema também tem sido. 0 Processamento Digital de Imagens - PDI, tem várias fases durante sua execução conforme o problema que se deseja resolver, uma delas é a Filtragem. No entanto, apesar de ter sido uma tecnologia bastante estudada, deve-se atentar para os fundamentos matemáticos presentes nos cursos de Engenharia como Álgebra Linear, Cálculo Diferencial entre outros assuntos matemáticos abordados de extrema relevância.

\section{OBJETIVOS}

O processo de Filtragem em PDI, consiste em realizar uma transformação de imagens para obtenção de um resultado conforme a relação matemática aplicada. Este trabalho, procura explicitar o conteúdo com base nos seus fundamentos, utilizando-se dos princípios de Cálculo Diferencial e Integral e Álgebra Linear por meio da exemplificação em scripts e embasamento bibliográfico.

\section{MATERIAIS E MÉTODOS}

Este trabalho foi realizado utilizando Softwares Matemáticos e pesquisas bibliográficas, que objetivam o abordar os temas de PDI relevantes ao curso de Engenharia Eletrônica. 
Trata-se de um resultado do Projeto de Extensão STEM da Universidade do Estado do Amazonas, onde deve-se abordar Fundamentos Matemáticos presentes em Processamento Digital de Imagens.

O processo de pesquisa foi realizado utilizando-se de encontros quinzenais, mini-cursos, realizados pela plataforma Google Meet. Materias de estudos, foram disponibilizados na plataforma Google Classroom e pelo Youtube. As simulações e resultados desta pesquisa foram realizados através do uso do Software MATLAB na sua versão para aplicativos móveis, utilizando-se de sua versão gratuita.

\section{RESULTADOS}

Vamos agora enunciar alguns conceitos de análise para assim associarmos o Cálculo diferencial envolvido e mais adiante definirmos as máscaras digitais.

A fim de conectar o Processamento digital com o Cálculo Diferencial e Integral, relembraremos alguns conceitos importantes.

A derivada de uma função é dada por meio do quociente de Newton, representada pela Equação 1.

$$
f^{\prime}(x)=\lim _{\Delta x \rightarrow 0} \frac{f(x+\Delta x)-f(x)}{\Delta x}
$$

Neste caso a função em questão é a função brilho dada por

$$
\text { Im: } \mathbb{R}^{2} \rightarrow[0,255]
$$

que associa em cada pixel da imagem na posição $(x, y)$, a intensidade do brilho naquele ponto.

Lembremos que pelo fato de estarmos tratando de pontos isolados interpretados como os pixels, na Equação (1) só temos unidades inteiras, e assim $\Delta x \in \mathbb{Z}_{+}^{*}$.

Para que se faça a operação acima, temos que obter uma sequência de imagens como na Figura 1.

Portanto fazendo $\Delta x=1$, obtemos o primeiro operador diferencial aplicado em imagens. 


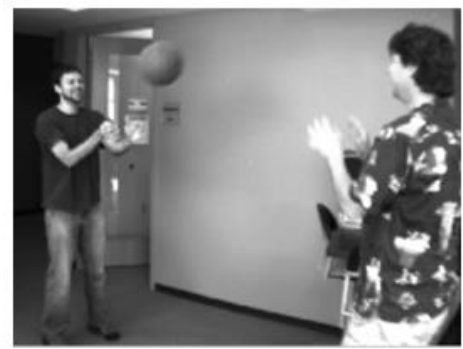

Imagem no intante $t$

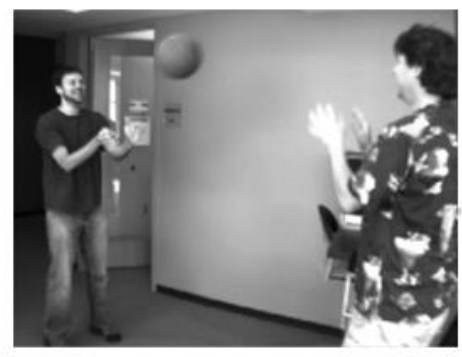

Imagem no instante $t+1$

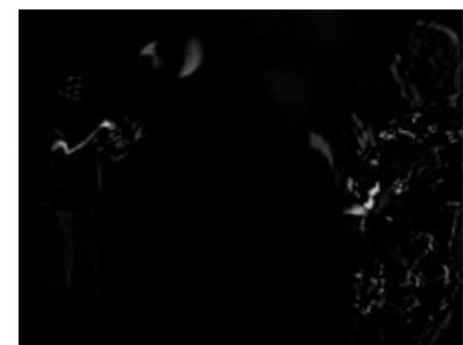

Imagem resultado da Derivada

Figura 1. À esquerda e meio a sequência de imagens dada por duas imagens tomadas em instantes conseguintes. À direita o resultado do operador derivada, localizando o contorno dos objetos contidos na sequência.

Tabela 1: Comandos utilizados no Software Matlab

\begin{tabular}{|c|c|}
\hline \multicolumn{1}{|c|}{ Comando } & Descrição \\
\hline imread('Nome.Ext') & Lê a imagem \\
\hline imshow('Nome.Ext') & Mostra a imagem \\
\hline rgb2gray(...) & $\begin{array}{c}\text { Converte a imagem colorida (RGB) para } \\
\text { escalas de cinza }\end{array}$ \\
\hline imbinarize (ImageGrayScale) & $\begin{array}{c}\text { Transforma a imagem em binaria pelo } \\
\text { Método de Otsu }\end{array}$ \\
\hline Imfilter(Imagem,Filtro) & $\begin{array}{c}\text { Obtém uma imagem a partir de um filtro } \\
\text { especifico. }\end{array}$ \\
\hline Imshowpair(ImA,ImB,metodo) & $\begin{array}{c}\text { Mostra varias imagens a partir de um } \\
\text { método especifico. }\end{array}$ \\
\hline fspecial() & $\begin{array}{c}\text { Gera um filtro a partir de seu nome Ex: } \\
\text { Sobel, Prewwit, Gaussian...etc }\end{array}$ \\
\hline
\end{tabular}

Para efeito de pesquisa, foi definido o tema de Detecção de Áreas

Desflorestadas na Floresta Amazônica, onde a partir de imagens aéreas, foram feitos scripts de obtenção de detecção dessas áreas a partir de filtros previamente estudados que será abordado abaixo:

\subsection{FILTRO SOBEL}

É um filtro passa-alta de detecção de bordas a partir de uma imagem em escalas de cinza. Em cada operação o filtro resulta no gradiente ou norma do vetor. Este é geralmente mais utilizado que o filtro Prewitt, devido a sua menor sensibilidade aos ruídos.

$$
\mathbf{G}_{\mathbf{x}}=\left[\begin{array}{ccc}
-1 & 0 & +1 \\
-2 & 0 & +2 \\
-1 & 0 & +1
\end{array}\right] * \mathbf{A} \quad \text { e } \quad \mathbf{G}_{\mathbf{y}}=\left[\begin{array}{ccc}
+1 & +2 & +1 \\
0 & 0 & 0 \\
-1 & -2 & -1
\end{array}\right] * \mathbf{A}
$$

Figura 2. Matrizes de Convolução no eixo X, e eixo Y (Filtro Sobel) 


$$
\mathbf{G}=\sqrt{\mathbf{G}_{\mathbf{x}}{ }^{2}+\mathbf{G}_{\mathbf{y}}{ }^{2}}
$$

Figura 3. Equação da Magnitude do Gradiente.

\subsection{FLLTRO PREWITT}

É também um filtro passa-alta de detecção de bordas e muito semelhante ao Filtro Sobel, no entanto, este por sua vez, faz a detecção de forma mais abrupta. 0 filtro é um operador de diferença em função da intensidade da imagem, assim como o Sobel, mas difere-se em suas máscaras de convolução como observado nas figuras abaixo.
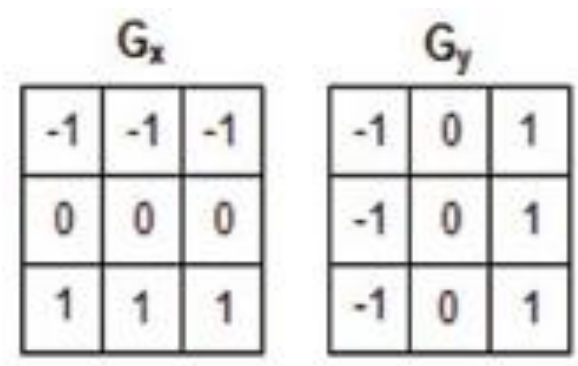

Figura 4. Mascaras de Convolução do Filtro Prewitt, nos eixos X, e Y.

Sua equação da magnitude do gradiente é igual a Figura 04, do Filtro Sobel.

Para realização das simulações foram obtidas imagens da internet de forma aérea, a esquerda tem-se uma imagem retirada do Google Maps na região próxima a Presidente Figueredo, e a direita uma imagem de desflorestamento obtida pela AFP (Agence Frace-Presse), sem localização definida.
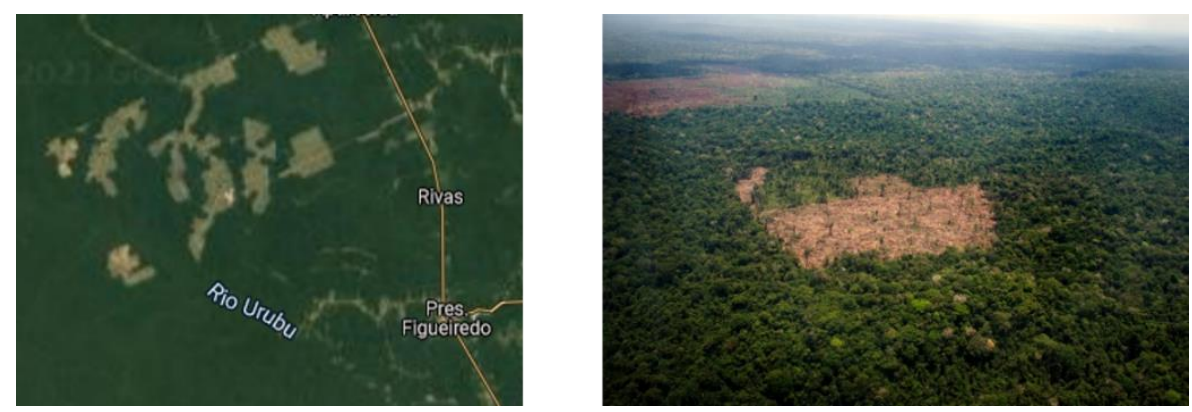

Figura 5. Imagens utilizadas da Simulação

Primeiramente foi utilizado o Filtro Sobel para detecção de bordas e realizado a diferença entre a imagem de Sobel e a imagem binarizada. 
A esquerda tem-se o script com filtro sobel na função fspecial(), e a direita o script com o filtro prewitt0.

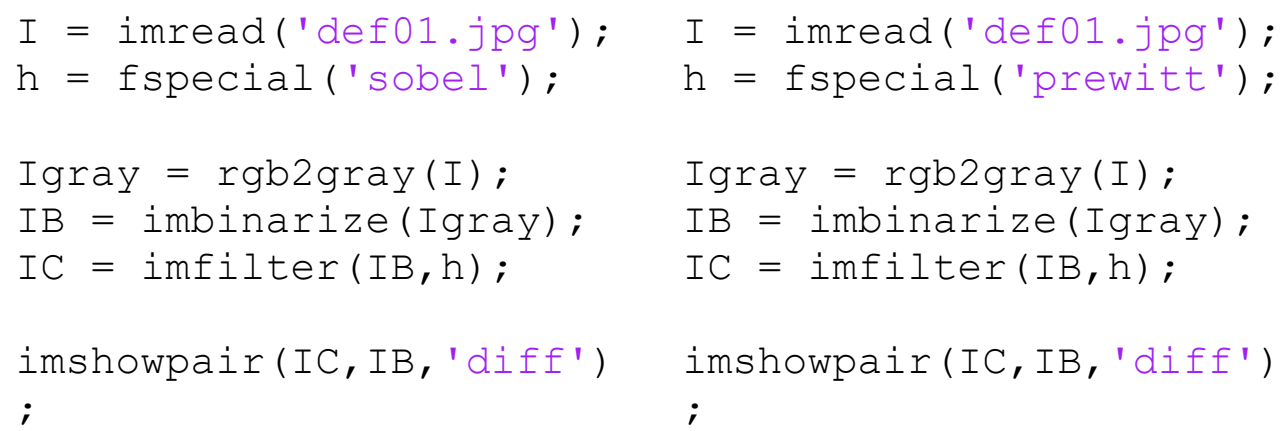

E obteve - se como resultado as seguintes imagens.
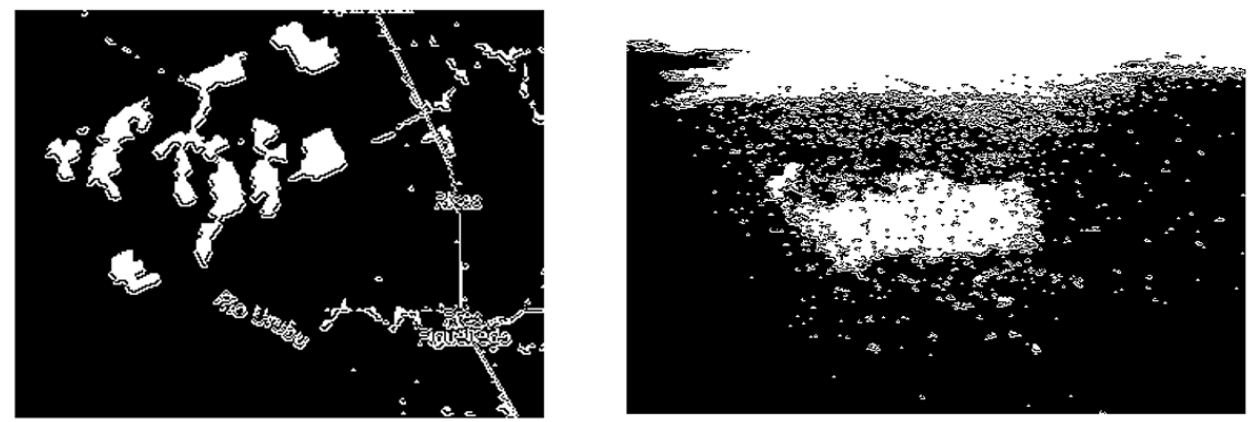

Figura 6. Filtro Sobel aplicado as imagens
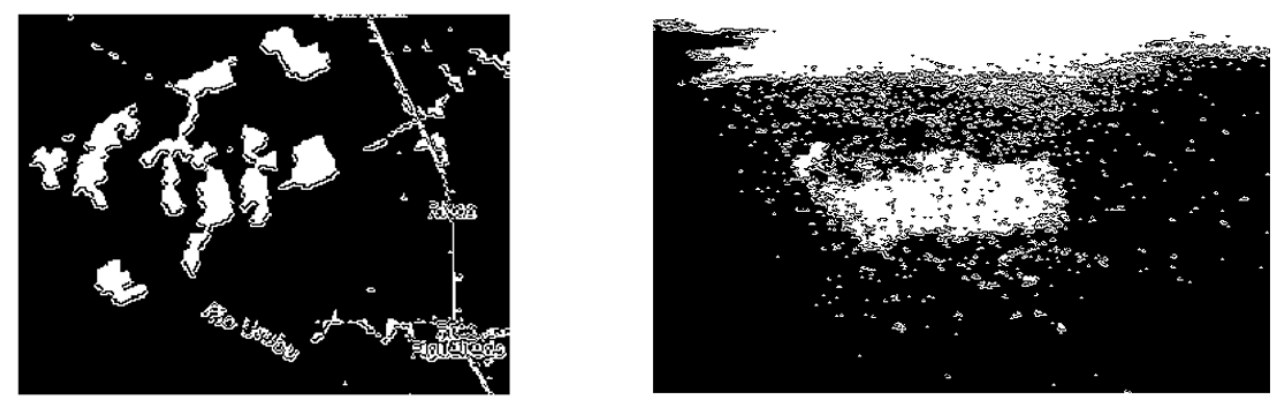

Figura 7. Filtro Prewitt aplicado as imagens

\section{CONCLUSÃO}

Com base nas pesquisas realizadas, e no método de ensino durante o Projeto STEM, é evidente a aprendizagem obtida durante o período. A Matemática aplicada a exemplos práticos como Processamento de Imagens, traz grande avanço no aprendizado, visto que durante o período foram aprendidas ferramentas de software como MATLAB e conceitos matemáticos que agregarão no restante do curso de Engenharia. 


\section{REFERÊNCIAS BIBLIOGRÁFICAS}

Gonzalez, R. C; Woods, R. E. "Processamento Digital de Imagens". 3a Edição. São Paulo. Person. 2010.

Maturana, Patrícia Salles. Algoritmos de detecção de bordas implementados em FPGA, Universidade Estadual Paulista. Unesp - Campus Ilha Solteira, FEIS, Automação, 2010.

MATHWORKS. MathWorks Help Center. Disponível em:

$<$ https://www.mathworks.com/help/matlab/>. Acesso em: 23 de setembro de 2021. 
SIMULAÇÃO DE UM PAINEL FOTOVOLTAICO MONOCRISTALINO DE 12V / 60W: MODELOS MATEMÁTICOS

\author{
Eduarda Barbosa Caldeira' \\ Weverson dos Santos Cirina'
}

1,2Escola Superior de Tecnologia (EST) - Universidade do Estado do Amazonas (UEA) CEP 69050-020 - Manaus - AM - Brasil ebc.eng20@uea.edu.br,wdsantos@uea.edu.br

\title{
1. INTRODUÇÃO
}

No atual cenário de geração de energia elétrica, as energias renováveis se destacam como uma solução sustentável e economicamente viável. Dentro de uma gama dessas energias renováveis podemos destacar a energia solar fotovoltaica como a mais promissora. Através do Efeito Fotovoltaico em uma célula de junção P$\mathrm{N}$, e sem a presença de nenhuma outra energia externa, somente com a radiação solar cobrindo toda a região da célula fotovoltaica, podemos então medir nos terminais da junção P-N uma tensão elétrica contínua. Para aumentar essa tensão é possível colocar várias células em série, depois, através de um processo industrial, empacotar essas células e produzir módulos, os quais, também em conjunto com outros módulos, vão dar origem aos painéis fotovoltaicos.

A junção P-N é constituída de material semicondutor. Uma célula fotovoltaica fornece pouca energia, cerca de 0,6 V e uma densidade de corrente de curto-circuito da ordem de $150 \mathrm{~mA} / \mathrm{cm}^{2}$, quando exposta a uma radiação solar de $1 \mathrm{~kW} / \mathrm{m}^{2}$.[1] Existem diversos tipos de células fotovoltaicas, tais como: silício monocristalino, silício policristalino e filmes finos, sendo as mais eficientes as células de silício monocristalino. 0 silício e o selênio são os materiais semicondutores mais utilizados na fabricação da junção P-N, pois são mais sensíveis perante a radiação solar e os que geram maior produto corrente-tensão. Outro motivo pela escolha do silício é devido à sua maior abundância na crosta terrestre.

Existem vários modelos matemáticos na literatura técnica que simulam o comportamento de uma célula fotovoltaica. Neste trabalho optou-se por dois deles, 
a saber: o modelo matemático simples e o modelo matemático com um diodo e dois resistores. Estes dois modelos podem ser vistos na Figura 1. [2]

\section{OBJETIVOS}

Este trabalho tem como objetivos desenvolver simulações que demonstrem o funcionamento de uma célula fotovoltaica policristalina utilizando os modelos matemáticos de um Circuito Simples e de um Circuito com diodo e resistores, sendo um em série e o outro em paralelo, através do software Matlab, e entender o funcionamento desses circuitos, bem como o funcionamento de uma célula fotovoltaica.

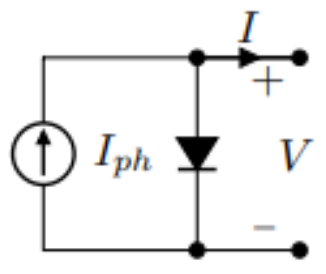

(a)

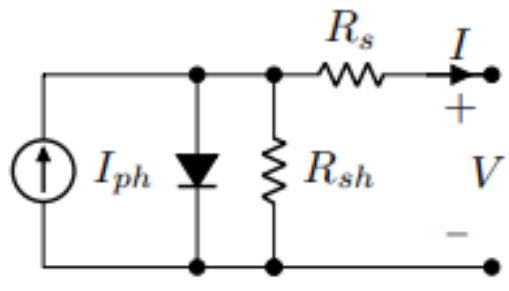

(b)

Figura 1. Circuito Equivalente de células fotovoltaicas. (a) Modelo Simples e (b) Modelo com 01 diodo e 02 resistores.

Fonte: (Nahla, 2014) [2].

\section{MATERIAIS E MÉTODOS}

A metodologia aplicada neste trabalho iniciou-se com a Pesquisa Exploratória buscando literatura sobre o funcionamento da célula fotovoltaica, modelos matemáticos que simulam o funcionamento de células fotovoltaica e sobre como programar em Matlab, mais precisamente, em sites de busca como o Google, Bing e Wolframalpha com palavras-chaves tais como: célula fotovoltaica, modelo matemático de célula fotovoltaica e programa em C, onde várias fontes de pesquisas, tais como: dissertações, artigos, projetos, livros e apostilas foram listadas, sendo que as principais constam neste trabalho como referências bibliográficas. A próxima etapa da metodologia foi a Pesquisa Explicativa, a qual estabelece uma explicação entre os modelos matemáticos e o funcionamento da célula fotovoltaica e como realizar essa relação dentro da programação em C. Para a simulação foram escolhidos dois tipos de modelo matemático, o circuito simples e o circuito que contém um diodo e dois resistores (um em série $R_{s}$ e outro em paralelo $R_{s h}$ ), os quais 
podem ser observados na Figura 1. [3] Com ajuda do software foram executadas as simulações e obtidos resultados para ambos os modelos/circuitos. Com base nesses resultados foram plotados gráficos de comparação entre os modelos e definido o mais adequado.

\section{RESULTADOS}

Ambos os modelos matemáticos foram implementados em programação no Matlab e executados de forma separados, sendo obtido o gráfico de saída da célula para cada modelo simulado, considerou-se como a entrada do sistema $G_{r}=$ $1000 \mathrm{Wm}^{2}$ (irradiação solar de referência) e $T_{r}=25^{\circ} \mathrm{C}$ (temperatura de referência). Para a estimação do parâmetro, em vista da sua convergência e precisão aprimorada, é utilizado o método de Newton-Raphson [4]. 0 fator de idealidade do diodo $D$ representa o componente da corrente de difusão, assim, $m=1 \sim 2 \mathrm{em}$ decorrência da teoria de difusão de Shockley (eq.2). 0 processo de iteração incrementa em 0,01 os valores de $R_{S}$ de modo a obter o valor de $R_{s h}$. Para o modelo simples, aplica-se a Lei de Kirchhoff das correntes e pode-se obter o valor da corrente elétrica de saída da célula, $I$, como sendo:

$$
I=I_{p h}-I_{D}
$$

Sendo $I_{p h}$ a corrente originada na junção P-N devido a radiação solar presente e $I_{D}$ a corrente conduzida pelo diodo, também conhecido para a equação de Shockley.

$$
\begin{gathered}
I_{D}=I_{0}\left[e^{\left(\frac{q \cdot V}{m \cdot k \cdot T}\right)}-1\right] \\
I_{p h}=\left(\frac{G}{G_{r}}\right)\left\{I_{s c}+\left[\alpha \cdot\left(T_{C}-T_{r}\right)\right]\right\} \\
I=I_{p h}-I_{0}\left[e^{\left(\frac{q \cdot V}{m \cdot k \cdot T}\right)}-1\right]
\end{gathered}
$$

Já para o modelo matemático do circuito com um diodo e dois resistores, a corrente elétrica de saída será dada pela seguinte equação 03:

$$
I=I_{p h}-I_{0}\left[e^{\left(\frac{q \cdot V}{m \cdot k \cdot T}\right)}-1\right]-\left(\frac{V+R_{s} \cdot I}{R_{s h}}\right)
$$

Na Figura 2 se pode observar as curvas $V x I$ de ambos os modelos simulados. Note que a curva Real é o circuito com diodo e resistores e a curva Ideal é o circuito somente com o diodo. 


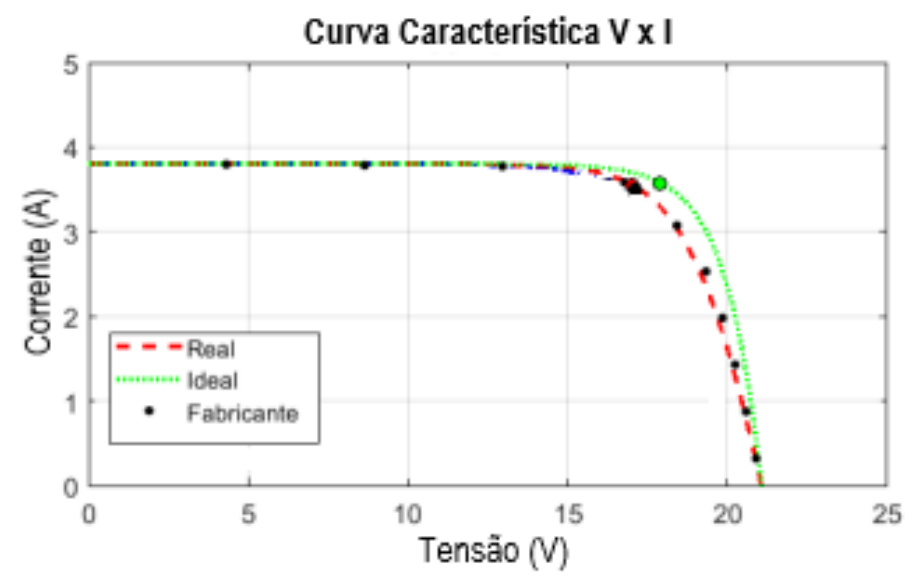

Figura 2. Curva Característica $V x I$ da célula fotovoltaica obtida pelo (a) Modelo Simples e pelo (b) Modelo com 01 diodo e 02 resistores.

Fonte: o próprio autor.

\section{CONCLUSÃO}

O crescente aumento por energia solar fotovoltaica está sendo impulsionado pelo aumento do preço da energia elétrica produzida pelas usinas hidrelétrica e termoelétricas provocado pela crise hídrica e fatores econômicos mundiais. A inserção de energias renováveis na matriz energética mundial tem sido enfatizada e aplicadas em conjunto com a geração distribuída, pois possuem características importantes, como: baixos níveis de ruído, baixo impacto ambiental e custo de implantação barato. Neste trabalho foram implementados dois modelos matemáticos, o modelo simples (Ideal) e o modelo com 01 diodo e 02 resistores (Real).

Como se pode observar, ambos os modelos foram executados e suas curvas características $V x I$ foram levantadas, sendo agora, comparadas com a curva característica do manual do fabricante do painel fotovoltaico.

Analisando as simulações constatou-se que o modelo real (circuito com 01 diodo e 02 resistores) apresentou em relação ao modelo ideal, uma aproximação mais coerente com o comportamento descrito pelo manual técnico do painel, aproximando-se da curva real disponibilizada pelo fabricante, em condições de temperatura e irradiância constantes. Desta forma, propõe-se como trabalhos futuros a consideração das variações de temperatura e irradiância além de verificar a real influência da umidade, considerando as variações climáticas do Amazonas, onde pressupõe-se que o modelo de dois diodos apresente melhores resultados. 


\section{REFERÊNCIAS BIBLIOGRÁFICAS}

[1] KRENZINGER, A.; BLAUTH, Y. B.; WISBECK, J. O.; Seguidor Dinâmico de Máxima Potência para Painéis Solares; apresentado no XIV Congresso Brasileiro de Automática, pp. 985-990, 2002.

[2] NAHLA M., SHANNAN, Nor Zaihar Yahaya, and SINGH, Balbir. Two diode model for parameters extraction of PV module. In 2014 IEEE Conference on Energy Conversion (CENCON), pages 260-264. IEEE, oct 2014.

[3] Notas das aulas sobre Energia Solar Fotovoltaica. Projeto STEM, Turma 1o Edital 2020/2021. Prof. Weverson dos Santos Cirino. Pilar Permanência. Escola Superior de Tecnologia - EST/UEA.

[4] NGUYEN, Xuan Hieu and PHUONG, Minh Nguyen. Mathematical modeling of photovoltaic cell/module/arrays with tags in Matlab/Simulink. Environmental Systems Research, 4(1):24, 2015. 
CONHECIMENTO E AVALIAÇÃO DAS EMISSÕES DE RADIAÇÃO ELETROMAGNÉTICA NÃO IONIZANTE (RNI) ORIUNDAS DE ESTAÇÕES RÁDIO BASE (ERB) NA CIDADE DE MANAUS

\author{
Francisco Carlos Mendança Cabral Júnior' \\ Bruno da Gama Monteiro'
}

${ }^{1}$ Escola Superior de Tecnologia (EST) - Universidade do Estado do Amazonas (UEA) CEP 69050-020 - Manaus - AM - Brasil fcmcj.ele17@uea.edu.br,bmonteiro@uea.edu.br

\title{
1. INTRODUÇÃO
}

A comunicação é fundamental para o desenvolvimento das relações sociais. Com o desenvolvimento das tecnologias em telecomunicações, aparelhos de radiocomunicação foram instalados em todos os lugares. Com isso, a população frequentemente está em um ambiente imerso em eletromagnetismo. Urge que sejam realizadas avaliações das tecnologias existentes e que estão por vir, no que tange a radiopropagação e os efeitos desses campos eletromagnéticos no ser humano. Nesse cenário, temos as estações rádios-bases, que pertencem a infraestrutura do serviço móvel pessoal. Estações estão espalhadas por todas as regiões da cidade, às vezes muito próximas de escolas, hospitais e centros comerciais. Estudos realizados comprovaram efeitos térmicos. (HIRATA et al, 2013). Alguns cientistas afirmam que, possivelmente, poderá haver um fator que desencadeie tumores carcinogênicos. (DOLK et al, 1997). Atentas a estes indícios, as comunidades científica e governamental organizaram grupos para que fossem tomadas medidas que promovessem a segurança das pessoas. Atualmente, a Comissão Internacional de Proteção Contra Radiação Não Ionizante (ICNIRP) é o órgão internacional responsável pela formulação de diretrizes nessa questão, formulando níveis de referência para limitação de exposição à RNI. No Brasil, a Agência Nacional de Telecomunicações (Anatel) atua na fiscalização da radiação não-ionizante, adotando praticamente na sua totalidade as orientações da ICNIRP. 


\section{OBJETIVOS}

Este projeto teve por objetivo compreender os mecanismos de interação da radiação não-ionizante no ser humano. Determinar teoricamente os valores de campo elétrico, magnético e densidade de potência de ERB's, na cidade de Manaus. Comparar os valores obtidos teoricamente com os valores medidos constantes no site da Anatel.

\section{MATERIAIS E MÉTODOS}

As delimitações de exposição foram baseadas nas diretrizes da Anatel. Os dados de medições de RNI podem ser acessados por meio do Mapa de Exposição a Campos Eletromagnéticos, constantes no site da Anatel. Os dados de RNI consistem do campo elétrico da maior frequência encontrada na estação, de modo geral superior a 2000MHz. Foram analisadas 2 (duas) estações para cada uma das seis zonas administrativas da cidade de Manaus, escolhidas de forma aleatória. A partir do valor medido fornecido, foram calculados o campo magnético e densidade de potência. Então, os três valores são comparados e avaliados com os níveis de referência. As frequências utilizadas pelas estações podem ser consultadas no site Spectrum-E:

Emissões, https://sistemas.anatel.gov.br/se/public/view/b/licenciamento.php, pertencente a Anatel.

\subsection{NÍVEIS DE REFERÊNCIA PARA EXPOSIÇÃO dO PÚBLICO A CAMPOS ELETROMAGNÉTICOS}

Tabela 1. Níveis de referência considerando frequências do serviço móvel pessoal

\begin{tabular}{cccc}
\hline $\begin{array}{c}\text { Faixas de } \\
\text { frequência }\end{array}$ & $\begin{array}{c}\text { Intensidade de } \\
\text { Campo Elétrico E } \\
(\mathrm{V} / \mathrm{m})\end{array}$ & $\begin{array}{c}\text { Intensidade de } \\
\text { Campo Magnético } \\
\mathrm{H}(\mathrm{A} / \mathrm{m})\end{array}$ & $\begin{array}{c}\text { Densidade de Potência } \\
\text { de Onda Plana } \\
\text { Equivalente } \mathrm{S}\left(\mathrm{W} / \mathrm{m}^{2}\right)\end{array}$ \\
\hline $\begin{array}{c}400-2000 \\
\mathrm{MHz}\end{array}$ & $1,375 f^{1 / 2}$ & $0,0037 f^{1 / 2}$ & $f / 200$ \\
\hline $2-300 \mathrm{GHz}$ & 61 & $160 \times 10^{-3}$ & 10 \\
\hline
\end{tabular}

Fonte: Adaptado pelo autor de Anatel (1999). 


\subsection{EQUAÇÕES PARA A DETERMINAÇÃO DOS VALORES DE REFERÊNCIA}

$$
\begin{gathered}
S=\frac{E^{2}}{377} \\
H=\sqrt{\frac{S}{377}}
\end{gathered}
$$

\section{RESULTADOS}

\begin{tabular}{|c|c|c|c|c|c|c|}
\hline Estação & $\begin{array}{l}\text { Campo } \\
\text { Elétrico } \\
\text { Medido } \\
(\mathrm{V} / \mathrm{m})\end{array}$ & $\begin{array}{c}\text { Campo } \\
\text { Elétrico } \\
\text { Máximo } \\
(\mathrm{V} / \mathrm{m})\end{array}$ & $\begin{array}{c}\text { Campo } \\
\text { Magnético } \\
\text { Medido }(\mathrm{A} / \mathrm{m})\end{array}$ & $\begin{array}{c}\text { Campo } \\
\text { Magnético } \\
\text { Máximo }(\mathrm{A} / \mathrm{m})\end{array}$ & $\begin{array}{c}\text { Densidade de } \\
\text { Potência } \\
\text { Medida } \\
\left(\mathrm{W} / \mathrm{m}^{2}\right)\end{array}$ & $\begin{array}{c}\text { Densidade } \\
\text { de } \\
\text { Potência } \\
\text { Máxima } \\
\left(\mathrm{W} / \mathrm{m}^{2}\right)\end{array}$ \\
\hline $\begin{array}{c}695641972- \\
\text { Cidade Nova } \\
(\mathrm{ZN})\end{array}$ & 1,46 & 61 & $3,87 \times 10^{-3}$ & $160 \times 10^{-3}$ & $5,65 \times 10^{-3}$ & 10 \\
\hline $\begin{array}{c}699805678- \\
\text { Monte das } \\
\text { Oliveiras } \\
\text { (ZN) }\end{array}$ & 1,56 & 61 & $4,14 \times 10^{-3}$ & $160 \times 10^{-3}$ & $6,45 \times 10^{-3}$ & 10 \\
\hline $\begin{array}{c}697489078- \\
\text { Compensa } \\
(\mathrm{ZO})\end{array}$ & 1,84 & 61 & $4,88 \times 10^{-3}$ & $160 \times 10^{-3}$ & $8,98 \times 10^{-3}$ & 10 \\
\hline $\begin{array}{c}699389704- \\
\text { Ponta Negra } \\
(\mathrm{ZO})\end{array}$ & 1,41 & 61 & $3,74 \times 10^{-3}$ & $160 \times 10^{-3}$ & $5,27 \times 10^{-3}$ & 10 \\
\hline $\begin{array}{c}697488950- \\
\text { Alvorada } \\
\text { (ZCO) }\end{array}$ & 1,37 & 61 & $3,63 \times 10^{-3}$ & $160 \times 10^{-3}$ & $4,98 \times 10^{-3}$ & 10 \\
\hline $\begin{array}{l}691539278- \\
\text { Da Paz (ZCO) }\end{array}$ & 0,52 & 61 & $1,38 \times 10^{-3}$ & $160 \times 10^{-3}$ & $0,72 \times 10^{-3}$ & 10 \\
\hline $\begin{array}{c}\text { 692844597 - } \\
\text { Flores (ZCS) }\end{array}$ & 0,87 & 61 & $2,31 \times 10^{-3}$ & $160 \times 10^{-3}$ & $2,01 \times 10^{-3}$ & 10 \\
\hline $\begin{array}{l}692960007- \\
\text { Aleixo (ZCS) }\end{array}$ & 1,43 & 61 & $3,79 \times 10^{-3}$ & $160 \times 10^{-3}$ & $5,42 \times 10^{-3}$ & 10 \\
\hline $\begin{array}{c}692844554- \\
\text { Centro (ZS) }\end{array}$ & 3,59 & 61 & $9,52 \times 10^{-3}$ & $160 \times 10^{-3}$ & $34,16 \times 10^{-3}$ & 10 \\
\hline $\begin{array}{l}699805562- \\
\text { Distrito } \\
\text { Industrial I } \\
\text { (ZS) }\end{array}$ & 1,69 & 61 & $4,48 \times 10^{-3}$ & $160 \times 10^{-3}$ & $7,58 \times 10^{-3}$ & 10 \\
\hline $\begin{array}{l}\text { 691539359 - } \\
\text { São José } \\
\text { Operário (ZL) }\end{array}$ & 1,82 & 61 & $4,83 \times 10^{-3}$ & $160 \times 10^{-3}$ & $8,79 \times 10^{-3}$ & 10 \\
\hline $\begin{array}{l}699823684- \\
\text { Jorge Teixeira } \\
\text { (ZL) }\end{array}$ & 3,11 & 61 & $8,25 \times 10^{-3}$ & $160 \times 10^{-3}$ & $25,65 \times 10^{-3}$ & 10 \\
\hline
\end{tabular}

Tabela 2. Valores medido e de referência para as estações analisadas

Fonte: Elaborado pelo autor. 


\section{CONCLUSÃO}

Considerando as várias tecnologias da rede de telefonia móvel e ainda as estações avaliadas nessa pesquisa, foi verificada a ocorrência de uso de frequência superior a $2000 \mathrm{MHz}$ em todas elas. Estabelecendo desta forma, os valores constantes de referência máximos, conforme diretriz da Anatel. Desta forma, após avaliação das medidas de campo elétrico, magnético e densidade de potência, e comparação com os valores de referência, verificou-se a conformidade com os níveis de segurança estabelecidos.

Extrapolando-se a quantidade de estações estudadas, não se verifica valores medidos superiores aos níveis de referência, conforme pode ser verificado em diversos trabalhos acadêmicos, como Souza e Gamberini (2018) e Tenório (2015). Entretanto, os níveis de segurança definidos, de acordo com ICNIRP (2020), foram estabelecidos considerando apenas estudos científicos que cumpriram certos critérios, como metodologia, repetitividade de estudo e qualidade das conclusões.

Assim sendo, apenas os efeitos de RNI que podem ser verificados a curto prazo e que possuem efeitos biológicos bem estabelecidos, como elevação da temperatura corporal e estímulos de nervos e músculos, foram considerados na elaboração das diretrizes. (ICNIRP, 2020).

Todavia a fonte de preocupação da comunidade científica reside nos efeitos a longo prazo de uma baixa dosimetria de RNI, como a que estamos expostos diariamente, como pôde ser verificado por esta pesquisa. Embora, a ICNIRP considere insuficiente os dados sobre a relação de cânceres e exposição à RNI, não se pode descartar a possibilidade de haver um mecanismo ainda não compreendido pela nossa ciência que seja a fonte de alterações dessa natureza.

É de interesse da coletividade a compreensão da natureza dos efeitos da radiação não ionizante nos seres humanos. Os órgãos regulamentadores possuem a responsabilidade de alertar a população sobre este fato e de atuar no sentido de limitar essas exposições para assegurar a saúde de todos. Embora as diretrizes atuais garantam a segurança sob exposições a curto prazo, podemos estar expostos a doses de radiação nocivas a longo prazo. 


\section{REFERÊNCIAS BIBLIOGRÁFICAS}

Agência Nacional de Telecomunicações (ANATEL). Diretrizes para Limitações da Exposição à Campos Elétricos, Magnéticos e Eletromagnéticos Variáveis no Tempo (até 300 GHz). Disponível em: https://www.anatel.gov.br/Portal/verificaDocumentos/documento.asp?nu meroPublicacao $=12999 \&$ assuntoPublicacao $=$ null $\&$ caminhoRel=null \&filtro= 1\&documentoPath=biblioteca/publicacao/diretriz_radiacao.pdf. Acesso em: 20 set. 2021.

Dolk, H.; Shaddick, H.; Walls, P.; Grundy , C.; Thakrar, B.; Kleinschmidt, I.; Elliot, P. Cancer incidence near radio and television transmitters in Great Britain, Part I. Sutton Coldfield Transmitter. Am. J. Epidemiol. 145:1 9; 1997a.

Hirata A, Laakso I, Oizumi T, Hanatani R, Chan $\mathrm{KH}$, Wiart J. The relationship between specific absorption rate and temperature elevation in anatomically based human body models for plane wave exposure from $30 \mathrm{MHz}$ to $6 \mathrm{GHz}$. Phys Med Biol 58:903 921; 2013.

International Commission On Non-Ionizing Radiation Protection (ICNIRP). Guidelines for limiting exposure to eletromagnetic fields (1 Hz-100 kHz). Health Phys, n. 118, v. 5, pp.483-524, 2020.

SOUZA, Isabelle Freire de; Gamberini, Leonardo Vieira Fraga. Análise dos níveis de radiação não ionizante em diferentes ambientes na faixa de $100 \mathrm{kHz}$ até $3 \mathrm{GHz}$. 2018. 97p. Trabalho de conclusão de curso - Bacharelado em engenharia de telecomunicações, UFF, Niterói.

TENÓRIO, Boaz Cavalcanti. Exposição humana aos níveis de radiações não ionizantes emitidas pelas estações rádio base. 2015. 86p. Dissertação Programa de pós graduação em engenharia ambiental, UFSC, Florianópolis. 


\title{
DESENVOLVIMENTO DE HARDWARE PARA
} MONITORAMENTO DE PARÂMETROS ELÉTRICOS DE MOTORES

\author{
Raissa V. Mendes' \\ Rubem S. D. Silva' \\ Israel Gondres Torné' \\ Lennon B. F. do Nascimento' \\ Karulayne Barbosa Martins'
}

${ }^{1}$ Escola Superior de Tecnologia (EST) - Universidade do Estado do Amazonas (UEA) CEP 69050-020 - Manaus - AM - Brasil rvm.eng17@uea.edu.br, rsds.eng17@uea.edu.br ,itorne@uea.edu.br ,lbfn.eng@uea.edu.br, kbm.ele16@uea.edu.br

\section{INTRODUÇÃO}

A maioria das indústrias localizadas no Brasil possui maquinários compostos por motores em sua essência. De acordo com dados de 2019 da Empresa de Pesquisa Energética (EPE), cerca de 35\% da energia produzida no Brasil é destinada à classe industrial. Estima-se que os motores elétricos são responsáveis pelo consumo de 50\% dessa energia, principalmente os motores de indução trifásico. Apesar da alta confiabilidade, os motores de indução estão sujeitos a fatores que poderão causar falhas, como envelhecimento, condições de instalação, aplicações inadequadas, esforços mecânicos e elétricos, que, na maioria das vezes, acarretam interrupção de processos produtivos. Portanto, em um cenário de competitividade industrial, aumenta-se a cobrança pelo crescimento da disponibilidade e confiabilidade dos equipamentos e pela redução de custos. 0 presente estudo visa o desenvolvimento de uma plataforma de Hardware capaz de realizar aquisição de parâmetros elétricos e mecânicos e disponibilizar esses dados em tempo real de uma maneira confiável utilizando um sistema operacional de tempo real e aplicando conceitos de Internet das Coisas. 


\section{OBJETIVOS}

Desenvolver uma plataforma de hardware capaz de realizar a medição de parâmetros elétricos e mecânicos em motores de indução trifásico para visualização de parâmetros de saúde do motor.

\section{MATERIAIS E MÉTODOS}

\subsection{MATERIAIS UTILIZADOS}

- Motor de indução

- Inversor delta

- Fonte de bancada

- Módulo HW-611 com sensor de temperatura BMP280

- Módulo GY-521 com acelerômetro MPU 6050

- Microcontrolador ESP32-WROOM-32D

- CI para medição de energia ADE7758

\subsection{SOFTWARE UTILIZADOS}

- Altium Designer é uma ferramenta de software utilizada para desenvolvimento de projetos eletrônicos para placas de circuito impresso.

\subsection{MÉTODOS UTILIZADOS}

\subsubsection{DESENVOL VIMENTOS DO HARDWARE}

0 projeto do hardware divide-se em duas placas de circuito impresso, no qual uma placa é responsável pela medição de energia como tensão e corrente do motor de indução, enquanto a outra placa consiste no gerenciamento dos dados dos sensores e do medidor de energia.

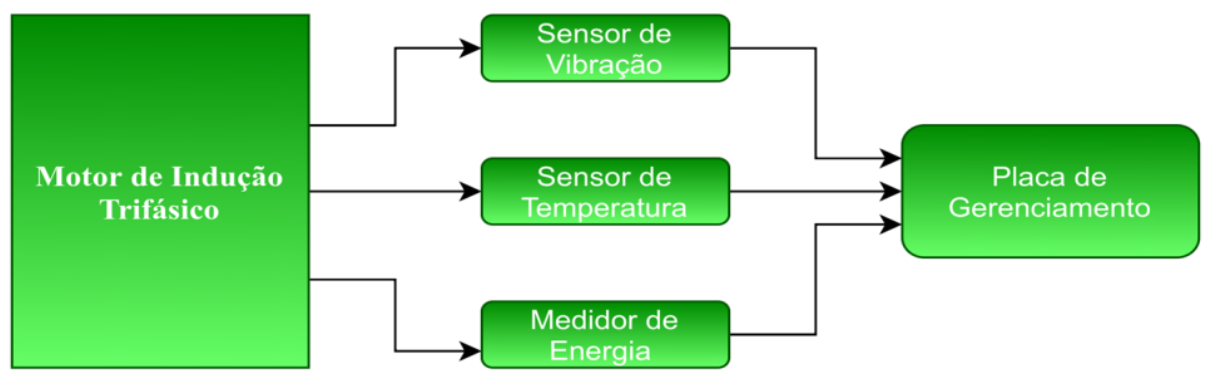

Figura 1. Fluxograma referente ao esquema de desenvolvimento do projeto.

No desenvolvimento da primeira placa do medidor de energia, optou-se pelo uso do circuito integrado ADE 7758 devido a sua capacidade de realizar medições 
de energia trifásicas com alta precisão utilizando o protocolo de comunicação SPI. Nesta primeira etapa no desenvolvimento da placa foram incluídos no projeto três canais reservados para medição de tensão juntamente com outros três canais para medição de corrente presente no ADE 7758 como pode ser observado na figura 2b. Para os canais de medição de corrente e tensão foram montados circuitos externos de proteção e tratamento para medição do sinal com qualidade. Além disso, utilizouse o isolador digital SI8663 para garantir a integridade dos componentes localizados na Placa de Gerenciamento integrada com microcontrolador durante a comunicação com o módulo de medição.

No desenvolvimento da Placa de Gerenciamento placa foi utilizado o microcontrolador ESP32-WROOM-32D devido aos recursos disponíveis como sua memória RAM, conectividade WIFI, suporte nativo para sistemas operacionais em tempo real, além de sua disponibilidade para dois núcleos de processamento. Vale citar que foram adicionados conectores para disponibilização aos seguintes barramentos de comunicação: I2C, SPI, UARTs e I2S. Essa disponibilização serviu para a leitura dos outros sensores que atuaram em conjunto com a placa do medidor de energia.

Ressalta-se que durante o projeto também foram considerados circuitos periféricos necessários ao funcionamento do microcontrolador, como o circuito de regulador de tensão para garantir uma tensão de alimentação segura, o circuito de clock responsável por controlar as velocidades de operações, os botões de reset e boot no circuito com a finalidade de resetar o sistema e reinicializar os dados da memória RAM, como também, foram adicionados capacitores próximos aos botões com o objetivo de diminuir o bounce (trepidação) quando os mesmos são acionados como pode ser observado na figura $2 \mathrm{a}$.

Por fim, levando em consideração recomendações dos fabricantes, observouse a necessidade de deixar a antena do ESP32-WROOM-32D para fora da placa para evitar o contato da mesma com o plano de referência elétrica da placa. 


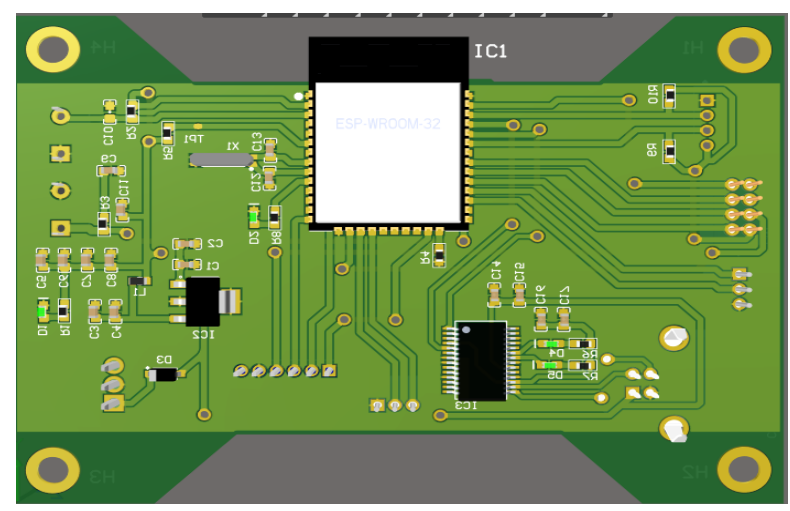

(a)

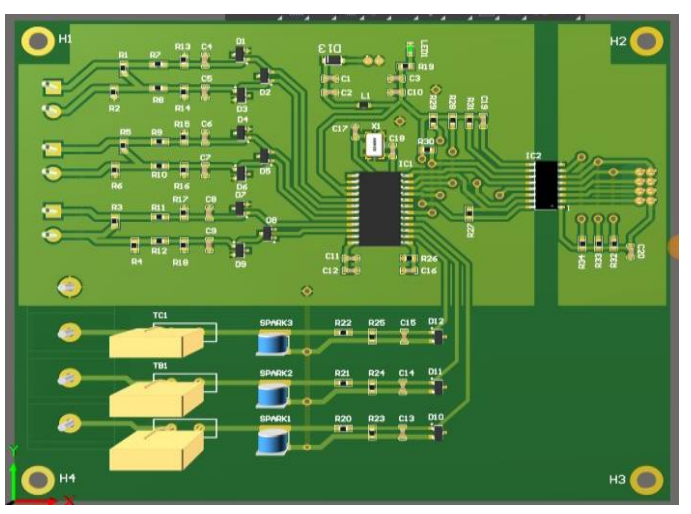

(b)

Figura 2. Representação em 3D placas de circuito impresso - (a) Placa de Gerenciamento (b) Medidor de energia.

\section{RESULTADOS}

Após a finalização do projeto das placas de circuito impresso no Altium, foi realizado a montagem das mesmas, a figura 3 ilustra o estágio final das placas de circuito impresso.

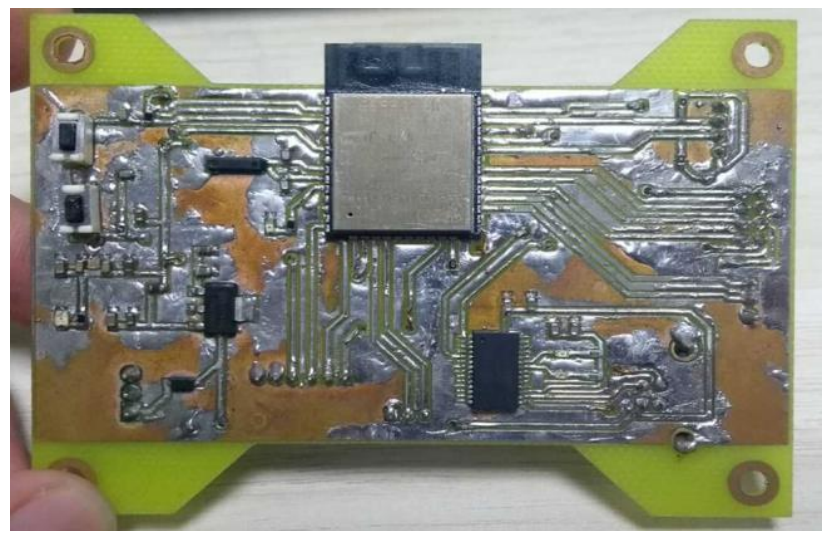

(a)

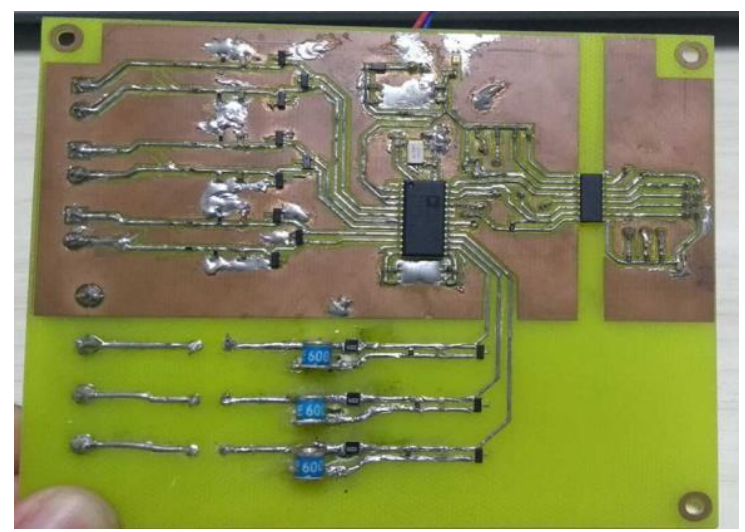

(b)

Figura 3. Placas de Circuito Impresso montadas - (a) Placa de Gerenciamento (b) Medidor de energia.

O teste realizado com o conjunto das placas possibilitou as medições de corrente utilizando um transformador de corrente conectado a uma fase do motor de indução como pode ser visualizado na Figura 4a. 


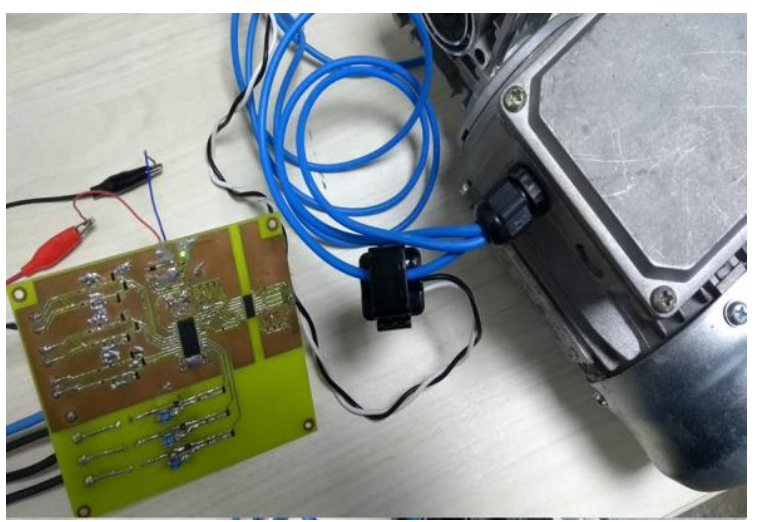

(a)

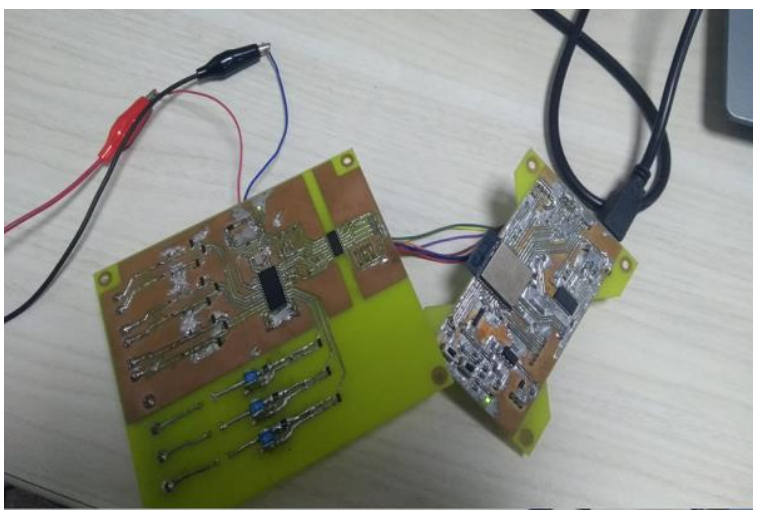

(b)

Figura 4. Etapa de testes e validação com motor de indução trifásico - (a) Integração do Medidor de energia com motor de indução. (b) Integração da Placa de gerenciamento com Medidor de energia.

Para a realização dos testes com os sensores de temperatura e vibração foram integrados os mesmos em cases para melhorar seu acoplamento no motor de indução, como evidenciado na ilustração 5 b.
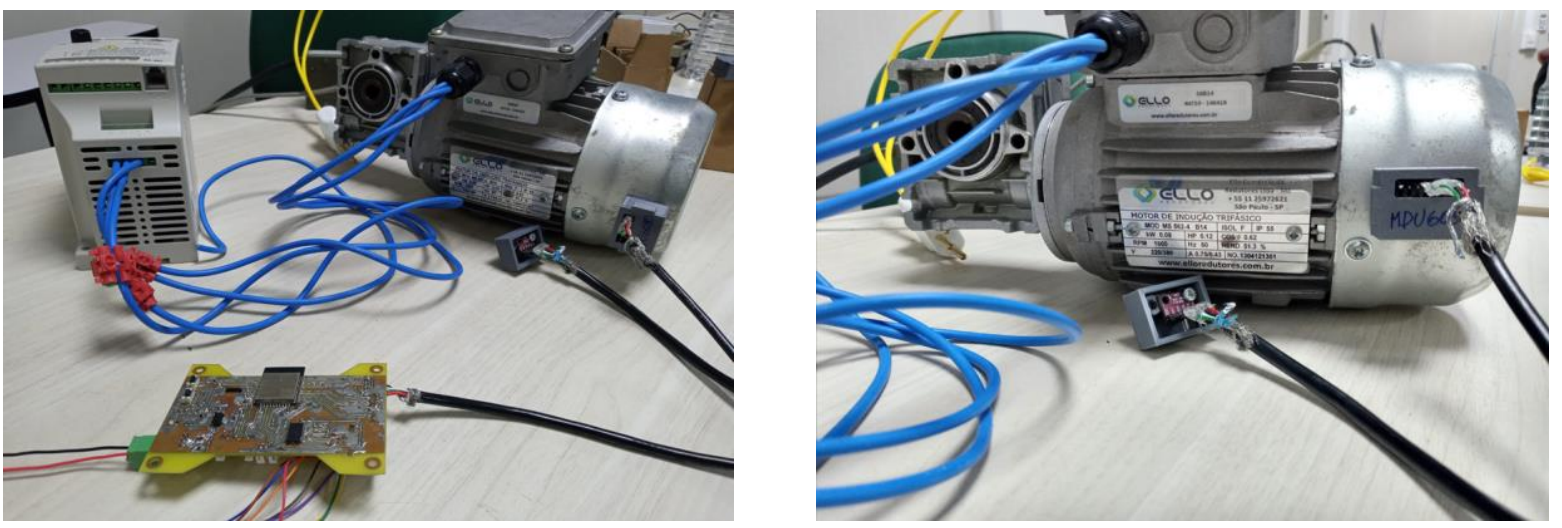

Figura 5. Etapa de testes e validação com motor de indução trifásico - (a) Integração da Placa de Gerenciamento, sensor de vibração e sensor de temperatura com motor de indução. (b) Instalação dos sensores no motor de indução.

\section{CONCLUSÃO}

A placa de desenvolvimento apresentou resultados satisfatórios em relação a medição dos sensores de vibração e de temperatura. 0 calor dissipado pelo motor era mínimo, pois na situação testada, ele estava sem carga no seu eixo. Todavia, observou-se que as medições de temperatura realizadas pelo sensor eram 
compatíveis com a temperatura ambiente, validando o correto funcionamento do mesmo.

Além disso, o sensor de vibração adotado, o acelerômetro, também logrou êxito, visto que foi possível acoplá-lo ao motor e realizar as medições de forma adequada desse parâmetro mecânico. Foi possível constatar isso quando foi realizada a variação da velocidade do motor que se refletiu também na mudança de vibração medida por parte desse sensor. É importante citar que a região próxima ao motor é suscetível a ruídos eletromagnéticos proveniente das bobinas. Isso ocasionou erros em etapas da medição que foi parcialmente solucionada com a utilização de cabos blindados.

0 teste realizado com a placa do medidor de energia obteve resultados próximos ao esperado em relações as medições efetuadas de corrente e tensão, contudo, os valores obtidos oscilaram de maneira incomum devido a limitações na montagem da placa. Ainda assim, foram obtidos bons resultados nas leituras dos sensores e no medidor de energia e o desempenho em conjunto das duas placas foi satisfatório durante os testes.

\section{REFERÊNCIAS BIBLIOGRÁFICAS}

Chapman, Stephen J. Fundamentos de Máquinas Elétricas, traduçao: Anatónio Laschuk. 5a Edição. Dados Eletrônicos. Porto Alegre: AMGH, 2013.

Denardin, Gustavo Weber. Sistemas Operacionais de tempo real e sua aplicação em sistemas embarcados. São Paulo: Blucher, 2019. 474 p. : il.

Saracino, A. M. S., \& Horimi, C. A. (2019). Detecção de defeitos em motores de indução trifásicos através da avaliação do comportamento térmico (Bachelor's thesis, Universidade Tecnológica Federal do Paraná).

Xiaodong Liang, Senior Member. Temperatura Estimation and Vibration Monitoring for Induction Motors. 2017, Electrical Power and Energy Conference(EPEC), IEEE.

Shyamala, D., Swathi, D., Prasanna, J. L., \& Ajitha, A. (2017, October). IoT platform for condition monitoring of industrial motors. In 2017 2nd International Conference on Communication and Electronics Systems (ICCES) (pp. 260265). IEEE. 


\title{
DESENVOLVIMENTO DE FIRMWARE E SOFTWARE
} PARA MONITORAMENTO DE MOTORES DE INDUÇÃO TRIFÁSICOS

\author{
Rubem S. D. Silva' \\ Raissa V. Mendes' \\ Israel Gondres Torné \\ Lennon B. F. do Nascimento' \\ Karolayne B. Martins'
}

1Escola Superior de Tecnologia (EST) - Universidade do Estado do Amazonas (UEA) CEP 69050-020 - Manaus - AM - Brasil rsds.eng17@uea.edu.br, rvm.eng17@uea.edu.br, itorne@uea.edu.br, lbfn.eng@uea.edu.br. kbm.ele16@uea.edu.br

\section{INTRODUÇÃO}

Os motores de indução compõem grande parte da indústria moderna. Eles são equipamentos que requerem alta confiabilidade, e possuem larga margem de aplicações no setor industrial. Todavia, as máquinas são suscetíveis a falhas em diversas etapas do seu funcionamento, e seu constante uso leva ao desgaste do motor, fazendo necessário a realização frequente de monitoramento com intuito de realizar a manutenções preventivas do equipamento. 0 presente estudo visa o desenvolvimento de um firmware capaz de gerenciar os dados de sensoriamento de um motor de indução trifásico e realizar a transmissão dos dados adquiridos via Wifi por meio do protocolo MQTT (Message Queuing Telemetry Transport), além do desenvolvimento de uma plataforma para o recebimento e apresentação de dados em tempo real.

\section{OBJETIVOS}

Desenvolver um firmware capaz de gerenciar dados oriundos de múltiplos sensores e transmiti-los via protocolo MQTT, além de criar uma interface de visualização para recepção e apresentação desses dados em tempo real. 


\section{MATERIAIS E MÉTODOS}

\subsection{MATERIAIS UTILIZADOS}

- Módulo HW-611 com sensor de temperatura BMP280;

- Módulo GY-521 com acelerômetro MPU 6050;

- Sistema operacional de tempo real FreeRTOS;

- Microcontrolador ESP32-WROOM-32D;

- CI para medição de energia ADE7758;

- Broker MQTT Mosquitto;

- Biblioteca PubSubClient;

- Biblioteca Matplotlib;

- Cliente MQTT paho.

\subsection{MÉTODOS UTILIZADOS}

O sistema proposto é composto por duas funcionalidades principais: A primeira consiste na aquisição e transmissão de dados. Primeiramente é realizada a leitura simultânea de três periféricos de aquisição de dados por meio de uma placa contendo um microcontrolador ESP32-WROOM-32D. Em seguida, os dados coletados são transmitidos via protocolo MQTT. A segunda funcionalidade se trata da recepção e exibição de dados em um dispositivo conectado à mesma rede de computadores do microcontrolador. Esse processo pode ser visualizado na figura 01.

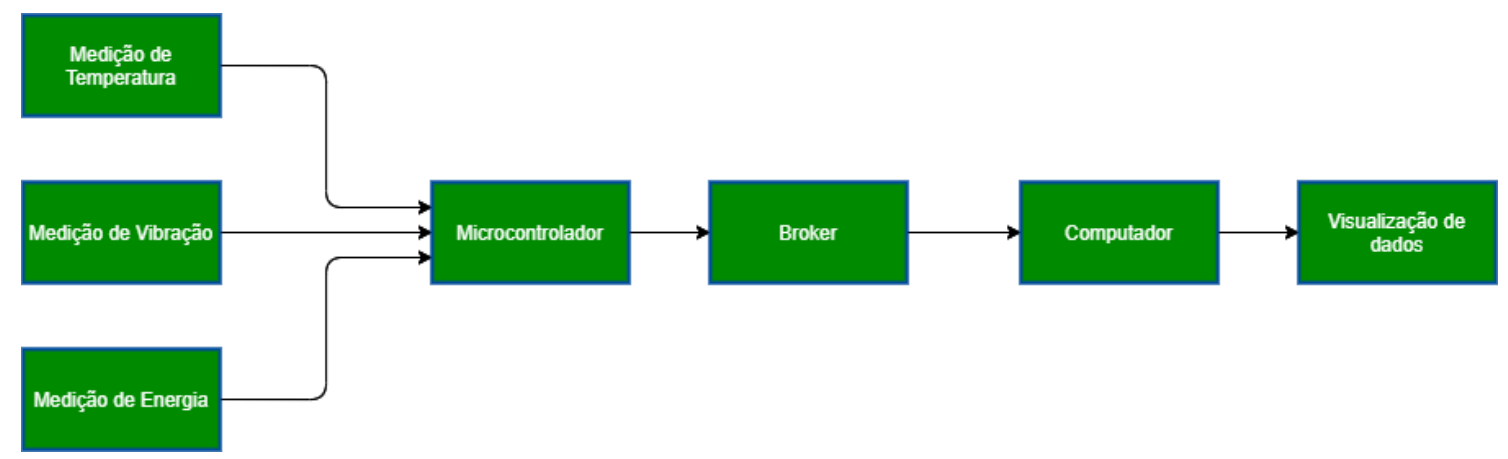

Figura 1. Estrutura do sistema.

\subsubsection{DESENVOL VIMENTOS DO FIRMWARE}

A estrutura da aplicação teve como base o sistema operacional de tempo real FreeRTOS, o qual permite separação de diferentes fluxos de processamento denominadas tasks. Mediante esta funcionalidade, foram criadas quatro tasks, três exclusivas para os periféricos de sensoriamento, e uma destinada a transmissão das 
medições realizadas ao Broker MQTT. Essa estrutura de tasks pode ser verificada na figura 02.

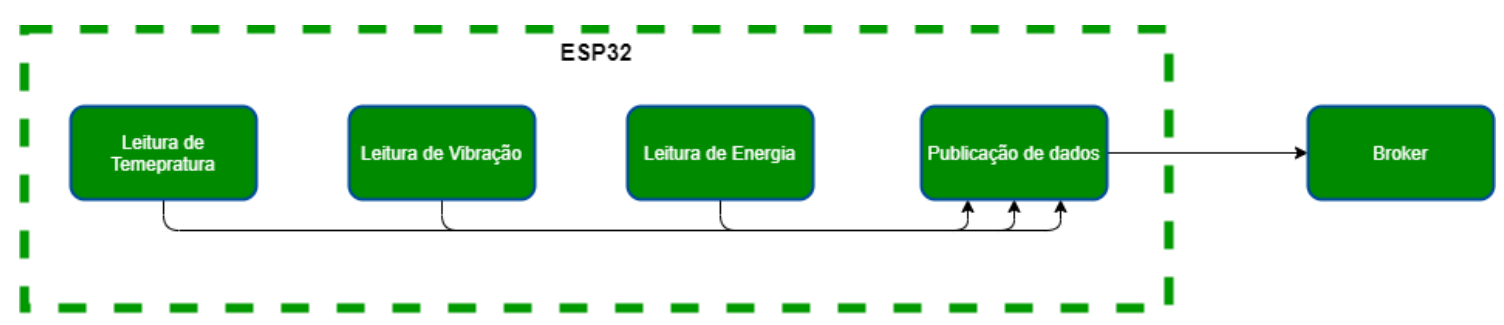

Figura 2. Estrutura de funcionamento do firmware.

\subsubsection{DESENVOL VIMENTOS DO SOFTWARE}

Para a recepção e visualização das medições realizadas pelos sensores, implementou-se um script em linguagem Python. Esse script foi responsável por instanciar um cliente MQTT que recebesse os dados advindos do microcontrolador, e os apresentar em uma interface. A figura 03 apresenta a divisão das funcionalidades dentro do programa desenvolvido, com a divisão de dois fluxos de processamento entre: conectividade com a internet e uma Dashboard para exibição de dados.

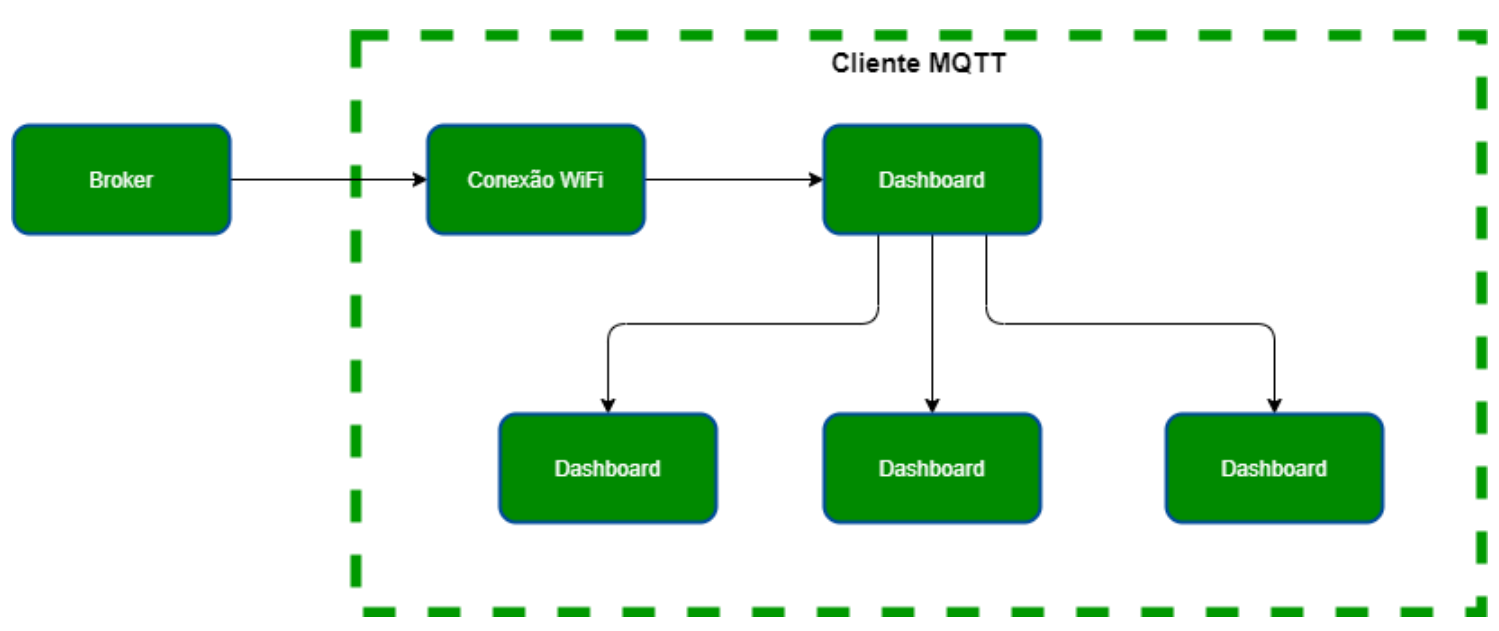

Figura 3. Estrutura de funcionamento do cliente MQTT.

O bloco Dashboard apresentado na figura 03 consiste em uma interface gerada a partir da biblioteca Tkinter. A interface é dividida em três páginas direcionadas a apresentação de cada parâmetro medido. Outro recurso utilizado foi a função FuncAnimation pertencente a biblioteca Matpltlib, que permite a 
apresentação periódica de um mesmo gráfico em tela e possibilita a exposição em tempo real dos valores obtidos pelo cliente MQTT.

\section{RESULTADOS}

Pôde-se estabelecer a conexão WiFi entre microcontrolador e Broker, bem como a divisão do processamento de leitura dos sensores. Além disso, as medições foram encaminhadas em tópicos diferentes do MQTT e puderam ser enviadas separadamente como pode ser observado na figura 04 .

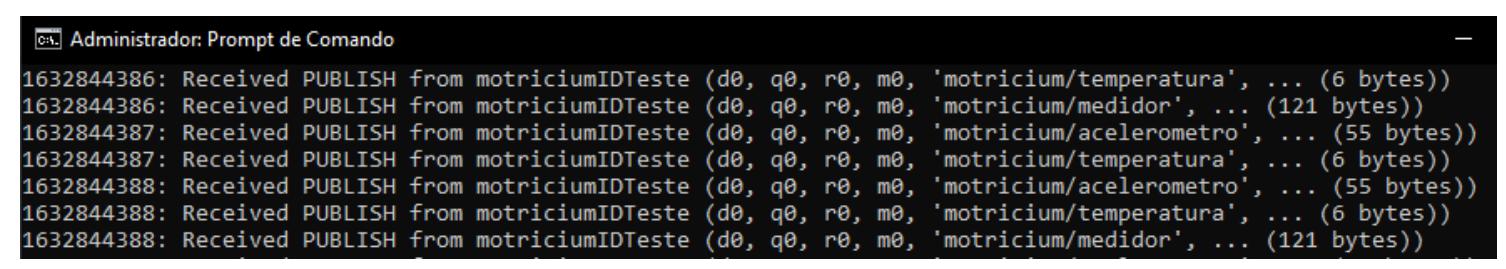

Figura 4. Status das mensagens recebidas pelo Broker.

Na figura 05, é possível verificar os gráficos gerados para visualização em tempo real de temperatura e vibração. Quantos às características elétricas do motor, foram dispostos tensão, corrente e fator de potência referentes às 3 fases do motor, como mostrado na figura 06.
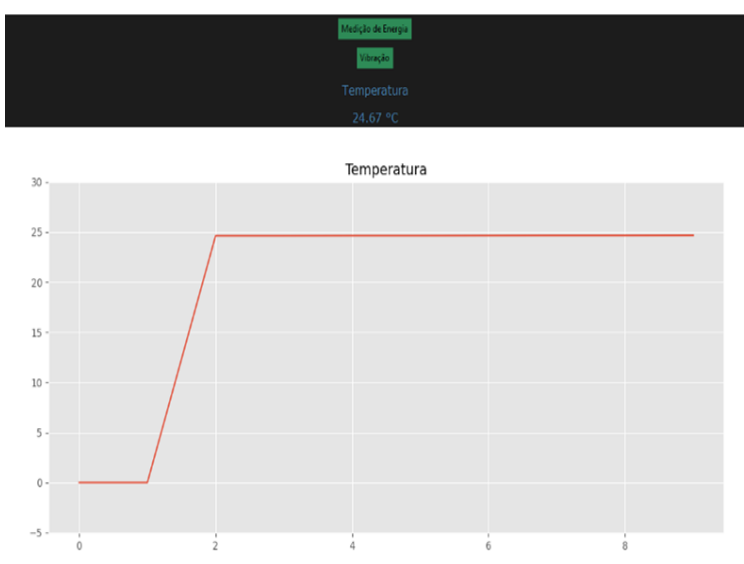

(a)

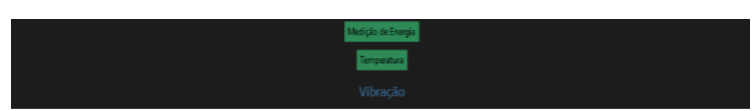

eixo $x$

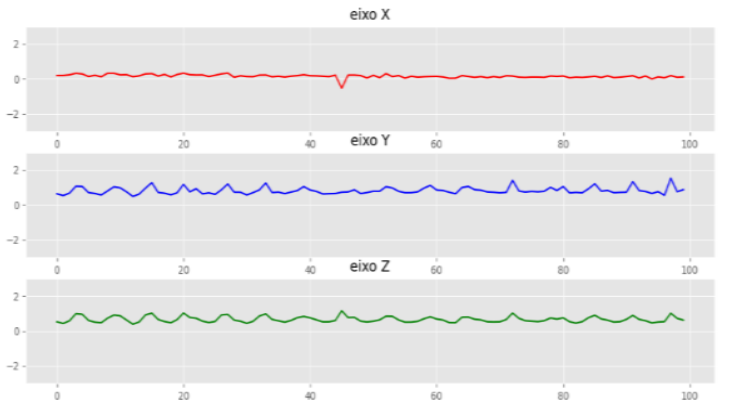

(b)

Figura 5. Plotagem em tempo real - (a) Níveis de temperatura e (b) níveis de vibração aferidos. 


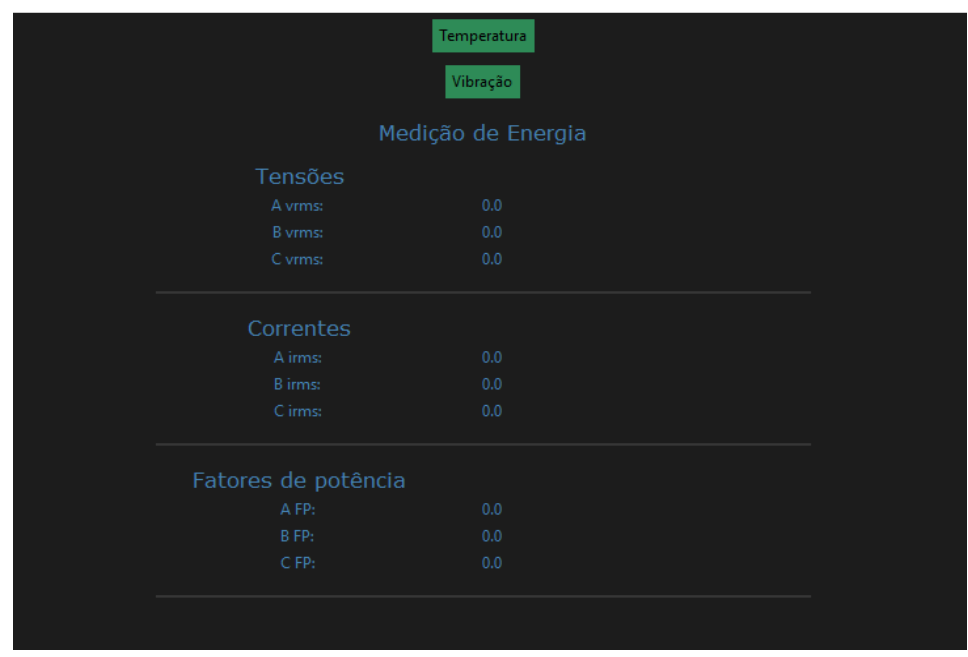

Figura 6. Exibição dos parâmetros elétricos do motor.

\section{CONCLUSÃO}

A aplicação desenvolvida apresenta um procedimento para administração de diferentes tarefas dentro de um microcontrolador. Além disso, realiza a disponibilização de informação em uma rede WiFi local. Vale citar também que foi implementado um software capaz de recepcionar e dispor as mensagens advindas do microcontrolador em uma interface própria. Como resultado obteve-se o funcionamento resiliente das duas aplicações tanto em unidade como em conjunto.

Mediante pesquisas realizadas durante o projeto e o desenvolvimento do sistema, viu-se a possibilidade de extrair informações significantes da análise da vibração do motor. Portanto, uma sugestão para pesquisas futuras seria a análise do espectro de frequência de vibração do motor, além da utilização de inteligência artificial para o reconhecimento do estado da máquina por intermédio das medições realizadas.

\section{REFERÊNCIAS BIBLIOGRÁFICAS}

Şen, M., \& Kul, B. (2017, September). IoT-based wireless induction motor monitoring. In 2017 XXVI International Scientific Conference Electronics (ET) (pp. 1-5). IEEE.

Choudhary, A., Jamwal, S., Goyal, D., Dang, R. K., \& Sehgal, S. (2020). Condition monitoring of induction motor using internet of things (IoT). In Recent Advances in Mechanical Engineering (pp. 353-365). Springer, Singapore.

Melot, N. (2009). Study of an operating system: FreeRTOS. 
Chen, B. (2014). Humidity sensor circuit using real time operating system (FREERTOS) Kernel.

Kodali, R. K., \& Valdas, A. (2018, August). Mqtt based monitoring system for urban farmers using esp32 and raspberry pi. In 2018 Second International Conference on Green Computing and Internet of Things (ICGCIoT) (pp. 395398). IEEE.

Nikolov, N., \& Nakov, O. (2019, September). Research of secure communication of Esp32 IoT embedded system to. NET core cloud structure using MQTTS SSL/TLS. In 2019 IEEE XXVIII International Scientific Conference Electronics (ET) (pp. 1-4). IEEE.

Smythe, R. J. (2021). Realtime Data Plotting and Visualization. In Advanced Arduino Techniques in Science (pp. 161-171). Springer, Berkeley, CA.

Zainudin, A., Syaifudin, M. F., \& Syahroni, N. (2019, November). Design and Implementation of Node Gateway with MQTT and CoAP Protocol for IoT Applications. In 2019 4th International Conference on Information Technology, Information Systems and Electrical Engineering (ICITISEE) (pp. 155-159). IEEE. 
UM HISTÓRICO DAS PRINCIPAIS ENERGIAS RENOVÁVEIS E APLICAÇÕES DE FERRAMENTAS DA INDÚSTRIA 4.0

John Kinderman de Freitas Barros'

Isabel Carril Gama'

Daniel Guzmán del Rio'

Daniel Sousa da Silva'

Escola Superior de Tecnologia (EST) - Universidade do Estado do Amazonas (UEA) CEP 69050-020 - Manaus - AM - Brasil icg.ele20@uea.edu.br, kindbarros@gmail.com,drio@uea.edu.br, dass.eng@uea.edu.br

\section{INTRODUÇÃO}

As energias renováveis são fundamentais para a expansão do desenvolvimento sustentável, pois fontes limpas de energia ajudam a reduzir o consumo de recursos. No Brasil, um reflexo de sua importância está na matriz energética nacional, visto que da energia utilizada no país, a maior parte é renovável. Bem como, os conceitos da quarta revolução industrial, também conhecida como indústria 4.0, tem-se fomentado com a globalização, e mediante a isso vê-se a integração de seus conceitos eletrônicos e os conceitos de energias renováveis. De certo, a geração de energia limpa não só é imprescindível como também pode envolver a evolução dos processos na indústria e modo econômico e prático quando se trata do uso da microeletrônica na indústria 4.0.

\section{OBJETIVOS}

Esse artigo tem a proposta de realizar um estudo sobre a utilização de energias renováveis bem como a aplicação da eletrônica em seu meio, trazendo a análise da aplicação de conceitos da indústria 4.0 pois a integração desses conceitos traz uma ideia mais abrangente e definida do que são as aplicações da eletrônica e formas de como a inovação nessa área pode ocorrer. 


\section{MATERIAIS E MÉTODOS}

Os materiais apresentados não só foram obtidos através de pesquisas bibliográficas e artigos acadêmicos mas também por meio de reuniões, os quais conteúdos e imagens foram oferecidos pelos colaboradores.

\section{FUNDAMENTOS DE ENERGIA RENOVÁVEL}

Mesmo com o petróleo sendo uma das principais formas de se gerar energia, investir apenas nesse artifício era cada vez mais inconstante devido a ser um recurso limitado e não-renovável e também por conta da imprevisibilidade de custos. Ademais, existem efeitos que são naturais e partem da interação do petróleo de forma direta e indireta na natureza como a acidificação dos oceanos devido a liberação de dióxido de carbono (CO2) na atmosfera produzido pela queima de combustíveis, o agravamento do efeito estufa contribui para o aumento da temperatura global e derramamentos acidentais de petróleo no ecossistema podendo provocar a morte de diversos animais. Em virtude disso, outros métodos foram elaborados e ainda são desenvolvidos como alternativa energética a fim de evitar estes malefícios. Em outras palavras, esses mecanismos foram engenhados para gerarem energia a partir de recursos renováveis e ilimitados de forma sustentável, evitando a extração desenfreada de recursos. Exemplos desses artifícios são a geração de energia solar, eólica, hídrica, biomassa entre outras, contudo devido às circunstâncias necessárias de cada uma, nem todas são aplicáveis em qualquer localidade.

\subsection{ENERGIA SOLAR}

A energia solar pode ser obtida através do efeito fotovoltaico, que pode ser entendido como a produção de correntes elétricas a partir da exposição da luz às células fotovoltaicas, ou a partir do calor gerado pelos raios solares como geralmente é aproveitado nas usinas heliotérmicas. Na primeira forma de se gerar energia solar é fundamentada na transformação da energia mecânica em energia elétrica pela movimentação de turbinas através da energia potencial do vapor comprimido, ocasionado pela concentração de raios solares. Na segunda, figura 1, mais comumente utilizada, a exposição dos painéis fotovoltaicos, (1) à radiação solar produz uma corrente contínua, por essa razão e outras existem outros 
membros nesse sistema como o inversor DC/AC (2), o qual pode ser ajustado para 220V-AC com destino de abastecer residências, sendo essencial para o aproveitamento da energia gerada. Assim como outros equipamentos como o medidor de energia (3), não tendo envolvimento com o processo de fornecimento da energia, ele mede tanto a energia gerada quanto a consumida, na maioria das vezes, a energia gerada excede a consumida, acarretando pontos extras na empresa de energia local caso o sistema esteja conectado à rede de energia (4).

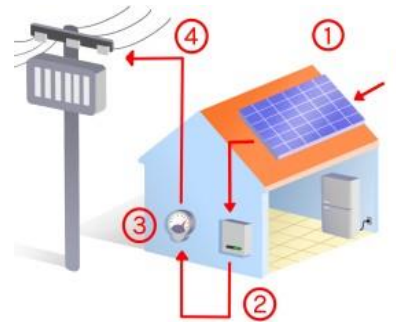

Figura 1. Sistema de energia solar fotovoltaico.

Fonte: Elaborada pelo autor

Levando em consideração as leis da termodinâmica, durante o processo de conversão de qualquer outra energia é possível perceber que sempre ocorrem perdas, dependendo de cada uma das suas propriedades ou dos processos as quais são submetidas. A eficiência de um painel solar é testada através das condições de STC(Standard Test Conditions) nos quais, segundo Li et al. (2005), são estabelecidos três critérios para o teste; A temperatura da célula deve ser de $25^{\circ} \mathrm{C}$ (por mais que seja comum uma célula atingir temperaturas muito mais altas quando estiverem operando), a irradiação solar ser de $1000 \mathrm{~W} / \mathrm{m}^{2}$ (Watts por metro quadrado) e o critério considerado mais difícil de se atingir que seria a massa do ar em 1,5. Em síntese, um painel solar considerado com um ótimo rendimento tem sua eficiência acima ou igual a $18 \%$ e um bom rendimento se encontra entre os valores de $16 \%$ a $16,9 \%$.

Quanto à sua instalação, é necessário tomar medidas para adequar o painel, tanto o ângulo em que é colocado quanto a quantidade de sombras ao redor podem influenciar positiva ou negativamente na produção de energia. Por isso, antes de sua instalação são feitos procedimentos como o conhecimento do local onde será aplicado e por conseguinte a modelagem 3D virtual do local para simulação da iluminação durante o dia todo, pois uma célula mal iluminada em um circuito funcionaria como uma carga às outras células, diminuindo assim a sua eficiência. 


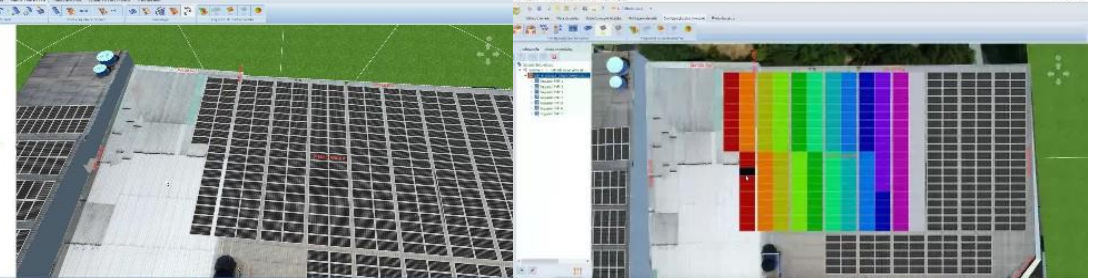

Figura 2. Modelagem e simulação de uma instalação predial

Fonte: Imagens fornecidas da empresa Criteria Energia

\subsection{ENERGIA HIDRELÉTRICA}

A maior parte da energia gerada no Brasil provém das usinas hidrelétricas assim como no mundo afora. Este tipo renovável é o mais usado no mundo, segundo dados da EPE (Empresa de Pesquisa Energética), a eletricidade gerada nas usinas hidrelétricas chega a ser aproximadamente $16 \%$ da energia gerada no planeta, a segunda mais produzida, perdendo apenas para os combustíveis fósseis. Em síntese, as usinas hidroelétricas têm um grande potencial ao gerar eletricidade em questão de escala e preço de produção. Das complicações que surgem ao empregar esse meio "limpo" de produção de eletricidade existe tanto a incerteza da quantidade de vazão de água durante certo período, como também existem os impactos ambientais que podem ser causados na implantação dessas usinas. Assim como outros tipos de geração de energia renovável, os recursos podem ser variáveis durante o ano, isto é, em certos períodos do ano ocorre a estiagem, condição hidrológica que afeta consideravelmente a eficiência das hidrelétricas, visto que a energia mecânica do fluxo das águas do rio é transformada em energia elétrica. Na tentativa de impedir a escassez nos casos mencionados, foram desenvolvidas soluções como a construção de reservatórios para o acúmulo de água, assim como podemos observar na ilustração:

\subsection{ENERGIA EÓLICA}




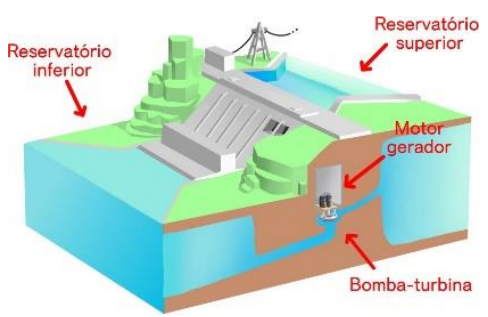

Figura 3. A diferença de altura entre os dois reservatórios faz que a energia potencial se transforme em energia mecânica a qual é convertida pelas turbinas hidráulicas em energia elétrica.

Fonte: Elaborada pelo autor.

Utilizando um aerogerador é possível converter a energia mecânica dos ventos em eletricidade através do uso de turbinas, mas são necessárias grandes áreas para a implantação desses sistemas chamados de parques eólicos. A energia gerada nesses parques é suficientemente grande a ponto de o Brasil ser o $7^{\circ}$ no ranking mundial de capacidade de geração eólica segundo o IEA (International Energy Agency). Em relação à aplicação dos conceitos de Indústria 4.0 que ainda está em desenvolvimento, ela está envolvida não apenas no monitoramento, controle de informações e manutenção, mas como também em projetos de grande escala como a impressão 3D de turbinas eólicas inauguradas por uma das maiores fabricantes de turbinas mundialmente.

\section{A GERAÇÃO DE ENERGIA E INDÚSTRIA 4.0}

A indústria 4.0 caracteriza-se como um movimento de revolução que tem como fundamento tecnologias inovadoras que visam a integração dos processos realizados e melhorando assim a velocidade de respostas e promovendo uma comunicação interligada de suas diversas etapas.

Os principais conceitos para a Indústria 4.0 são: Internet das Coisas (Internet of Things-IoT) que consiste na interligação de serviços e componentes por meio da internet, realizando assim um meio de comunicação entre os processos que causa um grau maior de controle, Cloud Computing que consiste na computação realizada à distância em computadores com maior capacidade de processamento ao invés de utilizar uma máquina local, e Inteligência artificial que consiste no agrupamento de várias tecnologias que em conjunto conseguem simular capacidades humanas de processamento de informações, raciocínio, percepção de mundo e tomada de decisões. 
Essas tecnologias têm as mais diversas aplicações no meio de energias renováveis, como no monitoramento de rede elétrica com aplicações web e IoT, que foi apresentado por Wahlbrinck (2018), de modo que a rede seja monitorada e com possibilidade de ser alterada à distância sendo integrada e funcional. Dentro do

processo de geração de energia renovável em maior parte da utilização das ferramentas dessa nova revolução tecnológica, a simulação 3D e 2D de estruturas como: as turbinas eólicas na modelagem e simulação das estruturas e dinâmica de mesoescala, para estudo da estabilidade térmica, padrões dos ventos e efeitos da temperatura através de ferramentas computacionais; nas placas fotovoltaicas na utilização de simulação de instalações prediais durante a exposição do sol com intuito de verificar se a área é adequada, se há incidência de luz solar em todas as células fotovoltaicas, para enfim aplicá-las; nas hidrelétricas, em simulações de estruturas do reservatório e dos cálculos de energia e de vazão com o propósito de aumentar a eficiência de geração e ter uma produção mais segura; e na biomassa, modelagem e simulação de equipamentos como o gaseificador de biomassa, simulação numérica e análise da viabilidade do projeto.

\section{CONCLUSÃO}

A indústria 4.0 chegou para representar a flexibilidade e aumento crescente do uso da tecnologia de automação de processos e serviços nas indústrias, tudo isso para agilizar processos e executá-los com qualidade, na geração de energia também é um termo bastante crescente, já que a tecnologia nunca para de crescer, a fim de otimizar o fornecimento de energia limpa. Porém, a grande digitalização desses dados aumenta os riscos de segurança de privacidade de dados empresariais e industriais, assim como a falta de conhecimento no ambiente de mercado atual e como aplicar os métodos da Indústria 4.0 pode apresentar riscos.

\section{REFERÊNCIAS BIBLIOGRÁFICAS}

THOMAS E. JOSÉ. Fundamentos de Engenharia do Petróleo. Rio de Janeiro, 2001.

DANNY H.W. LI, GARY H.W. CHEUNG, JOSEPH C. LANG. Analysis of the operational performance and efficiency characteristic for photovoltaic system in Hong Kong. Hong Kong, 2004.

BRITO M.C.; SILVA J.A.; Energia fotovoltaica: conversão de energia solar em electricidade. Lisboa, 2006. 
DORADO R.G.; TRINDADE L.B; ROSALES LUZ J.L.; FREITAS FILHO D.G.; MORAES M.R.;

PETRY A.P.; BODMAN B. Aplicação de Modelo de Mesoescala para Desenvolvimento de Projetos Eólicos. Porto Alegre, 2013.

ALBERTO B.A.; SANTOS P.; LIMA T.D.F.M.; CHARRUA-SANTOS F.M.B. Indústria 4.0: desafios e

oportunidades

WAHLBRINCK, ALAN JUNIOR. Monitoramento da rede elétrica por meio de aplicação WEB e IOT. BS thesis. 2018.

TINOCO, BEZERRA JATOBA. Indústria 4.0 e Energia Eólica: Um Diagnóstico das Empresas de Serviços do Setor Eólico de RN. Rio Grande do Norte 2021 https://www.iea.org/data-and-statistics

https://www.epe.gov.br/pt/publicacoes-dados-abertos/publicacoes/planonacional-de-energia-pne https://replicario.com.br/a-ge-fabricara-turbinaseolicas-mais-altas-usando-impressao-3d/ 


\title{
ALGORITMOS BARE METAL PARA CONTROLE E USO DE PERIFÉRICOS DE PLATAFORMAS EMBARCADAS MICROCONTROLADAS
}

\author{
Nádila da Silva de Azeveda' \\ Ana Beatriz Santos Leite ${ }^{2}$ \\ Maysa Jhiovanna Dalvino Marques ${ }^{3}$ \\ Rubens de Andrade Fernandes ${ }^{4}$ \\ Israel Gondres Torné ${ }^{5}$ \\ Ingrid Sammyne Gadelha Figueireda ${ }^{6}$
}

Escola Superior de Tecnologia (EST) - Universidade do Estado do Amazonas (UEA) CEP 69050-020 - Manaus - AM - Brasil ndsda.eng19@uea.edu.br, absl.eng19@uea.edu.br, mjdm.eng19@uea.edu.br,rdafr.eng@uea.edu.br, itorne@uea.edu.br, ifigueiredo@uea.edu.br

\section{INTRODUÇÃO}

Em projetos de sistemas embarcados, torna-se necessário o aprendizado dos recursos oferecidos pelo processador em uso a fim de se obter melhores desempenhos, eficiência e eficácia na operação do sistema. Contudo, muitas das instruções e funcionalidades presentes no hardware do processador não são abstraídas a nível de software. Dessa forma, é importante que o desenvolvedor encontre alternativas de programação em linguagem de máquina para acessar tais recursos. Uma dessas alternativas é a programação Bare Metal, que se apresenta como uma opção para elaboração de algoritmos em baixo nível, permitindo a execução do firmware pelo acesso aos periféricos presentes na plataforma. Isso propicia a otimização da memória nos microcontroladores a partir de códigos desenvolvidos em diversas linguagens, como C e Assembly [YVON,2020]. Apesar dos benefícios oferecidos neste método, pouco se aborda sobre o tema na literatura, o que dificulta a difusão dele no meio técnico-científico.

\section{OBJETIVOS}

Como alternativa para problemática exposta, este trabalho apresenta a implementação de algoritmos em Bare Metal utilizando linguagem C para uso dos recursos presentes nas plataformas embarcadas desenvolvidas. 


\section{MATERIAIS E MÉTODOS}

Nesta seção serão apresentadas as ferramentas utilizadas para o desenvolvimento do projeto, tais como microcontroladores, software e periféricos.

\subsection{FERRAMENTAS COMPUTACIONAIS E DE HARDWARE}

Foram utilizados os microcontroladores STM32F103C8T6 e o ATMega328P nos seguintes ambientes de desenvolvimento: Arduino IDE e STM32CubeIDE 1.6.0, respectivamente. Os algoritmos foram desenvolvidos para controle de GPIOs, uso da interface serial UART, uso da interface SPI e para ocorrências assíncronas de disparos nos periféricos. No ATMega328P, foi possível utilizar a interface UART para upload do firmware embarcado devido ao bootloader presente no microcontrolador [Marcin Lewandowski, 2017]. No STM32F103C8T6, utilizou-se a interface SWD do microcontrolador para gravação e o software Putty para visualização dos dados seriais. Por fim, o software Altium Designer versão 20.0.13 foi empregado na elaboração das placas de circuito impresso.

\section{REFERENCIAL TEÓRICO}

\subsection{REGISTRADORES}

Os registradores são circuitos digitais que armazenam dados em bits e definem o funcionamento de periféricos [Rahul, Shrivastava, 2018]. Em GPIOs, por exemplo, pode-se definir a direção dos dados, o estado lógico e a leitura dos pinos utilizados através de registradores específicos para este periférico. Na Figura 1 ilustra-se a configuração de um GPIO em Bare Metal para alterar o estado lógico de um pino a cada segundo.

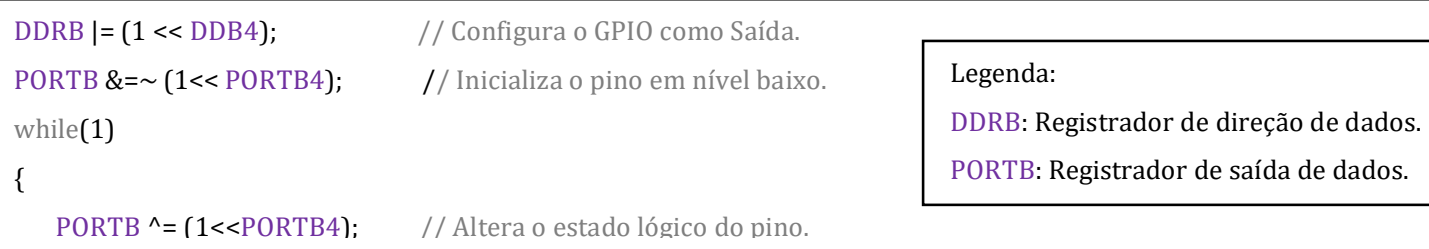

Figura 1. Configuração de um GPIO em Bare Metal no microcontrolador ATMega328P.

Fonte: Autoria própria 


\subsection{COMUNICAÇÃO SERIAL}

A comunicação Serial pode ser definida como o envio sequencial de informações em que a transmissão e a recepção de dados são repassadas bit a bit [Yuan, 2019]. Essa comunicação com os periféricos dos microcontroladores foi atribuída por meio dos protocolos SPI e UART. A Figura 2 ilustra os dados transmitidos pela interface serial UART do microcontrolador STM32F103C8T6 com o software Putty.

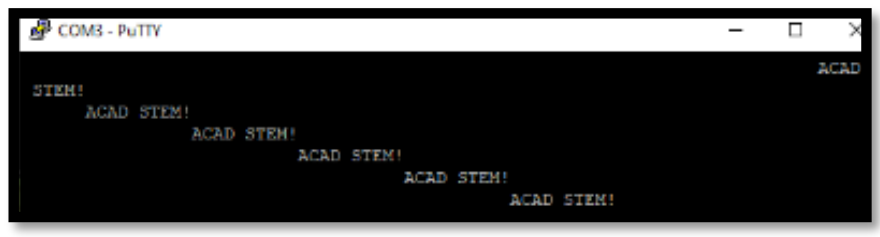

Figura 2. Transmissão de dados via Serial UART do microcontrolador STM32F103C8T6. Fonte: Autoria Própria

\subsection{INTERRUPÇÕES}

Uma interrupção ou ISR (Interrupt Service Routine), acontece quando o sistema sofre um disparo do periférico. Ele pode ocorrer através de um sinal externo ou interno, levando a suspensão do programa principal enquanto a rotina declarada dentro da função de interrupção começa a ser executada.

\subsection{TEMPORIZADORES}

A temporização do sistema é responsável pelos processos de contagem para a criação de eventos. Dessa forma, os temporizadores são programados para contar até o estouro de seu registro (overflow) ou até um valor pré-estabelecido (comparação). Na Figura 3 pode-se observar um trecho de código para alterar o nível lógico de um GPIO utilizando temporização por overflow.

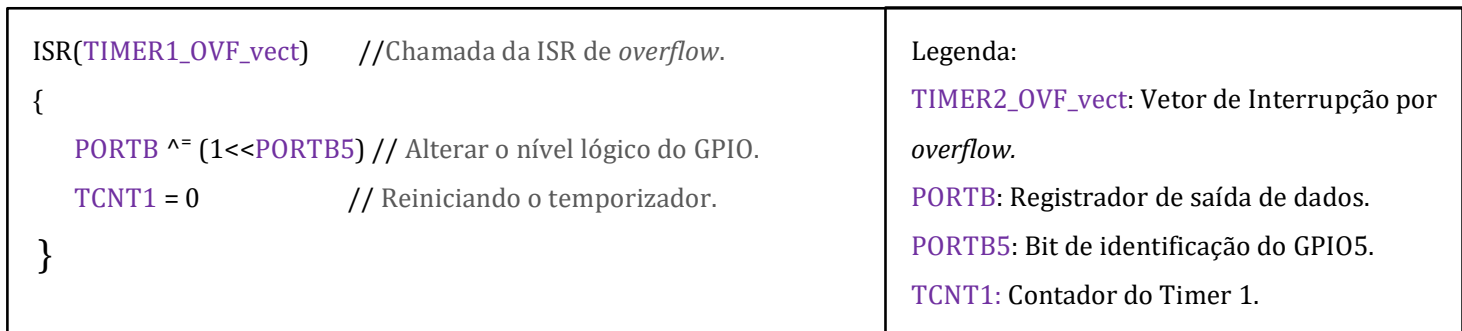

Figura 3. Código Bare metal por overflow.

Fonte: Autoria Própria 


\section{RESULTADOS}

Abaixo, encontram-se os projetos implementados em linguagem $\mathrm{C}$ no formato Bare Metal. Utilizando o Software Altium Designer, foram desenvolvidas duas placas de circuito impresso para testes destes algoritmos. A primeira placa foi desenvolvida para monitoramento de água da chuva, em que se utilizou uma função de interrupção para o comparador analógico a fim de acionar um LED no momento em que o sinal analógico do sensor ultrapassasse certo limite de tensão. Na Figura 4 ilustra-se um trecho do código implementado, em seguida, um fluxograma para o código elaborado é ilustrado na Figura 5 e a placa de circuito impresso desenvolvida é apresentada na Figura 6.

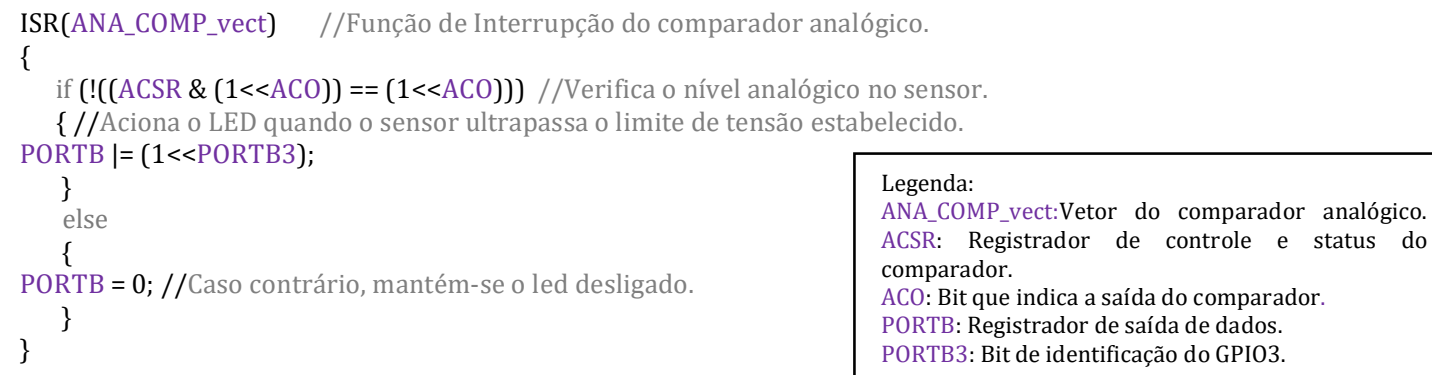

Legenda:

ANA_COMP_vect:Vetor do comparador analógico.

ACSR: Registrador de controle e status do comparador.

ACO: Bit que indica a saída do comparador.

PORTB: Registrador de saída de dados. PORTB3: Bit de identificação do GPIO3.

Figura 4. Código Bare metal de monitoramento de água por Interrupção.

Fonte: Autoria Própria

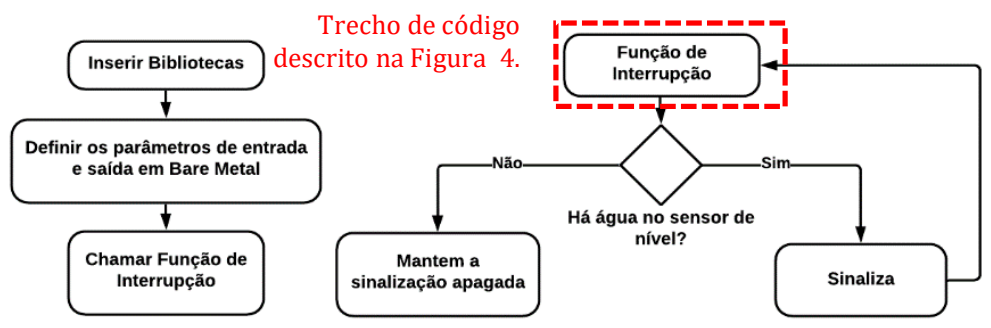

Figura 5. Fluxograma do algoritmo de monitoramento do nível de água da chuva implementado.

Fonte: Autoria Própria. 


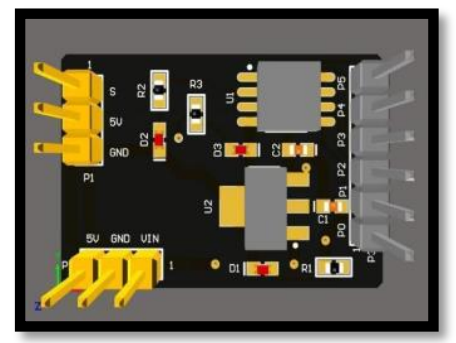

Figura 6. Placa desenvolvida para monitoramento do nível de água da chuva.

Fonte: Autoria Própria.

A segunda placa tem como principal atividade verificar o nível lógico na entrada de um botão para determinar o estado do relé e, portanto, acionar uma lâmpada. Podemos conferir um trecho de código em Bare metal na Figura 7 que mostra essa verificação.

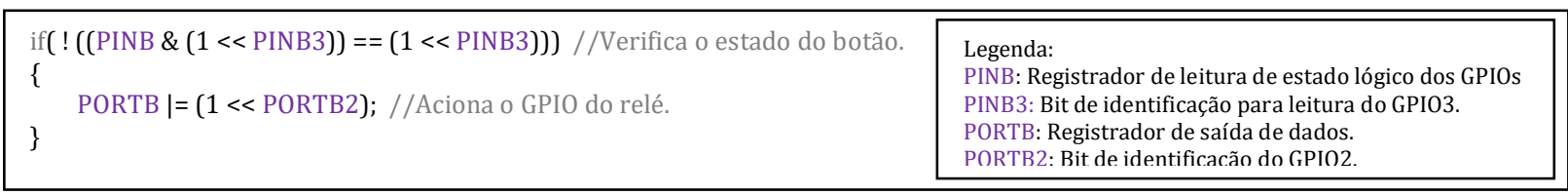

Figura 7. Código Bare metal de Acionamento de uma lâmpada.

Fonte: Autoria Própria.

No fluxograma da Figura 8, nota-se que caso o botão estivesse em nível baixo, o relé seria acionado e a lâmpada ligaria. Caso contrário, o relé não seria acionado e a lâmpada permaneceria no mesmo estado. 0 modelo $3 \mathrm{D}$ da placa de circuito impresso é ilustrado na Figura 9.

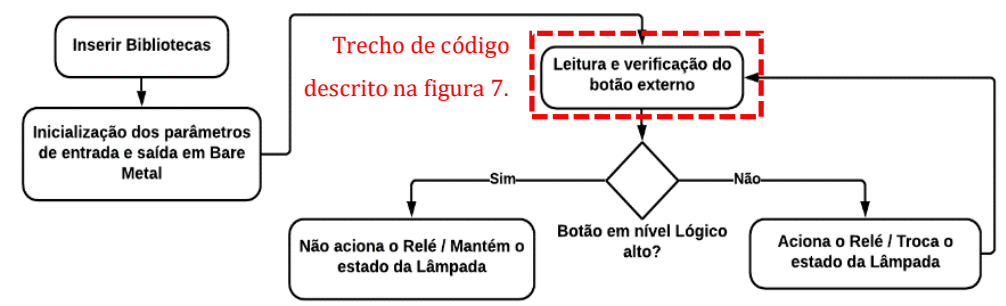

Figura 8. Fluxograma para controle de acionamento de uma Lâmpada.

Fonte: Autoria Própria 


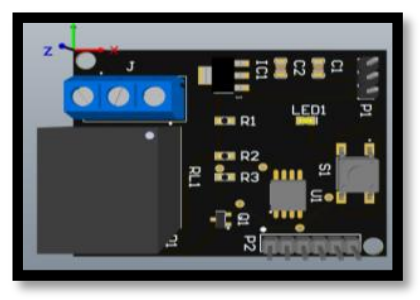

Figura 9. Placa desenvolvida para controle de acionamento de uma lâmpada.

Fonte: Autoria Própria.

\section{CONCLUSÃO}

Com base no que foi apresentado a respeito da programação Bare Metal e das plataformas utilizadas, conclui-se que é necessário ter conhecimento não só das características da plataforma utilizada, mas também dos atributos de programação já citados (interrupções, temporizadores, interfaces seriais, etc.). Além disso, as práticas realizadas para a documentação dos códigos elaborados mostraram-se essenciais para a absorção do conteúdo, o que contribuiu para o aperfeiçoamento técnico dos autores.

\section{REFERÊNCIAS BIBLIOGRÁFICAS}

Lewandowski, M., Orczyk, T., \& Porwik, P. (2017, June). Dedicated AVR bootloader for performance improvement of prototyping process. In 2017 MIXDES-24th International Conference" Mixed Design of Integrated Circuits and Systems.

Shrivastava, R., \& Sarawadekar, K. (2018, October). Multi-Voltage GPIO Design and its Physical Implementation. In 2018 4th International Conference for Convergence in Technology.

Y. Tian and Z. Xu, "Research and Implementation on Serial Communication Based on Qt," 2019 International Conference on Computer Network, Electronic and Automation (ICCNEA), 2019.

YVON, Samuel; FEELEY, Marc. Running Scheme On Bare Metal. In: Functional Programming.

RANKOVSKA, Valentina V.; GORANOV, Goran D. Interrupts in Teaching Microcontrollers Using Arduino. In: 2020 XXIX International Scientific Conference Electronics (ET). IEEE, 2020. 
PESQUISA BIBLIOGRÁFICA E IMPLEMENTAÇÃO DE PROGRAMAS EM LINGUAGEM PYTHON PARA MEDIDAS DE INFORMAÇÃO E CODIFICAÇÃO PARA COMPRESSÃO DE DADOS

Williams Cavalcante de Dliveira'

Paulo Cesar de Souza Cavalcante ${ }^{2}$

${ }^{1}$ Aluno da Escola Superior de Tecnologia (EST) - Universidade do Estado do Amazonas (UEA) CEP 69050-020 - Manaus - AM - Brasil wco.ele18@uea.edu.br

2Professor da Escola Superior de Tecnologia (EST) - Universidade do Estado do Amazonas (UEA) CEP 69050-020 - Manaus - AM - Brasil pcscavalcante@gmail.com, pcavalcante@uea.edu.br

\section{INTRODUÇÃO}

O presente projeto tem o objetivo de desenvolvimento de módulos em linguagem Python para realização de cálculos de medida da informação e para compressão de dados, abordados em parte do conteúdo da disciplina Teoria da Informação e Codificação (TIC). Para tanto, foi realizada revisão bibliográfica no material didático de TIC e no material para aprendizagem básica da linguagem de programação Python. Foram desenvolvidos módulos de programa para cálculos de medidas da informação e módulos para implementação dos algoritmos de compressão, baseados em estatística: Shannon-Fano, Huffman, Aritmético, e baseado em dicionários: Lempel Ziv. Os módulos desenvolvidos permitirão que os alunos de TIC, ou outros interessados, verifiquem na prática suas realizações teóricas das funções necessárias para comunicação digital em canais ruidosos ou para sua armazenagem de forma compactada.

\section{OBJETIVOS}

O objetivo geral do projeto é a criação e disponibilização de ferramentas adicionais para consolidação de conhecimentos durante o curso da disciplina de Teoria da Informação. Os objetivos específicos, contribuintes para o atingimento do objetivo geral são: exercício de trabalho em equipe; aprendizado da linguagem de 
programação Python; consolidação dos conhecimentos didáticos transmitidos sobre medidas da informação e compressão de dados.

\section{MATERIAIS E MÉTODOS}

O projeto foi desenvolvido em cumprimento das seguintes etapas: 1) indicação de pelo Orientador de bibliografia básica para pesquisa; 2) realização de pesquisa pelo Orientando em documentação física e material disponível na Internet; 3) elaboração pelo Orientando de breve referencial teórico sobre Medida da Informação e compressão de dados utilizando seguintes codificações: ShannonFano, Huffman, Aritmético e Lempel-Ziv; 4) Implementação pelo Orientando de módulos em linguagem Python para realização de cálculos de Medida da Informação e codificação utilizando as codificações especificadas. 5) Avaliação e orientação pelo Orientador em cada um dos temas especificados na terceira etapa, a medida em que eram concluídas; 6) Elaboração conjunta pelo Orientador e Orientando do presente Resumo Expandido, e 7) Elaboração pelo Orientando, com supervisão do Orientador, da Apresentação do Projeto em conferência.

A bibliografia indicada pelo Orientador na primeira etapa foi: Notas de Aula de Teoria da Informação [Cavalcante 2021]; vídeo de minicurso Matemática com Python [INPE 2020]; site para acesso a Documentação do Python [Python Software Foundation 2021].

\subsection{FUNDAMENTAÇÃO TEÓRICA}

Nesta subseção será exposta a base teórica sobre Medidas de Informação e Codificação para Compressão de Dados digitais, ou seja dados que são expressos utilizando-se a base de numeração binária, onde só existem dois símbolos: 0 e 1.0 material a seguir exposto foi extraído das Notas de Aula de Teoria da Informação [Cavalcante 2021].

\section{I) Medida de Informação}

A Informação é tudo aquilo que é produzido por uma fonte para ser transferido ao utilizador. No que diz respeito à medida de informação pode-se considerar dois pontos de vista: do Utilizador, a medida da informação está relacionada com a incerteza (em relação à mensagem que foi transmitida), e da Fonte, a medida da informação é uma indicação da liberdade de escolha exercida 
pela fonte ao selecionar uma mensagem. Se a fonte possuir muitas mensagens diferentes: a probabilidade de cada mensagem tende a diminuir com o número de mensagens. O utilizador terá mais dúvidas (mais incerteza, mais informação) em relação à mensagem que vai ser escolhida. Por exemplo, se a fonte possuir somente uma mensagem possível: A probabilidade será máxima, igual a 1.0 utilizador não terá dúvida (não há incerteza, não há informação) em relação à mensagem que vai ser escolhida.

\section{A) Medida de Informação de Hartley ou Auto-informação}

Hartley (1928) propôs como medida da quantidade de informação provida pela observação de uma variável aleatória discreta X. A informação de um único símbolo, I(X), é sugerida por logb $\mathrm{K}$, onde $\mathrm{K}$ é o número de possíveis valores de $\mathrm{X}$. A probabilidade de ocorrência de um dos possíveis valores de $\mathrm{X}$ é $\mathrm{P}_{\mathrm{X}}=1 / \mathrm{K}$. Assim, $\mathrm{K}=$ $1 / P_{X}$, ou seja K é o inverso da probabilidade de ocorrência de um símbolo. A medida de informação de Hartley:

$$
I(X)=\log _{b} K=\log _{b}\left(\frac{1}{P_{X}}\right)=-\log _{b} P_{X}
$$

Assim a medida de informação de Hartley pode ser definida como uma grandeza logarítmica ligada ao inverso da probabilidade de um evento. A base do logaritmo usada, define a unidade da medida de informação. Se utilizada a base 2, caso em comunicações digitais, a unidade será bit. Para exemplificar, sejam as probabilidades de emissão por uma fonte dos bits 0 e 1 , respectivamente: $\mathrm{P}_{0}=1 / 4$; $\mathrm{P}_{1}=3 / 4$, temos: Informação transportada pelo dígito $0: \mathrm{I}_{0}=-\log 21 / 4=2$ bits e Informação transportada pelo dígito $1: \mathrm{I}_{1}=-\log 23 / 4=0,41$ bits.

B) Medida de Informação de Shannon ou Entropia

Shannon (1948) definiu que em geral, se o i-ésimo valor de $X$ tem probabilidade $\mathrm{P}_{\mathrm{x}}\left(\mathrm{x}_{\mathrm{i}}\right)$, então a informação de Hartley $\log 1 / \mathrm{P}_{\mathrm{x}}\left(\mathrm{x}_{\mathrm{i}}\right)=-\log \mathrm{P}_{\mathrm{x}}\left(\mathrm{x}_{\mathrm{i}}\right)$ para este valor deveria ser ponderada por $\mathrm{P}_{\mathrm{X}}\left(\mathrm{x}_{\mathrm{i}}\right)$, fornecendo:

$$
H(X)=\sum_{i} P_{X}\left(x_{i}\right) \log _{2} \frac{1}{P_{X}\left(x_{i}\right)}=-\sum_{i} P_{X}\left(x_{i}\right) \log _{2} P_{X}\left(x_{i}\right)
$$

A medida de Shannon poderia ser considerada como informação média de Hartley. Shannon chamou esta medida de informação de entropia. A entropia de 
uma fonte significa que, em média esperamos obter $H$ bits de informação por símbolo. Reescrevendo a fórmula da entropia como:

$$
\mathbf{H}\left(\mathbf{P}_{1}, \mathbf{P}_{2}, \ldots, \mathbf{P}_{M}\right)=\sum_{j=1}^{M} \mathbf{P}_{j} \log _{2} \frac{1}{\mathbf{P}_{j}}=-\sum_{j=1}^{M} \mathbf{P}_{j} \log _{2} \mathbf{P}_{j}
$$

Para exemplificar, supondo-se que uma fonte $\mathrm{X}$ emita quatro símbolos $\mathrm{x}_{0}, \mathrm{x}_{1}$, $\mathrm{x}_{2}$ e $\mathrm{x}_{3}$ com probabilidades $1 / 2,1 / 4,1 / 8$ e 1/8, respectivamente. A incerteza, ou entropia $\mathrm{H}(\mathrm{X})$ é dada por: $\mathrm{H}(\mathrm{X})=(1 / 2) \log 2+(1 / 4) \log 4+(1 / 8) \log 8+(1 / 8) \log$ $8=1,75$ bits/símbolo.

\section{II) Codificação para Compressão de Dados}

O processo de compressão de dados é realizado por algoritmos que recebem M mensagens, sequências de bits de comprimento $\mathrm{N}$, e as codificam para transmissão ou armazenamento em M mensagens, cujo comprimento é menor que $\mathrm{N}$ bits das mensagens originais, sem que haja perda das informações (Técnicas de compressão sem perdas). Os modelos estatísticos, ou de codificação por entropia, precisam conhecer a estatística de ocorrência dos símbolos a serem codificados. Os modelos adaptativos, ou baseados em dicionário, executam a compressão sem necessitarem da estatística da fonte. As técnicas abordadas na presente pesquisa se encontram expostas no Quadro 1 abaixo.

Quadro 1. Técnicas de Compressão sem Perdas

\begin{tabular}{|c|c|}
\hline $\begin{array}{c}\text { Exemplos de Modelos } \\
\text { estatísticos }\end{array}$ & $\begin{array}{c}\text { Exemplos de Técnicas baseadas em } \\
\text { dicionários }\end{array}$ \\
\hline $\begin{array}{c}\text { Códigos: Shannon-Fano, } \\
\text { Huffman e Aritmética }\end{array}$ & $\begin{array}{c}\text { Códigos Lempel-Ziv(LZ): Lempel-Ziv (LZ 77), } \\
\text { Lempel-Ziv (LZ 78) e Lempel-Ziv-Welch } \\
\text { (LZW) }\end{array}$ \\
\hline
\end{tabular}

O comprimento médio das palavras-código resultantes da codificação para compressão de dados é determinado por:

$$
\bar{L}=\sum_{i=0}^{M-1} p_{i} l_{i}
$$

onde $l_{i}$ é o número de bits da palavra código correspondente ao símbolo $i$, que ocorre com probabilidade $p_{i}$. A eficiência de codificação pode ser definida pela relação entre a entropia da fonte ou da mensagem e o comprimento médio das palavras de código: 


$$
\eta=\frac{H(S)}{\bar{L}}
$$

A taxa de compressão $T_{c}$ de um código compressor é definida pela expressão abaixo:

$$
\mathbf{T}_{\mathrm{c}}=\frac{\text { Qde bits texto sem compressão }- \text { Qde bits texto com compressão }}{\text { Qde bits texto sem compressão }} \times 100
$$

\subsection{DESENVOLVIMENTO DOS MÓDULOS EM PYTHON}

O desenvolvimento dos módulos em linguagem Python foram realizados na plataforma Intergrated Development Environment (IDE) PyCharm, em produção em plataforma computacional com sistema operacional Windows 10. Foram implementados os seguintes módulos Python para cálculo da entropia e compressão utilizando a codificação pelos respectivos algoritmos: Entropia; Shannon-Fano; Huffman; Aritmético; Lempel-Ziv LZ 78. Os módulos desenvolvidos se encontram no documento Listagens dos módulos Python [Oliveira e Cavalcante 2021a].

\section{RESULTADOS}

Foram realizados os testes de compressão de mensagens pelos módulos Python desenvolvidos. Os Quadro 2 e Quadro 3 seguintes apresentam uma consolidação dos dados extraídos da execução dos módulos, constantes do documento Resultados dos testes dos módulos Python [Oliveira e Cavalcante 2021b]. Os dados expostos são a própria codificação e parâmetros de medidas expostos na fundamentação teórica deste trabalho. 
Quadro 2. Teste de compressão da Mensagem em ASCII (8 bits/ simb.): DEMONSTRAÇÃO PARA FIRST AMAZON STEM ACADEMY CONFERENCE

\begin{tabular}{|c|c|c|c|c|c|c|c|c|c|c|c|}
\hline \multicolumn{3}{|c|}{ Simbolos texto } & \multicolumn{3}{|c|}{ Código Shannon Fano } & \multicolumn{3}{|c|}{ CódigoHuffman } & \multicolumn{3}{|c|}{ Código LZ78 } \\
\hline $\mathbf{s}$ & qde $s$ & $\mathrm{p}(\mathrm{si})$ & Pal.-codigo & bits/s & tot bits/s & Pal.-codigo & bits/s & tot bits/s & Segmentos $\mathbf{M}$ & Pal.-codigo & bits/s \\
\hline A & 7 & $7 / 54$ & 000 & 3 & 21 & 100 & 3 & 21 & 'DE' & 00001100100 & 11 \\
\hline ESP & 6 & $1 / 9$ & 001 & 3 & 18 & 101 & 3 & 18 & 'MO' & 00011101001 & 11 \\
\hline$E$ & 6 & $1 / 9$ & 010 & 3 & 18 & 110 & 3 & 18 & 'NS' & 00100001100 & 11 \\
\hline$M$ & 4 & $2 / 27$ & 0110 & 4 & 16 & 0010 & 4 & 16 & 'TR' & 00110101011 & 11 \\
\hline 0 & 4 & $2 / 27$ & 0111 & 4 & 16 & 0011 & 4 & 16 & 'AÇ' & 00000110001 & 11 \\
\hline $\mathrm{N}$ & 4 & $2 / 27$ & 100 & 3 & 12 & 0100 & 4 & 16 & 'ÃO' & 01000001001 & 11 \\
\hline $\mathrm{S}$ & 4 & $2 / 27$ & 1010 & 4 & 16 & 0101 & 4 & 16 & 'P' & 00000001010 & 11 \\
\hline $\mathrm{R}$ & 4 & $2 / 27$ & 1011 & 4 & 16 & 111 & 3 & 12 & 'AR' & 00000101011 & 11 \\
\hline$T$ & 3 & $1 / 18$ & 1100 & 4 & 12 & 0111 & 4 & 12 & 'A' & 00000100000 & 11 \\
\hline $\mathrm{D}$ & 2 & $1 / 27$ & 11010 & 5 & 10 & 00010 & 5 & 10 & 'Fl' & 00010100110 & 11 \\
\hline $\mathrm{F}$ & 2 & $1 / 27$ & 11011 & 5 & 10 & 01100 & 5 & 10 & 'RS' & 00101101100 & 11 \\
\hline $\mathrm{C}$ & 2 & $1 / 27$ & 11100 & 5 & 10 & 01101 & 5 & 10 & 'T' & 00110100000 & 11 \\
\hline ç & 1 & $1 / 54$ & 111010 & 6 & 6 & 000000 & 6 & 6 & 'AM' & 00000100111 & 11 \\
\hline$\tilde{\mathrm{A}}$ & 1 & $1 / 54$ & 111011 & 6 & 6 & 000001 & 6 & 6 & 'AZ' & 00000101111 & 11 \\
\hline $\mathrm{P}$ & 1 & $1 / 54$ & 111100 & 6 & 6 & 000010 & 6 & 6 & 'ON' & 00100101000 & 11 \\
\hline 1 & 1 & $1 / 54$ & 111101 & 6 & 6 & 000011 & 6 & 6 & 'S' & 00000001100 & 11 \\
\hline$z$ & 1 & $1 / 54$ & 111110 & 6 & 6 & 000110 & 6 & 6 & 'TE' & 00110100100 & 11 \\
\hline $\mathrm{Y}$ & 1 & $1 / 54$ & 111111 & 6 & 6 & 000111 & \begin{tabular}{|l|}
6 \\
\end{tabular} & 6 & 'M' & 00011100000 & 11 \\
\hline \multirow[t]{2}{*}{18} & 54 & 1,00 & \multicolumn{2}{|c|}{ Tot. bits codificação -> } & 211 & \multicolumn{2}{|c|}{ Tot. bits codificação -> } & 211 & 'AC' & 00000100010 & 11 \\
\hline & & & & & & & & & 'AD' & 00000100011 & 11 \\
\hline \multicolumn{3}{|c|}{ Texto sem codificação } & & Código & Comp. & Eficiência & Taxa & & 'EM' & 00010000111 & 11 \\
\hline & & & & & Médio & Código & Compressão & & 'Y' & 00111000000 & 11 \\
\hline \multicolumn{3}{|c|}{ Total de bits } & & & (Form. 4) & (Form.5) & (Form. 6) & & 'CO' & 00001001001 & 11 \\
\hline \multicolumn{3}{|c|}{$54 \times 8$ bits $/ s=432$ bits } & & Shannon & $3,9 \mathrm{~b} / \mathrm{s}$ & $99,21 \%$ & $51,16 \%$ & & 'NF' & 00100000101 & 11 \\
\hline & & & & Huffman & $3,9 \mathrm{~b} / \mathrm{s}$ & $99,21 \%$ & $51,16 \%$ & & 'ER' & 00010001011 & 11 \\
\hline \multicolumn{3}{|c|}{ Entropia do texto } & & LZ78 & $11 \mathrm{~b} / \mathrm{s}$ & $35,18 \%$ & $31,25 \%$ & & 'EN' & 00010001000 & 11 \\
\hline \multicolumn{3}{|c|}{ ( Fórmula 3) } & \multicolumn{5}{|c|}{ Nota: O código LZ-78 não se utiliza da estatística da } & & 'CE' & 00001000100 & 11 \\
\hline \multicolumn{3}{|c|}{$H(P)=3,87 \mathrm{bis} / \mathrm{s}$} & \multicolumn{5}{|c|}{ fonte, é baseado em dicionário (adaptativo) } & & & Tot. bits codificação -> & 297 \\
\hline
\end{tabular}

Embora não tenham ocorrido erros nos testes de compressão realizados conforme Quadros 2 e 3, em outros testes foram verificadas algumas inconformidades nos módulos de Entropia (totalização de probabilidades), Aritmético (erro de conversão valor decimal para binário) e Lempel-Ziv LZ-78 (supressão da codificação do último segmento de mensagem), as quais já se encontram em análise para eliminação.

Quadro 3. Teste de compressão da Mensagem em ASCII (8 bits/ simb.): asadacasa 


\begin{tabular}{|c|c|c|c|c|c|c|c|}
\hline \multicolumn{4}{|c|}{ Simbolos texto } & \multicolumn{2}{c|}{ Código Aritmético } & \multicolumn{2}{c|}{ Código LZ78 } \\
\hline s & qde s & $\mathbf{p}(\mathbf{s i})$ & Intervalo Codificado & Pal.-codigo & Segmentos M & Pal.-codigo & bits/s \\
\hline a & 5 & $5 / 9$ & {$[0.365896,0.365928)$} & $\mathbf{1 0 1 1 1 0 1 1 1}$ & 'as' & $\mathbf{0 0 0 0 1 1}$ & 6 \\
\hline c & 1 & $1 / 9$ & Conv.Pal.-cód em Dec & Dentro & 'ad' & $\mathbf{0 0 0 0 1 0}$ & 6 \\
\hline d & 1 & $1 / 9$ & $0,101110111(2)=$ & Intervalo? & 'ac' & $\mathbf{0 0 0 0 0 1}$ & 6 \\
\hline s & 2 & $2 / 9$ & $0.365910(10)$ & Sim & 'asa' & $\mathbf{0 1 0 0 0 0}$ & 6 \\
\hline $\mathbf{4}$ & $\mathbf{9}$ & $\mathbf{1 , 0 0}$ & Tot. bits codificação -> & $\mathbf{1 0}$ & & Tot. bits codificação -> & $\mathbf{2 4}$ \\
\hline
\end{tabular}

\begin{tabular}{|c|c|c|c|c|}
\hline \multicolumn{5}{|l|}{ Texto sem codificação } \\
\hline & Código & Comp. & Eficiência & Taxa \\
\hline Total de bits & & Médio & Código & Compressão \\
\hline $9 \times 8$ bits $/ s=72$ bits & & (Form. 4) & (Form.5) & (Form. 6) \\
\hline & Aritmético & $10 \mathrm{~b} / \mathrm{s}$ & - & $86,11 \%$ \\
\hline Entropia do texto & LZ78 & $6 \mathrm{~b} / \mathrm{s}$ & - & $51,16 \%$ \\
\hline (Fórmula 3) & \multicolumn{3}{|c|}{ Nota: $O$ código LZ-78 não se utiliza da estatística da } & \\
\hline$H(P)=1,65 \mathrm{bis} / \mathrm{s}$ & \multicolumn{3}{|c|}{ fonte, é baseado em dicionário (adaptativo) } & \\
\hline
\end{tabular}

\section{CONCLUSÃO}

O objetivo geral de desenvolvimento e disponibilização de ferramentas para consolidação de conhecimentos de Teoria da Informação e Codificação foi alcançado em toda sua plenitude. Durante os trabalhos para atingimento do objetivo geral os objetivos específicos listados na seção Objetivos deste documento foram plenamente desenvolvidos. Assim, as inconformidades citadas na seção de Resultados já estão sendo trabalhadas e o projeto pode ser considerado concluído.

\section{REFERÊNCIAS BIBLIOGRÁFICAS}

Cavalcante, P. C. S. (2021) " Teoria da Informação e Codificação Notas de Aula", Disponível em: https://drive.google.com/file/d/1yrLavmXmpQYfdGVspUwtEWOfAGqsGcB/view?usp=sharing, Acesso em: 14 set. 2021.

INPE (2020) - Instituto Nacional de Pesquisas Espaciais "Vídeo SNCT - Minicurso: Matemática com Python Usando o Mumpy, Matplotlib e Scipy", Disponível em: https://youtu.be/_iTYsURupgE, Acesso em: 14 set. 2021.

Oliveira,W. C. e Cavalcante, P. C. S. (2021a) "Listagem de Códigos dos Módulos Python desenvolvidos durante a Pesquisa". Disponível em: https://drive.google.com/file/d/16azruxrezcq52pi2I4au1wxUeNjuKRay/vi ew?usp=sharing, Acesso em: 15 set. 2021.

Oliveira,W. C.e Cavalcante, P. C. S. (2021b) "Resultados dos testes dos Módulos Python desenvolvidos durante a Pesquisa". Disponível em: https://drive.google.com/file/d/1aXyyPJp3K-

vLqXROqKk7XvdSHKqJXh82/view?usp=sharing, Acesso em: 15 set. 2021.

Python Software Foundation (2021) “Documentação do Python”, Disponível em: ttps://docs.python.org/pt-br/3.9/index.html, Acesso em: 14 set. 2021. 


\title{
APLICAÇÕES ELÉTRICAS EM FONTES RENOVÁVEIS DE ENERGIA — INDÚSTRIA 4.0
}

\author{
Edmundo Alves Das Santos Neto \\ Carlos Eduardo Araújo Da Silva Medeiros \\ Micaela Machado Figueira, Daniel Guzmán Del Rio \\ Daniel Sousa Da Silva
}

Escola Superior de Tecnologia (EST) - Universidade do Estado do Amazonas (UEA) CEP 69050-020 - Manaus - AM - Brasil eadsn.eng20@uea.edu.br, ceadsm.eng20@uea.edu.br, mmf.eng20@uea.edu.br,

drio@uea.edu.br, dass.eng@uea.edu.br

\section{INTRODUÇÃO}

A forma com que a energia elétrica foi produzida e consumida por muitos anos afetou diretamente no comportamento climático ocasionando na intensificação do efeito estufa ao longo dos anos e com previsão de cada vez mais altas temperaturas nos próximos anos. Uma forma de tentar amenizar esse impacto é substituindo energias que utilizem combustíveis fósseis por fontes de energia renováveis, tais como solar, biomassa, hidrelétrica e eólica. As energias renováveis vêm sendo impulsionadas pela necessidade que as nações estão sentindo de promover ações que possam resultar na mitigação dos impactos ambientais (Freitas, G. S., \& Dathein, R.,2013).

Somado a este desafio temos a Indústria 4.0 (ou Quarta Revolução Industrial) em uma configuração atual que contempla além da automatização dos processos produtivos sua informatização mais avançada, visando a eficiência produtiva. A característica da Indústria 4.0 é o aumento da competitividade por meio de equipamentos inteligentes, fazendo uso de informações sobre locais de altos salários, mudanças demográficas, recursos, eficiência energética e produção urbana (Heck \& Rogers, 2014) 0 novo formato da indústria somado às fontes renováveis de energia são uma forma consciente, tecnológica e inovadora para a nova configuração do mundo atual. 


\section{OBJETIVOS}

Esta pesquisa tem por objetivo apresentar o funcionamento e a eficácia de três diferentes fontes de energia renováveis, a elétrica, biomassa e hidrelétrica. Estas foram selecionadas pelo seu alto rendimento, sua complexidade e sua previsão de crescimento no Brasil.

\section{MATERIAIS E MÉTODOS}

O estudo foi realizado a partir de pesquisas bibliográficas e documentais para as quais fez se o uso de ferramentas disponíveis na rede mundial de computadores para melhor variabilidade de informações para obter-se maior veracidade do texto.

A pesquisa foi acompanhada de observações semanais realizadas pelo orientador, nos quais foram encaminhadas melhores metodologias para realização da pesquisa.

\section{RESULTADOS}

\subsection{FOTOVOLTAICA}

A energia fotovoltaica, fonte de energia proveniente da conversão da irradiação solar em energia elétrica, tomou atenção mundial por ter potencial imensurável no que se trata de energia limpa e renovável, visto que o sol envia em uma hora mais energia do que a terra consome em 1 ano (C. T.; Miranda, F. S.,2014).

O Brasil, por possuir posição geográfica favorável, tem enorme potencial na geração fotovoltaica. Por conta disso, é possível estudar diferentes aplicações desta fonte, como por exemplo, fazendo uso da hidrografia da região amazônica, que feito pelo projeto de energização fotovoltaica na região do Alto Rio Solimões: “A caracterização do processo de implantação de energização solar fotovoltaica na Região do Alto Rio Solimões permitiu conhecer os mecanismos socioculturais de aceitação e utilização da tecnologia fotovoltaica por parte dos comunitários. A principal característica foi a não modificação dos processos tradicionais de trabalho utilizados no cotidiano das populações humanas nas comunidades."(NOGUEIRA, 2021).

Tal aplicação é uma solução ao problema energético das comunidades ribeirinhas, que por se localizarem em zonas remotas, não conseguem acesso à linha 
de distribuição elétrica da concessionária. Outro exemplo bem sucedido dessa aplicação fica na cidade flutuantedoCatalão, uma comunidade ribeirinha que pertence ao município de Iranduba, no interior do Amazonas, que hoje é abastecida por uma produção fotovoltaica flutuante, emmeioaolagoCatalão (Carlos Fontinelle,2021).

A indústria 4.0 chega para aperfeiçoar as tecnologias referentes às fontes renováveis de energia. Isso acontece por meio de ferramentas de manipulação de dados que, trabalhados da maneira correta, vêm a adaptar e melhorar os processos de manutenção e manutenção preventiva de sistemas fotovoltaicos. Como exemplo, podemos citar o uso de algoritmos inteligência artificial - principal ferramenta da indústria 4.0 - na gestão de uma usina fotovoltaica em Londrina(Paraná), onde a cada 15 minutos, um sistema coleta dados sobre operação da usina e armazena em um banco e com o cruzamento com outros parâmetros-como condições meteorológicas, níveis de radiação solar, temperatura ambiente, período do ano pode realizar a predição de capacidade de geração de energia, por exemplo, para 15 minutos, horizonte considerado imediato, ou para 24 horas e até uma semana, em horizontes mais longos ( ZANARDI,2020).

\subsection{BIOMASSA}

Do ponto de vista energético, a biomassa é toda matéria orgânica que tenha origem animal ou vegetal que possa ser usada como combustível para produzir energia (ANEEL,2002). Com o passar do tempo a conversão de energia foi ganhando força ampliada pela tecnologia, o que nos garante hoje um aproveitamento melhor do material e da energia produzida. Foram desenvolvidos processos de conversão classificados como: termo químico, bioquímico e físico-químico. A energia térmica, oriunda da combustão da biomassa é convertida em energia mecânica e, em última instância, em energia elétrica. As tecnologias termelétricas são classificadas termodinâmicamente por ciclos de potência, que indicam processo termodinâmico correspondente a cada tecnologia (HIROSHI MATSUMURA, E.,2018).

O biogás é adquirido a partir de um biodigestor (processo bioquímico) que funciona sema

presença de oxigênio e resulta em biofertilizantes, metano e gás carbônico. Que podem ser úteis para energia elétrica, energia térmica e veicular. Para que o biogás possa ser utilizado como combustível, seja em motores, turbinas a gás ou 
microturbinas, é necessário identificar sua vazão, composição química e poder calorífico, parâmetros que determinam o real potencial de geração de energia elétrica, além de permitir dimensionar os processos de pré tratamento do biogás, como a remoção de H2S (ácido sulfídrico) e da umidade, como propósito de evitar danos aos equipamentos da instalação e aumentar seu poder calorífico(COELHO, 2006 A). A proporção de cada gás na mistura depende de vários parâmetros, como o tipo de digestor e o substrato (matéria orgânica a digerir). De qualquer forma, esta mistura é essencialmente constituída por metano ( $\mathrm{CH} 4)$ e dióxido de carbono (CO2), estando o seu poder calorífico diretamente relacionado com a quantidade de metano existente na mistura gasosa. (COELHO, 2006 B). De acordo com MARCHAIM(1992), os motores básicos que podem ser executados com o biogás são os de ciclo Otto e os de ciclo Diesel.

\begin{tabular}{|c|c|c|c|c|}
\hline & Motores a Gas & $\begin{array}{l}\text { Motores Diesel: } \\
\text { Biogis + Diesel }\end{array}$ & $\begin{array}{c}\text { Turbinas a Gás para } \\
\text { Biogas de Pequeno - } \\
\text { Médio Porte }\end{array}$ & $\begin{array}{l}\text { Microturbinas } \\
\text { (CAPSTONES) }\end{array}$ \\
\hline Potencia & $30 \mathrm{~kW}-20 \mathrm{MW}$ & & $500 \mathrm{~kW}-150 \mathrm{MW}$ & $30 \mathrm{~kW}-100 \mathrm{~kW}$ \\
\hline $\begin{array}{l}\text { Rendimento } \\
\text { com biegds }\end{array}$ & $30 \%$ a $34 \%$ & $30 \%$ a $35 \%$ & $20 x$ a $30 x$ & $24 \%$ a $28 \%$ \\
\hline $\begin{array}{l}\text { Emissbes de } \\
\text { NOx }\end{array}$ & $\begin{array}{l}<3000 \mathrm{ppm} \\
\text { Motores com laika } \\
\text { emissta }<250 \mathrm{ppm}\end{array}$ & $\begin{array}{l}\text { Media em torno de } \\
27 \mathrm{ppm}\end{array}$ & Medtia aprox. 35 a $50 \mathrm{ppm}$ & $<9 \mathrm{ppm}$ \\
\hline Obs: & & $\begin{array}{l}\text { Necessita diesel com } \\
\text { baixo teor de " } \mathrm{s} \text { " }\end{array}$ & & \\
\hline
\end{tabular}

Figura 1. Comparação de tecnologia disponível para conversão de energia Fonte: PECORA, 2006

A modificação de um motor Otto é relativamente fácil, pois o motor é projetado para funcionar com uma mistura ar / combustível com ignição por faísca. A modificação básica é o fornecimento de ar / misturador de gás, em vez de carburador. 0 controle do motor é feito pela

variação da mistura de abastecimento. Um aumento na taxa de compressão é desejável, e prevê um aumento do processo a partir do ponto de vista termodinâmico. Assim, menor consumo específico de combustível e maior potência pode ser esperado (MIHIC, 2004).No Ciclo diesel a combinação correta da pressão e da temperatura, os combustíveis se auto incendiariam. Portanto, o motor deve ser projetado para o combustível destinado, como temperatura e pressão corretas. A razão para combustível estequiométricas encontrados em estudos anteriores foi de 5,71 m3 por m3 de ar de gás metano para produção de biogás de 60\%.Esta relação 
deve ser seguida para a combustão completa de biogás (CONSTANTE NAVEAU,1989).

\subsection{HIDRELÉTRICA}

Segundo as definições gerais, a energia hidrelétrica é a energia provinda das usinas hidrelétricas, que por sua vez funcionam de uma maneira que no geral é simples: as usinas são construídas nos leitos dos rios para que com as forças das correntes das águas, as turbinas sejam giradas e dessa forma, com a energia cinética que será encaminhada para um gerador e este terá o papel de conversão de energia cinética para energia elétrica. A Usina Hidrelétrica é dividida em diversas funções, que apesar de simples são muito importantes para o bom funcionamento dela. Em suma , o processo de uma usina hidrelétrica começa com a barragem , local que irá de certa forma direcionar a corrente de água para as turbinas, que por sua vez operam num movimento que em geral é circular e dessa maneira gerando através das turbinas a energia cinética, que passa através dos geradores da usina para que assim sejam transmitidas através das linhas de transmissão de energia elétrica para os centros de distribuição, estes por sua vez são responsáveis pela distribuição do consumidor final.

Além de um entendimento da parte de layout físico, precisamos também entender como funcionam os cálculos por trás das usinas, relacionando conceitos aprendidos através de estudos, como vazão, altura útil, rendimento, entre outros.

\begin{tabular}{|l|}
\hline $\mathrm{P}=$ Potência instalada $(\mathrm{Kw})$ ou $(\mathrm{CV})$ conforme a \\
fórmula utilizada; \\
$\mathrm{Q}=$ vazão $\left(\mathrm{m}^{3} / \mathrm{s}\right)$ \\
$\mathrm{Hu}=$ altura útil; \\
$\boldsymbol{Y}=$ peso específico da água $\left(\mathrm{kgf} / \mathrm{m}^{3}\right)$ \\
$\mathbf{\eta} \mathrm{t}=$ rendimento total; \\
$\mathbf{\eta t u}=$ rendimento da turbina; \\
$\mathbf{\eta g}=$ rendimento do gerador
\end{tabular}

Através dessa imagem, vemos que conceitos simples constituem os cálculos fundamentais presentes no funcionamento de uma usina hidrelétrica. Podemos observar por exemplo gravidade, altura, rendimento (estudado em física) vazão, entre outros. Estes cálculos são fundamentais para a manutenção das usinas para que elas continuem sempre em funcionamento o mais eficaz possível.

No Brasil, segundo o governo federal, a matriz elétrica provém de 83\%de matrizes de energias renováveis, sendo $68 \%$ das hidrelétricas do país, tendo em 
vista a amplitude e vastidão dos rios do país, já que é uma fonte de energia barata e de pouca manutenção sendo comercialmente a mais viável para o nosso país. Ao redor do mundo a hidrelétrica não é mais utilizada por conta de sua disponibilidade , pois apesar de ser uma fonte barata, os países que resolveram adotar ela como fonte de energia tem que ter de recursos hídricos capazes de satisfazer as necessidades e por conta disso não torna-se a energia mais usada do mundo .Em suma o Brasil é quase que completamente dependente da energia provinda da energia hidráulica, o baixo custo de manutenção e pelo fato de ser uma energia renovável facilitam a implementação dessa matriz nos países, mesmo que em um primeiro momento ocorra uma desestabilização no ecossistema do local. A projeção é que daqui alguns anos as hidrelétricas cresçam cada vez mais visando a instalação de fontes renováveis e não poluentes e veem na hidrelétrica uma ótima opção para o futuro.

\section{CONCLUSÃO}

O processo de automação crescente nas indústrias chegou ao setor energético com grande potencial de aprimoramento de processos. Não é à toa que as fontes de energia renováveis são, hoje, grande alvo de pesquisas acadêmicas.0 uso de dados, coletados e manipulados, tem permitido o melhor gerenciamento de serviços e matérias, visto que se pode realizar manutenção preventiva dos sistemas de geração a partir destes dados. As fontes de energias renováveis tornam-se, no cenário atual , a principal matriz energética das novas indústrias , por conta da sua alta rentabilidade e aplicação diversa, aliando-se aos ideais de energias não poluentes ao meio ambiente .Por conta de seus desempenhos altamente satisfatórios , as aplicações das fontes de energias renováveis no setor da indústria 4.0 , sejam elas as mais variadas, vem se tornando cada vez mais comuns, levando as mais diversas empresas a apostarem no ramo de pesquisa e desenvolvimento nessa área .0 desenvolvimento de uma sociedade está altamente ligado às suas matrizes energéticas, o que não é diferente no âmbito industrial, logo quanto mais uma indústria investe em matriz energética de origem limpa e renovável , mas ela atrela desenvolvimento sustentabilidade aos seus ideias, requisitos que estão cada vez mais em pauta, principalmente na indústria 4.0 . 
SANCHES, Bianca C., A INDÚSTRIA 4.0 E SUAS CONTRIBUIÇÕES À SUSTENTABILIDADE

MACHADO, C. T. Miranda, F. S.* Energia Solar Fotovoltaica: Uma Breve Revisão

NOGUEIRA, Carlos Alexandre dos Santos - Energização Solar Fotovoltaica na Região do Alto Rio Solimões no estado do Amazonas

FARIA, Waltenir Alves De -ESTUDO DE SOMBREAMENTO PARCIAL EM MÓDULOS FOTOVOLTAICOS ATRAVÉS DA RESISTÊNCIA SÉRIE E DAS REDES NEURAIS

\section{ZANARDI,}

ReinaldoC.https://operobal.uel.br/cce/2020/10/22/projetodauelusaalgoritmosde inteligenciaartificial

COELHO, S.T. A conversão da fonte renovável em energia. In: Anais do CongressoBrasileiro de Planejamento Energético, Políticas públicas para a Energia: Desafios para o próximo quadriênio. Brasília - DF, 2006b. p. 145149

COELHO, S.T. Geração de Energia Elétrica a partir do Biogás Proveniente do Tratamento de Esgoto Utilizando um Grupo Gerador de $18 \mathrm{~kW}$. In: Anais do Congresso Brasileiro de Planejamento Energético, Políticas públicas para a Energia: Desafios para o próximo quadriênio.Brasília - DF, 2006 A. p.140144.

TOLMASQUIM, M. T. Energia Renovável: Hidráulica, Biomassa, Eólica, Solar, Oceânica. Empresa de Pesquisa Energética (EPE): 2016. (Energia Renovável: hidráulica, biomassa, eólica, solar, oceânica

HIROSHI MATSUMURA, E. Papel da biomassa na expansão da geração de energia elétrica. Ministério de Minas e Energia - MME: Empresa de Pesquisa Energética - EPE 2018.

MATSUMURA, E. H. Papel da Biomassa na expansão da geração de energia elétrica. FERREIRA, T. V. B. Empresa de Pesquisa Energética - EPE 2018.

Revista Brasileira de Tecnologia Aplicada nas Ciências Agrárias, Guarapuava-PR, v.4, n.1, p.221 -- 237, 2011. Revisão Literária

Pesquisa Aplicada \& Agrotecnologia v.4, n.1, Jan/abr. (2011) Print-ISSN 1983-6325 (On line) e-ISSN 1984-7548 


\title{
CONSTRUÇÃO DE APLICATIVOS EM FÍSICA
}

\author{
Levi Castro Dias Trindade' \\ Cynthia Graça De Souza' \\ Fabian Larduso Litaiff ${ }^{3}$
}

${ }^{1}$ Escola Superior de Tecnologia (EST) - Universidade do Estado do Amazonas (UEA) CEP 69050-020 - Manaus - AM - Brasil lcdt.eai20@uea.edu.br ${ }^{1}$, cdsh.eng20@uea.edu.br ${ }^{2}$, flitaiff@uea.edu.br ${ }^{3}$

\section{INTRODUÇÃO}

A tecnologia está cada vez mais presente no cotidiano das pessoas, especificamente na atual era que estamos vivenciando, influenciando positivamente ou negativamente nossa forma de viver.

Segundo Kenski (2010, p.21), a evolução tecnológica não se restringe apenas aos novos usos de determinados equipamentos e produtos. Ela altera comportamentos. A ampliação e a banalização do uso de determinada tecnologia impõem-se à cultura existente e transformam não apenas o comportamento individual, mas o de todo o grupo social. (...). As tecnologias transformam suas maneiras de pensar, sentir e agir. Mudam também suas formas de se comunicar e de adquirir conhecimentos.

A tecnologia atrelada a educação torna-se uma grande ferramenta para a melhoria e aperfeiçoamento de aprendizagem. E diante do atual cenário do mundo, causado pela pandemia, a educação sofreu mudanças significativas quanto ao ensino-aprendizagem, tornando possível novas maneiras de comunicação, como por exemplo: os aplicativos educacionais. Os aplicativos educacionais podem melhorar e auxiliar no ensino-aprendizagem dos estudantes (NICOLAU; MARINHO; MARINHO, 2017). Pela facilidade da utilização de celulares e outros aparelhos eletrônicos a tecnologia tem gerado mudanças na educação, promovendo alternativas no processo de disseminação de informações.

Diante dessas informações, propôs-se a construção de um aplicativo exclusivamente de física, contendo um conteúdo especifico: Termodinâmica, com intuito de ajudar alunos com dificuldades no conteúdo referido, pois o mesmo é uma ferramenta simples, acessível e prática. Para a construção do aplicativo utilizou-se 
o software Kodular, uma plataforma que fornece ferramentas e suporte para a criação de aplicativos online.

\section{OBJETIVOS}

\section{Objetivo Geral:}

Desenvolver o aprendizado de Física para alunos do ensino médio de modo fácil e descomplicado utilizando uma interface gráfica mobile, assim ajudando-os a praticar e melhorar suas habilidades teóricas e práticas na disciplina de Física, visando remover o desequilíbrio que há entre a Física e as demais matérias do ensino médio.

\section{Objetivos Específicos:}

- Alcançar jovens e adolescentes com dificuldade em Física.

- Desenvolver o aprendizado de Física através de um aplicativo.

- Acessibilidade de estudo para todos.

\section{MATERIAIS E MÉTODOS}

O aplicativo foi dividido em 5 etapas: pesquisa, tema foco/assunto abordado, divisão de tarefas no trello, desenvolvimento e design.

\subsection{PESQUISA}

Foi necessário uma pesquisa aprofundada para saber quais os maiores desafios e/ou problemas que os alunos do ensino médio tem ao se deparar com física na sua caminhada escolar. Foi constatado que a maior dificuldade dos alunos não está em algum ano especifico, e sim na jornada do ensino médio, e isso acontece principalmente com alunos vindo anteriormente de escolas públicas, onde se tem ausência da prática experimental, dependência excessiva do livro didático, método expositivo, reduzido número de aulas, currículo desatualizado e descontextualizado e profissionalização insuficiente do professor (PEDRISA, 2001; DIOGO; GOBARA, 2007).

\subsection{TEMA FOCO}

Sabendo que a dificuldade é presente em todo ensino médio, buscamos analisar qual seria o tema ideal para abordar no aplicativo, é possível perceber que existem assuntos que se destacam na grade curricular como: mecânica, cinemática, 
termodinâmica, eletricidade, entre outros. Com o auxílio do nosso coordenador, escolhermos a termodinâmica como nosso tema principal. Após a escolha do tema, iniciou-se a elaboração de tarefas na plataforma Trello outra ferramenta importante para o projeto, pois através do Trello organizamos o projeto por meio de quadros (boards).

\subsection{DESENVOLVIMENTO}

Inicialmente para a criação da aplicação, foi escolhido o "MIT App Inventor 2" utilizando a programação por blocos (Exemplo: Scratch), e a base do aplicativo, ou seja, sua tela inicial e algumas seguintes foram criadas nele, porém, no App Inventor existe um limite de telas que podem ser geradas, como o tema escolhido é extenso, foi necessário migrar para outra interface de programação por blocos levando o arquivo (.aia) para essa plataforma nova. Para a nova plataforma foi escolhido o "Kodular" (versão 1.5.2 Fenix), nela foi realizado o desenvolvimento de toda a aplicação, seu design e suas funções.

\subsection{DESIGN}

Com a base da aplicação finalizada, se deu início a elaboração do design visando a neutralidade e usualidade para o conforto do usuário. De acordo com Santos (2000) "cada indivíduo reage de diferentes formas a determinada cor, dependendo de sua intensidade, luminosidade e saturação"[...] e visando uma aparência agradável para o aplicativo utilizou-se de cores neutras e claras.

Foi utilizada a extensão "DynamicComponents" para se criar um efeito de telas curvadas nas páginas, além do uso do site "Coolors" para a escolha das cores da aplicação, e do "Google Fonts" para a escolha final das fontes utilizadas nos textos.

\section{RESULTADOS}

Um protótipo do aplicativo foi criado e testado gerando bons resultados. De maneira geral, o projeto alcançou seu objetivo principal e por meio desses resultados obtemos uma avaliação satisfatória. 

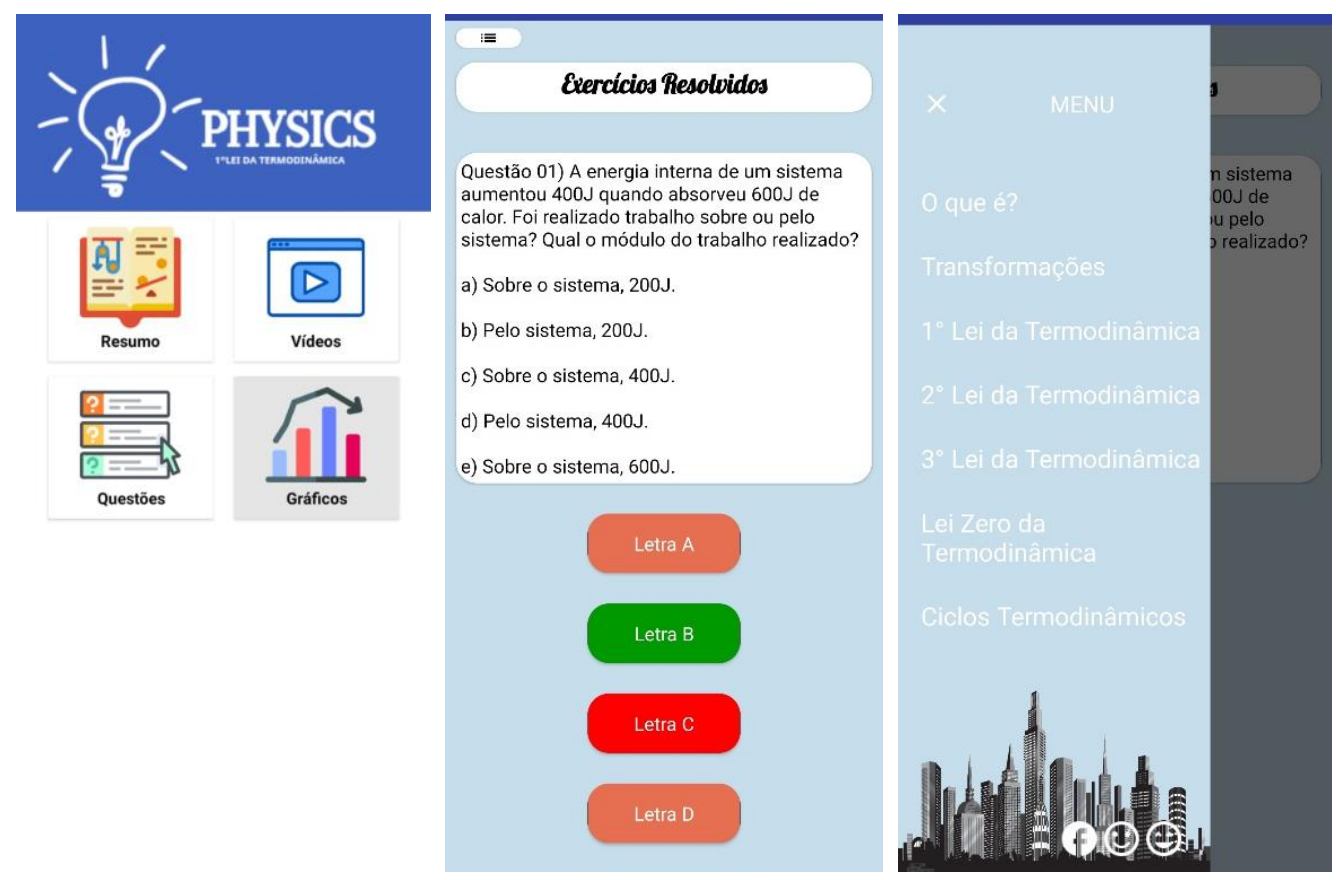

Figura 1. Tela inicial e tela de exercícios.

\section{CONCLUSÃO}

Os usuários foram capazes de interagir com uma interface gráfica mobile para o estudo na área de Física, desenvolvendo seu conhecimento e o melhorando, além de poder praticar o que foi estudado através de exercícios resolvidos e quando houve alguma dúvida, pôde-se consultar seu cálculo e resolução detalhadamente na própria interface. 0 aplicativo funcionou devidamente nos testes realizados, resultando em uma excelente opção de estudo.

\section{REFERÊNCIAS BIBLIOGRÁFICAS}

NASCIMENTO, Karoline Costa et al. "O uso de aplicativos móveis como ferramenta pedagógica no ensino-aprendizagem de Língua Inglesa”. 2017

SOUZA, Paulo Henrique da Silveira et al. "Aplicativos educacionais: um estudo de caso no desenvolvimento de um aplicativo na plataforma App Inventor2 para auxílio no ensino de produção textual nas aulas de português". 2017.

GERBELLI, Nelson Fabbri e Valéria Helena P. Gerbelli. "Kodular: Desenvolvimento Android sem código". Disponível em: https://books.google.com.br/books/about/Kodular.html?id=Yg7ADwAAQBAJ\&red ir_esc=y. Acesso em: 25 de mar. de 2021.

FONTES do google. Google Fonts, 2021. Disponível em: https://fonts.google.com/. Acesso em: 20 de jul. de 2021.

CORES para sites. Coolors, 2021. Disponível em: https://coolors.co/. Acesso em: 25 de jul. de 2021. 


\section{DESENVOLVIMENTO DE UMA PLATAFORMA WEB} PARA DISPONIBILIZAÇÃO DE DADOS HIDROCLIMÁTICOS

Gian Carlos Pedrosa Vieira'

Francis Wagner Silva Correia'

1Escola Superior de Tecnologia (EST) - Universidade do Estado do Amazonas (UEA) CEP 69050-020 - Manaus - AM - Brasil gcpvr.eng16@uea.edu.br, fcorreia@uea.edu.br

\section{INTRODUÇÃO}

Os eventos de secas e enchentes fazem parte da variabilidade natural da bacia Amazônica; entretanto, nas últimas décadas têm se observado mudanças e variações extremas no clima e na hidrologia da bacia (Espinoza et al., 2019). Nos últimos 20 (vinte) anos ocorreram duas grandes secas, em 2005 e 2010, e quatro grandes enchentes na bacia, em 2009, 2012 e 2014 e 2021 (Marengo e Espinoza, 2016). Esses eventos afetaram de forma direta a biodiversidade e ecossistemas (incêndios florestais), os recursos hídricos, a economia, a agricultura, a navegação fluvial, a geração de energia, e principalmente os povos e comunidades mais vulneráveis da região Amazônica (Guimberteau et al., 2013; Aragão et al., 2018). A bacia do Rio Madeira sofreu com inundações e chuvas históricas no verão de 2014 (Marengo e Espinoza, 2016). Esse evento produziu inundações e deslizamentos em várias cidades e comunidades na bacia do Rio Madeira, trazendo transtornos e prejuízos para população e comunidades vulneráveis. Diante das consequências negativas decorrentes dos eventos climáticos (secas e enchentes) é de fundamental importância a elaboração de uma plataforma tecnológica para disponibilização de dados hidroclimáticos na Região Amazônica. Essa plataforma contribuirá no apoio aos tomadores de decisão (poder público) no planejamento de ações para redução e mitigação dos efeitos das secas e enchentes nos povos e comunidades da bacia do Rio Madeira. 


\section{OBJETIVOS}

Esse projeto teve por objetivo geral o desenvolvimento de uma plataforma WEB para disponibilizar informações hidroclimáticas (observação e previsão) para a bacia do Rio Madeira. Os objetivos específicos são: a) Desenvolvimento de uma plataforma WEB para disponibilização de dados observados de precipitação, cota (nível do rio) e vazão (descarga) e b) Disponibilização de dados de previsão de precipitação, cota (nível do rio) e vazão (descarga), utilizando a plataforma WEB desenvolvida.

\section{MATERIAIS E MÉTODOS}

\section{1. ÁREA DE ESTUDO E MODELOS HIDROCLIMÁTICOS}

A área de estudo corresponde a bacia do Rio Madeira. A bacia apresenta uma área total de aproximadamente 1,42 milhões de $\mathrm{km}^{2}$, representando aproximadamente $23 \%$ da bacia Amazônica e com área de drenagem de 1,37 milhões de $\mathrm{km}^{2}$. Os dados observados de precipitação foram provenientes do Instituto Nacional de Meteorologia (INMET) e os dados de cota e vazão foram da Agência Nacional de Águas (ANA). Para realização das previsões hidroclimáticas utilizou-se o modelo climático regional Eta do Centro de Previsão de Tempo e Estudos Climáticos (CPTEC/INPE) (Chou et al. 2014) e o modelo hidrológico distribuído - Modelo de Grandes Bacias (MGB) do Instituto de Pesquisas Hidráulicas (IPH/UFRGS) (Collischonn et al., 2007).

\subsection{ELABORAÇÃO DA PLATAFORMA WEB}

Para o desenvolvimento da plataforma WEB utilizou-se a ferramenta WordPress. 0 WordPress é uma das maiores plataforma de gerenciamento de conteúdo na atualidade. Com lançamento em 2003, essa ferramenta domina $70 \%$ desse mercado e $23 \%$ de toda a Internet, abrangendo diversos nichos de sites: blogs, sites institucionais, e-commerce e entre outros. A plataforma foi escrita em PHP com banco de dados MySQL, que permite instalação de plug-ins, temas e outros API'S. A plataforma oferece um ambiente seguro e robusto, ideal para a utilização nesse projeto. Para elaboração da plataforma, as seguintes tarefas foram realizadas: a) Preparação do ambiente de desenvolvimento (instalação e configuração do sistema operacional). b) Instalação da ferramenta Wordpress, versão 5.3.2. c) Instalação de 
um banco de dados Mysql, d) Implementação do código e upload dos arquivos para publicação do site, e finalmente, e) Testes e atualizações

\section{RESULTADOS}

Nesse projeto se desenvolveu uma plataforma WEB para disponibilizar informações hidroclimáticas (observação e previsão) para a bacia do Rio Madeira. A plataforma desenvolvida denomina-se LABCLIM - Laboratório de Modelagem do Sistema Climático Terrestre (http://labclim.uea.edu.br/). 0 Laboratório de Modelagem do Sistema Climático Terrestre da Universidade do Estado do Amazonas (LABCLIM/UEA) corresponde a dois Sistemas de Processamento Alto Desempenho "Higth Performace Computing", compostos pelos Cluster Tambaqui e Aruana. Nos dois sistemas são integrados modelos matemáticos que representam o clima e a hidrologia, assim como suas variações, em diferentes escalas espaciais e temporais. O LABCLIM tem por propósito fornecer uma estrutura computacional robusta a fim de apoiar a formação de recursos humanos capacitados e qualificados a nível de Graduação e de Pós-graduação (Especialização, Mestrado e Doutorado); assim como, apoiar o desenvolvimento de pesquisas básicas nas áreas Ambiental, Hidrologia, Clima, Variabilidade e Mudanças no Clima. A Figura 1 apresenta a estrutura da plataforma WEB e a página principal do LABCLIM. Nessa página temos os ícones: a) Início - que apresenta o LABCLIM, definição, missão, objetivo e a infraestrutura do LABCLIM; b) Projetos - que apresenta os Projetos de Pesquisa \& Desenvolvimento (P\&D) e Projetos de iniciação cientifica e os Projetos de Pósgraduação (Mestrado e Doutorado); c) Equipe do LABCLIM; d) Produtos Hidroclimáticos; e) Publicações e f) Contatos. Na parte dos Produtos são apresentadas as principais variáveis hidroclimáticas, tanto decorrentes de dados observacionais, quanto das previsões realizadas por modelos climáticos e hidrológicos. 


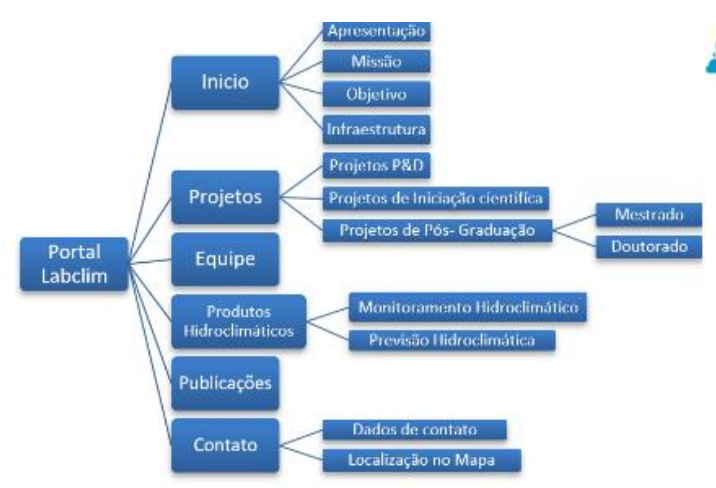

http:/labclim.uea.edu.br

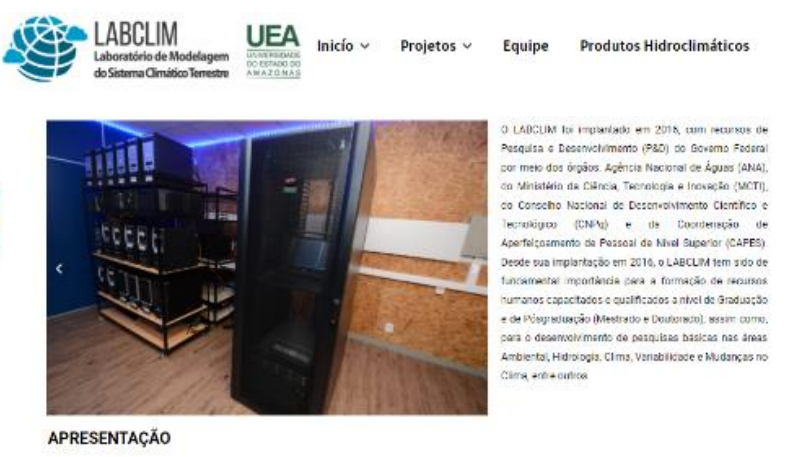

APRESENTAÇÄO

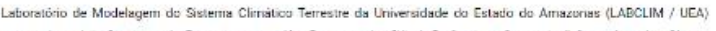

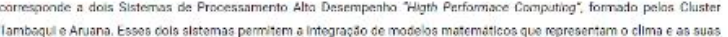

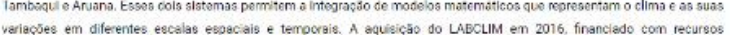

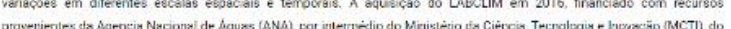
Corselho Nacional te Dene de Nulel Siperor (CAPES), Q

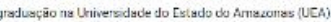

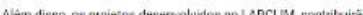

Figura 1. Estrutura da plataforma WEB e a página principal do LABCLIM. (http://labclim.uea.edu.br/).

O LABCLIM tem sido utilizado no desenvolvimento de diferentes pesquisas, com destaque para avaliação dos efeitos das mudanças no clima decorrentes do aumento dos gases do efeito estufa, desmatamento e urbanização na Amazônia. Em termos de produtos, o LABCLIM também tem disponibilizado informações observacionais de variáveis hidroclimáticas de interesse público e de gestão. Além disso, o LABCLIM, em parceria com Instituto Nacional de Pesquisas Espaciais (INPE), tem produzido e disponibilizado dados de previsões hidroclimáticas para a Bacia Amazônica, em destaque a bacia do Rio Madeira. As principais variáveis hidroclimáticas são: Precipitação, Descarga (vazão) e Cota (nível) dos rios. Em breve novos parâmetros serão incluídos nesses produtos. As Figuras 2 e 3 apresentam as principais variáveis hidroclimáticas observacional e de previsão disponibilizadas na plataforma WEB - LABCLIM, respectivamente. A Figura 2 Apresenta a variação sazonal média (climatológica) de precipitação e descargas referente ao período de 1980 a 2020 para a bacia do Rio Madeira. Os trimestres de DJF e MAM caracterizamse pelo período mais úmido e chuvoso sobre a bacia do rio Madeira, com precipitação média de $12 \mathrm{~mm}^{-d_{i a}{ }^{-1}}$ (Figura 2a). A variação sazonal da precipitação esta associada ao regime de monção na América do Sul, e as variações nos sistemas meteorológicos: Zona de Convergência do Atlântico Sul (ZCAS) e Zona de Convergência Intertropical (ITCZ). 

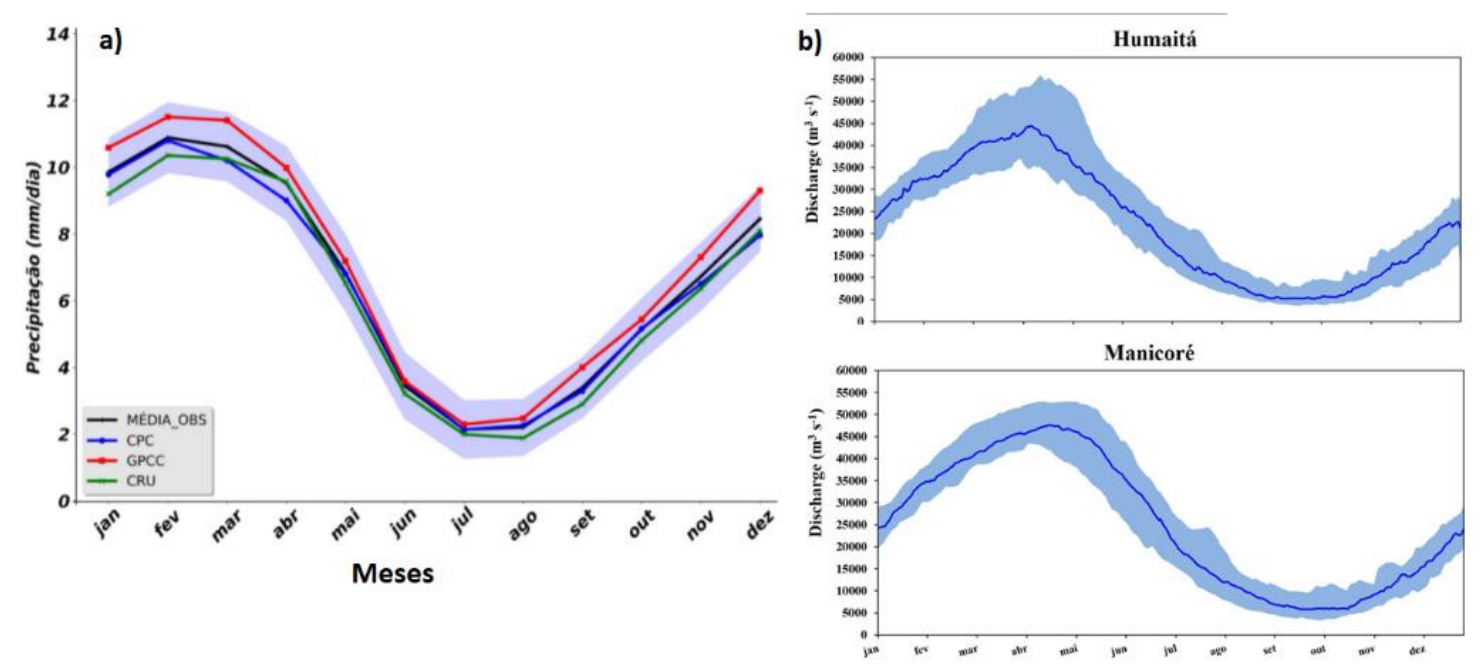

Figura 2. Variação sazonal climatológica da precipitação e descargas observadas (1980-2020) para a bacia do Rio Madeira. Unidades: $\mathrm{mm} \cdot \mathrm{dia}^{-1}$. e $\mathrm{m}^{3} \mathrm{~s}^{-1}$.

A Figura 2b apresenta a variação sazonal das descargas (vazão) observacionais para os municípios de Humaitá e Manicoré (Rio Madeira). A figura mostra uma pronunciada variação sazonal apresentando máximas ocorrendo nos meses de março e abril $\left(45.000 \mathrm{~m}^{3} . \mathrm{s}^{-1}\right)$ e vazões mínimas $\left(5.000 \mathrm{~m}^{3} . \mathrm{s}^{-1}\right)$ nos meses de setembro e outubro.

As previsões sazonais hidroclimáticas (vazão e cota), realizadas pode modelos numéricos, são apresentadas na Figura 3. De forma geral, os modelos conseguiram representar a variação sazonal das vazões nas estações de Humaitá e Manicoré; assim como reproduzir os eventos de cheias e estiagens nessas estações. O modelo hidrológico conseguiu representar o efeito de remanso (barramento) e das planícies de inundação, com valores de vazões máximas estando mais suavizados e dentro dos padrões apresentados nos dados observados provenientes da Agência Nacional de Águas (ANA). Com relação a cota (nível do rio), o modelo hidroclimático conseguiu representar a translação das ondas de cheia e sua amplitude de variação. Entretanto, o modelo subestimou no período de máxima e superestimou durante a vazante na estação de Manicoré. 

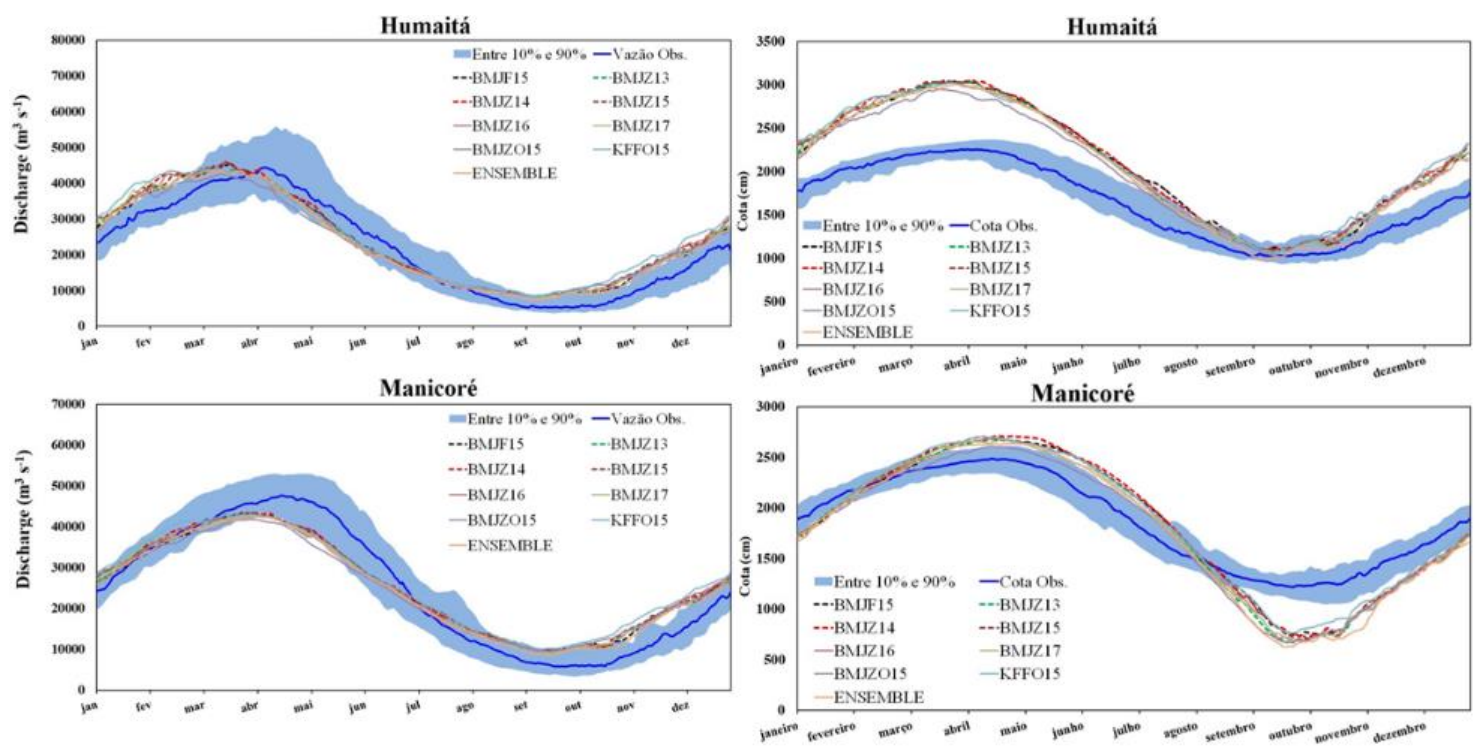

Figura 3. Previsões sazonais hidroclimáticas (descarga e vazão) para as estações de Humaitá e Manicoré (Rio Madeira). Unidade: $\mathrm{m}^{3} \mathrm{~s}^{-1} \mathrm{e} \mathrm{cm}$.

\section{CONCLUSÃO}

Nesse projeto foi desenvolvido uma plataforma WEB para disponibilizar informações hidroclimáticas para a bacia do Rio Madeira. A plataforma desenvolvida denomina-se LABCLIM - Laboratório de Modelagem do Sistema Climático Terrestre (http://labclim.uea.edu.br/). A plataforma LABCLIM apresenta informações importantes sobre o monitoramento e previsão numérica de precipitação, descarga (vazão) e cota (nível) dos rios para a bacia do Rio Madeira. De forma, os modelos hidroclimáticos conseguiram representar a variação sazonal da precipitação e vazão na bacia do Rio Madeira, assim como reproduzir os eventos de cheias e estiagens nessas estações. Entretanto, o modelo subestimou no período de máxima e superestimou durante a vazante na estação de Manicoré, necessitando de ajuste e calibração. A plataforma LABCLIM contribuirá no apoio aos tomadores de decisão (poder público) no planejamento de ações para redução e mitigação dos efeitos nocivos das secas e enchentes para os povos e comunidades na bacia Amazônica, principalmente na bacia do Rio Madeira.

\section{REFERÊNCIAS BIBLIOGRÁFICAS}

Aragão, L. E., Anderson, L. O., Fonseca, M. G., Rosan, T. M., Vedovato, L. B., Wagner, F. H., .Aguiar, A. P. (2018). 21st Century drought-related fires counteract the decline of Amazon deforestation carbon emissions. Nature communications, 9(1), 1-12. 
Chou, S. C., Lyra, A., Mourão, C., Dereczynski, C., Pilotto, I., Gomes, J., ... \& Marengo, J. (2014). Assessment of climate change over South America under RCP 4.5 and 8.5 downscaling scenarios. American Journal of Climate Change, 3(05), 512

Collischonn, W., Morelli Tucci, C. E., Clarke, R. T., Chou, S. C., Guilhon, L. G., Cataldi, M., \& Allasia, D. (2007). Medium-range reservoir inflow predictions based on quantitative precipitation forecasts. Journal of Hydrology, 344(1), 112-122. doi:https://doi.org/10.1016/j.jhydrol.2007.06.025

Espinoza, J. C., Sörensson, A. A., Ronchail, J., Molina-Carpio, J., Segura, H., Gutierrez Cori, O., ... \& Wongchuig-Correa, S. (2019). Regional hydro-climatic changes in the Southern Amazon Basin (Upper Madeira Basin) during the 1982-2017 period. Journal of Hydrology: Regional Studies, 26, 100637.

Guimberteau, M., Ronchail, J., Espinoza, J. C., Lengaigne, M., Sultan, B., Polcher, J., . Ciais, P. (2013). Future changes in precipitation and impacts on extreme streamflow over Amazonian sub-basins. Environmental Research Letters, 8(1), 014035.

Marengo, J. A., \& Espinoza, J. C. (2016). Extreme seasonal droughts and floods in Amazonia: causes, trends and impacts. International Journal of Climatology, 36(3), 1033-1050. 


\title{
ASPECTOS ERGONÔMICOS DO TELE ESTUDO DURANTE A PANDEMIA DO COVID-19
}

\author{
Carla Letícia Nascimento Sardinha' \\ Luis Fernando Ramalho de Freitas' \\ Nadja Polyana Felizola Cabete'
}

1Escola Superior de Tecnologia (EST) - Universidade do Estado do Amazonas (UEA) CEP 69050-020 - Manaus - AM - Brasil clns.eng20@uea.edu.br, lfrdf.eng20@uea.edu.br, ncabete@uea.edu.br

\section{INTRODUÇÃO}

De acordo com o último censo escolar divulgado pelo Inep (2021), desde março de 2020, cerca de 48 milhões de estudantes deixaram de frequentar as atividades presenciais nas mais de 180 mil instituições de ensino do Brasil como forma de prevenção à propagação do coronavírus. Ao seguir as orientações da Organização Mundial da Saúde (OMS), muitas empresas encontraram no teletrabalho a forma de evitar aglomerações e preservar a saúde de colaboradores e clientes. As escolas e as universidades seguiram o mesmo caminho ao explorar a educação à distância como alternativa para a longevidade do distanciamento.

O termo tele estudo refere-se a todo estudo que seja feito a prestação de ensino (docente) ou recepção de ensino (discente) fora da sede da instituição. Os educadores desenvolvem e disponibilizam seus conteúdos didáticos utilizando ferramentas de comunicação em meio digital, e cada instituição de ensino adota uma estratégia de acordo com seus objetivos educacionais. Apesar do tele estudo já ser uma realidade na educação brasileira, ele estava direcionado quase que na sua totalidade para o Ensino Superior, sendo outra parte para os cursos técnicos profissionalizantes. Na Educação Básica (Educação Infantil, Ensinos Fundamental e Médio) quando utilizavam o ensino a distância, em suma, era apenas como forma de educação complementar, sendo autorizado o ensino a distância para casos específicos do Ensino Médio, especialmente para cursos profissionalizantes. Além disso, o parágrafo 4º do art. 32 da Lei no 9.394, de 20 de dezembro de 1996 [Brasil, 1996] (Lei de Diretrizes e Bases da Educação - LDB) define que "O ensino fundamental será presencial, sendo o ensino a distância utilizado como 
complementação da aprendizagem ou em situações emergenciais". 0 Covid-19 nos levou a uma dessas situações emergenciais.

Apesar das vantagens e comodidades do tele estudo, o período singular da pandemia do Covid-19 impôs aos alunos e educadores a carência de estruturas física e mental, que normalmente seriam encontradas no ambiente das instituições de ensino, o que interfere diretamente na qualidade do aprendizado, pois infraestrutura e mobiliário adequado proporcionam uma sensação de bem-estar, não somente para o estudante como também para os professores, abrindo espaço para oportunidades de aprendizado e a possibilidade do desenvolvimento intelectual, social e profissional [Barbosa; Tavares; Silva, 2020]. Para entender mais profundamente e encontrar soluções para este problema é preciso consultar a ergonomia, disciplina científica que se preocupa com a adaptação do trabalho ao homem, trabalho sendo toda situação em que ocorre relacionamento entre o homem e uma atividade produtiva [Iida, 2005].

Levando em consideração todos os pontos expostos, o seguinte trabalho objetiva apresentar os aspectos ergonômicos relevantes a serem considerados para o tele estudo, os riscos associados, bem como propor orientações que possam auxiliar na melhoria desse processo para seus participantes através da elaboração de uma pesquisa quali-quantitativa, de forma descritiva, que analisa os dados coletados a partir dos trabalhos de Análises Ergonômicas do Trabalho (AET) realizadas pelos alunos da disciplina Ergonomia, turma de 2020/1, os quais apresentam dados relacionados ao desenvolvimento da atividade de tele estudo no período de Agosto a Dezembro de 2020.

\section{OBJETIVOS}

Este trabalho objetiva observar os riscos ergonômicos trazidos pelo tele estudo e teletrabalho no período de pandemia, analisá-los, e apresentar orientações que auxiliem na realização das atividades necessárias.

Esta finalidade é alcançada através dos seguintes objetivos específicos: compreender os conceitos de ergonomia e levantar dados da literatura; compilar os aspectos ergonômicos de destaque no cenário sendo estudado; analisar, com base nos aspectos já definidos, os trabalhos de Análise Ergonômica do Trabalho (AET) realizados pelos alunos de Ergonomia, turma 2020/01, no período de Agosto a 
Dezembro de 2020; averiguar as condições de realização das atividades dos alunos, comparando com a literatura e expondo as indicações da literatura para ditas atividades.

\section{MATERIAIS E MÉTODOS}

Esta pesquisa trata-se de uma pesquisa aplicada, com foco na compreensão da realidade do problema de adaptação das aulas da disciplina ergonomia do curso de engenharia de produção da UEA ao ambiente virtual. Quanto aos seus objetivos, ela classifica-se como descritiva do fenômeno de adaptação desta tarefa a este novo ambiente. Foi realizada sob uma abordagem quali-quantitativa para coleta e análise de dados, a partir de aulas expositivas e revisão bibliográfica sobre o assunto em foco.

\subsection{FONTE DE PESQUISA}

Para fundamentação teórica, foram utilizados, além dos trabalhos acadêmicos de Análises Ergonômicas do Trabalho (AET) realizado por alunos da turma 2020/1, que fornece dados relativos ao desenvolvimento de atividades de tele estudo no período de agosto a dezembro de 2020, foram levantados textos publicados no portal acadêmico do Google, sobre o tema de "Ensino remoto", "Tele estudo", “COVID-19 - Ensino Remoto”, e, posteriormente, no Portal de Periódicos da CAPES, Cientific Electronic Library Online (SciELO), ScienceDirect (plataforma de literatura revisada da Elsevier), ABERGO - Associação Brasileira de Ergonomia, para reconhecimento contextual num primeiro momento, por meio dos descritores "Ergonomia”, “Análise Ergonômica do Trabalho - AET”.

\subsection{ASPECTOS ERGONÔMICOS A SEREM CONSIDERADOS}

Para maior eficiência na realização do trabalho, foi criada uma lista com os aspectos ergonômicos relevantes considerados nas AETs realizadas pelos alunos. Este guia compreende os aspectos do posto de trabalho como o mobiliário e equipamentos, incluindo seus dimensionamentos, as posturas adotadas durante o trabalho, a iluminação, cores, ruídos sonoros e temperatura do ambiente. Também abrange aspectos organizacionais como os horários em que o trabalho é realizado, pausas tomadas, e a motivação dos alunos são fatores a serem considerados. Esses aspectos serão analisados e comparados com o que é expresso pelas normas. 


\section{RESULTADOS}

Foram realizadas catorze Análises Ergonômicas do Trabalho, sendo consideradas apenas treze que estavam de acordo com o que foi solicitado.

A NR 17 (norma regulamentadora que estabelece parâmetros básicos e gerais para que o trabalho seja executado com segurança, eficiência e conforto para o trabalhador) recomenda que, sempre que possível, o trabalho seja realizado de forma sentada, o que é feito por todos os alunos, logo, por trabalharem em média por 6 h e 15min diários, é essencial que os mobiliários usados por esses sigam certas recomendações para que os fatores de risco sejam os menores possíveis.

Para minimização dos riscos, a norma informa que mesas/bancadas e assentos devem possuir dimensões compatíveis com o trabalhado sendo realizado e com o usuário. Alguns fatores que participam nessa compatibilidade são a altura da mesa, a distância entre o assento e o tampo da mesa, o alcance dos objetos, entre outros. Dentre os trabalhos, somente um aluno disse ter uma mesa com altura inadequada, similarmente, outro reclamou sobre ter uma área de trabalho muito pequena.

Os assentos, além de estarem a uma certa distância do tampo da mesa, não podem possuir conformações (que se encaixam nas nádegas), para permitir mudanças de posturas, pois essas aumentam a oxigenação dos tecidos que normalmente sofrem com altas pressões enquanto estamos sentados [Reenalda et al., 2009]. Nas análises, somente um assento apresentou conformações, ao passo que três não possuem bordas frontais arredondas e um disse não possuir encosto para lombar, outras indispensabilidades apontadas pela norma.

Doze dos alunos afirmam possuir algum tipo de notebook ou computador, destes, quatro fazem alguma reclamação sobre a altura e ângulo de suas telas, logo, é preciso ter uma postura adequada para a cabaça e nuca, estas não podendo estar em um ângulo de inclinação maior que 15o para frente por muito tempo [Grandjean, 1998], portanto, as telas dos dispositivos devem ter seus limites superiores elevados à altura dos olhos. Para que essa elevação seja possível é necessário utilizar dispositivos externos, como teclado independente e mouse, porém apenas cinco alunos dizem utilizar teclado externo e mouse, e dois utilizam apenas mouse. 
A falta de mobílias e equipamentos apropriados é refletida em $77 \%$ dos alunos (10) afirmando ou comentando sobre inadequação de suas posturas corporais.

A iluminação adequada, de acordo com a norma, deve ser sem problemas de ofuscamento, reflexos, sombras e contrastes excessivos, e de forma difusa e uniformemente distribuída, somente um aluno afirma tê-la. A maioria dos alunos considera adequados os níveis de ruídos em seus locais, ou seja, dentro do limite de 65dB estabelecido pela NR17 para atividades que exijam demanda intelectual e atenção constante, enquanto quatro reclamaram de altos níveis de ruídos, provenientes de fatores externos. Já no que se refere às condições temperamentais, sete alunos afirmam não serem adequadas. Comumente são utilizadas formas de ventilação artificial para alcançar as temperaturas recomendadas pela norma, entre 20o e 23oC, contudo apenas três alunos dizem utiliza-las durante todo o dia, sendo mais frequente a utilização somente à noite, gerando diversas queixas das altas temperaturas nos horários mais quentes do dia.

A organização das horas de trabalho é feita de diversas formas e leva em consideração diferentes fatores, alguns alunos evitam seus horários de baixa produção, outros tentam manter os horários que teriam no estudo presencial, e para aqueles que realizam atividades além das acadêmicas pesa a disponibilidade. Além destes aspectos, devem ser considerados as questões fisiológicas, como o ciclo circadiano. Este está relacionado às funções do ser humano, especialmente o sono e a capacidade de produção [Grandjean, 1998]. A boa organização do trabalho visa trabalhar em concordância com o ritmo circadiano para evitar ou diminuir problemas como a fadiga, o estresse e a monotonia.

Quatro alunos afirmaram realizar pausas breves sem um horário determinado, enquanto apenas três delimitaram pausas formais. A falta de determinação de pausas formais pode ocasionar a não realização delas, ou a realização de muitas pausas desnecessárias, desmotivando o trabalho.

Nenhum aluno expressou o que lhes motiva a realizar suas atividades, no entanto cinco alunos declararam os tipos de pressões que sofrem para realização de suas tarefas, sendo essas internas e externas, com destaque à prazos. Apesar de não ser mencionada na norma, é preciso entender as questões que são levadas em conta 
para realização das atividades. Identicamente, cinco alunos concluíram que seus postos de trabalho não correspondiam com as normas ergonômicas de trabalho.

\section{CONCLUSÃO}

Por consequência da atual crise pandêmica, uma das questões mais discutidas no contexto educacional está relacionada ao tele estudo, situação a qual as escolas encontraram como solução para a manutenção das aulas neste período. Ergonomicamente, esta situação se caracteriza com uma atividade produtiva, que necessita de atenção especial para ser bem executada e assim poupar alunos e professores de problemas de saúde relacionados desgaste mental, atividades repetitivas e prolongadas, má postura, dentre outras.

O presente estudo visou explorar essa atividade de tele estudo, buscando fundamentos teóricos em artigos científicos que abordam a temática e dados empíricos obtidos a partir de resultados angariados de trabalhos feitos por alunos da disciplina de Ergonomia da Universidade do Estado do Amazonas.

Observa-se que a modalidade do tele estudo apresenta menor incidência de danos físicos como fraturas e lesões, tanto para docente quanto para discente, porém, estarão expostos a diferentes situações e que podem gerar danos psicológicos e estresses frequentes, provenientes de condições inadequadas nos respectivos ambientes de trabalho em que cada indivíduo desenvolve sua atividade no ensino remoto.

Os resultados obtidos por meio das AET desenvolvidas pelos alunos mostraram que, grande parte dos ambientes cumpriam com as normas básicas de ergonomia, realizando as atividades sentados com os objetos de estudo sobre a mesa e dentro dos limites recomendados para alcance, mas notou-se que há insuficiência de dados relacionados às medidas mais técnicas como medidas do mobiliário, dados ambientais e ângulos de postura. Possivelmente, isso se deve à inexperiência dos alunos neste tipo de análise, uma vez que esta disciplina é a primeira disciplina específica do curso e os alunos não tiveram a possibilidade de desenvolver atividades em laboratório previamente, utilizando os instrumentos adequados, os quais nem todos têm acesso em suas residências.

Observou-se que a frequência de dor ou desconforto musculoesquelético relatada pelos escolares é muito elevada, principalmente relacionada ao pescoço, 
punhos/mãos, dedos e lombar, devido principalmente à manutenção prolongada da posição sentada, repetições de movimentos, assim como a seleção e/ou uso indevido do mobiliário para estudo. Outros estudos comparativos, também relacionados ao tele estudo, também apontaram o mesmo padrão de queixas relacionadas à postura.

Concluímos, desta forma, que as questões ergonômicas relacionadas às atividades de tele estudo possuem grande relevância nas decisões sobre a modalidade de ensino definida pelas instituições de ensino, e que professores e alunos estão sujeitos a riscos ergonômicos que podem vir a causar problemas de saúde no decorrer do tempo, pois nem todos os ambientes domiciliares possuem equipamentos, mobiliários ou condições adequadas para a realização da atividade de tele estudo de forma regular.

Da mesma forma, os alunos de outros cursos que não tem acesso ao conteúdo de ergonomia e não tem o conhecimento necessário para realizar a análise do ambiente de trabalho, ficam ainda mais vulneráveis aos problemas ergonômicos, uma vez que realizam suas atividades sem uma visão crítica sobre o risco a que possam estar sujeitos.

Recomendamos, assim, que a decisão pelo tele estudo passe por uma análise das questões ergonômicas e que, em se decidindo pela manutenção desta modalidade, mesmo que parcialmente, professores e alunos sejam orientados quanto aos cuidados necessários para prevenir riscos à sua saúde e bem-estar no desenvolvimento destas atividades.

\section{REFERÊNCIAS BIBLIOGRÁFICAS}

ABERG0, Associação Brasileira de Ergonomia. "O que é Ergonomia", http://www.abergo.org.br/internas.php?pg=o_que_e_ergonomia.

BARBOSA, G. M.; TAVARES, L. B. F.; SILVA, H. R. (2020) “Estudo Preliminar sobre Desconforto Ergonômico em um Curso de Graduação em Engenharia de Produção", In: XL ENCONTRO NACIONAL DE ENGENHARIA DE PRODUÇÃO "Contribuições da Engenharia de Produção para a Gestão de Operações Energéticas Sustentáveis", 20 a 23 de outubro, Foz do Iguaçu, Paraná, Brasil. Anais, http://www.abepro.org.br/biblioteca/TN_STO_349_1794_39752.pdf.

BRASIL. "Lei de Diretrizes e Bases da Educação Nacional”, LDB. 9394/1996.

GRANDJEAN, E. (1998) "Manual de Ergonomia: adaptando o trabalho ao homem", Tradução: João Pedro Stein, Porto Alegre: Artes Médica Sul. 
IIDA, Itiro (2005) "Ergonomia: projeto e produção", 2. ed. rev. e ampl, São Paulo: Edgard Blucher.

INSTITUTO NACIONAL DE ESTUDOS E PESQUISA EDUCACIONAIS ANÍSIO TEXEIRA (2021), "Sinopse Estatística do Questionário Resposta Educacional à Pandemia de Covid-19 no Brasil - Educação Básica”, Brasília: Inep.

MINISTÉRIO DO TRABALHO. Portaria n.o 3.214, de 08 de junho de 1978. NR 17 Ergonomia. Diário Oficial da União, Poder Executivo, Brasília, DF, 06 jul. 1978

REENALDA, J. et. al. (2009) "Analysis of healthy sitting behavior: Interface pressure distribution and subcutaneous tissue oxygenation", In: Journal of Rehabilitation Research \& Development, [s. l.], v. 46, n. 5, p. 577-586, 23 Mar. DOI: $\quad$ 10.1682/JRRD.2008.12.0164. Disponível em: https://www.rehab.research.va.gov/jour/09/46/5/reenalda.html. 


\title{
FERRAMENTAS DE ACESSIBILIDADE E FLUXO DE
} COMUNICAÇÃO PARA PESSOAS COM DEFICIÊNCIA VISUAL

\author{
Luís Fernando Andrade Pinto' \\ Rejane Gomes Ferreira' \\ Carly Pinheiro Trindade'
}

1Escola Superior de Tecnologia (EST) - Universidade do Estado do Amazonas (UEA) CE0 69050-020 - Manaus - AM - Brasil ifap.eng20@uea.edu.br, rejane@uea.edu.br, ctrindade@uea.edu.br

\section{INTRODUÇÃO}

Este artigo tem por finalidade analisar o fluxo de comunicação e a relação entre usuário e aplicativos de inclusão utilizados pelas pessoas com deficiência visual no âmbito tecnológico.

Jorge e Duarte (2017), afirmam que a acessibilidade digital é o acesso integral de qualquer pessoa a um produto que está na internet (seja uma rede social ou uma página institucional, por exemplo). 0 aprimoramento dessa, surge com o propósito de promover a inclusão social em âmbitos diversos; inclusive, a priori, com a inclusão digital, já que conforme o e-MAG (Modelo de Acessibilidade em Governo Eletrônico), o crescimento das tecnologias de informação e comunicação atingem um elevado número de usuários, possibilitando o acesso à informação por conhecimentos científicos e tecnológicos. Isso é possível com a apresentação da informação de forma descrita, escrita, em áudio e de maneira facilmente compreensiva.

Para Navarro (2015) o conhecimento das limitações e dificuldades de pessoas com deficiência visual é cada vez mais vivenciada e a demanda por programas de inclusão social cresce constantemente. Desta maneira o deficiente visual vem se tornando um consumidor relevante, com cada vez mais conhecimento, informação, maior poder aquisitivo e independência para atender não só suas necessidades básicas, assim como a buscar e requerer objetos que tragam satisfação emocional e auto realização. 
Para compreender o contexto do trabalho, acrescenta-se o que diz a Lei Brasileira de Inclusão (Lei 13.146 de 2015), que conceitua a deficiência em seu Artigo 2o como:

"Considera-se pessoa com deficiência aquela que tem impedimento de longo prazo de natureza física, mental, intelectual ou sensorial, o qual, em interação com uma ou mais barreiras, pode obstruir sua participação plena e efetiva na sociedade em igualdade de condições com as demais pessoas".

Os números da população brasileira do censo do IBGE de 2010 revelam que do total da população brasileira, 45,6 milhões de pessoas $(23,9 \%)$ declararam algum tipo de deficiência e a deficiência visual foi a mais comum atingindo 3,5\% da população. Outros números se somam ao cenário, como a baixa escolaridade.

0 termo deficiência visual se refere a categorias que incluem desde a perda visual até a ausência total de visão, o que define a cegueira total e a baixa visão. Então, já se tem o conhecimento que essas pessoas têm prejuízo da função visual mesmo após tratamentos, bem como o comprometimento da capacidade para realizar as atividades diárias (FIOCRUZ, 2017). Diante da questão da acessibilidade e comunicação, pretende-se contribuir para a compreensão do fluxo da informação e da acessibilidade.

\section{OBJETIVOS}

\subsection{OBJETIVO GERAL}

Analisar o fluxo de informação e a acessibilidade a aplicativos desenvolvidos para pessoas de baixa visão e cegas.

\subsection{OBJETIVOS ESPECIFICOS}

- Realizar um levantamento das ferramentas digitais de acessibilidade disponíveis em plataformas gratuitas;

- Compreender o fluxo de informação para os usuários dos aplicativos;

- Analisar as dificuldades e facilidade encontradas pelos usuários.

\section{MATERIAIS E MÉTODOS}

Foi desenvolvido um estudo qualitativo descritivo do tipo exploratório durante o período de março a agosto de 2021, visando compreender o fluxo da 
informação e a acessibilidade à Internet de pessoas com deficiência visual. 0 estudo descritivo de acordo com Cervo, Bervian e Silva, (2007) trabalha sobre dados ou fatos colhidos da própria realidade, como nesta pesquisa, foram considerados os dados obtidos na web.

O estudo oportunizou um planejamento mais flexível e a obtenção de dados se deu nos sítios da web em que se encontram disponibilizados 5 (cinco) aplicativos. A ferramenta de coleta utilizada foi o Google a partir dos termos "aplicativos+deficiência visual". A seleção dos aplicativos estudados foi intencional e foram considerados na pesquisa os aplicativos de acesso gratuito. Os dados foram analisados também a partir da percepção dos pesquisadores sobre o uso dos aplicativos.

\section{RESULTADOS}

A partir dos conhecimentos adquiridos ao realizar a pesquisa de ferramentas de acessibilidade destinados a pessoas com deficiência visual e cegas, formulou-se o Quadro 1, que contém os dados da análise, como o nome das ferramentas, o público alvo e o tipo de serviço oferecido. Pode-se verificar que os aplicativos atendem na sua totalidade as pessoas cegas. As ferramentas de acessibilidade estudadas dispõem aos usuários formas de acesso que atendem às suas necessidades do dia-adia. Estas formas de atender aos usuários referem-se ao tipo de serviço, como o Braille e comando de voz, vídeo chamada e narração de tela, que são os serviços, ofertados como ferramentas de acessibilidade.

Os 5 (cinco) aplicativos pesquisados têm como público alvo pessoas cegas (Quadro 1). Quanto ao tipo de serviço prestado, apenas o Google BrailleBlack disponibiliza um teclado em Braille conectado por Bluetooth, que atua por comando de voz e se encontra disponível para Android.

Quadro 1. Ferramentas de acessibilidade pesquisadas.

\begin{tabular}{|l|l|l|}
\hline \multicolumn{1}{|c|}{ Nome do aplicativo } & \multicolumn{1}{c|}{ Público Alvo } & \multicolumn{1}{c|}{ Tipo de serviço } \\
\hline Google Braille Back & Cegos e pessoas com deficiência visual & Braille e Comando de voz \\
\hline Be My Eyes & Cegos & Vídeo chamada \\
\hline Eye-D & Cegos e pessoas com deficiência visual & Vídeo Chamada \\
\hline Android Acessibillity Suite & Cegos & Narração da tela \\
\hline Dina & Cegos e pessoas com deficiência visual & Captura de imagem e narração \\
\hline
\end{tabular}

Fonte: Autores, 2021. 
Para compreender o fluxo da informação em um aplicativo para pessoas com deficiência, escolheu-se o Be My Eyes em português para representação (Figura 1).

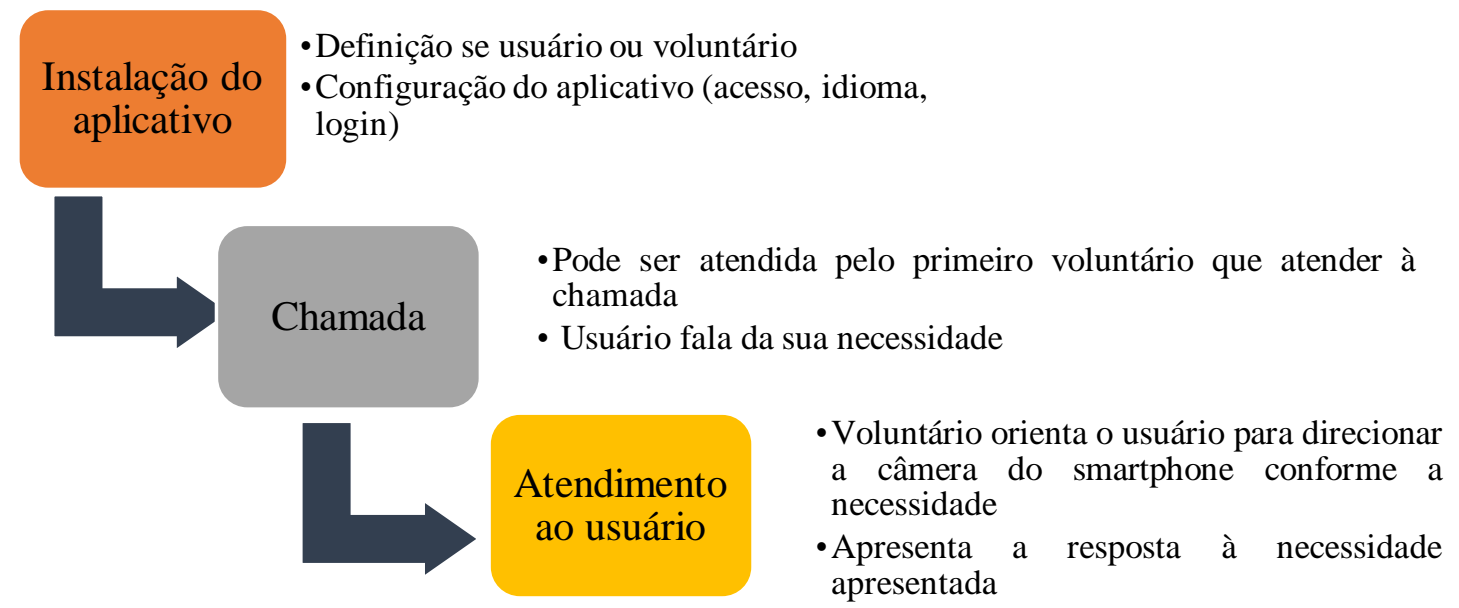

Figura 1. Fluxo da informação no uso do aplicativo Be My Eyes.

Fonte: Autores, 2021.

O aplicativo Be My Eyes pode ser baixado pelo Google Play com o auxílio de uma pessoa vidente e requer sistema Androide 5.0 ou mais. Após instalado o aplicativo, pode ser configurado. Quando um usuário cego ou com visão limitada solicita ajuda através do aplicativo, o Be My Eyes manda uma notificação para vários voluntários. 0 aplicativo funciona conectando um usuário cego ou com visão limitada com um voluntário que consegue ver, baseado na língua que eles falam e no fuso horário. 0 primeiro voluntário que responder à solicitação é conectado ao usuário e recebe uma transmissão de vídeo ao vivo, via câmera traseira do smartphone do usuário. A conexão de áudio permite que o usuário e o voluntário resolvam a tarefa juntos.

No Android Accessibility Suite, pode-se verificar que a informação, surge quando o usuário acessa as configurações do smartphone, ao acessar o menu de acessibilidade, clica na opção ativar o talkback, se o usuário quiser ouvir o assistente apenas aperta sim.

O Google Brailleback traz um teclado em Braille que contém uma mistura deste com falas para que possam ser entendidos os elementos da tela do Android. As falas guiam o usuário até cada ícone da tela, enquanto o teclado em braille pode facilitar a navegação no aplicativo. 
O Dina é um aplicativo novo, gratuito, disponível no Google Play, em sua versão 2.0, que reconhece objetos, textos e cores e por meio da câmera do celular "os fala" em voz alta.

\section{CONSIDERAÇÕES FINAIS}

O deficiente visual está se inserindo mais intensamente junto aos meios comunicação virtual e vem tendo sua acessibilidade ampliada por meio de aplicativos, o que vem transformando uma realidade, tornando-os cada vez mais independentes e isso tem se dado pelo uso dos aplicativos de inclusão que facilitam suas rotinas.

Ao realizar a análise do fluxo de informações constatou-se que para a maioria dos usuários dos quatro aplicativos, o fluxo de informação ocorre forma clara e atende às expectativas, tornando-se assim um meio de acessibilidade. Para o Dina, a dificuldade se refere à captação do objeto e transformação do áudio, requerendo melhorias.

Poucas foram as dificuldades encontradas pelos usuários das plataformas de acessibilidade, as quais estão sendo trabalhadas pelos desenvolvedores. Já as facilidades encontradas são muitas, pois cada aplicativo ajuda seus usuários nas mais diversas necessidades, possibilitando que se sintam independentes e realizados.

\section{REFERÊNCIAS BIBLIOGRÁFICAS}

BRASIL, 2015, Lei n. 13.146, de 6 de jul. de 2015. Disponível em: http://www.planalto.gov. Acesso em 2 de janeiro de 2021.

Censo Brasileiro de 2010. Rio de Janeiro: IBGE, 2012. INSTITUTO BRASILEIRO DE GEOGRAFIA E ESTATÍSTICA (IBGE). Disponível em: http://ibge.gov.br. Acesso em: 2 jan. 2021.

CERVO, A. L.; BERVIAN, P. A.; SILVA, R. Metodologia científica. São Paulo: Person, 2007.

FIOCRUZ. Deficiência visual atinge cerca de 1,4 milhão de pessoas no mundo. Notícias, Rio Janeiro, jun. 2017. Disponível em: https://portal.fiocruz.br/noticia/ deficiencia-visual-atinge-cerca-de-14milhao-de-criancas-no-mundo. Acesso em: 30 jun. 2021. 
JORGE, C. O.; DUARTE, G. D. Bibliotecas digitais do governo brasileiro: um estudo sobre acessibilidade digital envolvendo pessoas com deficiência visual. In: $\mathrm{V}$ CONFERÊNCIA INTERNACIONAL PARA A INCLUSÃO, 2019. Livro de atas da V Conferência Internacional para a Inclusão - 2018 [...]. Leiria: Politécnico de Leiria, 2019. p. 80-92. Disponível em: http://hdl.handle.net/10400.8/4544. Acesso em: 2 jul. 2021.

NAVARRO, J. J. A inclusão social dos deficientes visuais e a publicidade brasileira: um breve panorama. Brasília (DF): UnB, 2012. Disponível em: https://bdm.unb.br. Acesso em: 2 jul. 2021. 
LOGÍSTICA DO TRANSPORTE FLUVIAL DE ENCOMENDAS PARA O INTERIOR DO ESTADO DO AMAZONAS

\section{Beatriz Freitas de Souza' \\ Fernanda Tavares Pereira' \\ Pedro Luka Castro da Silva' \\ Lucas Correa Sarraff de Rezende' \\ Anderson Paulo Viana de Araújo' \\ Ingrid Sammyne Gadelha Figueiredo' \\ Rejane Gomes Ferreira'}

${ }^{1}$ Escola Superior de Tecnologia (EST) - Universidade do Estado do Amazonas (UEA) CEP 69050-020 - Manaus - AM - Brasil bfds.eng20@uea.edu.br, ftp.eng20@uea.edu.br, plcds.eng20@uea.edu.br, lcsdr.eng20@uea.edu.br, apvda.eng20@uea.edu.br, ifigueiredo@uea.edu.br, rejane@uea.edu.br

\section{INTRODUÇÃO}

A proposta traz no seu escopo um estudo que visa contribuir para a melhoria da informatização do serviço de transporte e logística no envio de encomendas por via fluvial aos municípios do estado do Amazonas. 0 cenário observado é que o usuário desconhece com exatidão os horários de saída e chegada dos barcos, os destinos e dias da semana que realizam as viagens a esses locais. Para tanto, os usuários do serviço de transporte fluvial precisam se dirigir presencialmente aos Portos de Manaus em busca destas informações, o que implica em custos e desperdício de tempo.

O Amazonas é composto por 62 municípios e detém a maior bacia hidrográfica do mundo. 0 rio Amazonas é internacionalmente conhecido como o maior do mundo, possuindo um curso de 6.300 quilômetros. Perante toda essa imensidão e riqueza hidrográfica, o principal modal do estado é o hidroviário, que consiste na locomoção de cargas e encomendas feitas por meio de barcos, navios, ferryboats e balsas, através de vias fluviais (AMAZONAS, 2021).

Ballou (2001) afirma que a principal da missão da logística é oferecer o produto ou serviço certo, no tempo certo, lugar certo e com as condições combinadas, gerando um chamado "mix de marketing" indispensável. Ainda sim para Fleury et al. (2000), o que vem tornando a logística um conceito moderno são 
duas linhas fundamentais de transformações: a econômica e a tecnológica. As constantes mudanças econômicas no mundo globalizado permitem a criação de ambientes competitivos e as transformações tecnológicas geram o aumento da eficiência e eficácia dos serviços prestados.

Então, a situação verificada demanda o emprego da tecnologia a esse tipo de serviço, não apenas pelos inúmeros benefícios, mas com o intuito de agregar informação e veracidade nos dados disponibilizados, uniformizando-os em um website com acesso gratuito, simples e rápido, com a intenção de auxiliar às pessoas que utilizam esse tipo de modal para realizar o envio de encomendas aos municípios de forma contínua, bem como aquelas que, posteriormente, poderão usufruir deste recurso.

\section{OBJETIVOS}

\subsection{OBJETIVO GERAL:}

Desenvolver uma interface de um website chamado de "AmazonBoats: Informações Fluviais", referente ao serviço de transporte e logística no envio de encomendas por via fluvial aos municípios do estado do Amazonas.

\subsection{OBJETIVOS ESPECÍFICOS:}

- Realizar um levantamento dos dados das embarcações que realizam o serviço de transportes de encomendas por via fluvial nos Portos de Manaus, como seus destinos, dias de partida aos municípios, horários;

- Compreender as principais rotas de logística fluvial para os transportes de encomendas aos interiores do Amazonas;

- Fornecer à população em geral, informações verdadeiras e atualizadas para o envio de cargas por via fluvial aos municípios do Amazonas, em cada Porto de Manaus.

\section{MATERIAIS E MÉTODOS}

Foi desenvolvida uma pesquisa de campo exploratória, no intuito de buscar uma maior familiaridade com o problema, a fim de torná-lo mais explícito, de forma que as informações iniciais obtidas junto aos donos de embarcações pudessem suprir o conhecimento quanto aos serviços prestados, no que se referiu ao 
transporte de encomendas e transformá-lo numa plataforma de serviços à população amazonense. De acordo com Gil (2017), pesquisa de campo possibilita observar o problema junto à realidade e em nível exploratório uma maior flexibilidade quanto à obtenção dos dados.

Para o presente trabalho foi utilizada a divisão do Amazonas em 13 microrregiões (SEPLANCTI, 2016) e identificadas as microrregiões que possuiam extenso número de embarcações que realizavam o trajeto de logística das encomendas.

Os dados foram coletados diretamente com os proprietários das embarcações e realizadas 4 coletas nos meses de março a julho, em dias de segundafeira, quarta-feira e sexta-feira, além da busca por meio de plataformas da internet bem como Facebook e Instagram. Essa estratégia de coleta de dados foi possível apenas nesses dias devido às restrições de circulação devido à pandemia por Covid19.

Todos os dados coletados foram tabulados e organizados em uma planilha, que subsidiou o início à criação da interface do projeto, tendo como apoio de uma plataforma online específica para criação e edição de sites, chamada de WIX. Também foram utilizados vídeos na web que pudessem contribuir para a elaboração de um protótipo inicial do projeto.

\section{RESULTADOS}

A Tabela 1 descreve a quantidade de barcos que realizam o transporte de encomendas por meio fluvial a cada uma das localidades estudadas. Além disso, e as informações quanto aos dias de saída, horários e destinos. Foram identificados 55 municípios do Amazonas beneficiados pela logística do modal hidroviário. No total, 84 embarcações que atendem a estes locais, distribuídas entre os portos: Manaus Moderna, São Raimundo e Ceasa. Apenas no porto do Roadway, não foi possível realizar o levantamento de informações, devido às negativas de acesso da equipe do projeto.

As microrregiões Rio Negro e Alto Solimões se destacaram como as principais rotas de deslocamento, tendo o maior número de embarcações transportando as mercadorias a esses municípios do Amazonas. A microrregião de Japurá e Boca do Acre possuem o menor atendimento quanto a essas rotas, usufruindo de poucas 
opções quanto a esse tipo de serviço de acordo com os dados coletados. Os munícipios de Itacoatiara, Presidente Figueiredo e Rio Preto da Eva não foram escolhidos para o estudo, por possuir maior acessibilidade via terrestre, bem como alguns municípios onde seu acesso é feito principalmente por meios aéreos.

Tabela 1. Dados da distribuição dos barcos e municípios atendidos.

\begin{tabular}{|c|c|c|c|}
\hline $\begin{array}{l}\text { Microrregiõ } \\
\text { es }\end{array}$ & Municípios atendidos & $\begin{array}{l}\text { Quant. } \\
\text { de } \\
\text { barcos }\end{array}$ & $\begin{array}{l}\text { Dias de } \\
\text { saída }\end{array}$ \\
\hline $\begin{array}{c}\text { Alto } \\
\text { Solimões }\end{array}$ & $\begin{array}{l}\text { Amaturá, Benjamin Constant, Fonte Boa, } \\
\text { Jutaí, Santo Antônio do Içá, São Paulo de } \\
\text { Olivença, Tabatinga e Tonantins. }\end{array}$ & 12 & $\begin{array}{l}\text { Quinta, } \\
\text { sábado e } \\
\text { domingo }\end{array}$ \\
\hline Juruá & Carauari e Juruá. & 5 & $\begin{array}{l}\text { Sábado e } \\
\text { terça }\end{array}$ \\
\hline Purus & Canutamã, Lábrea e Tapauá. & 6 & $\begin{array}{l}\text { Quartas } \\
\text { e } \\
\text { sábados }\end{array}$ \\
\hline Manaus & $\begin{array}{c}\text { Autazes, Careiro da Várzea, Careiro e } \\
\text { Manaquiri. }\end{array}$ & 4 & $\begin{array}{l}\text { Segunda } \\
\text { e sexta. }\end{array}$ \\
\hline Parintins & $\begin{array}{c}\text { Barreirinha, Boa Vista do Ramos, Maués, } \\
\text { Nhamundá, Parintins, São Sebastião do } \\
\text { Uatumã e Urucará. }\end{array}$ & 9 & $\begin{array}{l}\text { Segunda } \\
\text { a } \\
\text { domingo }\end{array}$ \\
\hline Itacoatiara & $\begin{array}{c}\text { Itacoatiara, Itapiranga, Nova Olinda do } \\
\text { Norte, Silves e Urucurituba. }\end{array}$ & 7 & $\begin{array}{l}\text { Segunda } \\
\text { a sábado }\end{array}$ \\
\hline $\begin{array}{l}\text { Boca do } \\
\text { Acre }\end{array}$ & Boca do acre. & 2 & $\begin{array}{l}\text { Terça e } \\
\text { sábado }\end{array}$ \\
\hline Coari & $\begin{array}{l}\text { Anamã, Anori, Beruri, Caapiranga, Coari e } \\
\text { Codajás. }\end{array}$ & 7 & $\begin{array}{l}\text { Quarta a } \\
\text { sábado }\end{array}$ \\
\hline Tefé & Alvarães, Tefé, Uarini & 6 & $\begin{array}{l}\text { Quarta e } \\
\text { sexta }\end{array}$ \\
\hline Japurá & Japurá, Maraã & 2 & Sexta \\
\hline Madeira & $\begin{array}{c}\text { Apuí, Borba, Humaitá, Manicoré, Novo } \\
\text { Aripuanã }\end{array}$ & 8 & $\begin{array}{l}\text { Terça, } \\
\text { quinta e } \\
\text { sexta }\end{array}$ \\
\hline Rio Negro & $\begin{array}{l}\text { Barcelos, São Gabriel da Cachoeira, Santa } \\
\text { Isabel do Rio Negro e Novo Airão }\end{array}$ & 16 & $\begin{array}{l}\text { Terça, } \\
\text { quarta e } \\
\text { sexta }\end{array}$ \\
\hline
\end{tabular}

Fonte: Dados obtidos na pesquisa, 2021.

Como informação adicional, o processo de precificação para as mercadorias nas embarcações é dado pelo volume que a mesma ocupa no seu meio, independentemente de seu peso ou material. Muitos barcos se utilizam dessa metodologia de cobrança pelo espaçamento de sua embarcação, ou seja, quanto maior o espaço a ser ocupado pela encomenda, maior será o preço de seu transporte. 
Diante de todos os aspectos acima expostos, foi criada a interface do website do projeto, ilustrada na Figura 1. A página inicial solicita informações ao usuário como: o local de onde a encomenda será enviada, o destino da encomenda e o dia que o usuário deseja fazer o envio. Ao preencher as informações necessárias, o usuário dá continuidade, de forma que o banco de dados do website, implementado com as informações necessárias, dará o feedback ao usuário sobre quais barcos estarão disponíveis.

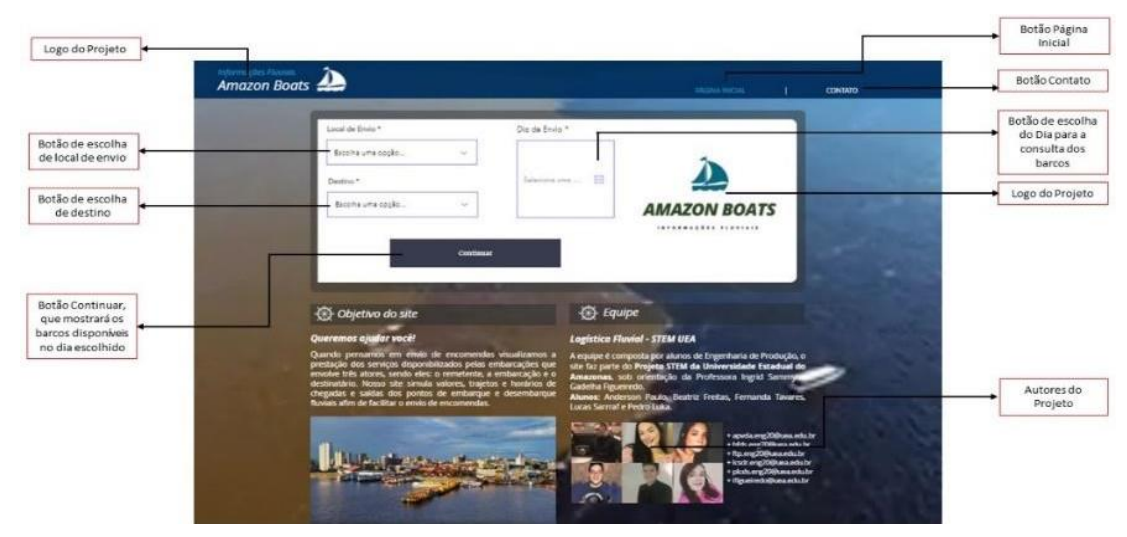

Figura 1. Interface criada para o website.

Fonte: Autores, 2021.

\section{CONSIDERAÇÕES FINAIS}

A plataforma tecnológica desenvolvida neste projeto em um website traz recursos que podem auxiliar o usuário que necessita do transporte fluvial de encomendas para o interior do estado do Amazonas. Nesse sentido, o acesso as informações necessárias para a logística das encomendas a esses municípios podem ser facilmente consultadas por meio de um dispositivo móvel, garantindo ampliar a acessibilidade à informação, a redução de custos de deslocamentos e a perda de tempo dos usuários deste serviço, que são os maiores beneficiários da solução apresentada no presente projeto.

\section{REFERENCIAS}

AMAZONAS. Dados. Portal do Governo do Estado do Amazonas, Manaus, 2021. Disponível em: http://www.amazonas.am.gov.br/o-amazonas/dados/. Acesso em: 20 de set. 2021.

BALLOU, Ronald H. Gerenciamento da Cadeia de Suprimentos. $4^{\mathrm{a}}$ ed. Porto Alegre: Bookman, 2001. 
FLEURY, A.; FLEURY, M. T. L. Estratégias empresariais e formação de competências. São Paulo: Atlas, 2000.

GIL, A. C. Como Elaborar Projetos de Pesquisa. 6ae ed. São Paulo: Atlas, 2017.

SEPLANCTI. Amazonas em mapas. Manaus: DEPI, 2016. Disponível em: http:// http://www.sedecti.am.gov.br/. Acesso em 20 set. 2021. 


\title{
ENSINANDO DE PROGRAMAÇÃO USANDO PYTHON EJOGOS ELETRÔNICOS
}

\author{
Arthur Gustavo Paiva Carvalha' \\ Allef Dliveira Ramos' \\ Emanuel Henrique Dliveira Dias' \\ Josué Costa dos Santos Alves' \\ Matheus de Almeida Damgaard Nielsen' \\ Ronald Carvalho Boadana' \\ Jucimar Maia da Silva Jr'
}

1Escola Superior de Tecnologia (EST) - Universidade do Estado do Amazonas (UEA) CEP 69050-020 - Manaus - AM - Brasil agpc.eng20@uea.edu.br, aor.eng20@uea.edu.br, ehod.eng20@uea.edu.br, jcsa.eng17@uea.edu.br, mdadn.eng20@uea.edu.br, rcb.eng20@uea.edu.br, jjnior@uea.edu.br

\section{INTRODUÇÃO}

Ensinar arte de programar computadores é uma tarefa complexa pois exige do aprendiz uma disciplina de treinos e repetições constantes. São passadas listas de questões que deveriam ser desenvolvidas pelos alunos. Porém, na maioria das vezes, as questões não têm a ver com o mundo real do aluno e por isso são consideradas enfadonhas e trabalhosas. Os alunos simplesmente fazem porque são obrigados a ter uma nota. Isso leva desistência e o não-aprendizado. Não se sentem motivados. Em contrapartida há uma atividade que eles dedicam espontaneamente e alegremente horas e horas do seu tempo: jogar jogos eletrônicos.

Jogos eletrônicos são, na maioria das vezes, o primeiro contato de um jovem com o computador. Esse contato se dá por meio de smartphones, consoles ou computadores pessoais ${ }^{1}$. 0 jovem então passa a dedicar bastante tempo a atividade de jogar. Isso ocorre porque os jogos são projetados para incentivar o jogador a

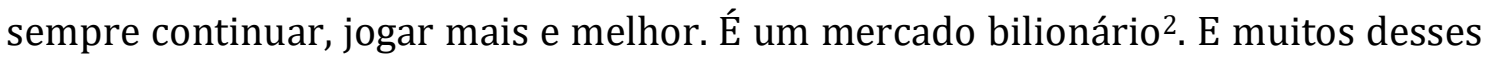
jogadores tem a vontade de entender como os jogos são feitos e, principalmente, criar seus próprios jogos. Utilizando-se esse desejo, é possível incentivar os alunos

1 https://olhardigital.com.br/2019/07/05/noticias/segundo-pesquisa-83-dos-brasileiros-usamsmartphone-para-jogar/

2 https://epocanegocios.globo.com/Empresa/noticia/2019/06/mercado-de-games-deve-gerarreceita-de-us-152-bilhoes-em-2019.html 
a aprender programação se ao invés de listas de questões, eles aprendessem a desenvolver seus próprios jogos.

\section{OBJETIVOS}

O objetivo deste projeto é ensinar programação e técnicas de engenharia de software aos alunos fazendo que eles apliquem isso no desenvolvimento de jogos.

\subsection{OBJETIVOS ESPECÍFICOS}

- Ensinar boas práticas de programação em Python

- Ensinar boas práticas em desenvolvimento de jogos

- Ensinar boas práticas de Engenharia de Software

- Ensinar desenvolvimento de software em equipe

- Desenvolver 3 (três) jogos em Python

\section{MATERIAIS E MÉTODOS}

Nesta seção é descrita como o trabalho foi desenvolvido.

\subsection{MATERIAIS}

Neste projeto foram utilizados:

- Python $3.9^{1}$ - Linguagem de programação de alto nível adotada por ser simples, os alunos já terem alguma familiaridade e possuir bibliotecas gráficas que ajudam no desenvolvimento

- Turtle - Biblioteca python usada para desenhar

- PyGame ${ }^{2}$ - Biblioteca python criada para o desenvolvimento de jogos

- Linux - Sistema operacional usado por programadores python. É o sistema operacional padrão usado nas universidades para ensinar programação.

- Git/Github ${ }^{3}$ - Sistema de controle de versão. É um sistema que auxilia o programador a gerenciar o código-fonte de seu projeto.

- PyCharm - Ambiente de desenvolvimento python voltado para produtividade do programador

\footnotetext{
${ }^{1}$ https://www.python.org/

2 https://www.pygame.org/

3 https://github.com/
} 


\subsection{MÉTODOS}

Os jogos escolhidos foram jogos estilo fliperama (árcade) por serem mais simples de desenvolver e aplicar as ferramentas escolhidas

\section{Pong}

O primeiro jogo desenvolvido foi o Pong [Atari, 1972]. A primeira versão foi criada em Turtle para explicar a aplicação das ferramentas, boas práticas de programação, rastreamento e consertos de erros (bugs). Uma segunda versão do Pong foi desenvolvida em PyGame para mostrar o uso da biblioteca, como ela é mais produtiva que o Turtle e sua aplicação com técnicas de engenharia de software. Uma função que controlava o adversário e simulava uma inteligência artificial também foi criada.

\section{Snake}

O jogo Snake ${ }^{1}$ consiste em uma cobra que deve comer o máximo possível de frutas e foi muito famoso nos smartphones. Para esse jogo, os alunos aprenderam a gerenciar seus códigos-fonte usando Git/Github. Após foram desenvolvidas 3 versões: Snake1 desenvolvida desde o zero. Snake2, desenvolvida utilizando técnicas de programação modular. Snake3, desenvolvida usando técnicas de Programação Orientada a Objetos e Design Patterns [Design Patterns, 2021].

\section{Asteroids}

O jogo Asteroids [Atari, 1979] foi muito popular nos fliperamas e requer técnicas mais avançadas. Os alunos aprenderam a criar o Documento de Projeto de Jogos $^{2}$ (Game Design Document -GDD). Esse documento permite separar o jogo em partes conhecidas como mecânicas. Cada mecânica é então especificada o que facilita o planejamento e o desenvolvimento. 0 jogo foi desenvolvido usando todas as técnicas aprendidas anteriormente.

\section{RESULTADOS}

Os resultados do projeto foram alcançados: os alunos aprenderam a programar melhor programando jogos. A Figura XXXX mostra o jogo Asteroid

\footnotetext{
1 https://en.wikipedia.org/wiki/Snake_(video_game_genre)

2 https://en.wikipedia.org/wiki/Game_design_document
} 
funcionando. Os código-fontes podem ser acessados no repositório: https://github.com/LUDUS Lab/stem-games.

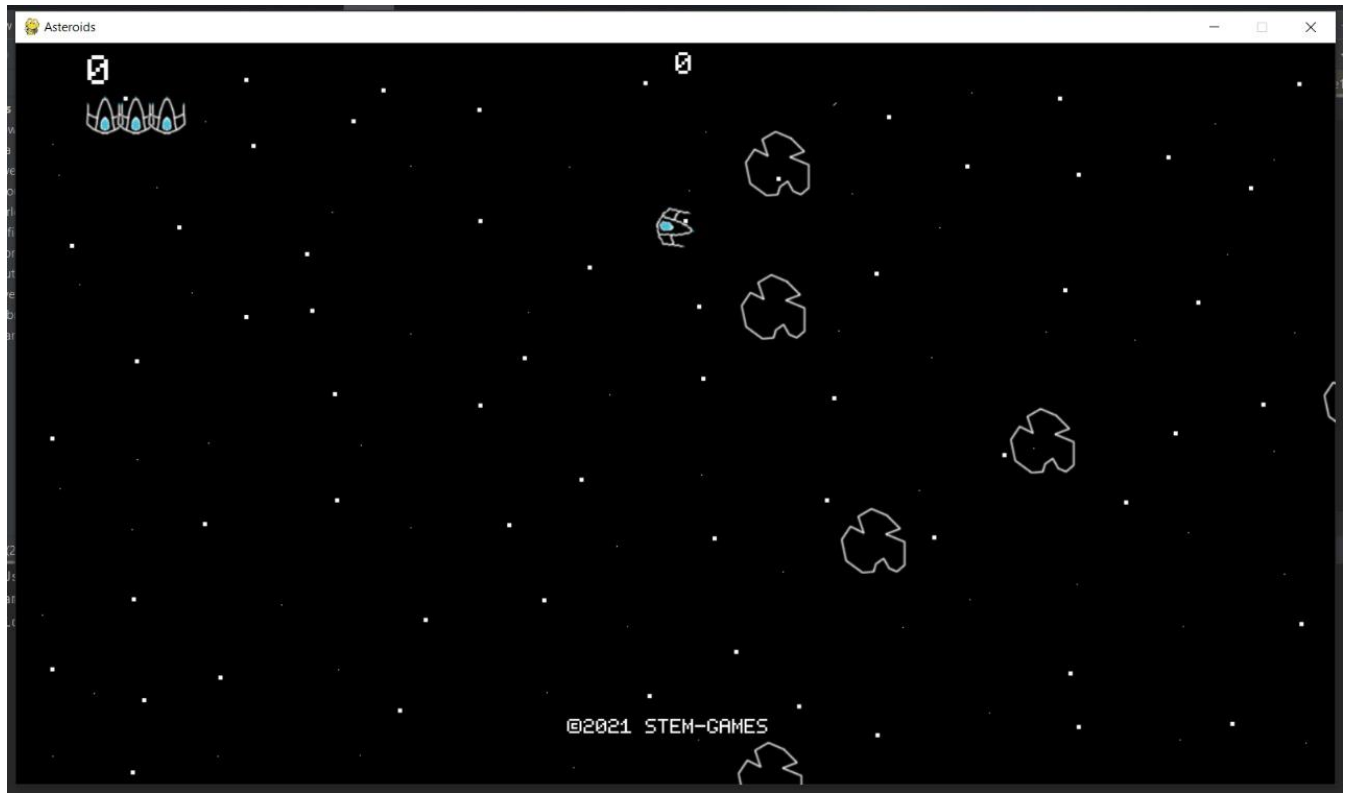

\section{CONCLUSÃO}

Ensinar programação usando jogos melhorou a motivação dos alunos. Eles trabalharam com compromisso e zelo pois todos queriam ver seus jogos funcionando. Técnicas e ferramentas foram inseridas no processo de desenvolvimento e absorvidas pelos desenvolvedores, algo bastante complicado se usado no método convencial de listas de questões.

O projeto foi útil não só para a evolução profissional dos alunos na área de tecnologia, como também foi um grande auxílio a assuntos abordados em períodos mais avançados nos cursos que tem a programação com um de seus fundamentos. Não somente, como também o projeto deu uma base sólida para todos aqueles que estão determinados a ingressar no mercado de jogos eletrônicos.

É notável o incentivo à socialização, baseado nas atividades realizadas em grupo, algo que é fundamental para todo profissional não só do ramo da engenharia e tecnologia como de qualquer área, pois a comunicação é fundamental para que os trabalhos sejam desenvolvidos da melhor forma possível. 0 projeto demonstrou com êxito como o desenvolvimento de jogos pode ser simples, desmistificando e respondendo diversas dúvidas que permeiam a área. 
Uma sugestão para trabalhos futuros seria a utilização de novos jogos para ensinar outras tipos de software (ex. sistemas distribuídos).

\section{REFERÊNCIAS BIBLIOGRÁFICAS}

Design Patterns. Refactoring Guru: Design Patterns (2021). Disponível em: $<$ https://refactoring.guru/design-patterns $>$. Acesso em 22 de setembro de 2021.

Table of Contents. Game Programming Patterns (2021). Disponível em: < gameprogrammingpatterns.com/contents.html >. Acesso em 22 de setembro de 2021.

Atari (1972). Disponivel em :< https://pt.wikipedia.org/wiki/Pong>. Acesso em 22 de setembro de 2021.

Atari

(1979).

Disponivel

em

$:<$

https://en.wikipedia.org/wiki/Asteroids_(video_game) >. Acesso em 22 de setembro de 2021. 


\section{LOGÍSTICA DE VENDAS DE PRODUTOS DE SUPERMERCADO EM MANAUS (AM)}

Jones Rubens Batista Façanha'

Lenara Ramires dos Reis ${ }^{1}$

Nicole Vicente Russo'

Yasmim de Souza Costa'

Arlen Ricarda Melgueiros Nunes'

Rejane Gomes Ferreira'

Carly Pinheiro Trindade'

${ }^{1}$ Escola Superior de Tecnologia (EST) - Universidade do Estado do Amazonas (UEA) CEP 69050-020 - Manaus - AM - Brasil jrbf.eng20@uea.edu.br, lrdr.eng20@uea.edu.br, nvr.eng20@uea.edu.br,ydsc.eng20@uea.edu.br, armn.eng20@uea.edu.br, rejane@uea.edu.br, ctrindade@uea.edu.br

\section{INTRODUÇÃO}

A tecnologia da informação desempenha um papel cada vez mais relevante na sociedade, levando os indivíduos de qualquer lugar a interagirem com os dispositivos móveis e a tomar decisões mais exatas (OSSUNA; PUGAS, 2018). Em especial no momento atual, a tecnologia ganhou destaque, quando desde o início do ano de 2020 a pandemia COVID-19, demandou que novos modelos de negócios fossem pensados, visando a melhoria da competitividade e a oportunidade de satisfazer de forma mais fácil às necessidades dos clientes.

A logística é um termo que surgiu há décadas, no período das grandes guerras, quando os generais estabeleciam estratégias para que seus oficiais tivessem mantimentos e armamentos, com objetivo de atacar os seus inimigos. A logística integra planejamento, transporte, armazenagem entre outros, para a disponibilização de bens e serviços aos consumidores, desde a origem até o consumo (MENEZES, 2012). Também é um campo de pesquisa e que precisa ser considerado pelas organizações, frente à globalização.

Então, diante dessa possibilidade de contribuir para o conhecimento da logística de vendas de produtos de supermercados em Manaus, desenvolveu-se um estudo com a finalidade de compreender melhor o comércio eletrônico de produtos de supermercado e a logística de vendas desses produtos, identificando os desafios enfrentados e as oportunidades. 


\section{OBJETIVOS}

\subsection{GERAL}

Compreender a logística de vendas de produtos de supermercados no comércio eletrônico em Manaus.

\subsection{ESPECIFICOS}

- Verificar a logística de vendas de artigos de supermercados no comércio eletrônico;

- Analisar o funcionamento desse tipo de serviço e identificar os desafios e oportunidades;

- Elaborar um panorama da venda de itens de "supermercado" via comércio eletrônico;

\section{MATERIAIS E MÉTODOS}

Foi desenvolvido um estudo qualitativo-quantitativo descritivo do tipo exploratório durante o período de março a agosto de 2021, baseado na observação e coleta de dados publicados na internet por organizações/empresas. A pesquisa descritiva tem como característica a descrição de características de uma determinada população (GIL, 2017) e diversas técnicas podem ser empregadas para a coleta de dados. 0 estudo limitou-se ao ambiente $w e b$, tendo em vista o momento de pandemia causada pelo Covid-19.

A primeira etapa deste trabalho consistiu em uma pesquisa bibliográfica e foram consultados artigos sobre a logística de vendas no comércio eletrônico, ferramentas da $w e b$, vantagens e desvantagens deste modelo de negócio. Para o cumprimento desta etapa, foi realizado o levantamento em sites dos periódicos CAPES (Coordenação de Aperfeiçoamento de Pessoal de Nível Superior.), Scielo, Repositórios de Universidades sobre a temática do projeto.

Na segunda etapa da pesquisa foi realizada a coleta de dados por meio da web e empregadas as palavras-chave aplicativo+supermercado+manaus e site+supermercado+manaus, visando captar conteúdo importante gerado por sites e aplicativos, e público em atividades de interação com as empresas atuantes em Manaus. Utilizou-se como meio de registro e apresentação dos dados uma planilha em Excel. 


\section{RESULTADOS}

Foram identificadas na pesquisa 19 empresas que comercializam produtos de supermercado via e-commerce. Verificou-se um certo equilíbrio quanto às empresas que usam somente o site e outras só o aplicativo. E ainda existe a preferência em utilizar as duas plataformas no caso site e aplicativo em simultâneo, com objetivo de alcançar mais o usuário. Na Tabela 1 estão representados os tipos de vínculos que as empresas utilizam na web.

Tabela 1. Preferência das empresas no ambiente web e o tipo de serviço.

\begin{tabular}{c|c|c|c|c}
\hline \multirow{2}{*}{$\begin{array}{c}\text { Típo de } \\
\text { vínculo no } \\
\text { ambiente } \\
\text { Web }\end{array}$} & $\begin{array}{c}\text { Comercializaç } \\
\text { ão/entrega } \\
\text { (própria) }\end{array}$ & $\begin{array}{c}\text { distribuição/e } \\
\text { ntrega } \\
\text { (terceirizada) }\end{array}$ & $\begin{array}{c}\text { divulgação } \\
\text { online de } \\
\text { ofertas }\end{array}$ & $\begin{array}{c}\text { Quantidade } \\
\text { de empresas }\end{array}$ \\
\hline Site & 3 & 0 & 3 & 6 \\
\hline Aplicativo & 3 & 1 & 2 & 6 \\
\hline $\begin{array}{c}\text { Site e } \\
\text { aplicativo }\end{array}$ & 2 & 5 & 0 & 7 \\
\hline Total & 8 & 6 & 5 & 19 \\
\hline
\end{tabular}

Fonte: Dados dos autores, 2021.

Sobre o tipo de serviço prestado, verificou-se que a maioria das empresas pesquisadas prestam os serviços de comercialização e entrega própria, ou seja, a empresa é a própria fornecedora e distribuidora dos seus produtos. A segunda opção mais utilizada é a terceirizada, onde a empresa contrata os serviços de outra companhia que detém a responsabilidade da distribuição das mercadorias do contratante. A divulgação online em folhetos digitais de ofertas é a alternativa pouco buscada devido ao baixo investimento e retorno.

Verificou-se que as Empresas Demais (Médio e Grande Porte) lideram no ecommerce (Tabela 2). Notou-se a baixa participação das pequenas empresas nessa área, principalmente no uso do aplicativo. 
Tabela 2. Distribuição das empresas quanto ao porte.

\begin{tabular}{|c|c|c|c|c|}
\hline Porte da empresa & Site & Aplicativo & $\begin{array}{c}\text { Site e } \\
\text { Aplicativo }\end{array}$ & Total \\
\hline $\begin{array}{c}\text { Empresa Demais } \\
\text { (Médio e Grande } \\
\text { Porte) }\end{array}$ & 3 & 4 & 4 & 11 \\
\hline $\begin{array}{c}\text { Empresa de Pequeno } \\
\text { Porte (EPP) }\end{array}$ & 1 & 0 & 1 & 2 \\
\hline Microempresa (ME) & 2 & 2 & 2 & 6 \\
\hline Total & 6 & 6 & 7 & 19 \\
\hline
\end{tabular}

Fonte: Dados dos autores, 2021.

A maioria das empresas utiliza dois tipos de entrega: o delivery e a retirada no balcão. As formas de pagamento são variadas e consumidor também tem a opção de realizar o pedido online e o pagamento é feito através do link enviado pela empresa.

Como ponto positivo, verificou-se que os aplicativos prezam pela qualidade de seus produtos na hora da entrega e empregam estratégias de venda para o consumidor realizar a compra online, sendo: promoções, programas de recompensa, cashback, etc., visto que a maioria teve uma avaliação considerada boa. Ainda destaca-se a praticidade dos apps no rápido atendimento e entrega dos produtos e o acompanhamento pelo usuário em tempo real.

Como pontos negativos tem-se os altos preços e taxas de pagamento dos produtos e atualizações dos seus estoques e falhas no sistema. Dentre as avalições dos usuários, nenhuma das empresas teve avaliação ruim.

De acordo o levantamento feito pela SBVC (Sociedade Brasileira de Varejo e Consumo) as compras por meio virtual tiveram crescimento de $70 \%$. Conforme a SBVC $60 \%$ das pessoas que compraram, foram idosos acima de 60 anos e desses, 18\% compraram pela primeira vez na pandemia (E-COMMERCE BRASIL, 2020). Segundo o relatório da Mastercard SpendingPulse, o e-commerce brasileiro apresentou um crescimento de $75 \%$ em 2020 se comparado ao ano anterior, isso se deu, sobretudo, após o isolamento social. 


\section{CONSIDERAÇÕES FINAIS}

O e-commerce está em alta e durante a pandemia teve um crescimento significativo em vários segmentos, principalmente no varejo. As empresas precisaram se reinventar para não fecharem as portas diante do novo cenário, então optaram pelo investimento no comércio eletrônico.

As altas taxas cobradas aos comerciantes e consumidores tem inviabilizado o acesso de mercadinhos, quanto então as grandes redes acabam dominando o comércio eletrônico. Nesse estudo, evidenciou-se a importância das plataformas eletrônicas e o celular se mostrou o meio mais eficaz para a venda de produtos em mercadinhos nos bairros.

A recomendação oriunda deste estudo é do atendimento a alguns requisitos básicos do e-commerce, como o acesso ao estabelecimento mais próximo, a rapidez na entrega, o feedback ao cliente, a qualidade dos produtos fornecidos, a assistência ao cliente, o acompanhamento em tempo real da entrega. Ainda dentro desse aspecto, o marketing local via redes sociais poderia ser um diferencial para a fidelização de clientes e incremento nas vendas. A logística de entrega ainda se mostra deficiente, pois para algumas localidades não há rotas disponíveis.

\section{REFERÊNCIAS BIBLIOGRÁFICAS}

OSSUNA, V. S.; PUGAS, M. A. R. A percepção dos clientes de uma empresa de grande porte quanto à usabilidade do aplicativo de cartão no município de Rondonópolis-MT. Repad Revista Estudos e Pesquisas em Administração, Rondonópolis, v. 2, n. 3, 2018. Disponível em: https://periodicoscientificos.ufmt.br/ojs/index.php/repad/article/view/7 770/5228. Acesso em: 29 jan. 2021.

GIL, A. Como elaborar projetos de pesquisa. 6. ed. São Paulo: Atlas, 2009.

Sociedade Brasileira de Varejo e Consumo. COVID-19: 61\% DOS CONSUMIDORES AUMENTARAM VOLUME DE COMPRAS ONLINE. SBVC Sociedade Brasileira de Varejo e Consumo. São Paulo. 2020. Disponível em: http://sbvc.com.br/consumidores-aumentaram-compras-online/. Acesso em: 11 ago. 2021. 
E-COMMERCE - DESAFIOS NO CENÁRIO MANAUARA

\author{
Hadassa Ribeiro Feitosa \\ Jaãa Victor Pessoa Da Silva \\ Katarina Jeovana Ferreira Moura \\ Marcos Vinicius Dutra Saares \\ Thiago Narciso Edwards Mesquita \\ Carly Pinheiro Trindade \\ Rejane Gomes Ferreira.
}

Escola Superior de Tecnologia (EST) - Universidade do Estado do Amazonas (UEA) CEP 69050-020 - Manaus - AM - Brasil hrf.eng20@uea.edu.br, jvpds.eng20@uea.edu.br ,kjfm.eng20@uea.edu.br, mvds.eng20@uea.edu.br, tnem.eng20@uea.edu.br.

\title{
1. INTRODUÇÃO
}

Em meados dos anos 90, a internet no Brasil foi desenvolvida através dos serviços de rede no país, isto possibilitou novas formas de trocas de informações entre as pessoas. Posteriormente iniciaram-se as vendas online, tornando ainda mais popular essa prática no Estado. Uma década à frente, o "boom da internet" chegou em Manaus e vem revolucionando a sociedade manauara desde então, o que levou ao desenvolvimento do e-commerce no município, embora muitas empresas ainda estejam receosas sobre a viabilidade desta nova modalidade.

Em Manaus o Produto Interno Bruto tem se mantido em constante crescimento, inclusiveem 2020, período de recessão econômica devido a pandemia da covid-19. Calcula-se queentre março e maio 670 empresas fecharam as portas no Amazonas (Junta Comercial doEstado do Amazonas), neste período a solução para minimização dos danos econômicos foi o comércio virtual que proporcionou o aumento do fluxo de vendas em 0,04\%. Ampliando o mercado consumidor pois, mesmo aqueles mais resistentes a compra de produtos por meios digitais se viram obrigados a aderir a esta modalidade de comércio.

\section{OBJETIVOS}

Este trabalho tem como objetivo geral descrever o desenvolvimento do ecommerce na capital do Amazonas, e como objetivos específicos compreender o 
fluxo de compras pormeios digitais na cidade de Manaus, descrever os problemas enfrentados no e-commercena região, bem como analisar a viabilidade da criação de uma solução para acessibilidadede micro e pequenos comerciantes locais a uma plataforma de comércio digital.

\section{MATERIAIS E MÉTODOS}

O Amazonas é o segundo estado mais rico da região Norte do Brasil. A economia amazonense é diversificada, composta por polos agropecuários, indústrias e setor terciário, que é responsável pela metade da economia do estado.

Segundo o IBGE, o PIB de Manaus, capital do estado e município com maior economia;entre 2010 e 2018 apresentou contínuo crescimento. Pesquisa:

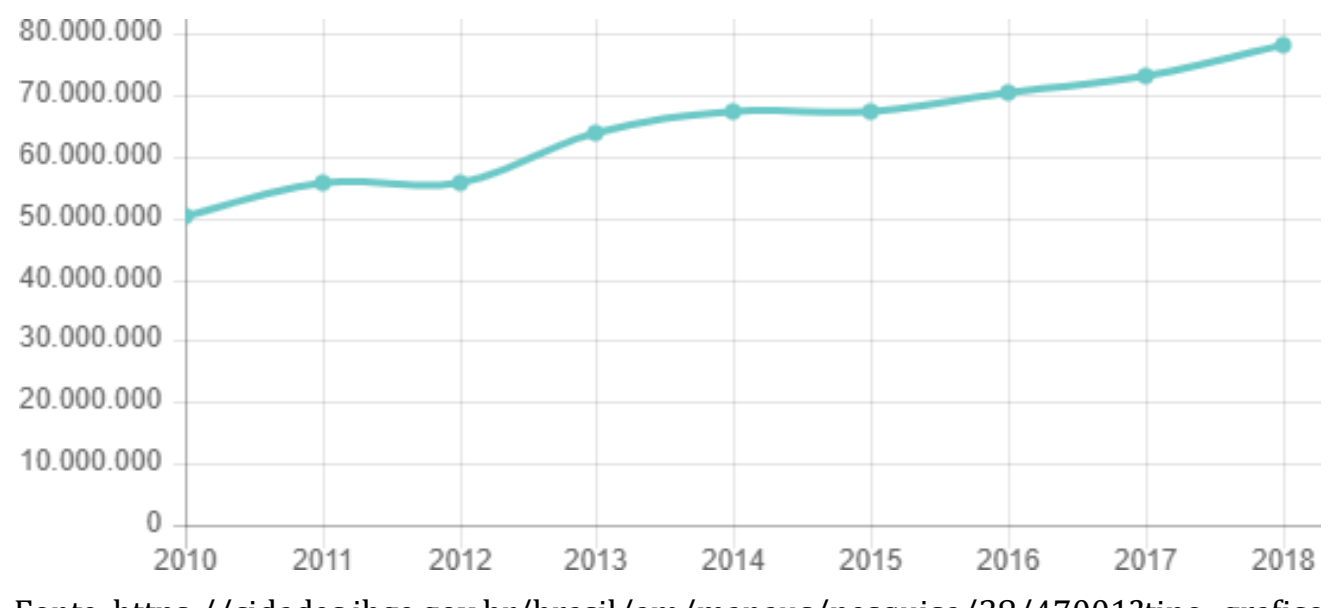

Fonte: https://cidades.ibge.gov.br/brasil/am/manaus/pesquisa/38/47001?tipo=grafico

Em 2020, ano em que as expectativas econômicas para o estado do Amazonas eram positivas devido realização das Olimpíadas, a Pandemia da Covid-19 forçou uma estagnação econômica principalmente para o setor terciário. Considerando a edição do Decreto n⿳0 42.061, de 16 de março de 2020, que "Dispõe sobre a decretação de emergência na saúde pública do Estado do Amazonas, em razão da disseminação do novocoronavírus (2019-nCoV), e institui o Comitê Intersetorial de Enfrentamento e Combateao COVID-19."; o Art. 2º deixou suspenso, pelo prazo de 15 (quinze) dias, o funcionamento de todos os estabelecimentos: comerciais, de serviços não essenciais, lazere recreação. Contudo, o decreto não perdurou apenas 15 dias, mas, 11 meses (com algumas poucas exceções quando a situação na saúde pública melhorava). 
Com o fechamento de escolas, shopping centers, academias de esportes, bares e restaurantes, salões de beleza e muitos outros, o mercado viu-se obrigado a encerrar suas atividades ou adotar um novo modelo de empreender. Quase simultâneo a todo esse acontecimento, o e-commerce, ou comércio eletrônico, que se refere aos negócios que estruturam seu processo de compra e venda na Internet cresceu em 75\% no estado do Amazonas.

No Brasil temos registros do primeiro e-commerce de uma grande livraria em 1996, contudo no Amazonas o acesso à internet foi mais lento; em 2018, por exemplo, o IBGEapontou que uma a cada cinco casas no Amazonas não tinham acesso a internet por falta de cobertura. Ainda assim, o acesso tem aumentado gradativamente, 0 programa federalWi-fi Brasil, por exemplo, tem colaborado para que no Amazonas, todos os 62 municípios contem com conexão gratuita. Em setembro de 2021 já são 800 pontos de internet instalados, assegurando conectividade para quem mais precisa: 443 antenas estão situadasem localidades rurais, distantes da sede municipais.

Dessa maneira, a progressão do $e$-commerce da região Norte teve crescimento expressivode $86,34 \%$, em julho de 2020 , frente ao mesmo período do ano passado. O faturamento do setor, na mesma base de comparação, também teve alta: 117,38\%. Os dados são do índice MCC-ENET, levantamento desenvolvido pelo Comitê de Métricas da Câmara Brasileira de Comércio Eletrônico (camara-e.net) em parceria com o Movimento Compre\& Confie.

Em 2021 o Amazonas foi o estado que mais aumentou as vendas por $e$ commerce em fevereiro, segundo a analista e jornalista Vanessa Lemes, devido a pandemia, comerciantes manauaras encontraram nas vendas online a solução para não ficarem no prejuízo. Por meio dessa estratégia, os lojistas tiveram um crescimento de $463 \%$ no rendimento deste ano, em relação ao mesmo período de 2020. Na pesquisa realizada com400 pessoas que moram no Amazonas, 93,5\% já havia realizado compras pela internet etodas conheciam alguém que fez.

No país, o Amazonas apareceu como o estado com maior aumento nas vendas virtuais, segundo pesquisa feita pela plataforma Nuvemshop. Ainda assim, pequenos empresários da capital afirmam que, mesmo com o resultado positivo no ecommerce, as vendas nas lojas físicas continuam em primeiro lugar; as principais 
insegurança no público amazonense com as compras virtuais é a entrega, confiabilidade e qualidade do produto,e golpe.

Avaliação semelhante é a do presidente da Câmara de Dirigentes Lojistas de Manaus (CDL Manaus), Ralph Assayag. Segundo ele, o e-commerce realmente ainda não consegue superar as vendas físicas. "Quando falam de 463\% parece muito, mas esse percentual é pouco em relação a venda de uma loja física. Porém, claro que qualquer crescimento é válido, ainda mais em meio à pandemia”, pontua. 0 segundo trimestre de 2020, a tradicional varejista viu o chamado "e-commerce caboclo" vender dez vezes mais se comparado a 2019. Tudo isso movido ao crediário financiado pela própria Bemol, empresa amazonense criadora da plataforma.

0 e-commerce é uma realidade nos mais diversos setores da economia. Sua assimilação e utilização tornaram-se parte da estratégia das empresas (ALBERTIN, 2012). Home page e e-mail são as aplicações mais comuns entre uma grande parte das empresas consolidadas. A tendência é buscar aplicações mais estruturadas (ALBERTIN, 2012). É possível analisar que no Amazonas há uma preocupação da parte consumidores pelo preço do frete; tendo em vista que é a região de mais difícil acessibilidade por sua posiçãogeográfica, muitas vezes o preço do frete é maior que do próprio produto pois é exigido maior investimento no transporte. Hoje, já existem voos fretados para garantir que os produtos cheguem mais rápido, que é a segunda prioridade dos consumidores, contudo nem sempre é garantido um preço justo.

Por outro lado, vemos que $72 \%$ da amostra costuma fazer compras em mais de um site. Para as empresas, o compartilhamento de plataformas e estratégias com os concorrentes é classificada como um ponto positivo e negativo. Para uma empresa entrante, essa facilidade de informações é um efeito benéfico pois agrega dados sobre o mercado. Para uma empresa já estabelecida, no entanto, suas estratégias tornam-se mais facilmente copiadas, reduzindo suas vantagens perante as demais. Já para os consumidores traz mais praticidade e facilidade, pois na ferramenta e-commerce pode-se reunir os mais variadosprodutos, além disto, há a redução dos preços e a comparação é facilitada. Um dos efeitosnegativos é que o preço se torna passa a ser o fator mais importante nas buscas, comprovando isso na pesquisa. 
0 ambiente online, permite que as relações cliente-empresa e empresafornecedores sejam melhor exploradas. É inegável que o mercado da internet influencia todos os mercados e empresas que busam se tornar ou permancer competitivas. Segundo a pesquisa realizada pelo Ziriga, as melhores plataformas para conseguir vender na internetsão: Facebook, Instagram e Tiktok. Plataformas de interação que se tornaram canais propícios ao marketing e que vem se atualizando também com ferramentas para vendas de pequenos à médios empreendedores.

\section{RESULTADOS}

A pesquisa feita com 400 pessoas de diferente sexo, idade, grau de escolaridade e municípios do Amazonas; traz a análise de que 72\% da amostra faz compras em mais deum site, isto e os demais dados apresentados nos materiais e métodos comprovam que a criação de um amplo comércio virtual é viável no Amazonas. Assim também podemos ver nos gráficos:

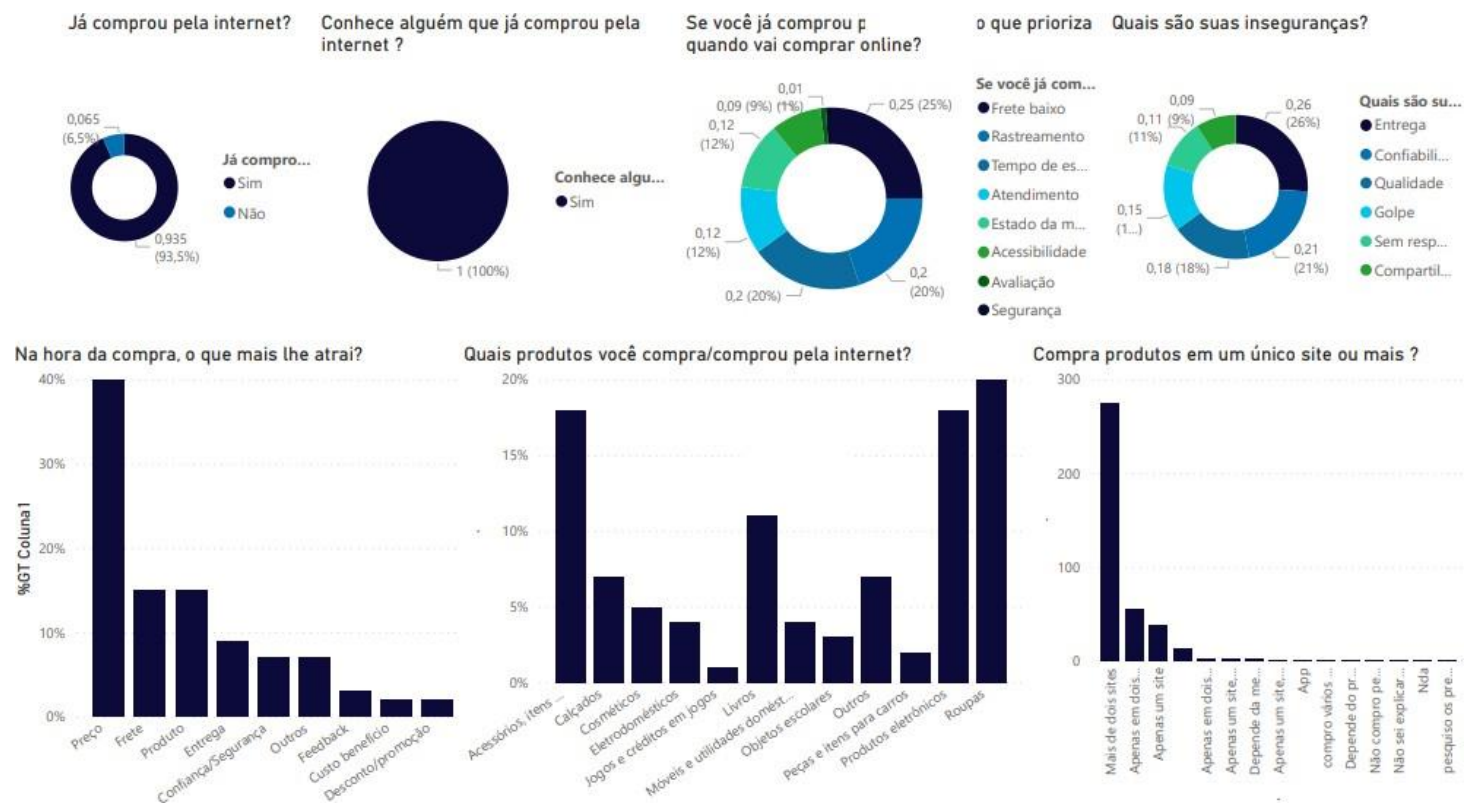

\section{CONCLUSÃO}

Tendo em vista a pesquisa apresentada, fica evidente que os impactos econômicos da pandemia da Covid-19 na região Norte desencadearam a adaptação forçada dos empreendedores a novos meios de vendas. Isto tornou notório que hoje, o caminho promissor para acessibilidade nas vendas é o mercado digital. Além disso, vemos que o e-commerce tem parcela de participação crescente no 
desenvolvimento da economia do setor terciário. Grandes empresas locais já identificaram que para garantir o espaço e crescimento dos negócios é necessário acompanhar as exigências do mundo moderno e pós pandêmico.

Em Manaus, empresas de micro e pequeno porte ainda não utilizam de plataformas digitais por falta de conhecimento ou de condições financeira. Isto torna conclusivo que é viável a criação de uma solução para estes pequenos e microempreendedores através de uma ampla plataforma de comércio digital. Conforme visto nos resultados da pesquisa, roupas, produtos eletrônicos e acessórios são os itens de massiva compra pela internet devido maior custobenefício; portanto, projetamos uma plataforma que possa unir a venda destes produtos a partir de empresários locais. Isto pode gerar benefícios econômicos ao público consumidor e vendedor, além de fortalecer a economia manauaracom uma nova referência de circulação monetária.

\section{REFERÊNCIAS BIBLIOGRÁFICAS}

ALBERTIN, Luiz Alberto. O mercado eletrônico evolui e consolida-se no mercado brasileiro. Comércio eletrônico: situação atual e tendências, São Paulo, v.40, n.4, p.94- 102 - Out./Dez. 2000. Disponível em: $<$ https://www.scielo.br/j/rae/a/th5K7bhggkX4CjbgG7CjhTb/?format=pdf\& lang=pt>, acesso em: 03 Ago de 2021.

MENDES, Laura Zimmermann Ramayana. E-commerce: origem, desenvolvimento e perspectivas. Lume Repositório Digital. 2013. Disponível em: < https://www.lume.ufrgs.br/bitstream/handle/10183/78391/000899483.p df?sequence $=1 \&$ isAllowed=y $>$, acesso em: 28 Mai de 2021

FRAZÃO, André. O IMPACTO DA COVID-19 SOBRE OS NEGÓCIOS EM MANAUS: A PERCEPÇÃO DO COMÉRCIO LOCAL. UEA, Manaus: Disponível em:<https://atlasodsamazonas.ufam.edu.br/images/Dados/PesquisaCOVID-19-UEA- download.pdf> Acesso em 05 de agosto de 2021.

VERDÉLIO, Andreia. Economia do Amazonas se acomoda em patamar ainda baixo (Contração de janeiro equivale à observada em abril de 2020). Agência Brasil, Brasília:

Disponível em:<https://agenciabrasil.ebc.com.br/economia/noticia/2021-

03/economia- do-amazonas-se-acomoda-em-patamar-ainda-baixo-diz-bc> Acesso em 03 de Junho de2021.

TOREZANI, Nathália. 0 crescimento do e-commerce no Brasil, E-commerceBrasil. Disponível em : $<$ https://www.ecommercebrasil.com.br/artigos/ocrescimento-do-e- commerce-no-brasil/> Acesso em 04 de agosto de 2021. 
FLEISCHMANN, Isabela. De ferry boat até as comunidades ribeirinhas: como a pandemia impulsionou o e-commerce da Bemol na Amazônia. LABS, Manaus: Disponível em: <https://labsnews.com/pt-br/artigos/negocios/como-apandemia-impulsionou-o-comercio-eletronico-da-bemol/> Acesso em $09 \mathrm{de}$ agosto de 2021.

GUIMARÃES, Cinthia. Crescimento do E- commerce na pandemia transforma o varejobrasileiro. Site Acrítica.com, Manaus: Disponível em:<https://www.acritica.com/channels/dinheiro/news/crescimento-doe-commerce-na- pandemia-transforma-o-varejo-brasileiro> Acesso em 09 de agosto de 2021. 


\title{
PLATAFORMA DE E-COMMERCE: MELICLOSET
}

\author{
Hadassa Ribeiro Feitosa \\ Jaão Victar Pessoa Da Silva \\ Katarina Jeovana Ferreira Moura \\ Marcos Vinicius Dutra Soares \\ Thiago Narciso Edwards Mesquita \\ Carly Pinheiro Trindade \\ Rejane Gomes Ferreira
}

Escola Superior de Tecnologia (EST) - Universidade do Estado do Amazonas (UEA) CEP 69050-020 - Manaus - AM - Brasil hrf.eng20@uea.edu.br, jvpds.eng20@uea.edu.br, kjfm.eng20@uea.edu.br, mvds.eng20@uea.edu.br, tnem.eng20@uea.edu.br.

\section{INTRODUÇÃO}

Em face do cenário atual do comércio manauara, foram desenvolvidas pesquisas no período de março de 2021, acerca do estado do comércio manauara com foco nos micros e pequenos empreendedores durante a pandemia da Covid-19. Observamos que a viabilidade da criação de uma plataforma para desenvolvimento do comércio eletrônico na cidade de Manaus é alta, em virtude das fragilidades apontadas em diversos aspectos comerciais e intensificados pela pandemia da Covid-19. Portanto, em equipe foi decidido criar uma plataforma online para auxiliar as compras e suportar novas formas de se fazer negócios na internet em Manaus, a plataforma meuCloset tem como meta ampliar as metodologias de venda dos pequenos e microempreendedores, indo para o meio digital que apresenta um grande crescimento nos últimos15 anos não só como na cidade de Manaus mas no mundo inteiro.

\section{OBJETIVOS}

Esse trabalho tem como objetivo geral a criação de uma plataforma digital de vendas online, afimde aproximar clientes aos pequenos e médios empreendedores manauaras, para proporcionar o aumento do fluxo de vendas, além de criar um ambiente organizado para desenvolvimento comercial manauara, através da simplificação das compras online visando aumento de acessos à plataforma por conta da acessibilidade e facilidade de compra. 
O trabalho tem como objetivos específicos, o estudo do mercado digital manauara e compreender suas exigências e suas abrangências, compilar os requerimentos de softwares para a elaboração da plataforma, além disso verificar qual os meios mais viáveis para construção do site de modo que seja compatível com os mais diversos dispositivos e navegadores mas também no estudo de desenvolvimento de hyperlinks para conversação da plataforma para com outras redes sociais, afim de que se possa gerir melhor os dados das empresas. A partir do armazenamento e vistoria de dados, a plataforma deve facilitar o marketing digital por meio da conversação com as redes sociais existentes. Com isso, o resultado será uma grande rede social de vendas, afim de aumentara visibilidade e criar novos laços entre os clientes e os comerciantes.

Desse modo, o trabalho reúne os métodos para criação da plataforma, além da estrutura em que o site será moldado, por conseguinte, destacam-se funcionalidades para plena execução dos objetivos internos do site.

\section{MATERIAIS E MÉTODOS}

Baseados nos dados apresentados no Resumo Expandido "E-commerce Desafios enfrentados no cenário Manauaras”, no qual abrange: pesquisas em sites, artigos, e o desenvolvimento de um formulário através do Google Formulário (realizado no período de março de 2021), pode-se ser feito a análise do cenário atual da cidade de Manaus e do Amazonas após os recentes eventos. Oformulário que teve a abrangência de 400 pessoas e contava com diversas perguntas acerca do ecommerce.

Através da criação de dashboards por meio do Power BI, enxerga-se os dados com mais clareza, analisando e moldando a plataforma por meio das informações coletadas pelo Google Formulário.Para criação do programa a plataforma escolhida foi a NING, uma plataforma online para criaçãode redes sociais, dentre as pesquisas realizadas sobre as expansões do site, o NING foi o melhor que incorporava o site, por seus métodos de criação e viabilidade de acesso.

A metodologia ficou centrada na análise dos dados obtidos através do formulário, com visualização em Power BI, e a construção do site ocorreu aos moldes das informações coletadas. 


\section{RESULTADOS}

Com o avançar da pandemia no globo, comerciantes de vários lugares no mundo sofreram com os impactos causados pela disseminação do vírus e medidas de lockdown e no Amazonas não foidiferente. Segundo a pesquisa realizada pelo curso de Ciências Econômicas da Escola Superior de Estudos Sociais da Universidade do Amazonas (ESO-UEA), com o apoio da Câmara dos Dirigentes Lojistas de Manaus (CDL-Manaus), pouco mais de 50\% dos estabelecimentos ficaram parcialmente paralisados, enquanto $34,5 \%$ paralisaram totalmente suas atividades. Houve então anecessidade de adaptação em meio a esse cenár :0/ das empresas mudaram suaforma de venda, adotando assim o e-cummerce.

Com base no questionário realizado no dia 3 de março de 2021, com 400 pessoas das zonas sul, centro e oeste da cidade de Manaus, foram obtidos dados que comprovam como o comércio eletrônico revolucionou e vem revolucionando as relações comerciais. Em virtude da coleta de informações é notório o interesse e afinidade da população para com o comércio eletrônico, no gráfico 1 aponta de cerca de $93 \%$ das pessoas já compraram alguma coisa pela internet. No gráfico2, o foco era identificar o que as pessoas mais priorizam em compras na internet.

Já comprou pela internet?

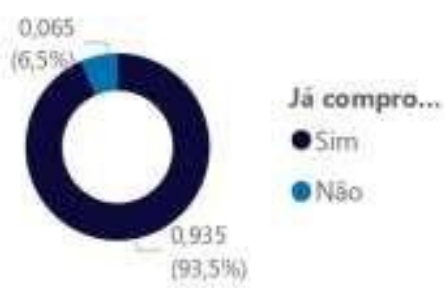

Gráfico 1
Se vocè já comprou pela internet, o que prioriza quando vai comprar online?

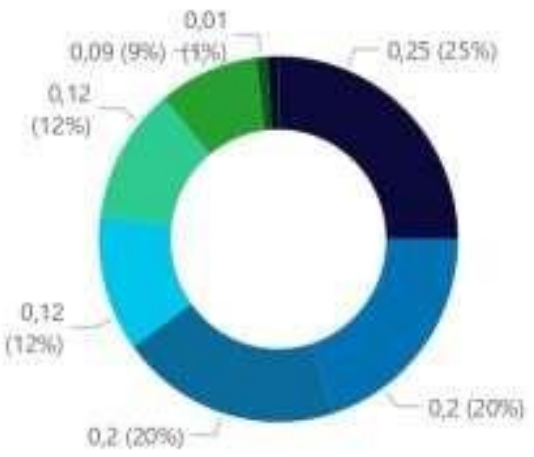

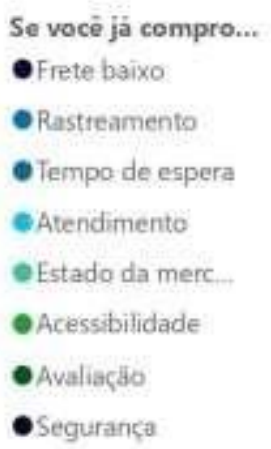

Gráfico 2

No gráfico 3, o enfoque foi em descobrir quais as maiores inseguranças das pessoas na hora de realizar as compras. 


\section{Quais são suas inseguranças?}

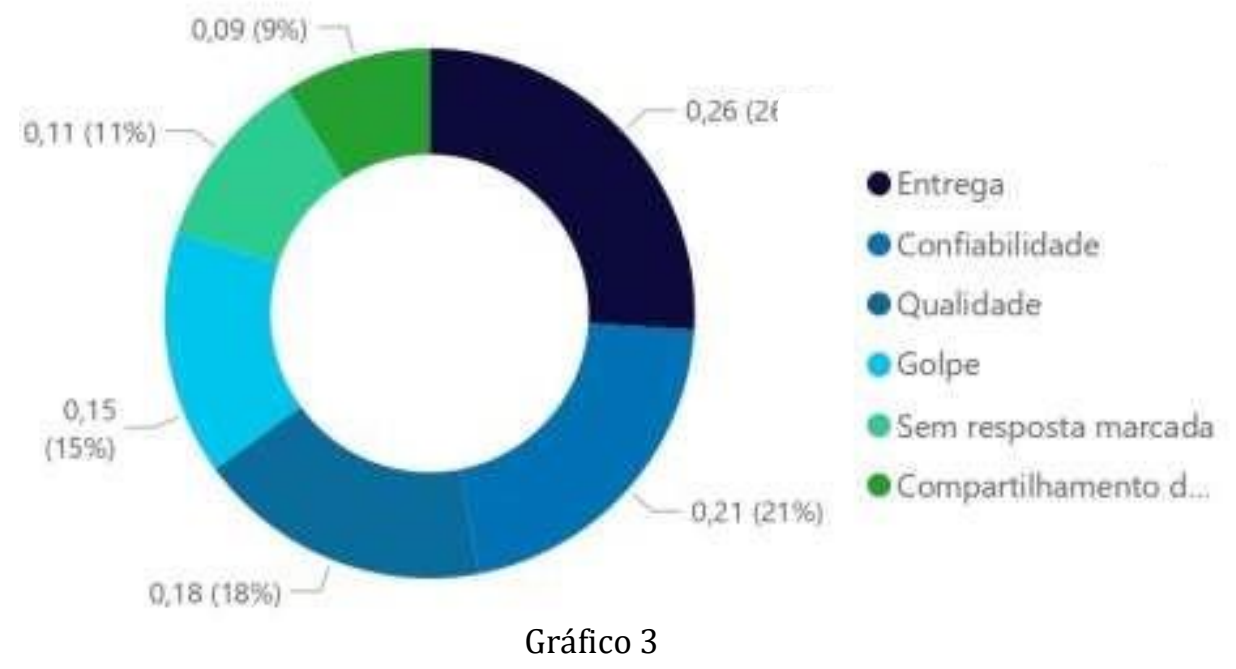

Com essa grande evolução do comércio e principalmente do e-commerce, a plataforma meuCloset vem com o objetivo de aprimorar as vendas online no segmento de roupas e acessórios, criar um ambiente seguro para as vendas, minimizando assim os golpes, estabelecer novas formas de relações entre as redes sociais e os sites de vendas, portanto, maximiza a relação cliente- empresário. Isto torna as vendas mais atrativas e dinâmicas, tornando-se a primeira rede social de vendas online do mundo.

Pré-visualização da plataforma (retirado do frame do vídeo demonstrativo):

tomens Mutheres Kads Modat Tendencias

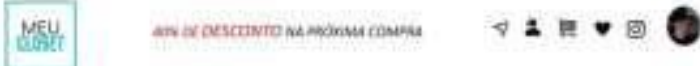

Camisetas Colcos Cosacos Assessorias koupas de banho meupet meutar Streetwear 5.ALE +

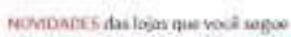
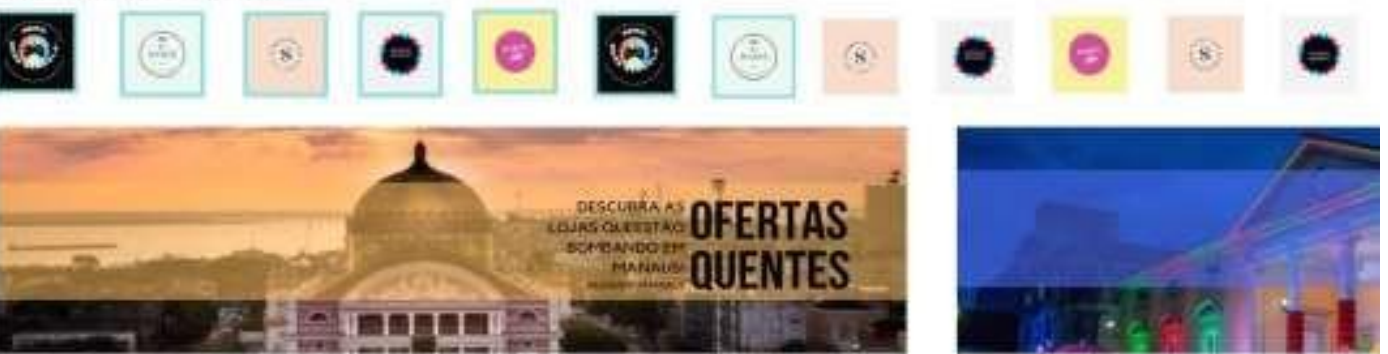

Produtos para vocé

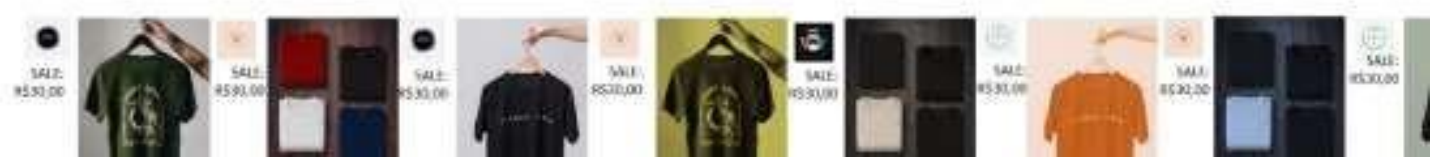


Plataforma de vendas virtual meuCloset é estruturada com NING, uma plataforma online paraprogramação de sites e redes sociais, com a programação nesta plataforma:

-meuCloset terá a aparência mais confortável aos olhos, atraindo até mesmo os consumidoresmais resistentes;

-Opções de monetização do site estão bem estabelecidas e seguras em virtude do NING! ser umadas fontes mais seguras do mundo por conta do sistema de segurança SSL;

-meuCloset conseguirá conversar com as redes sociais Instagram e Facebook por conta do seudesign HTML personalizado;

- Além de oferecer ferramentas de monitoramento para os empreendedores conseguiremvisualizar seus dados mensais.

\section{CONCLUSÃO}

A partir dos dados coletados, percebemos que há muito a explorar dos micros e pequenos empreendedores no espaço virtual, de forma que passem a ter mais resultados positivos com o e-commerce, e da mesma forma, os clientes passam a ter mais contato com o comércio local, conhecendo assim novos empreendimentos.

O público-alvo que se deseja alcançar é o da moda. Boa parte deste público sendo do sexo feminino. Segundo a pesquisa sobre compras online realizada pelo nosso grupo, 56\% são mulheres, e em geral, a maior parte dos produtos comprados são roupas, resultando num valor de $20 \%$ da pesquisa. Por consequente de $18 \%$ que compram ou já compraram acessórios e/ou itens em geral.

A partir disso, pode-se concluir que o aplicativo será uma ótima alternativa para o público que visa interação entre o vendedor e o cliente local pelo aplicativo, nuscando considerar a praticidadeda entrega, segurança no pagamento, facilidade para tirar dúvidas, trocar ou devolver o produto, estabelecerá com que o produto seja mais acessível ao comprador, gerando um feedback positivo. A plataforma meuCloset foi projetada pensando nos mínimos detalhes, com a finalidade principal em facilitar as compras, e na conversação com outras redes sociais já existentes.

O conceito original parte da concepção de "Um grande shopping virtual”, onde a reunião das maisdiversas micro e pequenas lojas de roupas e acessórios criassem um ecossistema saudável de competitividade entre os comércios. 
O objetivo final da plataforma se resume em:

-Ser a revolução no comércio eletrônico, propiciando um local seguro para crescimento de microse pequenos empreendedores, estabelecendo seu comércio;

-Ser a primeira grande rede social de compras no mundo, revolucionando as relações clientes- empresários e dando gatilho ao sonho do mercado consumidor manauara com espírito empreendedor;

-Otimizar os processos de compras online. Desenvolver os sonhos de jovens empreendedores. Segurança e sigilo acima de tudo. Facilitar divulgação das lojas.

Portanto, espera-se que o meuCloset atinja o público manauara, de forma que os cidadãos visem a facilidade e praticidade de fazer suas compras através de um aplicativo intuitivo, amplo e simples. Desta maneira, com base nos dados apontados e dos softwares utilizados, nota-se a viabilidade e rentabilidade da plataforma no qual irá beneficiar inúmeros manauaras, promovendo a autossustentabilidade do $e$ commerce regional.

\section{REFERÊNCIAS BIBLIOGRÁFICAS}

ALBERTIN, Luiz Alberto. 0 mercado eletrônico evolui e consolida-se no mercado brasileiro. Comércio eletrônico: situação atual e tendências, São Paulo, v.40, n.4, p.94-102 Out./Dez. $2000 . \quad$ Disponível em: <https://www.scielo.br/j/rae/a/th5K7bhggkX4CjbgG7CjhTb/?format=pdf\&lang=p t>, acessoem: 03 Ago de 2021.

MENDES, Laura Zimmermann Ramayana. E-commerce: origem, desenvolvimento e perspectivas. Lume Repositório Digital. 2013. Disponível em: < https://www.lume.ufrgs.br/bitstream/handle/10183/78391/000899483.pdf?seq uence=1\&isAllow ed=y>, acesso em: 28 Mai de 2021

FRAZÃO, André. O IMPACTO DA COVID-19 SOBRE OS NEGÓCIOS EM MANAUS: A PERCEPÇÃO DO COMÉRCIO LOCAL. UEA, Manaus: Disponível em:<https://atlasodsamazonas.ufam.edu.br/images/Dados/Pesquisa-COVID-19UEA- download.pdf> Acesso em 05 de agosto de 2021.

VERDÉLIO, Andreia. Economia do Amazonas se acomoda em patamar ainda baixo (Contração de janeiro equivale à observada em abril de 2020). Agência Brasil, Brasília: Disponível em:<https://agenciabrasil.ebc.com.br/economia/noticia/2021-03/economia-doamazonas-se- acomoda-em-patamar-ainda-baixo-diz-bc> Acesso em 03 de Junho de 2021.

Dados técnicos sobre a construção da plataforma: COMO criar uma rede social,NING,2020. Disponível em : < https://www.ning.com/pt-br/what-is-ning/ > Acesso em 07 de junho de 2021. 


\title{
PROGRAMAÇÃO COMPETITIVA
}

\author{
Santiago Monteiro \\ Hisrael Braga \\ Ítalo Santos \\ Victor Lima \\ Daniela Ferreira \\ Danielle Valente
}

Escola Superior de Tecnologia (EST) - Universidade do Estado do Amazonas (UEA) CEP 69050-020 - Manaus - AM - Brasil \{sadsm.eng19, hdsb.eng20, itfds.eng20, vhsdl.eng19, dff.eng20,dvalente\}@uea.edu.br

\section{INTRODUÇÃO}

Maratonas de Programação são eventos onde equipes de competidores de instituições de ensino superior resolvem problemas de lógica através do uso de programação em um tempo limitado. Tais competições são realizadas pelas IES e passam por diversas fases, a saber: regional, nacional e internacional. Tais competições são incentivadas por empresas de tecnologia e institutos de pesquisa.

Cada problema proposto em uma maratona é resolvido com base em dois principais pilares, Algoritmos, que são sequências finitas de passos lógicos criados para resolver um determinado problema e Estruturas de Dados, que são formas de organizar os dados utilizados pelo programador [CRLS, 2001], [SKIENNA, 2020], [ZIVIANI, 2007].

Participar de tais maratonas propicia aos participantes benefícios, tais como, trabalho em equipe, capacidade de resolver problemas sob pressão e com tempo limitado, criar conexões e redes de contatos com outros competidores do evento e com os representantes de empresas de tecnologia, e aprender os fundamentos do Desenvolvimento de Software.

Programadores que participam de maratonas de programação se aprofundam no raciocínio lógico para diferentes técnicas de programação, sendo um diferencial para atuarem no mercado de trabalho, independentemente da área de desenvolvimento de software, pois cada área é baseada na utilização dos fundamentos de algoritmos e estruturas de dados. 


\section{OBJETIVOS}

Este projeto teve como objetivo treinar alunos bolsistas do Projeto Stem nos fundamentos de algoritmos e as principais Estruturas de Dados e realizar competições de programação entre os bolsistas, com o objetivo de desenvolver seu raciocínio lógico para a resolução problemas de programação com técnicas avançadas, habilitando-os a atuar bem em qualquer um dos ramos da programação, desenvolvendo a capacidade de serem autodidatas e criadores de soluções em programação.

\section{MATERIAIS E MÉTODOS}

A ferramenta $\mathrm{C}++$ foi escolhida como ferramenta para o treinamento, pois é muito utilizada nas maratonas de programação e no mercado de trabalho pela sua versatilidade e desempenho.

O URI Online Judge [URI, 2021] é um portal online que contém um repositório de problemas de programação. A partir da criação de um perfil de usuário no portal, o site oferece a função de juiz online, permitindo a submissão de soluções para os problemas propostos em diversas linguagens de programação. Estas soluções são avaliadas e sua corretude depende da saída geradas ser idêntica à saída esperada. De modo geral, os problemas presentes no portal pertencem a um dos nove tópicos (iniciante, ad-hoc, strings, etc), e possui uma dificuldade de 1 a 10, além de ter enunciado, entrada e saída bem definidos. Este portal foi inicialmente utilizado para praticar a programação e organizar competições, sendo posteriormente substituído pelo Neps Academy (prática da programação) e o Virtual Judge (competições de programação).

O site Neps Academy é a plataforma sucessora do site CodCad [CODCAD, 2021], foi ao ar em 2016 por iniciativa do professor Thiago Nepomuceno e de três de seus alunos. 0 portal disponibiliza cursos voltados a quem busca se preparar para competições de programação. Nesse espaço há o conjunto de cursos gratuitos na plataforma inicial "CodCad". Foram trabalhados dois cursos no projeto: Programação Básica e Estruturas de Dados. A fim de complementar o entendimento do material disponibilizado no CodCad, aulas adicionais foram ministradas pela professora orientadora. 
O site Virtual Judge [VJUDGE, 2021] assim como o URI Online Judge, permite que se organize os chamados contests, que são competições de programação onde, de modo geral, há um limite de tempo e vários problemas de programação a serem resolvidos pelos participantes; vence quem submeter mais soluções corretas para os problemas selecionados e por fim, solucionar em menos tempo. Este site foi usado para organizar duas maratonas de programação.

\section{RESULTADOS}

Foram propostas duas competições de programação aos alunos bolsistas deste projeto tecnológico. A primeira competição foi realizada no dia 17/03/2021, após o estudo do curso básico do CodCad. Na Figura 1 observa-se que os alunos resolveram no máximo dois problemas propostos.

\begin{tabular}{|c|c|c|c|c|c|c|c|}
\hline Overview & \multirow[t]{2}{*}{ Problem } & \multirow[t]{2}{*}{ Status } & \multicolumn{2}{|c|}{ Rank (03:00:00) } & \multicolumn{3}{|c|}{0 Comments } \\
\hline & & & Setting & $\sum$ Favo & & Clone & Upde \\
\hline \multirow{2}{*}{ Rank } & \multirow{2}{*}{ Team } & \multirow{2}{*}{ Score } & \multirow{2}{*}{ Penalty } & A & \multirow{2}{*}{\multicolumn{2}{|c|}{$\begin{array}{c}\text { B } \\
0 / 0\end{array}$}} & \multirow{2}{*}{$\begin{array}{c}c \\
2 / 3\end{array}$} \\
\hline & & & & $6 / 7$ & & & \\
\hline 1 & italothiago02 (italothiago02) & 3 & 437 & $\begin{array}{c}02: 54: 05 \\
(-1)\end{array}$ & & & :01:45 \\
\hline 2 & DFox (Leikoden) & 2 & 28 & $00: 06: 28$ & & & $: 22: 18$ \\
\hline 3 & teodororo (teodororo) & 1 & 7 & $00: 07: 17$ & & & $(-1)$ \\
\hline 4 & santiagoaugusto (devsantiago) & 1 & 22 & $00: 22: 42$ & & & \\
\hline 5 & dvalente (Prof. Danielle) & 1 & 55 & $00: 55: 19$ & & & \\
\hline 6 & DanielaFerreira (danielarar) & 1 & 157 & $02: 37: 40$ & & & \\
\hline
\end{tabular}

Figura 1. Resultado geral da primeira maratona realizada no dia 17/03/2021.

Na segunda competição, realizada dia 20/08/2021, os alunos resolveram até seis dos problemas propostos, como pode ser visto na Figura 2. Sendo que foram exatamente os mesmos problemas da primeira competição, evidenciando o progresso destes alunos no domínio das técnicas de programação e no desenvolvimento do seu raciocínio lógico. 
Com base nos resultados, observou-se que após a capacitação proposta os bolsistas apresentaram melhora significativa, esta melhora se deve também ao fato de que durante a primeira maratona realizada, a interface ainda não era familiar e os bolsistas ainda não estavam familiarizados com a linguagem $\mathrm{C}++$.

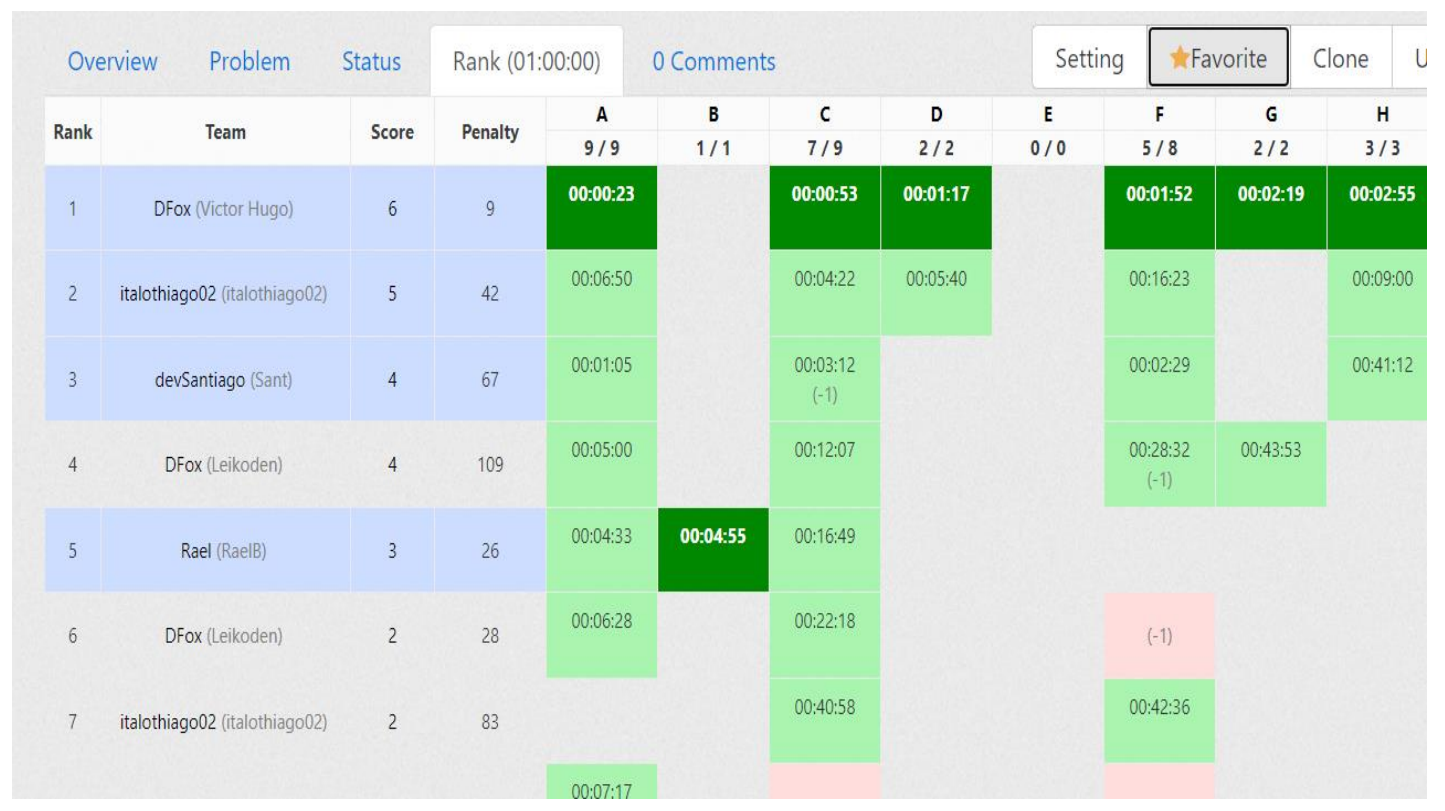

Figura 2. Resultado geral da última maratona realizada no dia 20/08/2021.

\section{CONCLUSÃO}

O objetivo geral do projeto Academia STEM reside em possibilitar a capacitação e formação profissional de estudantes, desenvolvendo, potencializando e divulgando as ciências exatas e engenharia, incluindo Engenharia da Computação. Para alcançar este objetivo, realiza suas ações visando à melhoria dos métodos de ensino, estimulando a interdisciplinaridade de projetos e estimulando a permanência dos alunos no curso de graduação, para que estes o finalizem com excelência e em tempo hábil.

Neste contexto, o projeto de programação competitiva, possibilitou aos seus o conhecimento e aplicação de técnicas de programação avançada baseadas na metodologia do Grupo de Análise e Pesquisa de Algoritmos, (GAPA), visando à melhoria de suas habilidades em programação através de capacitações guiadas por uma plataforma de estudos, aulas complementares e competições de programação. 
Das adversidades resultantes desse trabalho, constatou-se que apesar da metodologia adotada promover a produtividade e busca do aprimoramento individual, alguns bolsistas não tiveram o aproveitamento completo por não se adaptarem à necessidade de dedicação e autodidatismo, necessitando de acompanhamento mais próximo que não foi possível, devido à condição da universidade frente à pandemia do COVID19 com atividades remotas para professores e alunos.

Destacamos que as metas previstas no Projeto STEM, e seus pilares, foram alcançadas de maneira satisfatória, a aplicação da programação competitiva contribui efetivamente para a melhoria do desempenho dos estudantes, nas competições, resultados acadêmicos e consequente melhor capacitação para o mercado de trabalho.

\section{REFERÊNCIAS BIBLIOGRÁFICAS}

[CRLS, 2001] Cormen, T.H., Leiserson, C.E., Rivest, R.L., Stein, C. Introduction to Algorithms , 2nd edition, MIT Press \& McGraw-Hill, 2001.

[SKIENNA, 2020] Skiena, Steven, The Algorithm Design Manual, Third Edition. Texts in Computer Science, Springer 2020.

[ZIVIANI, 2007] Nivio Ziviani. Projeto de Algoritmos com implementações em Java e C++. Thomson Learning, 2007.

[URI, 2021] URI Online Judge. Disponível em: https://www.urionlinejudge.com.br/

[VJUDGE, 2021] Virtual Judge. Disponível em: https://vjudge.net/

[CODCAD, 2021] CodCad. Disponível em: https://neps.academy/br/codcad 


\title{
DISPOSITIVOS MÉDICOS INTELIGENTES
}

\author{
Carlos Gabriel da Silva Machada' \\ Dtoniel da Cunha Mendes' \\ Marcelo Weber Schiller'
}

${ }^{1}$ Escola Superior de Tecnologia (EST) - Universidade do Estado do Amazonas (UEA) CEP 69050-020 - Manaus - AM - Brasil cgdsm.eng18@uea.edu.br,omendes@uea.edu.br, mschiller@uea.edu.br

\section{INTRODUÇÃO}

Atualmente dispositivos inteligentes já são realidade em hospitais, portanto já são utilizados no tratamento de alguma doença ou até mesmo no dinamismo da consulta. Esses dispositivos podem ser vestíveis ou dispositivos super complexos que fazem uso de computação em nuvem, transferência de dados por bluetooth e outras tecnologias.

O potencial da Internet das Coisas na área médica é considerável. Inicialmente, a versatilidade dos dispositivos médicos comuns aumentou. Eles agora podem coletar e armazenar dados para análises mais detalhadas. Além disso, eles funcionam remotamente. Portanto, os dados podem ser coletados no dia a dia do paciente e transmitidos ao hospital para poder analisá-los na composição do histórico médico do paciente. Assim, por exemplo, os dispositivos vestíveis permitem aos profissionais controlar as alterações da pressão arterial do paciente com mais detalhes. Anteriormente, esse controle precisava ser realizado manualmente pelo paciente ou profissional de saúde. A diferença na precisão é óbvia, porque usando a Internet das Coisas na medicina, os pacientes podem continuar suas vidas normais e o dispositivo será registrado automaticamente. A segurança da Internet das Coisas depende do tipo de conexão do dispositivo. Deve ser criptografado e não pode ser um tipo aberto.

Ao sintetizar tudo isso podem aparecer alguns questionamentos quanto a segurança, a velocidade de transferência de dados 


\section{OBJETIVOS}

A ideia do projeto foi aprender sobre a variedade de dispositivos médicos, entender que tipo de dados eles podem capturar e transmitir e como eles podem fazer isso. Ainda, foi necessário elaborar um sistema web de gerenciamento de consultas com pacientes que tiveram dispositivos inteligentes implantados.

\section{MATERIAIS E MÉTODOS}

\subsection{SISTEMA WEB}

O sistema web foi desenvolvido utilizando Next.js que é uma biblioteca do famoso framework do javascript, o react. 0 Next.js foi escolhido pela facilidade e por muitas funcionalidades serem automatizadas, como por exemplo as rotas, o sistema busca do google, ainda, o javascript possui uma vasta quantidade de bibliotecas que podem ser usado a partir do NPM, que é o site onde todos as bibliotecas estão.

\subsection{BANCO DE DADOS}

O banco de dados utilizado foi um baseado em NoSQL pois ele é mais flexível a mudanças e mais atual, o que acaba sendo muito melhor comparado ao SQL.

\subsection{DESENVOLVIMENTO}

O desenvolvimento foi particionado em vários meses, além disso foi utilizada uma metodologia de desenvolvimento ágil, o SCRUM para coordenar o desenvolvimento do sistema com as pesquisas feitas e assim fazer um sistema coeso.

\section{RESULTADOS}

0 resultado obtido no desenvolvimento do sistema foi parecido com o que foi projeto pelo OpenEMR, que é um projeto de um sistema de gerenciamento de um hospital com calendário de consultas, gerenciamento de credenciais de paciente e equipe médica, além de muitas outras funcionalidades. 


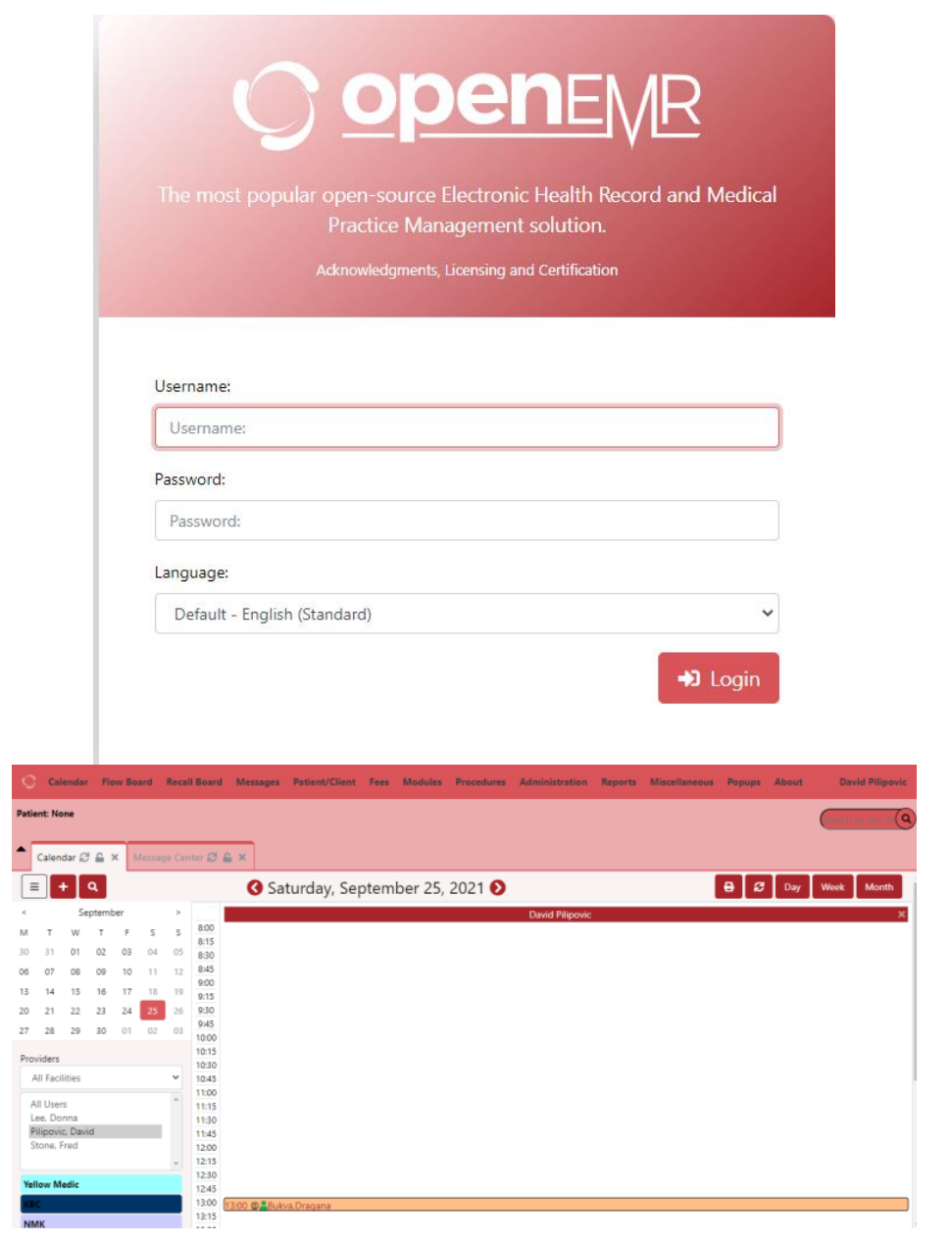

\section{CONCLUSÃO}

Por fim, o uso da Internet das Coisas na medicina tem muitas vantagens. 0 registro autônomo de informações, o monitoramento contínuo dos pacientes e o compartilhamento de dados entre instituições médicas podem ser alcançados. A conexão com a internet permite que esses processos sejam realizados por meio de armazenamento em nuvem, o que aumenta a segurança e a praticidade. A interação do dispositivo também é um recurso importante da Internet das Coisas na área médica. Isso melhora a eficiência do serviço, pois reduz o tempo gasto em tarefas repetitivas, por exemplo.

\section{REFERÊNCIAS BIBLIOGRÁFICAS}

Understanding Smart Medical Devices, Computer, 2021. Disponível em https://www.computer.org/csdl/magazine/co/2021/05/09426970/1tuvC BDc07m. Acesso em 23 de Setembro de 2021. 
Smart healthcare: making medical care more intelligent, ScienceDirect, 2021. Disponível

em https://www.sciencedirect.com/science/article/pii/S2414644719300508. Acesso em 23 de Setembro de 2021.

Iot na medicina: conheça algumas vantagens, ampliMed, 2021. Disponível em https://www.sciencedirect.com/science/article/pii/S2414644719300508. Acesso em 23 de Setembro de 2021.

How are smart medical devices enhancing telemedicine?, Prescouter, 2021. Disponível em https://amplimed.com.br/iot-na-medicina?utm_source=iotna-medicina\&utm_medium=organic\&utm_campaign=iot-na-medicina. Acesso em 23 de Setembro de 2021.

Alimentando dispositivos médicos: principais tendencias e considerações de projeto, $\quad$ Embarcados, 2021. Disponível em https://www.embarcados.com.br/alimentando-dispositivos-medicosprincipais-tendencias-e-consideracoes-de-projeto/.Acesso em 23 de Setembro de 2021.

OpenEMR, Disponível em https://www.open-emr.org/demo/. Acesso em 23 de Setembro de 2021. 


\section{ESTUDO E APLICAÇÃO DAS NOVAS FERRAMENTAS DA QUALIDADE}

Marcos Vinicius de Souza Pedrosa'

Lucas Wanderley Ribeiro'

Maria Eduarda Nascimento Souza'

Ana Beatriz da Silva Picanço'

Lazaro Augusto Guimarães Goes ${ }^{1}$

Carly Pinheiro Trindade'

Rejane Gomes Ferreira'

${ }^{1}$ Escola Superior de Tecnologia (EST) - Universidade do Estado do Amazonas (UEA) CEP 69050-020 - Manaus - AM - Brasil mvdsp.eng19@uea.edu.br, lwr.eng19@uea.edu.br, mens.eng19@uea.edu.br, abdsp.eng19@uea.edu.br, lagg.eng19@uea.edu.br, ctrindade@uea.edu.br, rejane@uea.edu.br

\section{INTRODUÇÃO}

Este artigo tem o intuito de analisar as aplicações recentes das técnicas de gestão da qualidade. A análise foi desenvolvida a partir do estudo sobre a concepção do conceito da qualidade, seguida pela sua importância para posteriormente, compreender a aplicabilidade de cada ferramenta.

0 termo "Novas Ferramentas" possibilita a diferenciação das ferramentas tradicionais, uma vez que as novas ferramentas surgiram na década de 70 e foram desenvolvidas para atender necessidades distintas, visando aumentar o nível de detalhamento.

Para a realização desta análise, adotou-se como procedimento metodológico a pesquisa bibliográfica. Pode-se inferir que as ferramentas de gestão da qualidade são passíveis de serem aplicadas às esferas estratégica, tática e operacional, aumentando a compreensibilidade do problema e facilitando a tomada de decisão para o gestor.

\section{OBJETIVOS}

O objetivo do trabalho foi desenvolver um estudo bibliográfico acerca de aplicações recentes das novas ferramentas da qualidade e possibilitar que o leitor possa compreender como essas ferramentas se integram aos processos produtivos. 
Dessa forma, pretende-se tornar o conhecimento sobre o assunto mais acessível, visto que as ferramentas tradicionais são mais empregadas do que as novas ferramentas da qualidade.

\section{MATERIAIS E MÉTODOS}

O trabalho foi desenvolvido em ambiente $w e b$, por meio de artigos científicos junto às bibliotecas Scielo, Portal de Periódicos da CAPES e aos acervos de instituições de reconhecimento científico. Focou-se na apresentação do conceito, metodologia e objetivo sobre as novas ferramentas da qualidade.

\section{AS “NOVAS FERRAMENTAS" DA QUALIDADE E SUAS APLICAÇÕES}

Juran (1992) define a qualidade como "adequação ao uso" e afirma que essa possui uma variedade de definições, como por exemplo: Qualidade focalizada em resultados e Qualidade relacionada ao aspecto de custo. 0 processo de qualidade torna-se importante para as organizações, uma vez que, com o desenvolvimento da qualidade, conduzirá a empresa a competir no mercado atual. Para que a empresa possa sobreviver é necessário desenvolver novos produtos ou serviços (melhores, mais baratos, mais seguros, de entrega mais rápida, de manutenção mais fácil etc. que os dos concorrentes). 0 quadro 1 mostra os resultados da pesquisa realizada, informando as características, utilização de cada ferramenta e aplicação.

Quadro 1. As novas ferramentas da qualidade e suas aplicações.

\begin{tabular}{|c|c|c|}
\hline FERRAMENTA & CARACTERÍSTICAS & UTILIZAÇÃO \\
\hline $\begin{array}{l}\text { Diagrama de } \\
\text { relações }\end{array}$ & $\begin{array}{l}\text { Esta ferramenta explicita a estrutura } \\
\text { lógica das relações de causa-efeito, de } \\
\text { um tema ou problema, visualizando de } \\
\text { maneira clara as variáveis que estão } \\
\text { diretamente ligadas ao problema } \\
\text { principal no diagrama. O diagrama é } \\
\text { composto por quadros, as quais estão } \\
\text { contidas as ideias, ligadas ao problema } \\
\text { por setas. Esses quadros contêm } \\
\text { números E/S, Entrada e Saída } \\
\text { respectivamente, para detectar agente } \\
\text { gerador de ações ou processador de } \\
\text { ações. Durante essa otimização deve- } \\
\text { se buscar pelo elemento que possui } \\
\text { muitas entradas e poucas saídas. }\end{array}$ & $\begin{array}{l}\text { Melhora a qualidade nos } \\
\text { processos de manufatura; } \\
\text { prover medidas em relação aos } \\
\text { problemas relacionados a } \\
\text { pagamentos e controle de } \\
\text { processos; } \\
\text { Aplicação: Melhoria em uma } \\
\text { empresa de transporte de } \\
\text { passageiros (JUNIOR, A. S. C.; } \\
\text { BUENO, A. F.; PIASSON, D., } \\
\text { 2015) }\end{array}$ \\
\hline
\end{tabular}




\begin{tabular}{|c|c|c|}
\hline FERRAMENTA & CARACTERÍSTICAS & UTILIZAÇÃO \\
\hline $\begin{array}{l}\text { Diagrama de } \\
\text { afinidade }\end{array}$ & $\begin{array}{l}\text { Lida com um grande volume de dados } \\
\text { qualitativos, facilitando o surgimento } \\
\text { de novas ideias ou maior compreensão } \\
\text { da situação. Sua representação é um } \\
\text { quadro, no qual estão dispostos } \\
\text { cartões rotulados, agrupando por } \\
\text { afinidade os dados verbais (ideias, } \\
\text { opiniões, comentários, etc.) } \\
\text { levantados em torno de um problema } \\
\text { complexo. Dessa forma, pode ajudar a } \\
\text { desenvolver produtos mais próximos } \\
\text { das necessidades dos consumidores. }\end{array}$ & $\begin{array}{l}\text { Organiza as informações } \\
\text { necessárias à solução de um } \\
\text { problema, organiza as causas de } \\
\text { um problema e fornece suporte } \\
\text { para a solução de um problema. } \\
\text { Aplicação: Melhoria em uma } \\
\text { empresa de transporte de } \\
\text { passageiros (JUNIOR, A. S. C.; } \\
\text { BUENO, A. F.; PIASSON, D., } \\
\text { 2015) }\end{array}$ \\
\hline $\begin{array}{l}\text { Diagrama de } \\
\text { árvore }\end{array}$ & $\begin{array}{l}\text { Permite fazer o mapeamento } \\
\text { detalhado dos caminhos a serem } \\
\text { percorridos para alcançar o objetivo e } \\
\text { assim definir uma estratégia de } \\
\text { abordagem. O diagrama se assemelha } \\
\text { a uma árvore, desdobrando um } \\
\text { objetivo primário em meios, até se } \\
\text { definir ações executáveis que } \\
\text { permitam atingir o objetivo } \\
\text { pretendido. O diagrama deve } \\
\text { responder algumas perguntas: o que? } \\
\text { Por que? Como? }\end{array}$ & $\begin{array}{l}\text { Criar um diagrama de Ishikawa, } \\
\text { desenvolver ideias para } \\
\text { resolver problemas } \\
\text { relacionados à qualidade, } \\
\text { mostrar graficamente as } \\
\text { respostas da técnica } 5 \mathrm{~W} 2 \mathrm{H} \text {. } \\
\text { Aplicação: Uso da modularidade } \\
\text { em vários produtos } \\
\text { manufaturados } \\
\text { et al., 2021). }\end{array}$ \\
\hline $\begin{array}{l}\text { Diagrama de } \\
\text { matriz }\end{array}$ & $\begin{array}{l}\text { Identifica o grau de relação entre dois } \\
\text { ou mais grupos de variáveis. Pode ser } \\
\text { representada em diversos formatos, } \\
\text { como matriz em L, matriz em T, matriz } \\
\text { em Y e em X. Os fenômenos analisados } \\
\text { são decompostos em fatores, } \\
\text { colocados em linhas e colunas para } \\
\text { identificar seu grau de } \\
\text { relacionamento, representados por } \\
\text { símbolos, podendo ser forte, médio ou } \\
\text { fraco. Com isso, fornece possíveis } \\
\text { melhorias e identifica as causas mais } \\
\text { impactantes de cada problema. }\end{array}$ & $\begin{array}{l}\text { Auxiliar na solução de } \\
\text { problemas, fornecer possíveis } \\
\text { melhorias, identificar causas } \\
\text { que possuem maior impacto de } \\
\text { cada problema, organizar dados } \\
\text { e atribuir responsabilidades. } \\
\text { Aplicação: Melhoria em uma } \\
\text { empresa de transporte de } \\
\text { passageiros (JUNIOR, A. S. C.; } \\
\text { BUENO, A. F.; PIASSON, D., } \\
\text { 2015) }\end{array}$ \\
\hline $\begin{array}{c}\text { Matriz de } \\
\text { priorização }\end{array}$ & $\begin{array}{l}\text { Essa ferramenta mostra quais } \\
\text { elementos e etapas serão priorizados. } \\
\text { A matriz GUT é um exemplo de matriz } \\
\text { de priorização, no qual os parâmetros } \\
\text { são baseados na gravidade, urgência e } \\
\text { tendência. A finalidade da ferramenta } \\
\text { é a escolha de ações de melhorias que } \\
\text { terão maior abrangência no } \\
\text { desenvolvimento de ações que terão } \\
\text { maior participação na solução de } \\
\text { problemas. }\end{array}$ & $\begin{array}{l}\text { Priorizar dados, mensurar } \\
\text { problemas, aplicar melhorias e } \\
\text { gerir riscos. } \\
\text { Aplicação: Uso na gestão } \\
\text { integrada de resíduos sólidos } \\
\text { (COSTA et al., 2017) }\end{array}$ \\
\hline
\end{tabular}




\begin{tabular}{|c|c|c|}
\hline FERRAMENTA & CARACTERÍSTICAS & UTILIZAÇÃO \\
\hline $\begin{array}{l}\text { Diagrama de } \\
\text { processo de } \\
\text { decisões }\end{array}$ & $\begin{array}{l}\text { Essa ferramenta traz todos os } \\
\text { caminhos possíveis para o alcance de } \\
\text { um determinado objetivo, } \\
\text { apresentando variados problemas e } \\
\text { possíveis medidas a serem tomadas } \\
\text { caso os problemas ocorram. É } \\
\text { composto por um fluxo básico } \\
\text { relacionado aos passos básicos para } \\
\text { determinada ação, um macro } \\
\text { diagrama de processo decisório (DPD) } \\
\text { e um micro DPD.A finalidade é } \\
\text { encontrar a melhor alternativa }\end{array}$ & $\begin{array}{l}\text { Desenvolver caminhos para } \\
\text { alcançar um objetivo, } \\
\text { apresentar soluções em } \\
\text { diferentes cenários, analisar } \\
\text { processo como um todo, } \\
\text { encontrar solução viável. } \\
\text { Aplicação: Aplicação em uma } \\
\text { indústria de bolacha (SOUZA, L. } \\
\text { S. T. et al., 2018) }\end{array}$ \\
\hline $\begin{array}{l}\text { Diagrama de } \\
\text { flechas ou } \\
\text { setas }\end{array}$ & $\begin{array}{l}\text { É um diagrama que mostra os } \\
\text { caminhos para chegar em um objetivo, } \\
\text { esses caminhos geram uma rede de } \\
\text { precedência, onde são seguidos de } \\
\text { setas. É uma ferramenta simples e } \\
\text { ótima para observar um trabalho } \\
\text { repetitivo e torná-lo mais eficiente }\end{array}$ & $\begin{array}{l}\text { Fornecer ordem requerida das } \\
\text { tarefas, criar um cronograma e } \\
\text { solucionar problemas de } \\
\text { recursos. } \\
\text { Aplicação: Aplicação em uma } \\
\text { empresa de elaboração de } \\
\text { múltiplos projetos (GARCIA, C. } \\
\text { H.; GASPERINI, R., 2016) }\end{array}$ \\
\hline
\end{tabular}

Fonte: Dellaretti, 1999.

\section{CONCLUSÃO}

Após estudo bibliográfico das novas ferramentas, foi possível observar que as representações gráficas aumentam a compreensibilidade do problema e facilitam a tomada de decisão para o gestor, dado o detalhamento e análise da complexidade dos dados. Isso pode ser observado nos diagramas de afinidade, de relação, matriz e priorização, os quais promovem a correspondência entre as variáveis que causam um determinado problema. Além disso, foi possível notar que algumas ferramentas mostram para os gestores os caminhos a serem seguidos, fazendo a identificação de fatores como gargalos nos processos, tempo do processo e facilidade na implementação, que é o caso do diagrama de árvore, diagrama de setas e de processo de decisões.

\section{REFERÊNCIAS BIBLIOGRÁFICAS}

CARNEVALLI, Análise da correlação do lean manufacturing com produtos modulares. Exacta: Engenharia de Produção, Uninove, São Paulo, v. 19. N. 2, p. 432-455, maio 2021. Disponível em: 
https://periodicos.uninove.br/exacta/article/view/11316. Acesso em: 22 set. 2021.

COSTA, A. R. S. et al. Aplicação da matriz GUT na gestão integrada de resíduos sólidos da cidade do Recife-PE. Revista AIDIS de Ingeniería y Ciencias Ambientales: Investigación, desarrollo y práctica, v. 10, n. 2, p. 201-213, ago. 2017. Disponível em: http://revistas.unam.mx/index.php/aidis/article/view/57757/54159. Acesso em: 23 set. 2021.

DELLARETTI FILHO, O. As sete ferramentas do planejamento da qualidade (7FPQ). Belo Horizonte: Universidade Federal de Minas Gerais. Escola de Engenharia. Fundação Christiano Ottoni, 1996.

GARCIA, C. H.; GASPERINI, R.. Aplicação da técnica PERT em uma empresa de elaboração de múltiplos projetos: um estudo de caso. 5a $\mathbf{a}$ JORNACITEC, out.2016. Disponível em:http://www.jornacitec.fatecbt.edu.br/index.php/ VJTC/VJTC/ paper/view/764. Acesso em: 23 set. 2021.

JURAN, J. M. A Qualidade desde o projeto. Os novos passos para o planejamento da qualidade em produtos e serviços. Reimpressão 2004. São Paulo: Pioneira, 1992.

JUNIOR, A. S. C.; BUENO, A. F.; PIASSON, D. Aplicação da ferramenta desdobramento da função qualidade (QFD) para a melhoria do nível de serviço em uma empresa do segmento de transporte de passageiros. Gestão de Serviços, v.2, p. 16-27, jan. 2015. Disponível em: https://www.researchgate.net/publication/322527146. Acesso em: 23 set. 2021

SOUZA, L. S. T. et al. Aplicação de ferramentas da qualidade em uma indústria de bolacha do interior do Rio Grande do Norte. Universidade Federal Rural do Semi-Árido: Angicos, 2018. TCC (Graduação) - Bacharelado em Ciência e Tecnologia. Disponível em: http://repositorio.ufersa.edu.br/handle/prefix/2382. Acesso em: 23 set. 2021. 


\section{CAPÍTULO XXXV}

\section{DIAGNÓSTICO DA RECICLAGEM NA CIDADE DE MANAUS (AM)}

Jussara Cristina de Souza Nobre'

Karen Cristina Freitas Gato'

Leticia Cristina de Souza Cunha'

Rodrigo Messias Moraes'

Mauro Henrique do Nascimento Lira'

Rejane Gomes Ferreira'

Carly Pinheiro Trindade'

${ }^{1}$ Escola Superior de Tecnologia (EST) - Universidade do Estado do Amazonas (UEA) CEP 69050-020 - Manaus - AM - Brasil jcdsn.eng20@uea.edu.br,kcfg.eng20@uea.edu.br,lcdsc.eng20@uea.edu.br,rmm.eng20@uea.edu.br,mhdnl.eng2 0@uea.edu.br,rejane@uea.edu.br, ctrindade@uea.edu.br

\section{INTRODUÇÃO}

O trabalho traz como cenário a reciclagem de resíduos sólidos na cidade de Manaus, e foi motivado pelo interesse dos participantes na temática, sob uma ótica sustentável. Acrescenta-se ao cenário a exposição negativa da cidade quanto à poluição de seus rios e igarapés que cortam e margeiam a capital amazonense. De acordo com dados do relatório da Secretaria Municipal de Limpeza Pública (SEMULSP, 2020), são produzidas 1.228.307 toneladas/ano de resíduos sólidos. E deste total, conforme dados do órgão no ano de 2019, apenas 0,05\% dos resíduos foram reciclados, sendo que 1,02\% foram destinados à compostagem e 98,93\% ao aterro sanitário.

Para o ano de 2020 ainda revelam que de janeiro a outubro a coleta foi de 2,395 toneladas (SEMULSP, 2020). Vale ressaltar que o Aterro de Resíduos Sólidos de Manaus é o único complexo de destino dos resíduos sólidos urbanos sob o gerenciamento da Prefeitura da cidade (SEMULSP, 2019). A pesquisa se justifica ainda pelo direito da sociedade à informação, controle social e a reciclagem de resíduos, com eixo da Lei de n.ำ12.305/2010, que institui a Política Nacional de Resíduos Sólidos (BRASIL, 2010).

Então, diante desses números, buscou-se compreender a reciclagem dentro desse cenário da cidade de Manaus, definida conforme o Art. 3.ํ da Lei n.ำ 12.305, de 2 de agosto de 2010, como "processo de transformação dos resíduos sólidos que 
envolve a alteração de suas propriedades físicas, químicas ou biológicas, com vistas à transformação em insumos ou novos produtos" (BRASIL, 2017). Esse termo surgiu no final da década de 80 , devido à compreensão do esgotamento dos recursos naturais para o sistema de consumo e a necessidade de preservação ambiental (SOUSA et al., 2016).

\section{OBJETIVOS}

\subsection{OBJETIVOS GERAL}

Realizar um diagnóstico da reciclagem de resíduos sólidos na cidade de Manaus (AM).

\subsection{OBJETIVOS ESPECIFICOS}

- Mapear por zonas da cidade as empresas e instituições públicas que realizam a reciclagem de resíduos sólidos;

- Identificar os elementos de análise quanto à reciclagem de resíduos sólidos na cidade;

- Analisar a situação da reciclagem de resíduos sólidos na cidade.

\section{MATERIAIS E MÉTODOS}

Para contextualizar o panorama da reciclagem na cidade de Manaus, foi desenvolvido um estudo qualitativo descritivo do tipo exploratório, baseado na observação e coleta de dados publicados na internet por organizações/empresas recicladoras durante o período de fevereiro a agosto de 2021. De acordo com Cervo, Bervian e Silva, (2007), este tipo de estudo desenvolvido sobre dados ou fatos colhidos da própria realidade facilitam o planejamento da pesquisa, consideração importante para esta pesquisa exploratória, que se limitou ao ambiente $w e b$, em decorrência inclusive pela falta de atividade das empresas em decorrência da Covid19.

Como estratégia de levantamento dos dados, foi utilizado o documento de zoneamento "Bairros por divisão distrital zonal" (SEMED, 2019) e desse modo a pesquisa foi direcionada para 8 zonas da cidade. Dentre elas estão as seguintes zonas: Sul, Oeste, Norte, Centro-sul, Leste I e Leste II, com exceção da zona Rural/Rodoviária e Rural/Ribeirinha. 
A coleta de dados ocorreu com o auxílio da ferramenta virtual Google Maps e outras plataformas digitais, como Facebook e Instagram, no propósito de encontrar as empresas responsáveis pela reciclagem em Manaus. Foram utilizados os termos reciclagem+manaus, empresas recicladoras+manaus e centros de reciclagem+manaus. Os dados obtidos foram tabulados com o auxílio do Excel.

\section{RESULTADOS}

Na Tabela 1, estão representadas as seis zonas da cidade de Manaus e os dados relativos às empresas/organizações recicladoras de resíduos sólidos, que serviram de base para o diagnóstico da reciclagem em Manaus. Foram identificadas 51 empresas/indústrias e organizações/associações que trabalham com a atividade de reciclagem nas zonas de Manaus, sendo 48 e 2 respectivamente. Quanto à distribuição por zonas, 16 estão situadas na zona Leste 1, 13 na Sul, 10 na Norte, 6 na Leste 2, 3 na Centro-sul e 3 na Oeste.

A maior concentração de recicladoras foi encontrada na zona Leste 1, enquanto as zonas oeste e centro-sul tiveram menores números de ação a favor da reciclagem. Os tipos de materiais reciclados levantados foram: plástico, papel, metal, cobre, bateria, ferro, alumínio, óleo, papelão, isopor, pneu, borra e cartucho de tinta, eletrodomésticos, eletroeletrônicos, resíduos industriais, comerciais e domésticos.

Tabela 1. Distribuição por zonas da cidade de Manaus de empresas/organizações que realizam a reciclagem de resíduos sólidos.

\begin{tabular}{l|c|c|c}
\hline Zona & $\begin{array}{c}\text { Categoria: Associações, } \\
\text { Empresa/Indústria }\end{array}$ & $\begin{array}{c}\text { Quantidade } \\
\text { (unid.) }\end{array}$ & Tipo de material reciclado \\
\hline Norte & Empresa/Indústria & 10 & $\begin{array}{c}\text { Plástico, papel, Metal, cobre, bateria, } \\
\text { ferro, alumínio, eletrodomésticos, } \\
\text { eletroeletrônicos, resíduos industriais, } \\
\text { comerciais e domésticos }\end{array}$ \\
\hline Sul & Empresa/Indústria & 13 & $\begin{array}{c}\text { Plástico, óleo, isopor, ferro, alumínio, } \\
\text { baterias }\end{array}$ \\
\hline Leste1 & $\begin{array}{c}\text { Empresa/Indústria e } \\
\text { Associação }\end{array}$ & 16 & $\begin{array}{c}\text { Papel, papelão, ferro, pneus, borras de } \\
\text { tinta }\end{array}$ \\
\hline Leste 2 & Empresa/Indústria & 6 & Plástico e óleo \\
\hline $\begin{array}{l}\text { Centro- } \\
\text { Sul }\end{array}$ & $\begin{array}{c}\text { Empresa/Indústria } \\
\text { Oeste }\end{array}$ & 3 & $\begin{array}{c}\text { Plástico e metal } \\
\text { Empresa/Indústria }\end{array}$ \\
\hline
\end{tabular}

Fonte: Autores, 2021. 
Verificou-se no estudo que 11 das empresas identificadas registraram fazer a reciclagem do plástico. Embora este estudo não seja quantitativo, o plástico foi o material mais reciclado nas empresas que fazem reprocessamento em Manaus e de acordo com uma notícia do Ministério do Meio Ambiente feita por Verdi (2012), a reciclagem deste produto é considerada uma das mais complexas em comparação com os demais materiais por ter uma variedade de composições e ter uma decomposição com duração de cerca de 400 anos.

Observou-se a reciclagem de metais, como o ferro e alumínio, em grande parte das empresas/indústrias e associações de Manaus.

Verificou-se na pesquisa que três empresas atuam na coleta e reprocessamento de resíduos eletrônicos e dentre estas, há uma de iniciativa privada que realiza campanhas de coleta, separação de materiais, cursos de montagem e manutenção de microcomputadores, reciclagem e venda de computadores a baixo custo para a população, inovando como solução e trazendo consigo um impacto social. Esse tipo de resíduo é um desafio, visto que o descarte correto tem seu custo elevado por não poder ser efetuado em aterros sanitários, em razão de este conter uma quantidade expressiva de matérias-primas e de metais pesados, tóxicos e degradantes para o meio ambiente (CUNHA et al., 2021).

No que refere à reciclagem do papel em Manaus, foram identificadas duas empresas que realizam a fabricação de papel higiênico a partir de papel e papelão coletados, contribuindo economicamente desta forma para a cadeia da reciclagem e para a questão ambiental. De acordo com Grigoletto (2012), era esperado que com o uso dos computadores, houvesse uma diminuição considerável no uso de papel, principalmente pelas grandes corporações e escritórios, entretanto, esse uso foi recorde nas duas últimas décadas.

Ao analisar a situação da reciclagem de resíduos sólidos em Manaus, houve dificuldade para identificar empresas/associações que praticam a reciclagem, devido ao grande número de empresas que utilizam o termo reciclagem serem responsáveis somente pela coleta e/ou transporte de resíduos. Além disso, também foram encontradas poucas informações e dados sobre as associações existentes na cidade em ambiente web. Em relação às demais empresas/associações que exercem de fato a reciclagem, foram observadas várias iniciativas a favor da sustentabilidade. 


\section{CONSIDERAÇÕES FINAIS}

Tendo em vista esse cenário identificado na pesquisa, faz-se necessário outras formas de mobilização na sociedade para a reciclagem, como o envolvimento das empresas com a comunidade manauara, visto que isso geraria lucro e participação de ambos. Um exemplo de retorno seria um programa com o cashback e soluções tecnológicas para a coleta e transformação de materiais. Em relação à educação ambiental, verifica-se a necessidade de ações junto a estudantes nas escolas e em comunidades, como oficinas ou projetos de interação com o ambiente.

Destarte, para estudos posteriores que podem decorrer dos dados deste trabalho, sugere-se o desenvolvimento de uma pesquisa do tipo estudo de caso, junto a uma das associações ou empresas recicladoras.

\section{REFERÊNCIAS BIBLIOGRÁFICAS}

CERVO, A. L., BEVIAN, A. P., SILVA, D. R.. Metodologia científica. 6. ed., São Paulo: Pearson Prentice Hall, 2007.

CUNHA, M. et al. Uma proposta inovadora no processo de reciclagem de materiais eletrônicos. Brazilian Journal of Development, 2021, vol. 7 n. 7, p. 66572 66586. Disponível em: https ://www.brazilianjournals.com/index.php/BRJD/article/view/32438.

Acesso em: 16 ago. 2021.

BRASIL, Lei no 12.305, de 02 de agosto de 2010. Política Nacional de Resíduos Sólidos (PNRS). Disponível em http://www.planalto.gov.br/ccivil_03/_ato20072010/2010/lei/l12305.htm. Acesso em: 9 jan. 2020.

GRIGOLETTO, Izabel Cristina Berger. Reaproveitar e reciclar o papel: propostas de conscientização da preservação ambiental. Monografias Ambientais, 2012, v.6, n.6, pp 1414 - 1422. Disponível em: www.ufsm.br/remoa. Acesso em: 25, jun. 2021.

SEMED, Secretaria Municipal de Educação. Mapas de Zoneamentos da Cidade De Manaus, Anexo III - bairro por divisão distrital zonal (2019) Disponível em:https://semed.manaus.am. content/uploads/2019/04/Anexo-III.pdf. Acesso em: 28: jan. 2021.

SEMULSP. Secretaria Municipal de Limpeza Urbana. Relatório de Gestão 2013 a 2020. Manaus, SEMULSP, 2020. Disponível em: https://semulsp.manaus.am.gov.br./wpcontent/uploads/2020/12/Relatorio-Semulsp-2013-a-2020-parcial.pdf. Acesso em: 9 jan. 2020. 
SOUSA, D. C. G., Matos L. L. e Araújo M. K. S.2 A importância do papel na melhoria da qualidade do meio ambiente", 2016. Disponível em: http://www.abepro.org.br/biblioteca/ tn_sto_234_366_30516.pdf, March.

VERDI, L. Sacolas plásticas em discussão na câmara, 2012. Disponível em: https://www. gov.br/mma/pt-br/noticias/sacolas-plasticas-em-discussaona-camara. Acesso em: 10 ago. 2021. 


\section{TESTE DE INTRUSÃO INDEPENDENCE}

Fernanda Araujo Alves Filha'

Adevan Neves Santos'

Paula Eduarda Ribeiro Cativo'

Áurea Hiléia da Silva Mela'

${ }^{1}$ Escola Superior de Tecnologia (EST) - Universidade do Estado do Amazonas (UEA) CEP 69050-020 - Manaus - AM - Brasil faaf.eng19@uea.edu.br, ans.eng20@uea.edu.br, perc.eng18@uea.edu.br, asmelo@uea.edu.br

\section{INTRODUÇÃO}

Segurança da informação consiste em um conjunto de práticas que visam garantir a integridade, disponibilidade e confidencialidade das informações. Para isso, existem padrões de segurança e métodos para determinar e reparar vulnerabilidades de um sistema. Em geral, nesta grande área existem dois tipos de profissionais: aqueles que trabalham com segurança defensiva (blue team) e aqueles que trabalham com segurança ofensiva (red team).

Teste de intrusão, também conhecido como teste de penetração, consiste em um método utilizados pelo time de segurança ofensiva para avaliar a segurança de um determinado sistema, simula-se um ataque cibernético para descobrir ou explorar vulnerabilidades e avaliar que tipo de informações ou que nível de acesso não-autorizado um invasor poderia conseguir. Este trabalho consiste em fazer um teste de intrusão numa aplicação web de uma organização real, que será referenciada como Independence.

\section{OBJETIVOS}

\subsection{OBJETIVOS GERAIS}

O objetivo do trabalho foi testar a segurança de uma aplicação web por meio de segurança ofensiva, que aborda um processo de investigação, ataque e análise dos resultados, indicando melhorias e métodos para tratar possíveis falhas identificadas. 


\subsection{OBJETIVOS ESPECÍFICOS}

Os objetivos específicos deste trabalho são: (i) conhecer de forma prática algumas ferramentas do Kali Linux, (ii) identificar e classificar em ordem de criticidade as vulnerabilidades encontradas no teste de segurança, (iii) sugerir um conjunto de ações e práticas para que a organização Independence melhore sua segurança da informação, por exemplo filtrar o acesso às informações da aplicação. Também discutir sobre os problemas com base em normas técnicas e a nova LGPD, vigente no ano de 2020.

\section{MATERIAIS E MÉTODOS}

O experimento foi conduzido com apoio de ferramentas de exploração que são usadas por invasores em situações reais de ataque, que permite obter a visão de um agente externo.

Utilizou-se ferramentas do Kali, uma distribuição Linux empregada em tarefas de auditoria de segurança da informação. Pode-se dividir o processo em 3 etapas, descritas a seguir.

\subsection{PREPARAR O AMBIENTE DE TRABALHO}

Esta etapa consistiu em mascarar o proxy, a fim de garantir o anonimato no processo, para isso foi utilizado um Proxy Chain(Cadeia de proxy), usufruiu-se do Dynamic Chain para mascarar o proxy, esta cadeia de proxy funciona da seguinte forma: A informação que o atacante passa para o servidor alvo passa por diversos servidores proxy antes de chegar ao alvo, dificultando a identificação do atacante em caso de investigação policial. 


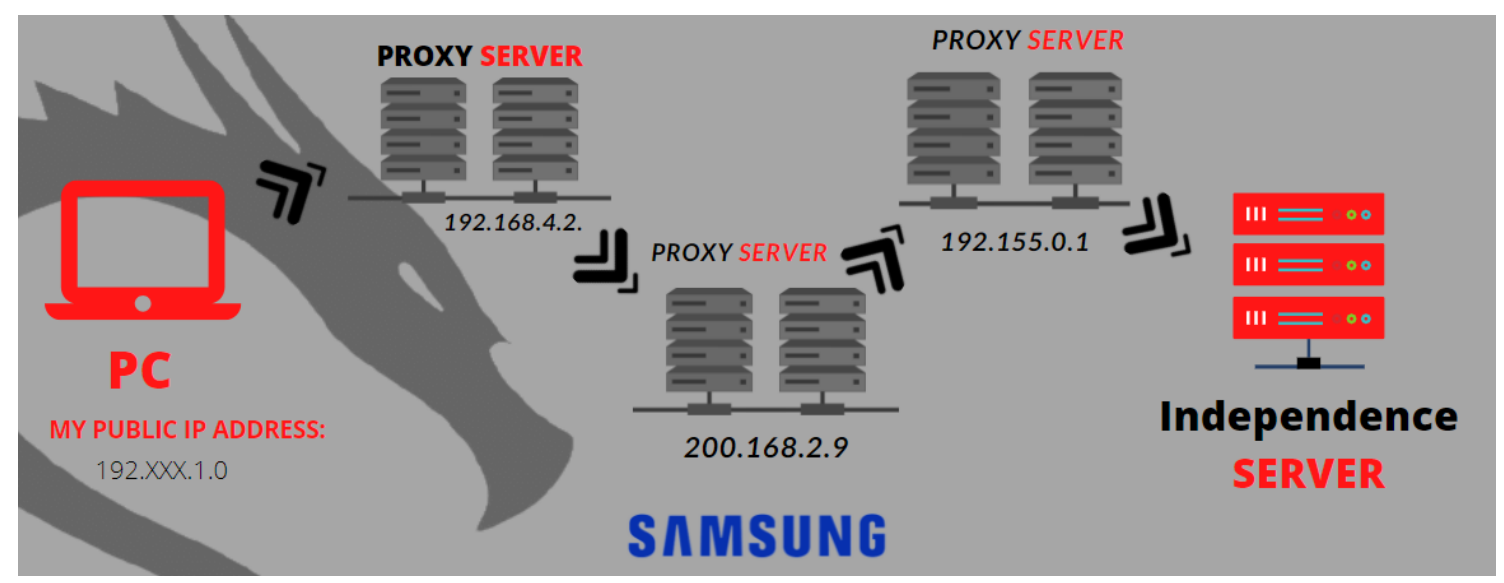

Figura 1. Funcionamento do Dynamic Chain. Todos os endereços de IP mostrados são fictícios. Fonte: Apresentação STEM - Fernando Araujo Alves Filho

\subsection{IDENTIFICAR VULNERABILIDADES}

A segunda etapa consistiu na identificação de vulnerabilidades. Utilizou-se a ferramenta Nmap, presente no próprio sistema operacional, a fim de extrair informações de serviços da rede. Após identificar serviços e protocolos do servidor, foram estudadas informações do domínio na internet, com objetivo de encontrar possíveis vulnerabilidades já exploradas.

\subsection{EXPLORAR VULNERABILIDADES}

A última etapa integrou a exploração das vulnerabilidades utilizando outras ferramentas do Kali Linux. Utilizou-se a ferramenta Zed Attack Proxy(ZAP), esta é uma ferramenta de teste de penetração que fornece scanners de um serviço web. Averiguou-se se de fato algo da rede poderia ser acessado remotamente por algum potencial invasor, para esta atividade, recorreu-se à ferramenta Ncat para enviar instruções ao servidor de rede. No Ncat, foi posto o endereço de IP do servidor, obtido por meio do Nmap. Com o servidor conectado através do Ncat, pode-se forçar respostas e enviar comandos da aplicação.

\section{RESULTADOS}

A partir de análises da terceira etapa, encontrou-se os seguintes alertas de vulnerabilidades:

1. "x-frame-options header is not included in the http response". Esta falha indica que o navegador não tem a informação se deve ou não acessar determinada página na web, este tipo de falha, caso corrigida pode evitar ataques do tipo clickjacking(roubo de clique), esta falha consiste em desviar 
cliques de uma determinada página para uma página possivelmente fraudulenta.

2. "Remove the private IP address from the HTTP response body". Esta falha indica que há informações que podem ser acessadas sobre o IP privado do servidor a partir de usuários remotos, este tipo de falha pode acarretar em intrusões, roubo de informações e outros danos à organização.

Com base nos resultados dos experimentos, nota-se que o serviço web em questão possui vulnerabilidades que podem ser exploradas por possíveis atacantes.

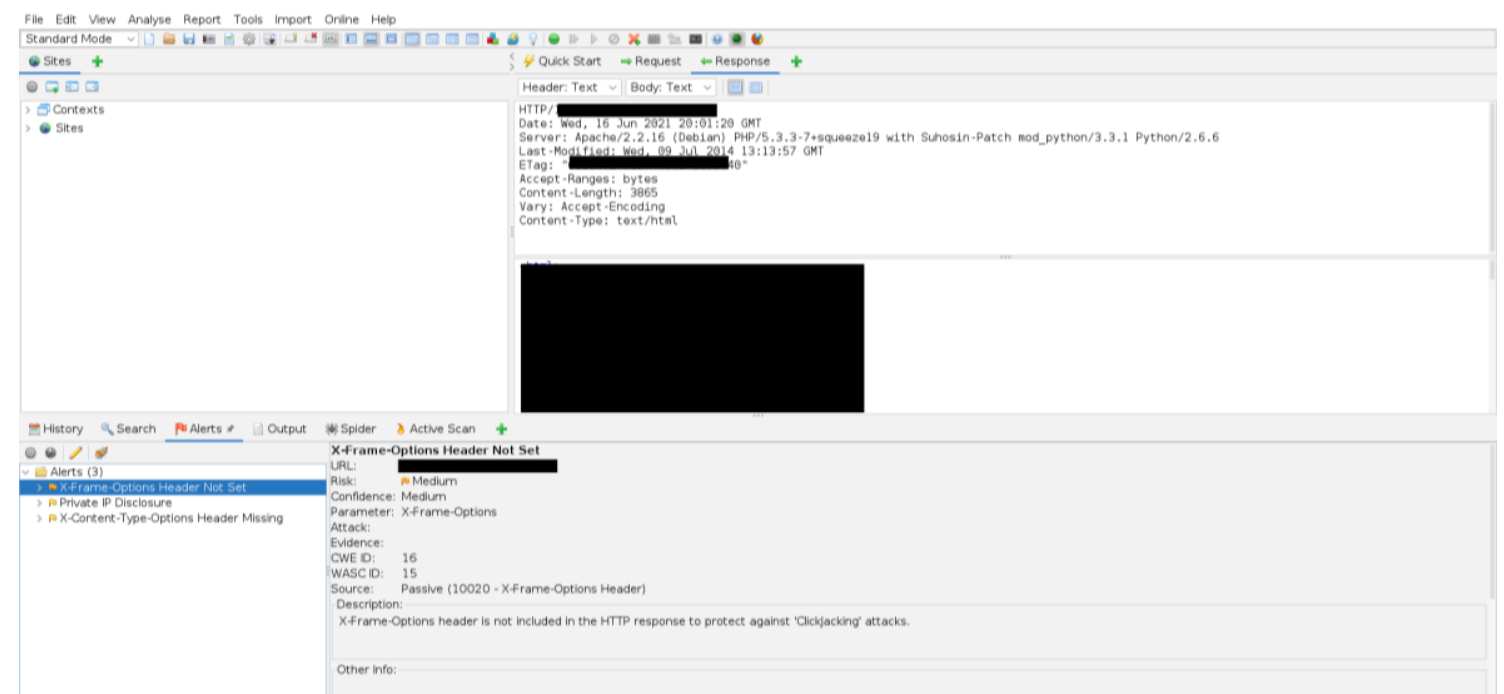

Figura 2. apresentação da vulnerabilidade encontrada. Falha: "x-frame-option header is not included in the http response"

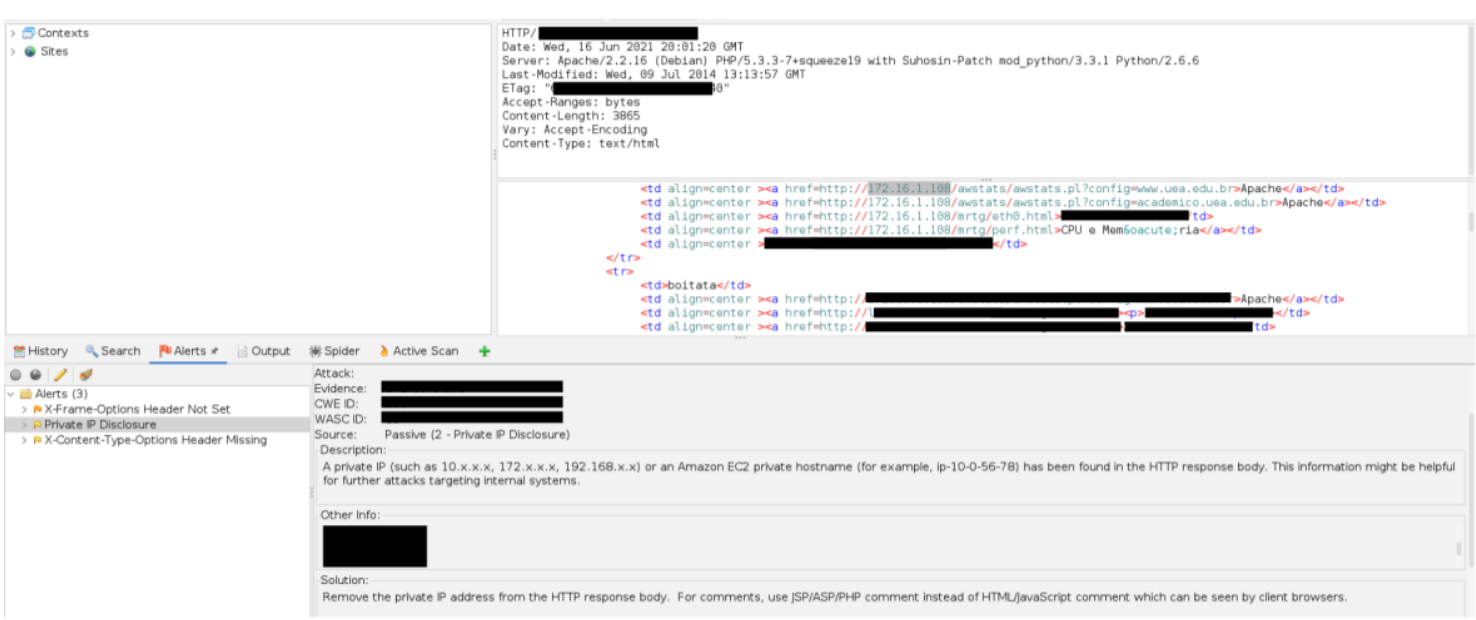

Figura 3. apresentação da vulnerabilidade encontrada. Falha: "Remove the private IP address from the HTTP response body".

\section{CONCLUSÃO}

A investigação resultou na identificação de duas falhas importantes. Além de enfatizar aspectos de segurança sob o olhar da Lei Geral de Proteção de Dados vigente desde 2020 no Brasil. A primeira falha, relacionada com o cabeçalho não 
incluso na resposta HTTP, possibilita a falta de integridade da informação acessada, expondo a página a ataques de clickjacking, pois o usuário pode não ser capaz de identificar a veracidade daquele conteúdo. A situação apresentada não atende ao princípio VII da lei 13.789, que suporta a informação do usuário contra a manipulação ilícita e/ou acidental de seus dados. A segunda, que diz respeito à obtenção de informações do servidor de maneira remota, tem potencial de prejudicar a confidencialidade das informações e, dependendo da criticidade do conteúdo, pode gerar vazamento de dados. Neste cenário, o artigo 52 parágrafo 7 determina que o controlador dos dados está sujeito a aplicação de penalidades, que podem ser multas e/ou sanções.

Para a defesa contra "Clickjacking", a maioria dos navegadores Web oferece suporte ao cabeçalho "HTTP X-Frame-Options", recomenda-se certificar que o cabeçalho está definido em todas as páginas web retornadas pelo site alvo. já para defesa contra "Remove the private IP address from the HTTP response body" pode ser solucionado configurando o servidor para filtrar as respostas entregues à requisições de usuários, bloqueando o acesso em informações que possam ser usadas contra a organização e monitorar preventivamente comportamentos incomuns de usuários.

Diante da situação descrita, a organização Independence pode rever sua Gestão de Risco, considerar que as falhas representam um risco elevado e aplicar boas práticas na segurança e configuração correta de ferramentas de rede com a intenção de prevenir incidentes posteriores.

\section{REFERÊNCIAS BIBLIOGRÁFICAS}

KALI LINUX TOOLS. Nmap Usage. Disponível em: www.kali.org/tools/nmap. Acesso em: 26 ago.2021.

GITLAB. ncat-W32. Disponível em: gitlab.com/kalilinux/packages/ncat-W32. Acesso em: 27 ago. 2021.

OWASP-ZAP. Getting Started. Disponível em: https://www.zaproxy.org/gettingstarted/. Acesso em: 27 ago. 2021. 


\title{
CAPÍTULO XXXVII
}

\section{ANÁLISE DA APLICAÇÃO DO ROBÔ HUMANOIDE NAO COMO AGENTE DE COMUNICAÇÃO, INCENTIVO E PERMANÊNCIA PARA OS ALUNOS DOS CURSOS DE ENGENHARIA DO PROJETO STEM}

\author{
Vinicius Bentes Vitor' \\ Paulo Fernando de Freitas Bastos' \\ Welithon Felipe Nobre do Nascimento' \\ Marlene Araújo de Farial
}

${ }^{1}$ Escola Superior de Tecnologia (EST) - Universidade do Estado do Amazonas (UEA) CEP 69050-020 - Manaus - AM - Brasil vbv.eai20@uea.edu.br, pffb.eai18@uea.edu.br, wfnn.eng17@uea.edu.br, mafaria@uea.edu.br

\section{INTRODUÇÃO}

Cada dia mais as tecnologias avançam e se tornam cada vez mais comuns no nosso cotidiano, tendo isso em vista torna-se fundamental que os alunos aprendam a conviver com essas tecnologias no seu meio de aprendizagem. Nesse contexto o robô é utilizado como instrumento de aprendizagem em experimento realizado em Núcleo de Tecnologia Assistiva da UEA que vem desenvolvendo pesquisas com o Robô Humanoide NAO no município de Manaus/Amazonas.

\section{OBJETIVOS}

O Projeto tem como objetivo apresentar o Robô HUMANOIDE NAO como um agente de comunicação para incentivo para permanência aos alunos de engenharia do Projeto STEM Núcleo de Tecnologia Assistiva da UEA.

\section{MATERIAIS E MÉTODOS}

O projeto pode ser desenvolvido através de métodos teóricos e computacionais. Utilizando o aplicativo Choregraphe, desenvolvido para o próprio robô é possível obter inúmeros movimentos interativos, sem precisar desenvolver diversas linhas de códigos, para quem ainda é iniciante na programação. Utilizando 02 exemplares do Robô Humanoide NAO, e duas Licenças do software Choregraphe. 


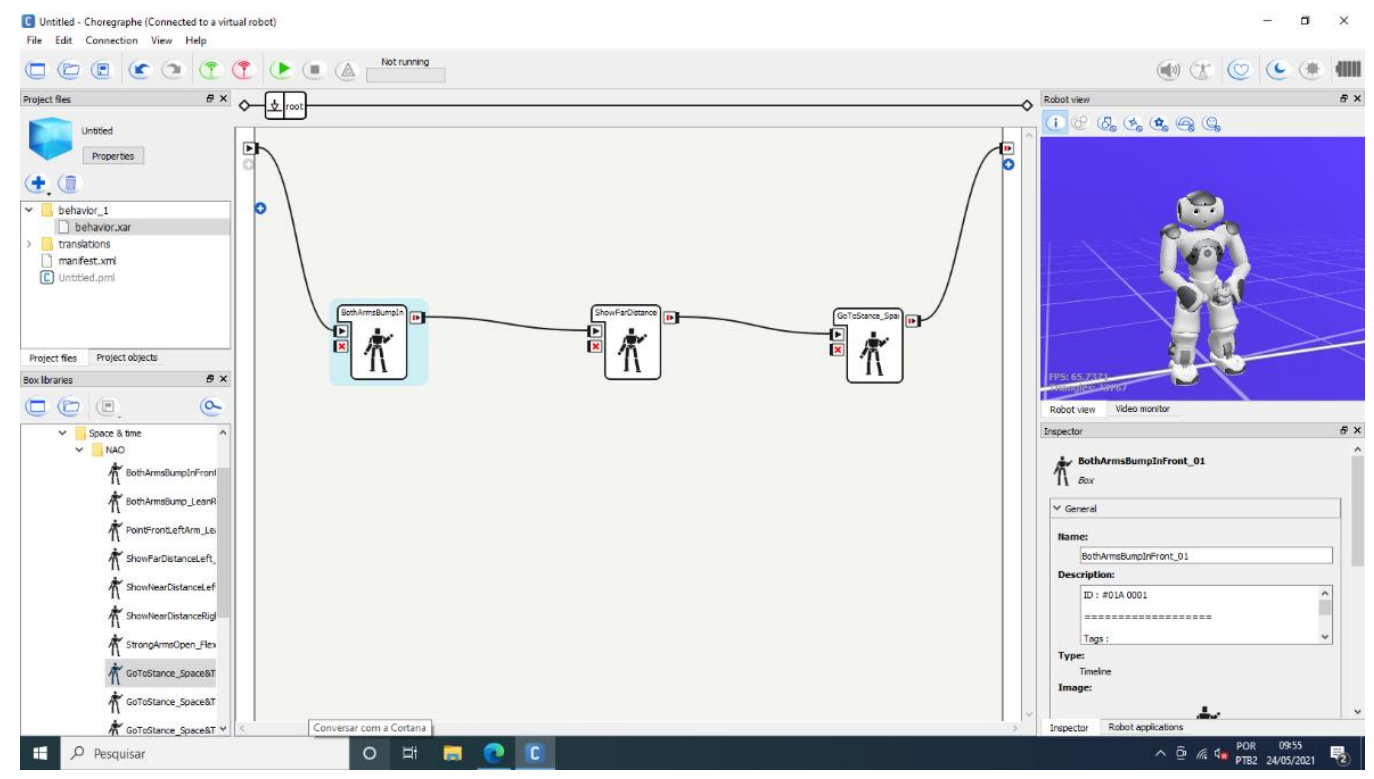

Figura 1. IDE nativa do Robô NAO com a programação em blocos

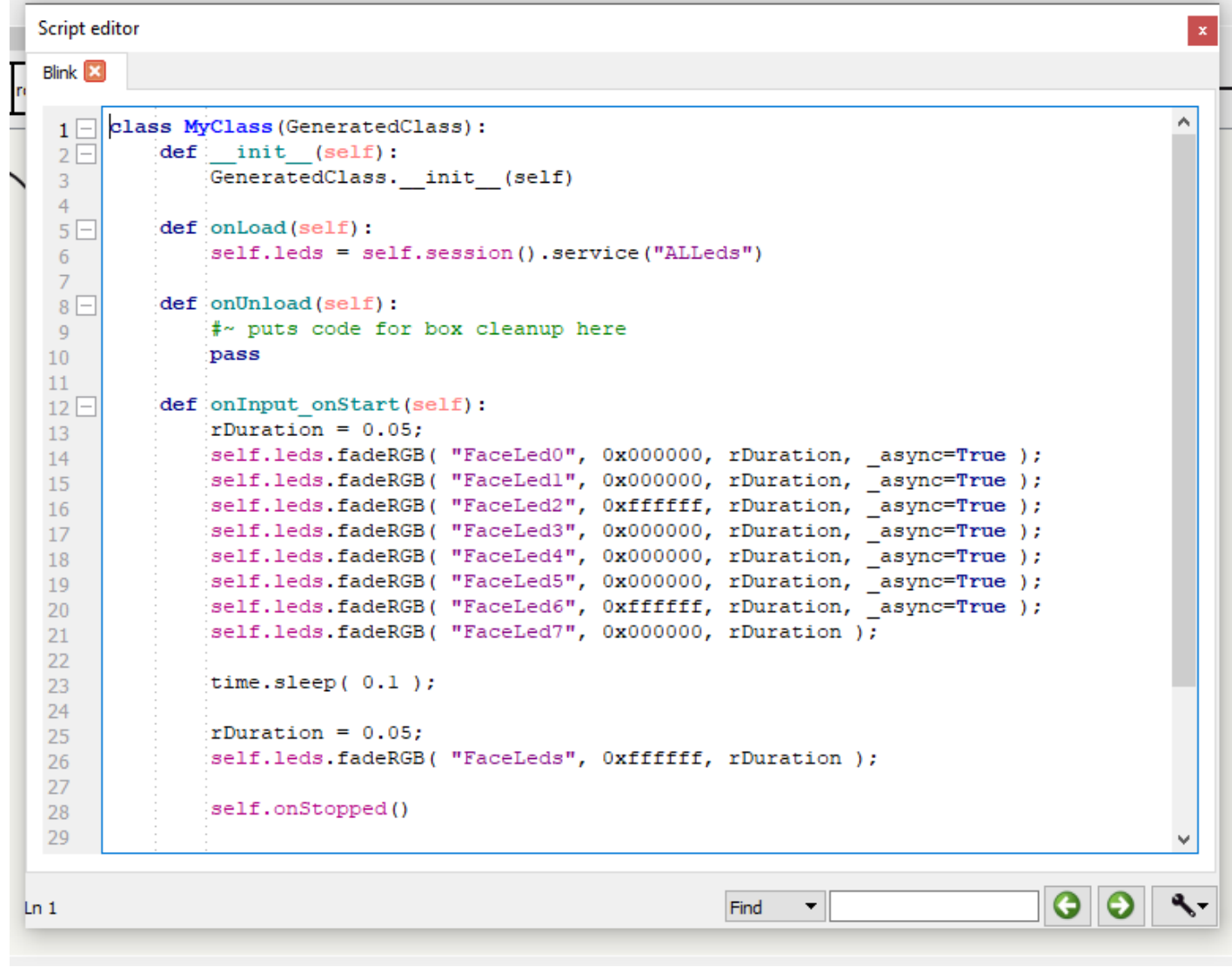

Figura 2. A IDE também aceita Python como linguagem de programação.

O programa Choreographe também é preparado para desenvolvedores mais desenvoltos com a linguagem Python, possibilitando a criação de programas mais complexos ao suprir certas necessidades que o código em blocos não seria capaz. 


\section{RESULTADOS}

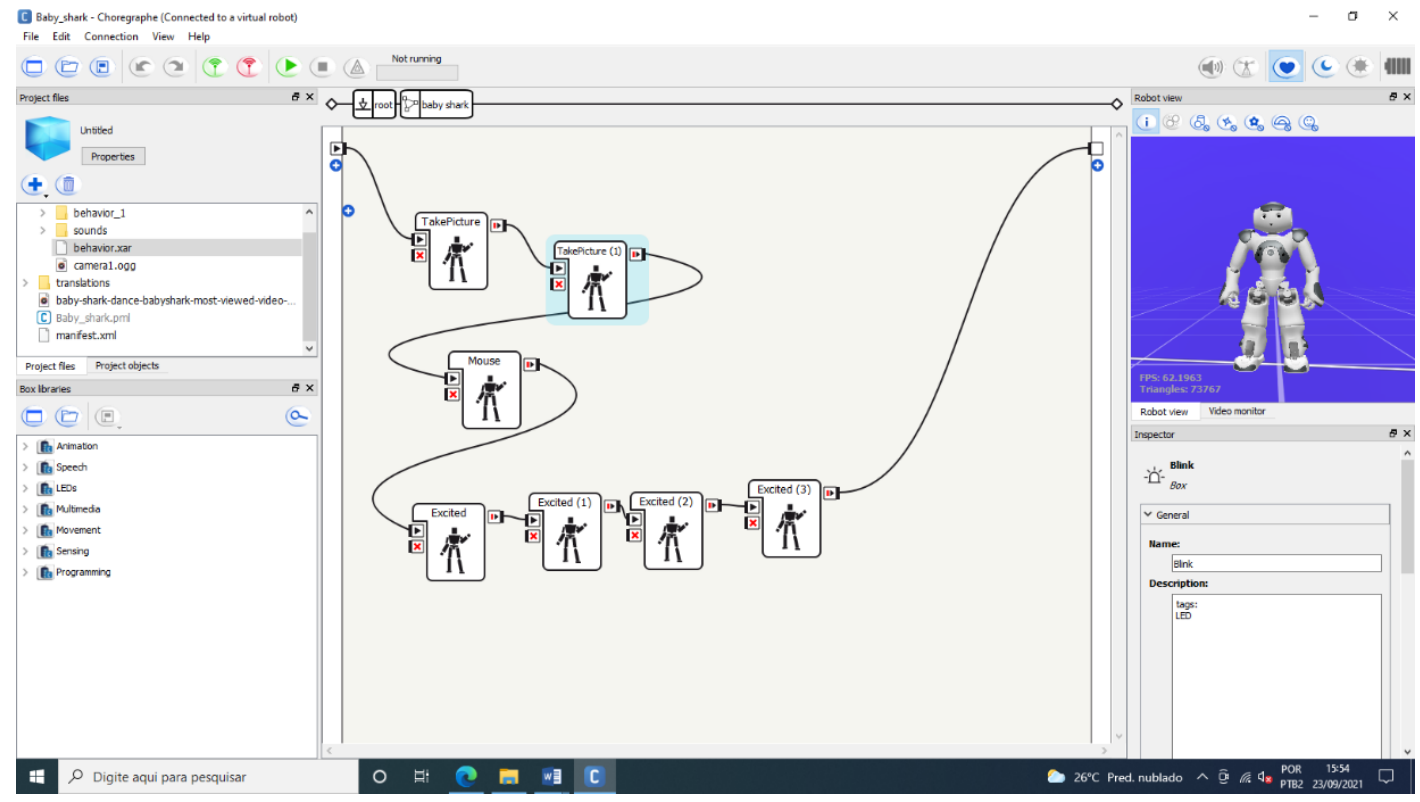

Figura 3. Programa finalizado com a coreografia da música "Baby Shark"

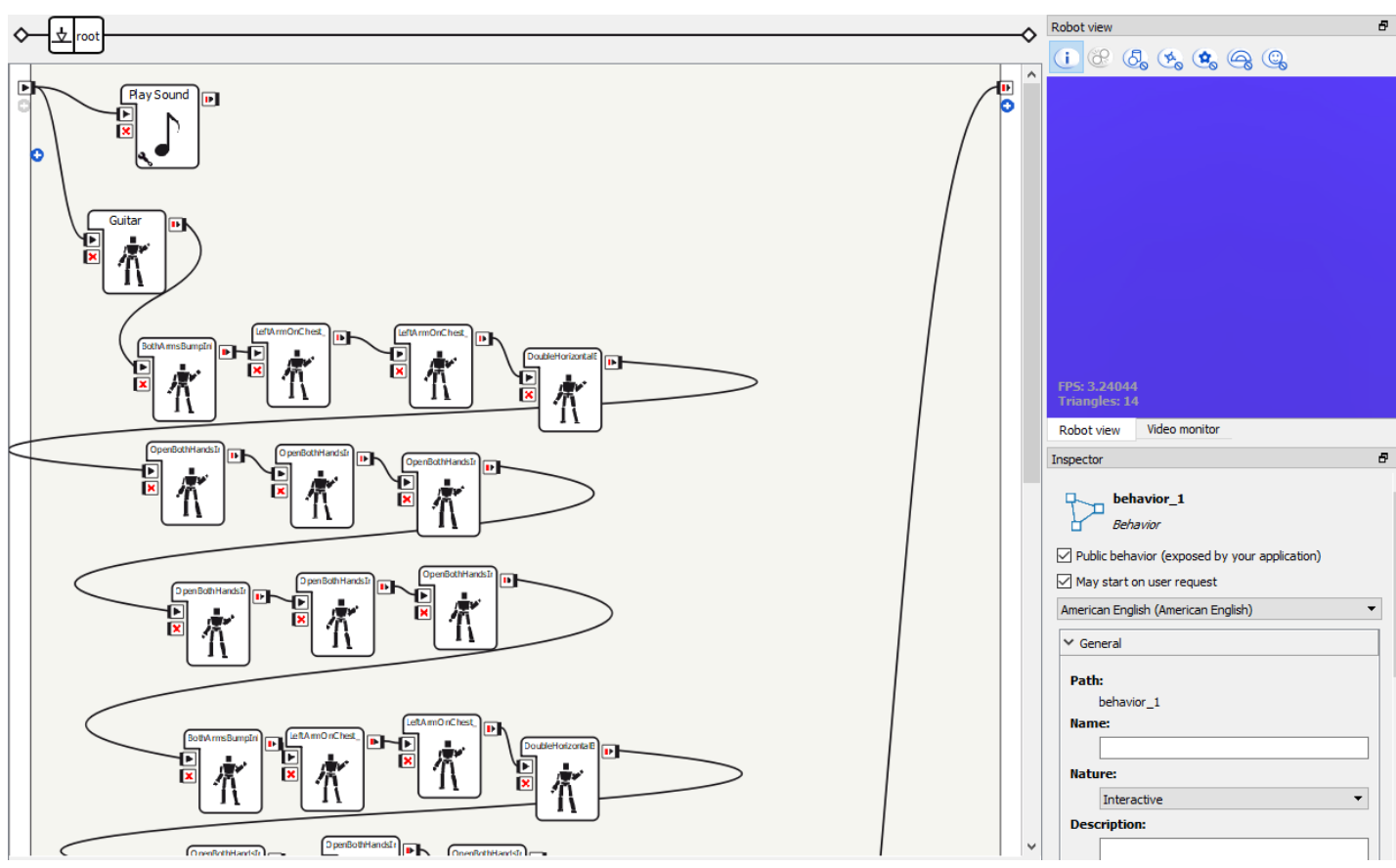

Figura 4. Coreografia finalizada baseada na música "A Baratinha" 


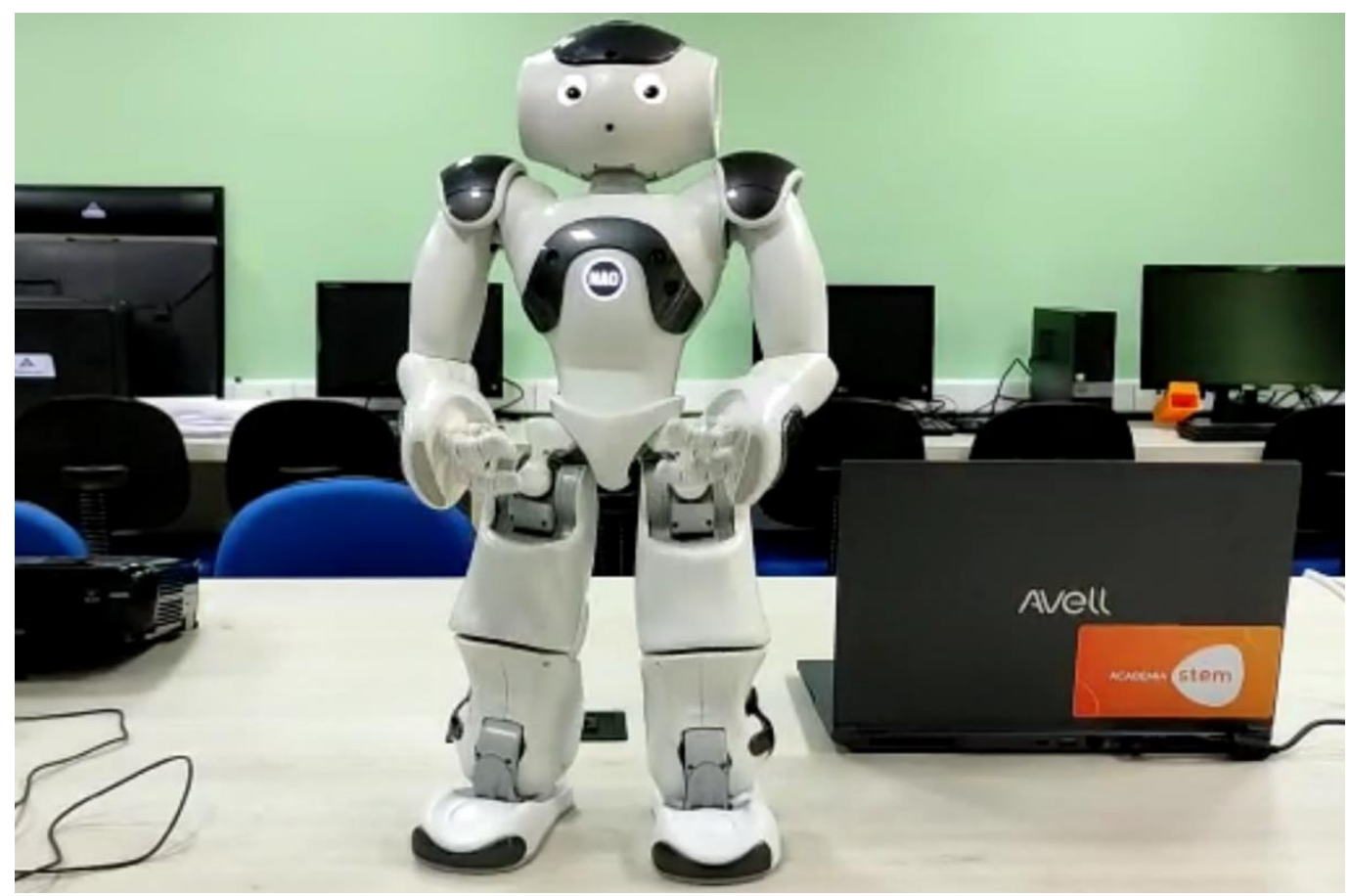

Figura 5. Robô Humanoide NAO praticando a coreografia da "Baratinha"

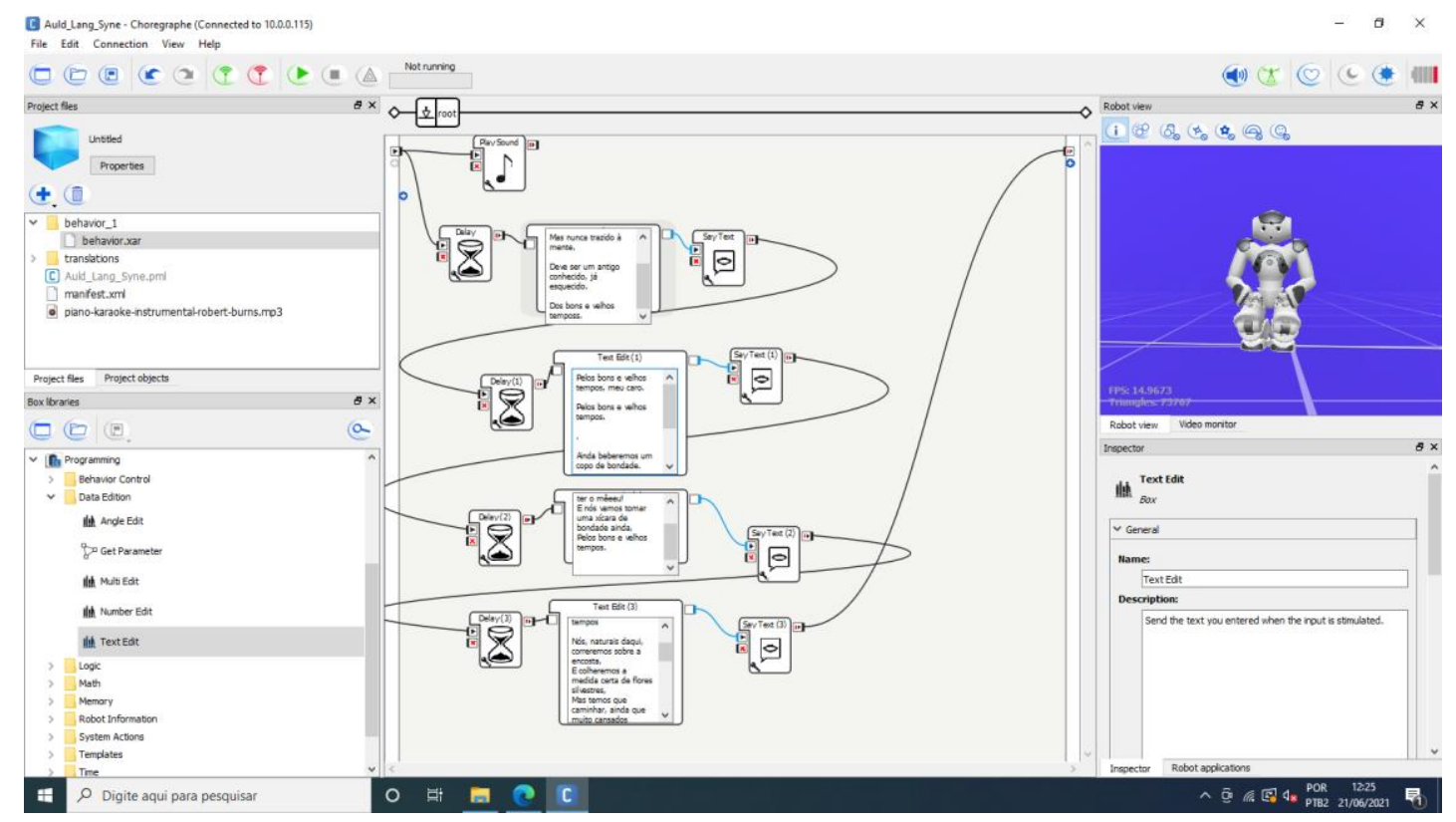

Figura 6. Programa desenvolvido usando a função de fala do Robô com a finalidade que ele cantasse a música "Auld Lang Syne"

\section{CONCLUSÃO}

0 projeto apresentou de maneira pratica e objetiva a importância da tecnologia nos métodos de ensino atuais. Foi de fundamental incentivo para a conclusão do curso de Engenharia de Controle e Automação, pois é muito 
importante ter contato com projetos complexos e importantes dentro da área, e foi o que ocorreu no projeto do robô NAO.

\section{REFERÊNCIAS BIBLIOGRÁFICAS}

ADA - AMERICAN WITH DISABILITIES ACT 1994. Disponível em: http://www.resna.org/taproject/library/laws/techact94.htm Acesso em 05 out 2015. BRASIL.

BEYER, Hugo Otto. Educação Inclusiva ou integração Escolar? Implicações pedagógica dos conceitos como ruptura paradigmática. Ensaios Pedagógicos, Brasil, 2007.

BERSCH, R. Tonolli, J. C. (2006). "Introdução ao Conceito de Tecnologia Assistiva e Modelos de Abordagem da Deficiência". Secretaria de Educação Especial Brasília: ABPEE - MEC: SEESP, Disponível em< http://www.bengalalegal.com/tecnologiaassistiva $>$, acessado em 01 jun 2015

BLIKSTEIN, I. Kaspar Hauser ou a fabricação da realidade. São Paulo: Cultrix / EDUSP, 1983.

BREMENKAMP, L. H. e MENEZES, A. C., Requisitos de Usabilidade em Interfaces para Ambientes de Aprendizagem em Engenharia de Produção: Um Estudo de Caso. Anais: XXXIX Congresso Brasileiro de Ensino de Engenharia, 2011

BREMENKAMP, L. H. e MENEZES, A. C., Requisitos de Usabilidade em Interfaces para Ambientes de Aprendizagem em Engenharia de Produção: Um Estudo de Caso. Anais: XXXIX Congresso Brasileiro de Ensino de Engenharia, 2011

COOK, A.M. \& HUSSEY, S. M. (1995) Assistive Technologies: Principles and Practices. St. Louis, Missouri. Mosby - Year Book, Inc. DECRETO № 5.296 de 02 de dezembro de 2004 - DOU de 03/122004. http://www.planalto.gov.br/ccivil_03/_ato20042006/2004/decreto/d5296.htm Acesso em jan 2016

ChiarotTino, Z. Psicologia e epistemologia Genética de Jean Piaget. São Paulo: E.P.U.,1988

DECRETO № 3.298, de 29 de dezembro de 1999. http://www.planalto.gov.br/ccivil_03/decreto/d3298.htm Acesso em dez 2015

EDEN, C.; HUXHAM, C. Pesquisa-ação no estudo das organizações. In: CLEGG, S. R.; HARDY, C.; NORD, W. R. (Org.) Handbook de Estudos Organizacionais. São Paulo: Atlas, 2001.v 2.p.93-117. 
FENG, Huanghao ; ZHANG, Jun; MAHOOR, Mohammad H.; GUTIERREZ, Anibal. Can NAO Robot Improve Eye-Gaze Attention of Children with High Functioning Autism? (2013) .Disponível em: http://dl.acm.org/citation.cfm?id=2550059, Acesso em jan 2016.

FIOCCO, M (2015). "Software Educacional, Brasil escola". Disponível em < http://meuartigo.brasilescola.com/informatica/software-educacional.htm> acessado em 21 abril 2015.

GOOSSENS,C. \& CRAIN, S.S. (1992) Utilizing Switch Interfaces with Children who are Severely Phisically Challenged. Autin, Texas. Pro.ed, 4 Inc. LIMA, Niusarete Margarida de. Legislação Federal Básica na área da pessoa portadora de Deficiência. Brasília: Secretaria Especial dos Direitos Humanos, Coordenadoria Nacional para Integração da Pessoa Portadora de Deficiência, 2007. PORTARIA INTERMINISTERIAL № 362, DE 24 DE OUTUBRO DE 2012. Disponível

em: http://www.pessoacomdeficiencia.gov.br/app/sites/default/files/arquivos /\% 5Bfield_generico_imagens-filefielddescription\%5D_58.pdf Acesso em jun 2015. 


\section{CAPÍTULO XXXVIII}

\section{CADEIRA DE RODAS DE PROPULSÃO MOTORIZADA}

Gabriel Barros de Almeida

Jaão Felipe de Paula Almeida

Helio Gama da Silva Junior

Marlene Araújo de Faria

Cleto de Souza Leal

1Escola Superior de Tecnologia (EST) - Universidade do Estado do Amazonas (UEA) CEP 69050-020 - Manaus - AM - Brasil gbda.eai20@uea.edu.br, jfdpa.eai20@uea.edu.br, hgdsj.eai20@uea.edu.br, mafaria@uea.edu.br, cleal@uea.edu.br.

\section{INTRODUÇÃO}

Os usuários de cadeira de rodas passam por diversas dificuldades em seu cotidiano e com o advento da tecnologia foi possível métodos para facilitar tanto a vida deles quanto de outras pessoas com deficiências, uma dessas formas de contornar esses problemas no dia a dia foram as cadeiras motorizadas, mas seu principal defeito é ter um preço muitas vezes inacessível.

\section{OBJETIVOS}

A maioria dos cadeirantes não tem recurso financeiro o suficiente para adquirir uma cadeira de rodas motorizadas que facilitam demais em sua vida, tendo isso em vista este projeto visa a adaptação de cadeira de rodas convencionais em um triciclo motorizado, diminuindo seu preço e sendo necessário apenas domínio dos membros superiores fazendo com que diminua os esforços físicos realizados nos trajetos do dia a dia.

\section{MATERIAIS E MÉTODOS}

Neste projeto, foram feitas pesquisas sobre quais eram as principais dificuldades dos cadeirantes e como eles gostariam de serem ajudados, também foi abordado sobre outras iniciativas que dão foco à esta pauta, como esportes, dança e mobilidade urbana.

Será preciso montar um regime de funcionamento como aceleração, frenagem e comandos, para se obter uma movimentação mais fluida para um uso 
satisfatório e completo de quem utilizar a cadeira e desenvolver mais o projeto foi necessário o uso de dois outros programas, o Proteus para circuitos elétricos e o NX para confecção de peças.

\subsection{PROTEUS}

Proteus Design Suite é um software para criação de projetos eletrônicos, composto por uma suíte de ferramentas, incluindo captura esquemática, simulação e módulos de projetos de placas de circuito impresso, usadas principalmente para o projeto de circuitos integrados. E esse programa foi utilizado nesse projeto para fazer os circuitos elétricos e suas respectivas placas, tendo esses circuitos o de acionamento, freio, ré e controle de velocidade.

\subsection{NX}

O Software $\mathrm{NX}^{\mathrm{TM}}$ da Siemens é uma solução flexível, integrada e poderosa que ajuda você a entregar produtos melhores mais rápida e eficientemente. 0 NX é a próxima geração de soluções de projeto, simulação e manufatura, para capacitar as companhias a aproveitar o valor do Gêmeo Digital. Essa ferramenta foi de exímia importância para o trabalho já que a partir dela que permitiu projetar as peças do kit de motorização.

\section{RESULTADOS}

Usando o Proteus para a elaboração do circuito elétrico, foi representado como entradas e saídas os T-Blocks, e os Switches como chaves ou botões de acionamento para controlar a velocidade, dar a ré e dar a partida direta ou parar o kit de motorização. Para que o circuito funcionasse da melhor maneira, foi necessário que englobássemos ele por completo dentro de uma ponte $\mathrm{H}$, que serve para dar a partida direta e reversa do motor (funcionando para que o kit vá para frente e dê ré), e a chave com 5 estados junto com seus resistores e transistor para controlar a velocidade do sistema inteiro. Conforme se muda a chave, a corrente para qual irá passar pelo motor será diferente, sendo que quanto maior a resistência selecionada (marcha), menor será sua corrente e velocidade, logo após isso teríamos a chave de ré em conjunto com a ponte $\mathrm{H}$, que depois que acionada muda o sentido da corrente fazendo com que o motor gire no sentido anti-horário. E nessa ponte $\mathrm{H}$ é necessário diodos e transistores que servem respectivamente para não deixar 
passar correntes no sentido contrário do desejado e para retificar essa corrente, mudando sua intensidade e para o trajeto para a qual irá prosseguir no circuito.

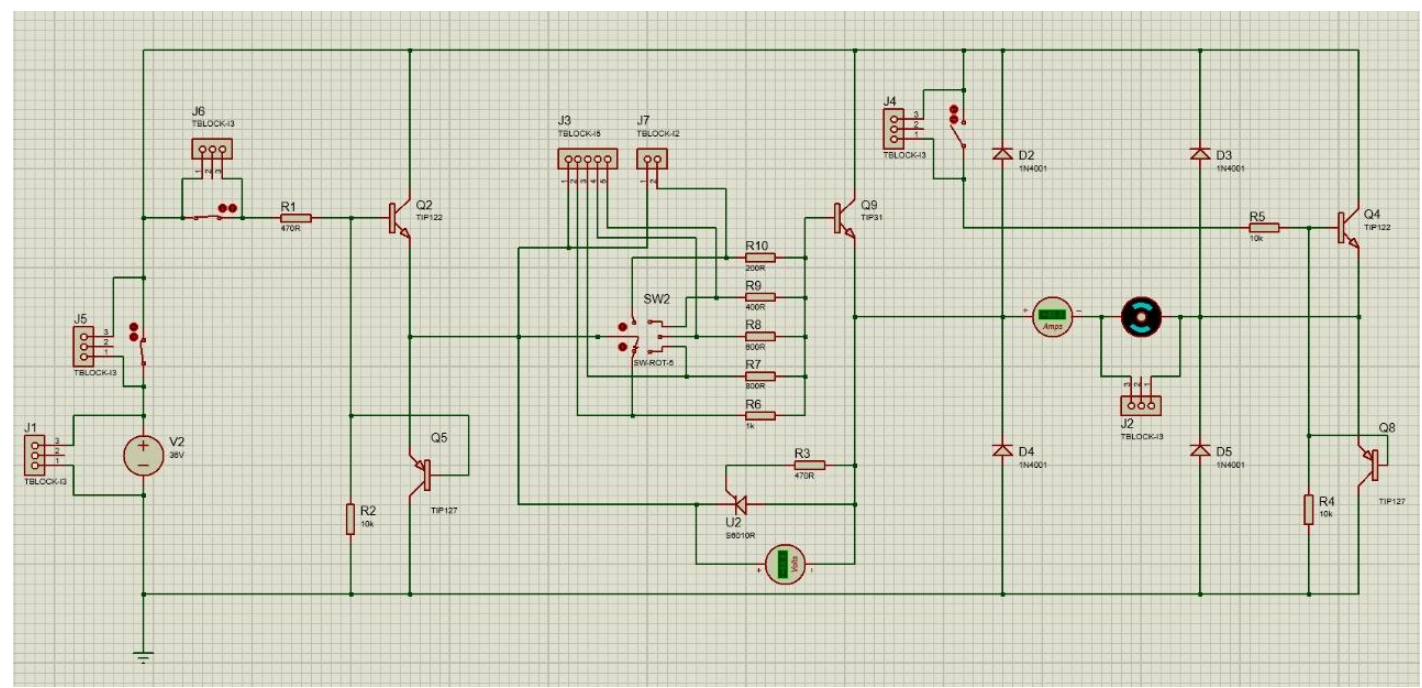

Figura 1. Circuito completo do kit de motorização

Utilizando a interface ARES (Advanced Routing and Editing Software), que advém do programa Proteus, criamos um layout da placa do circuito do kit de motorização da cadeira de rodas. Esta interface possibilitou com que os componentes e ligações usadas no esquema do circuito fossem simuladas, pegando tamanhos parecidos com a realidade para elaborar um futuro protótipo e ter uma noção de como seria. Além disso com sua ferramenta "Auto-Router" foi possível criar trilhas elétricas que servem de ligação do circuito entre seus componentes. $\mathrm{E}$ depois foi usado a ferramenta "3D Visualizer", do Proteus, em conjunto como ARES, para projetas a placa, bornes, componentes e trilhas, lembrando que é necessário ter um cuidado ao alocar os componentes visto que as trilhas podem dar diversos problemas, estourando se tiverem um corrente alta passando por elas, então na alimentação foram usadas trilhas com espessura maior do que nas de sinais, e para o aterramento usamos uma malha que cobre a placa, para que otimizasse a placa e prevenindo futuros problemas como falhas na transmissão de energia e curtos circuitos, e tendo espaço entre os transistores já que esses dissipam bastante calor, podendo danificar o circuito. 


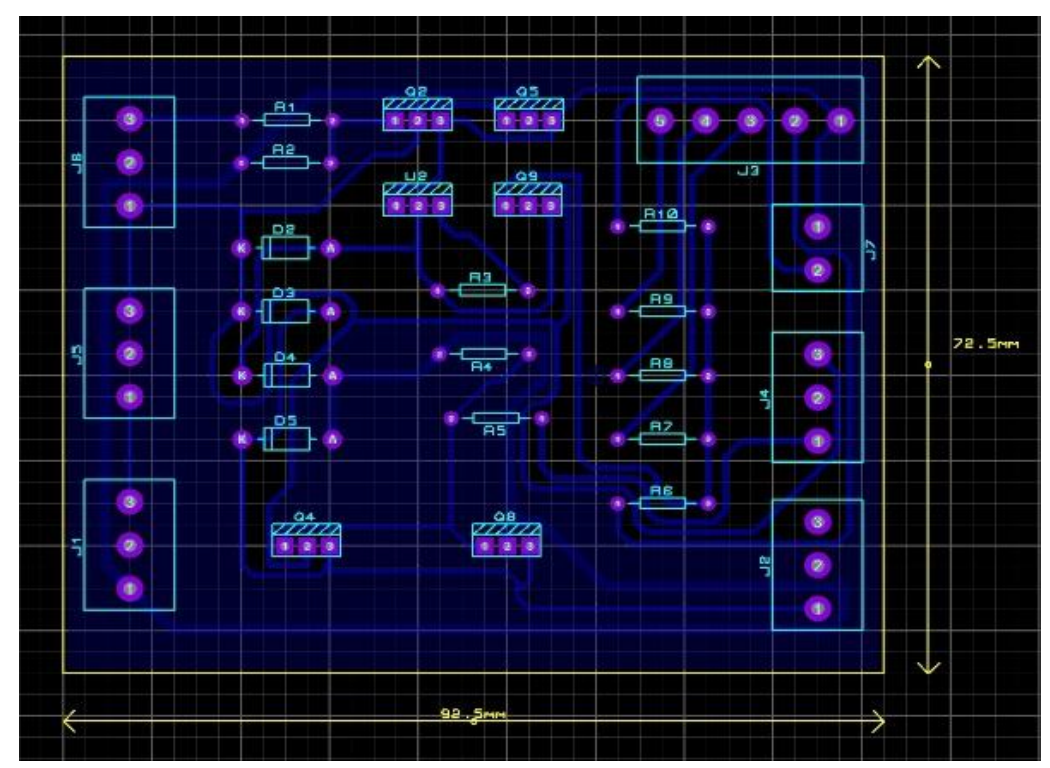

Figura 2. layout da placa do circuito

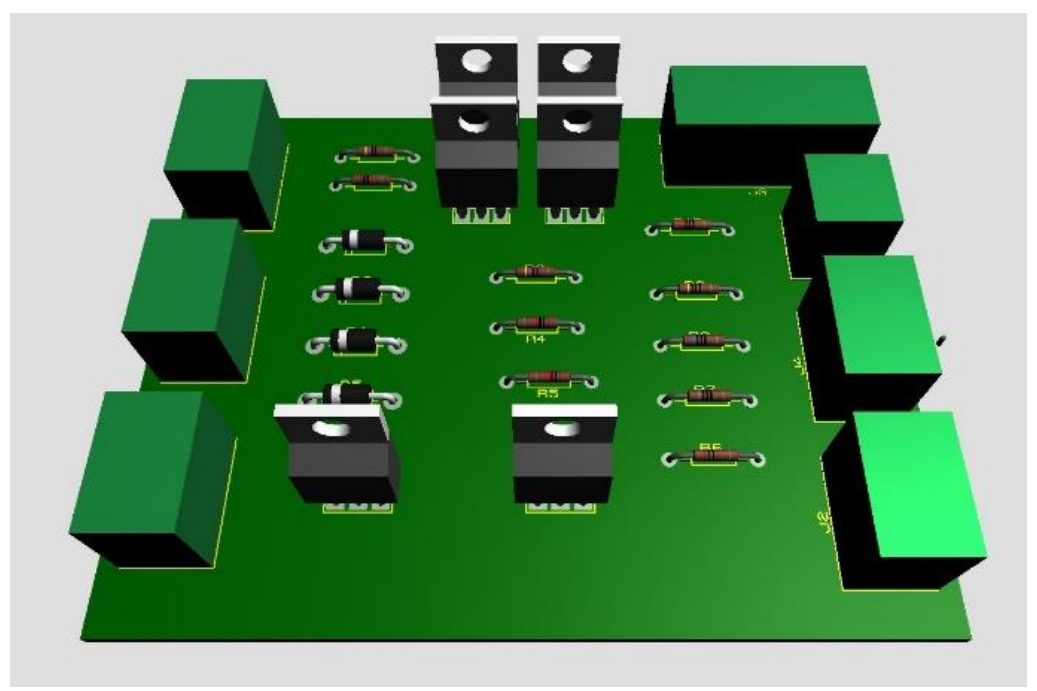

Figura 3. Visualização em 3D da placa

Utilizando o software Siemens NX 12.0 e com base nas informações dos desenhos técnicos foi possível elaborar um desenho em 3D da cadeira de rodas motorizada. Na imagem é possível ver a vista explodida da cadeira de rodas e suas respectivas peças. Utilizando o software Siemens NX 12.0 e com base nas informações dos desenhos técnicos foi possível elaborar um desenho em 3D da cadeira de rodas motorizada. Na imagem é possível ver a vista explodida da cadeira de rodas e suas respectivas peças. 


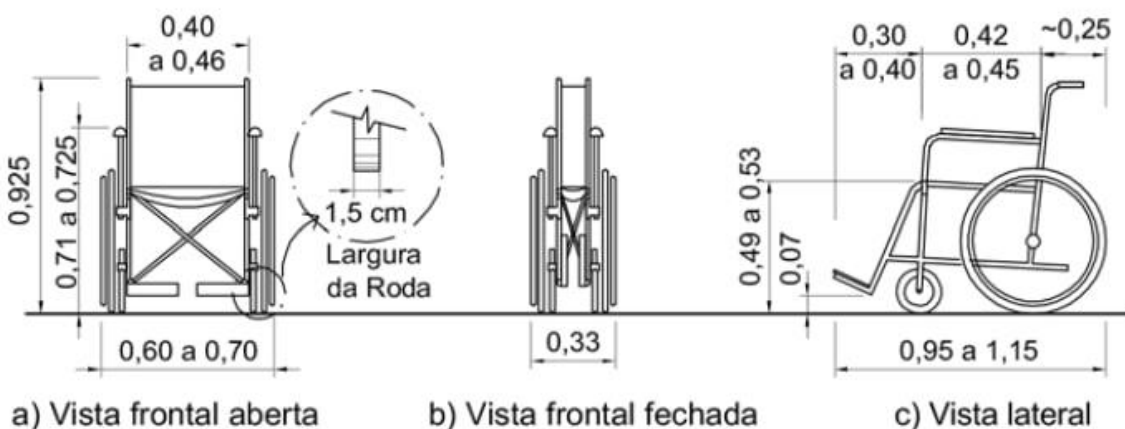

Figura 4. Cotas da cadeira de rodas

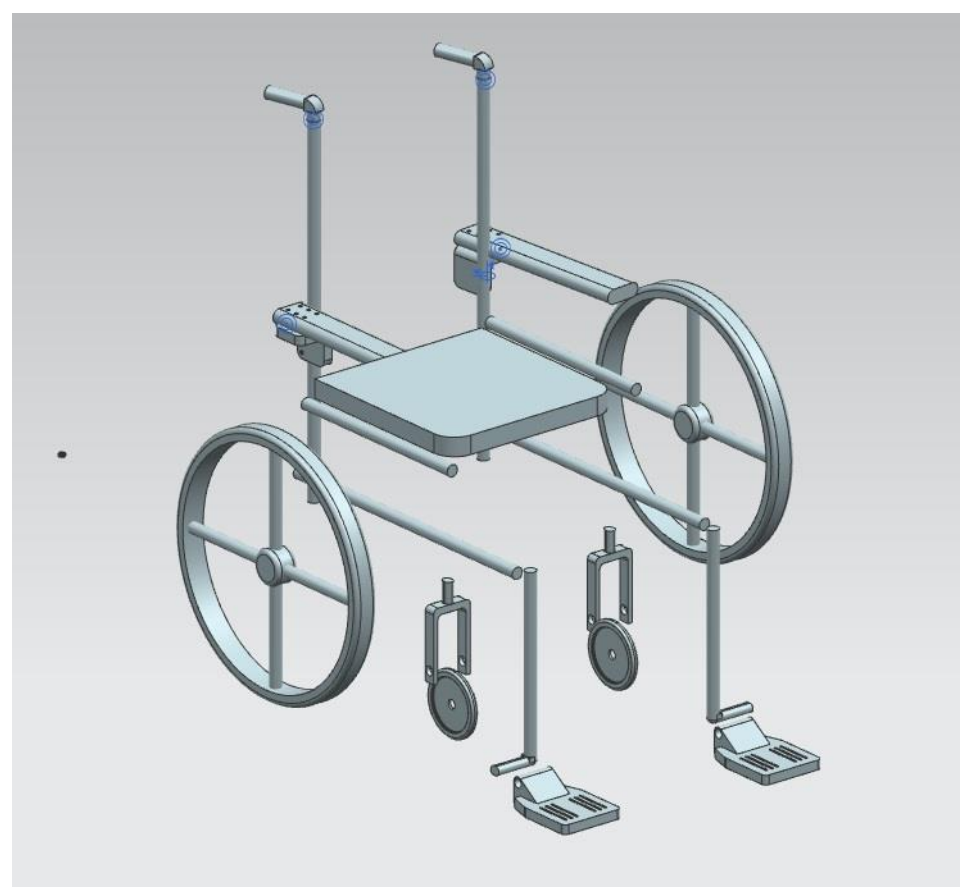

Figura 5. Captura de tela do software NX com a visão expandida parcial da cadeira de rodas e as suas peças.

\section{CONCLUSÃO}

A análise deste estudo permitiu, através de softwares, o princípio de funcionamento das cadeiras de rodas com o kit de motorização e, teoricamente, identificar as principais partes da cadeira e do circuito que fazem com que o sistema de propulsões funcione, juntamente estudando a biomecânica desse sistema. Este projeto deve auxiliar as pessoas com limitações motoras inferiores, dando uma nova alternativa de acessibilidade. Com esse kit de motorização, além do usuário se locomover mais facilmente, ele também deve estar acessível em orçamento. 
ALVARENGA, Flávia Bonilha. Desenvolvimento de Sistemas de Motorização Alternativa para Cadeiras de Rodas Convencionais. 2002. Dissertação (Mestrado em Engenharia Mecânica) - Universidade Estadual de Campinas, Campinas, SP, 2002.

FERREIRA, Eliana Lucia. Corpo - Movimento - Deficiência: As formas dos discursos da/na dança em cadeiras de rodas e seus processos de significação. 2003. Tese (Doutorado em Educação Física) - Universidade Estadual de Campinas, Campinas, SP, 2003.

ASSOCIAÇÃO BRASILEIRA DE NORMAS TÉCNICAS. NBR 9050: Acessibilidade a edificações, mobiliário, espaços e equipamentos urbanos. Rio de Janeiro. 2020.

INSTITUTO NACIONAL DE METROLOGIA, QUALIDADE E TECNOLOGIA - INMETRO - PROGRAMA DE ANALISE DE PRODUTOS: RELATORIO SOBRE A ANALISE EM CADEIRA DE RODAS. Rio de Janeiro, 2013.

MACHADO, Simone. Cadeirante, ex-atleta sobrevive como entregador de app no interior de SP. UOL, São Paulo, 8 de março de 2021. Disponível em: $<$ https://www.uol.com.br/esporte/ultimasnoticias/2021/03/08/cadeirante-ex-atleta-sobrevive-como-entregador-deapp-no-interior-de-sp.htm>. Acesso em 8 de março de 2021.

RISI, Daniel. Oficina de Usabilidade. UX, UI e Usabilidade, Usuário vs. Sistema, 10 heurísticas de usabilidade. In: Cursos Ocean Samsung, 2019, Anais Eletrônicos, São Paulo.

RISI, Daniel. Oficina: Design Thinking. Introdução ao Design Thinking, Métodos, ferramentas e prática, Atividade: Simulando um Design Sprint. In: Cursos Ocean Samsung, 2019, Anais Eletrônicos, São Paulo. 


\section{MODELAGEM DE FÍSICA EM PYTHON: GRAVITAÇÃO E DILATAÇÃO TÉRMICA}

Yuri Macedo Michele'

Vinícius Santos da Silva²

Fabian Cardoso Litaiff ${ }^{3}$

Escola Superior de Tecnologia (EST) - Universidade do Estado do Amazonas (UEA) CEP 69050-020 - Manaus - AM - Brasil vsds.eai20@uea.edu.br, ymm.eai20@uea.edu.br, flitaiff@uea.edu.br

\section{INTRODUÇÃO}

Na Aplicação de Gravitação, temos duas seções diferentes, uma se dá o resumo dos quatro principais assuntos da gravitação (Leis de Kepler, Lei da Gravitação Universal, Aceleração da Gravidade e Velocidade Orbital e Velocidade de Escape) e uma segunda seção onde se encontram quatro calculadoras, uma para cada assunto de gravitação. Na Aplicação de Dilatação Térmica, temos três seções diferentes, uma para cada aspecto da Dilatação Térmica (Dilatação Linear, Dilatação Superficial, Dilatação Volumétrica), onde encontram se um resumo sobre cada uma e uma opção de calculadora para cada parâmetro de cada aspecto da dilatação escolhida anteriormente.

\section{OBJETIVOS}

Facilitar o acesso à conteúdos de Física aos estudantes do Ensino Médio, desenvolvendo duas aplicações em Linguagem Python.

Otimizar os cálculos matemáticos dos assuntos de Física 1: Gravitação e Física 2: Dilatação Térmica buscando uma maior otimização para os códigos dos programas.

\section{MATERIAIS E MÉTODOS}

Com base nos resultados, foram utilizadas diversas bibliotecas desta linguagem, como o PyQt5 (que permitiu criar as janelas da aplicação), fastnumbers (Que permite a identificação de um número, se é decimal, inteiro), especificamente sobre a aplicação de Gravitação, é se utilizado duas janelas de código, uma que é 
usada como uma biblioteca extra chamada "Ajuda", que permite que muitos algoritmos de códigos que seriam repetidos durante o programa, como a criação de botões, janelas, textos e outros sejam resumidos em apenas uma linha de código. Então tem-se a janela principal, onde a aplicação é feita, nela pode-se verificar como a aplicação funciona, onde tem-se os códigos, cálculos e comentários que permitem a organização e funcionamento do software. É importante destacar que para cada parte incrementada nas linhas de códigos, foram realizados vários estudos, para evitar erros enquanto o programa estiver em uso. Na parte dos resumos também foi realizada uma intensa pesquisa para procurar sanar as dúvidas dos alunos que optarem por lê-lo e também é explicada as fórmulas usadas nas calculadoras.

Sobre a Aplicação de Dilatação Térmica, é se utilizado uma janela de código, uma que permite que alguns algoritmos sejam importados e outros repetidos durante a execução do programa, como a importação dos layouts criados em um outro programa (PyQt designer) e além da utilização do método de classe para simplificar as linhas de código. Na janela principal, onde a aplicação é feita, nela podemos verificar como a aplicação funciona, onde temos os códigos, cálculos e comentários que permitem a organização e funcionamento do software. É importante destacar que para cada parte incrementada nas linhas de códigos, foram realizados vários estudos, para evitar erros enquanto o programa estiver em uso. Na parte dos resumos também foi realizada uma intensa pesquisa para procurar sanar as dúvidas dos alunos que optarem por lê-lo e também é explicada as fórmulas usadas nas calculadoras.

\section{RESULTADOS}

Destaca-se como benefícios observados com relação ao desenvolvimento das aplicações, a exatidão dos resultados dos cálculos e constante possibilidade de melhoria dos softwares.

\subsection{QUANTO AO PROGRAMA DE GRAVITAÇÃO:}

Podemos observar as primeiras linhas de código da janela principal do programa de gravitação na figura 1, e a janela de ajuda na figura 2. Pela janela principal possuir mais de mil linhas de código, fica inviável fotografá-lo por completo. 
Na figura 3 podemos observar as telas da aplicação, sendo o item (a) o menu principal, os itens (b) e (c) sendo os menus de resumos e de calculadoras, respectivamente. Na figura 4 temos as telas de escolha de variável, que permite aos estudantes utilizarem as calculadoras para mais de um tipo de cálculo.

Por fim temos as figuras 5 e 6 que mostram as telas de resumos e as telas de calculadoras respectivamente:

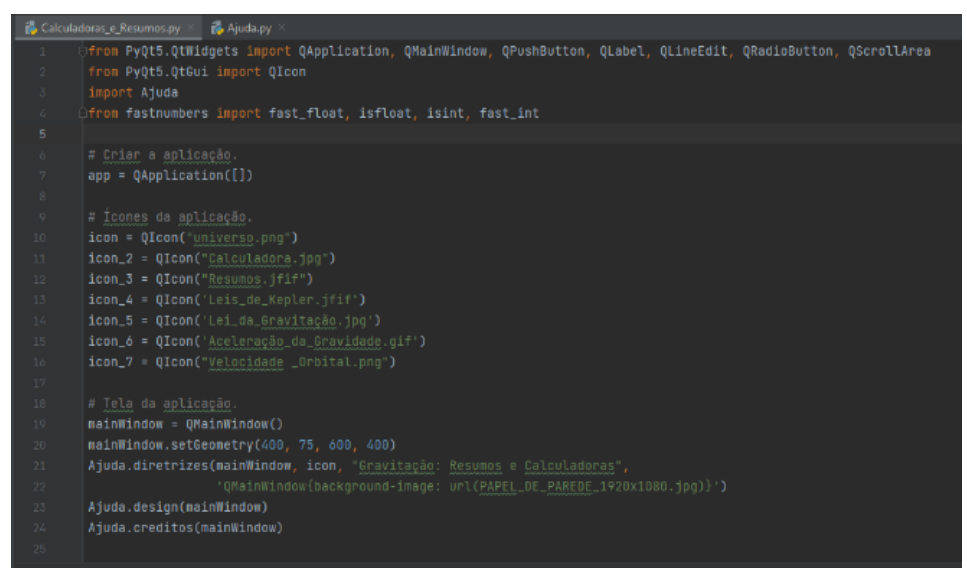

Figura 1. Primeiras linhas da janela principal

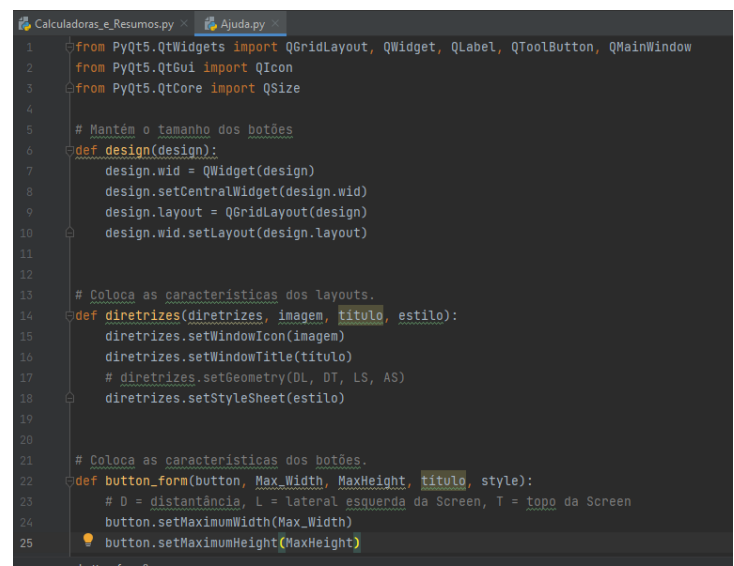

Figura 2. Primeiras linhas da janela de Ajuda 

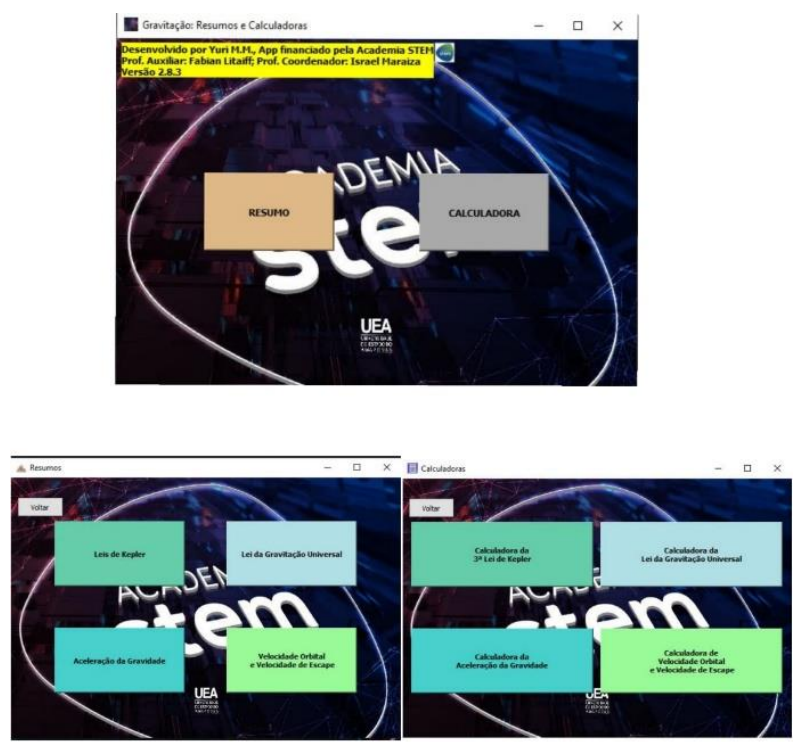

Figura 3. Menu principal, Menu de Resumos e Menu de Calculadoras
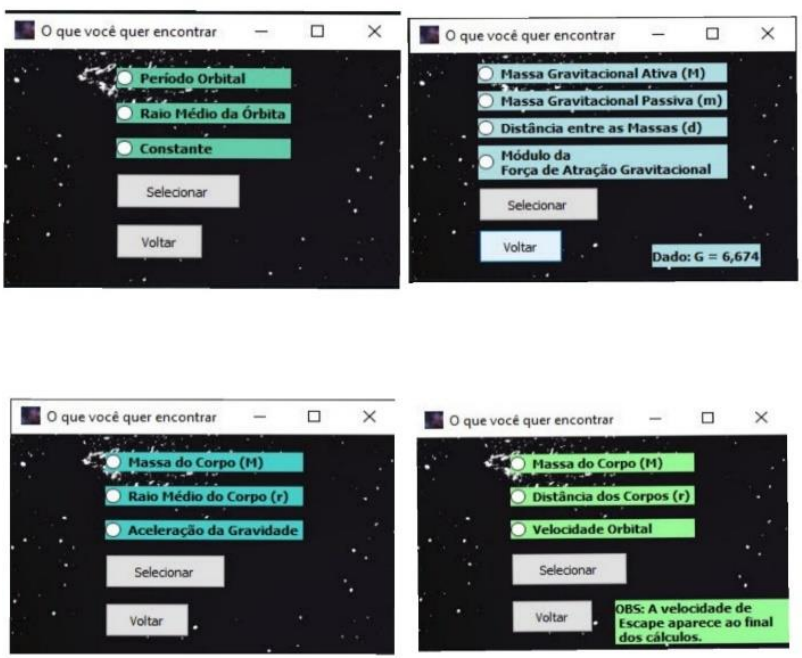

Figura 4. Telas de escolha de Variável 

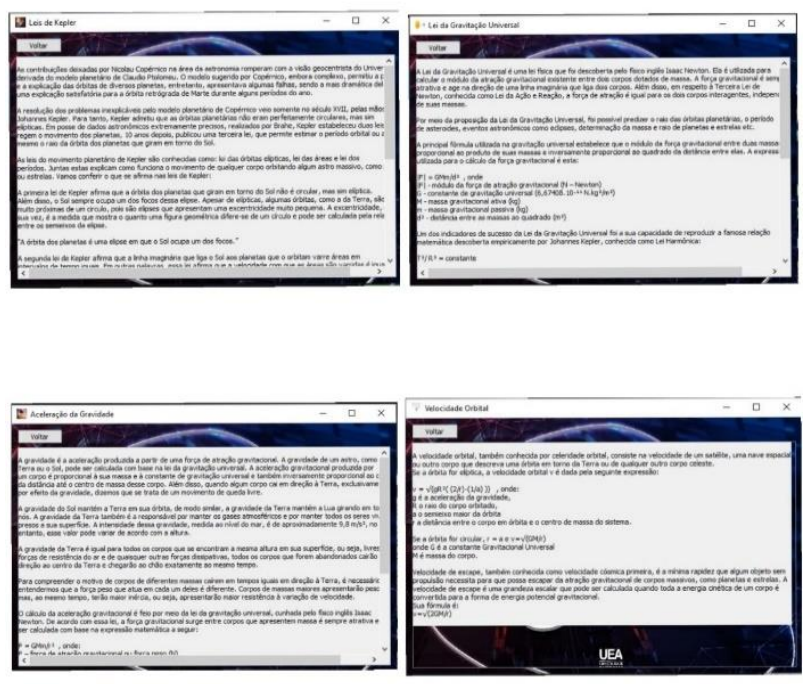

Figura 5. Resumos
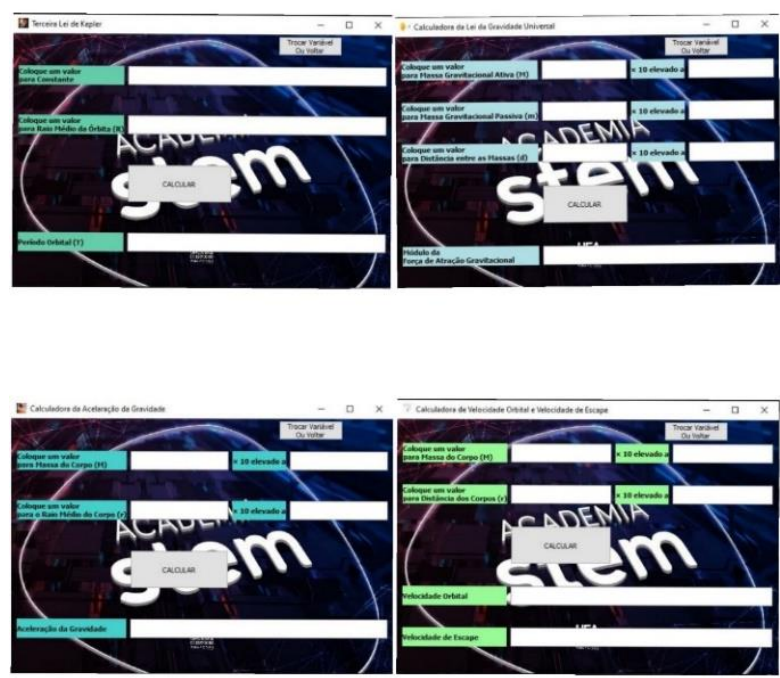

Figura 6. Calculadoras

\subsection{QUANTO AO PROGRAMA DE DILATAÇÃO TÉRMICA}

Podemos observar os primeiros de código que fazem a importação das telas utilizadas na aplicação do programa de dilatação na figura 7, em seguida, podemos observar o método de construção da janela de uma das janelas iniciais na figura 8, em seguida, podemos observar o modo como os cálculos foram adaptados a linguagem python na figura 9. Por conta de a interface principal possuir mais de 500 linhas de código, fica inviável fotografá-lo por completo.

Na figura 10 podemos observar as telas do menu inicial e do menu de seleção. Na figura 11 temos as telas de escolha dos parâmetros de cada dilatação, que permite aos estudantes utilizarem as calculadoras para mais de um tipo de cálculo. 
Por fim temos as figuras 12, 13 e 14 que mostram as telas das calculadoras de cada tipo de dilatação respectivamente:

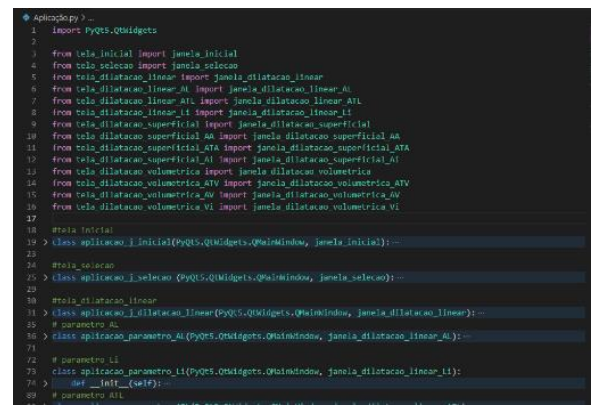

Figura 7. Primeiras linhas da aplicação

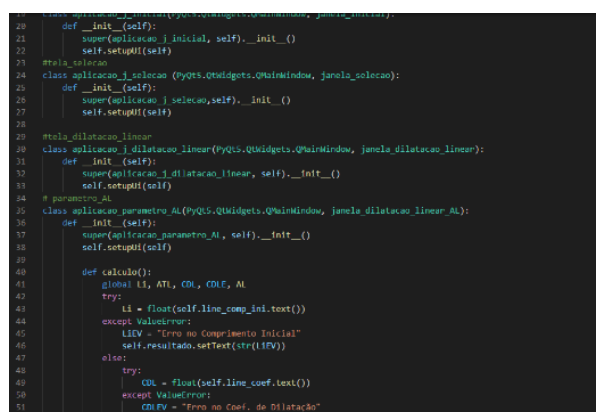

Figura 8. Primeiras linhas da construção em classe

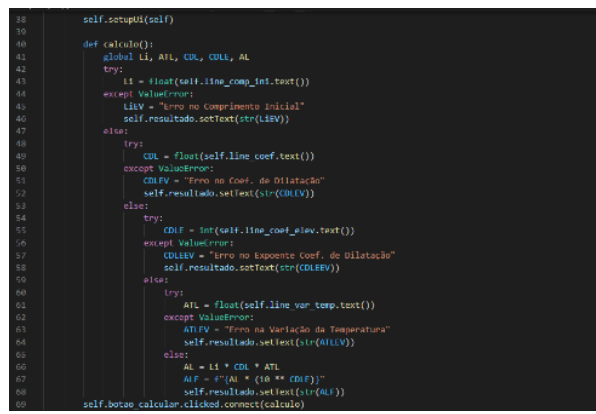

Figura 9. Primeiras linhas dos códigos do calculo
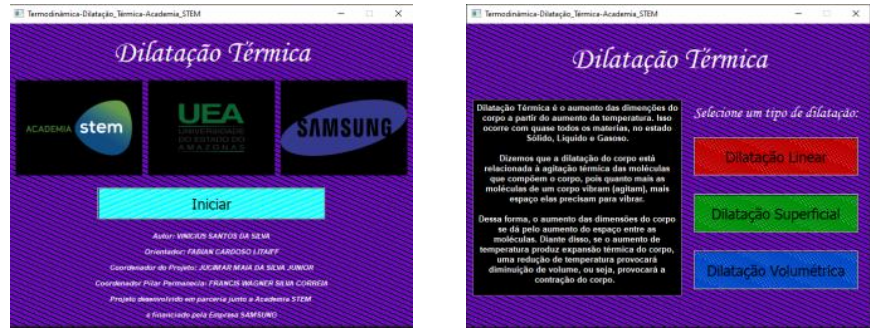

Figura 10. Menu inicial e Menu seleção 

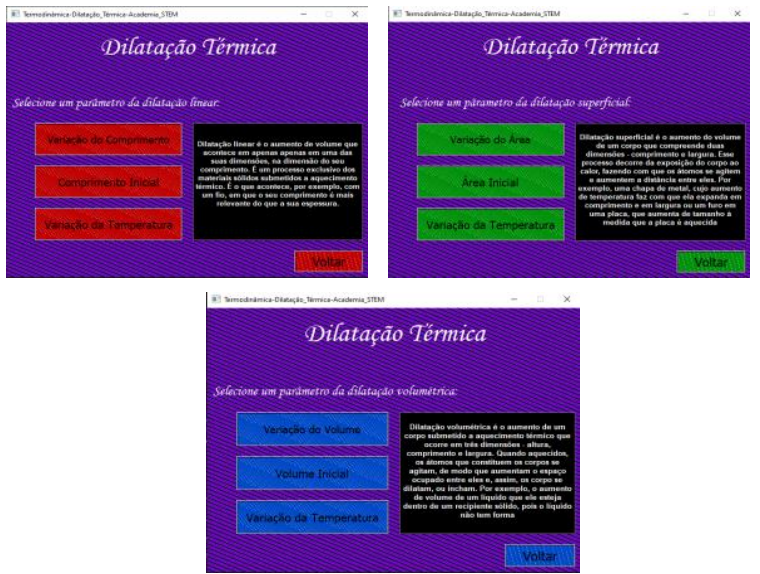

Figura 11. Menu de seleção de parâmetro
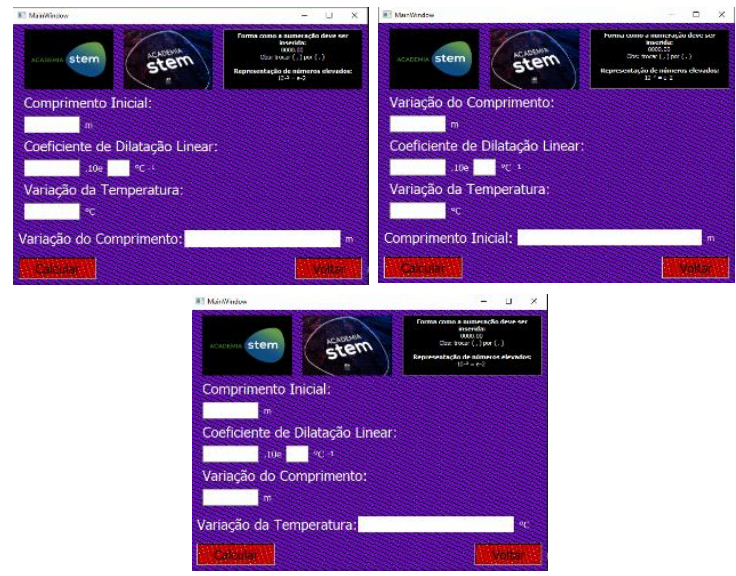

Figura 12. Calculadoras da dilatação linear
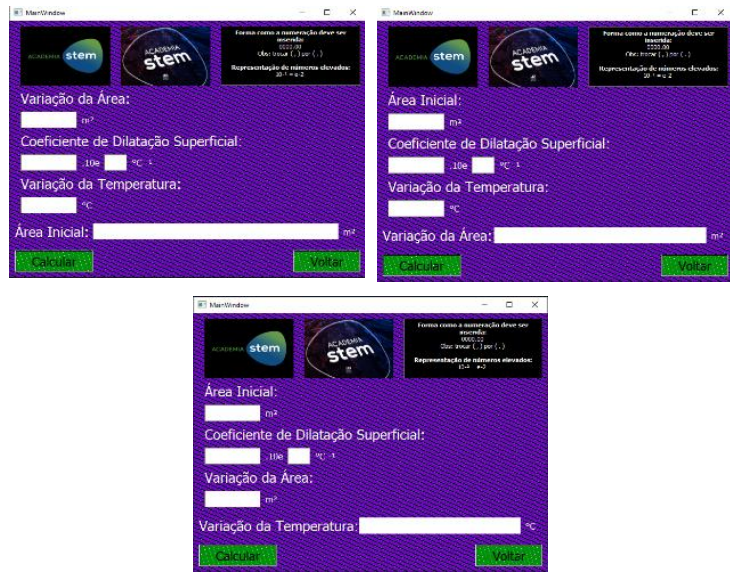

Figura 13. Calculadoras da dilatação superficial 

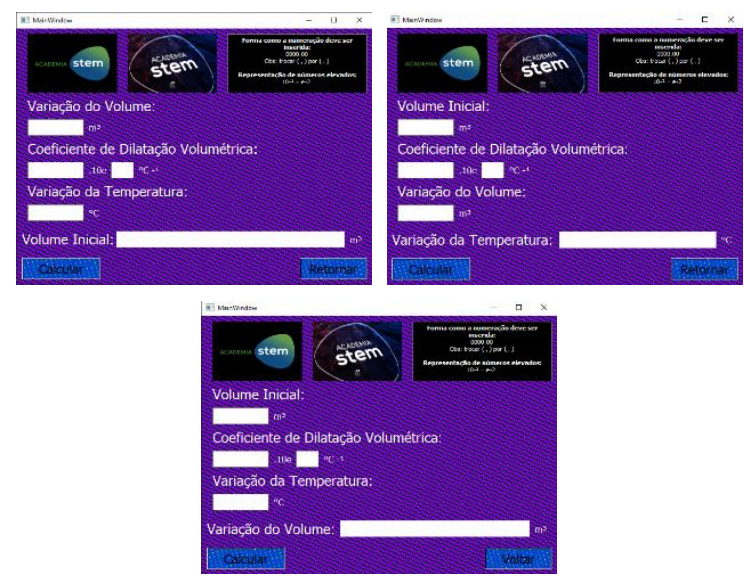

Figura 14. Calculadoras da dilatação volumétrica

\section{CONCLUSÃO}

Portanto, podemos concluir que a modelagem é uma ferramenta versátil e importante para a programação orientada a educação, pois dessa forma visa facilitar o acesso de conteúdos de Física aos estudantes. Desse modo com essas aplicações em Python para otimizar os cálculos matemáticos dos assuntos de Física 1: Gravitação e Física 2: Dilatação Térmica, sendo assim realizar todos os cálculos de todos esses assuntos através de calculadoras programadas especificamente para resolver as equações de desses assuntos, além poder obter alguns resumo dos quatro principais assuntos da Gravitação (Leis de Kepler, Lei da Gravitação Universal, Aceleração da Gravidade e Velocidade Orbital e Velocidade de Escape) e dos três principais assuntos da Dilatação Térmica (Dilatação Linear, Dilatação Superficial, Dilatação Volumétrica). Com isso, pode-se demonstrar que a Física pode se tornar mais simples e acessível aos estudantes, e posteriormente iremos aplicar esse processo a mais assuntos e a mais ferramentas dentro do programa, além de torná-lo mais acessível para outras plataformas.

\section{REFERÊNCIAS BIBLIOGRÁFICAS}

David Halliday, Robert Resnick e Jearl Walker, "Fundamentos de Física - vol.2 (Gravitação, Ondas e Termodinâmica)”, 9a. Edição (2011) Editora LTC.

Alaor Chaves, “Física Básica (Gravitação, Fluidos, Ondas, Termodinâmica)”, Editora LAB / LTC

H. M. Nussenzveig, "Curso de Física Básica - 2 (Fluidos, Oscilações e Ondas, Calor)”, Editora Edgard Blücher 


\section{SMART PRODUCTS}

Adalberto da Cruz Pinto

Kauê de Souza Martins

Jadson de Souza Maciel

Almir Kimura Junior

${ }^{1}$ Escola Superior de Tecnologia (EST) - Universidade do Estado do Amazonas (UEA) CEP 69050-020 - Manaus - AM - Brasil Kmds.eai20@uea.edu.br, adcp.eai20@uea.edu.br, jdsm.eai20@uea.edu.br, akimura@uea.edu.br

\section{INTRODUÇÃO}

Os Smart Products estimulam a automação do futuro e oferecem processos de produção inteligentes que se baseia em sistemas autônomos e instalações conectadas. Neste projeto abordaremos sobre uma aplicação robótica móvel multifuncional inteligente, com um design, feito no SolidWorks, que remete à um animal que mora nos nossos rios amazônicos, o Jacaré. Suas funções respectivamente são de seguir linha, identificar obstáculos para evitar colisões e também ser controlado via Bluetooth por um dispositivo móvel.

\section{OBJETIVO}

- Entender melhor o funcionamento de sensores ultrassônicos e de sensores infravermelhos em uma aplicação simples, porém bastante funcional, em nosso robô.

- Adquirir conhecimentos sobre impressora 3D, a fim de fazer a modelagem da carcaça do robô.

- Adquirir conhecimentos sobre elétrica, a fim de imprimir uma placa PCB para facilitar no desenvolvimento do projeto como um todo.

-Adquirir conhecimentos sobre programação, a fim de ser capazes de conseguir juntar as 3 funções em apenas um código utilizando portas digitais, sinal PWM e o Bluetooth serial que o ESP32 emite.

-Adquirir conhecimentos sobre modelagem e impressão 3D. 


\section{MATERIAIS E MÉTODOS}

\begin{tabular}{|c|c|}
\hline COMPONENTES & QUANTIDADE \\
\hline $\begin{array}{c}\text { MÓDULO SENSOR ÓPTICO } \\
\text { TCRT5000 }\end{array}$ & 2 \\
\hline $\begin{array}{c}\text { MÓDULO SENSOR } \\
\text { ULTRASSÔNICO HC-SR04 }\end{array}$ & 1 \\
\hline DRIVE PONTE H L298N & 1 \\
\hline MOTOR DC 3V-6V & 2 \\
\hline $\begin{array}{c}\text { RODA DE CARRO } \\
\text { INTELIGENTE }\end{array}$ & 2 \\
\hline RODA BOBA & 1 \\
\hline PILHA DE LITIO 18650 & 2 \\
\hline ESP32 & 1 \\
\hline PLACA PCB & 1 \\
\hline PLA & $250 \mathrm{~g}$ \\
\hline
\end{tabular}

\subsection{PROGRAMAÇÃ̃o}

\subsubsection{CONTROLE DE VELOCIDADE}

Para utilizarmos a função de segue linha deveremos habilitar o PWM do ESP32 a fim de diminuir a velocidade dos motores para um melhor funcionamento das funções. Diferentemente do PWM do Arduino, o PWM do ESP32 é tratado diferencialmente.

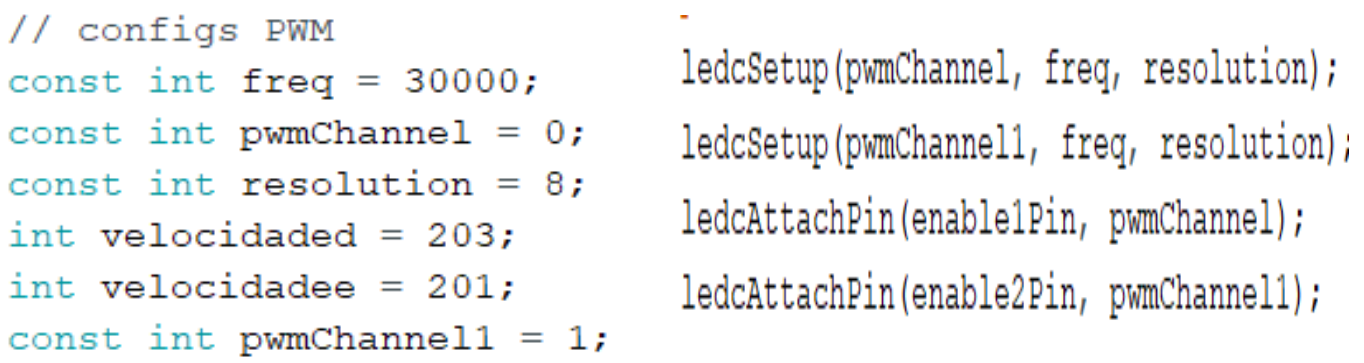

-Trechos do código relacionados exclusivamente ao PWM da ESP32

Estas são as configurações que utilizamos para variar as velocidades dos motores através somente do código. 


\subsubsection{MODOS SEGUE LINHA, DESVIO DE OBSTÁCULOS E BLUETOOTH}

Figura 1

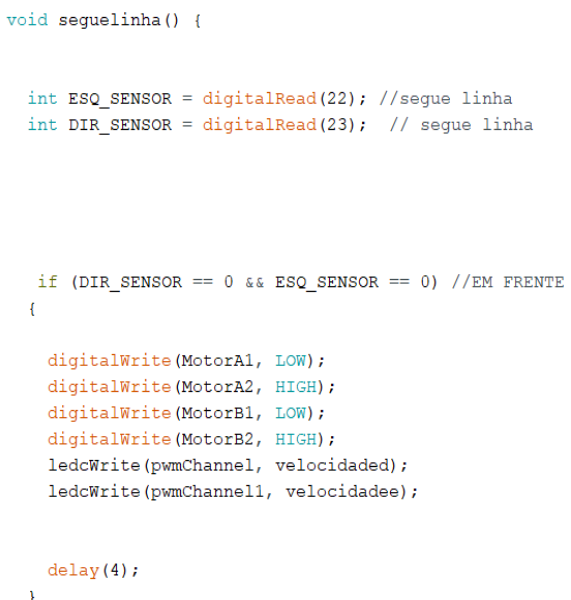

Figura 2

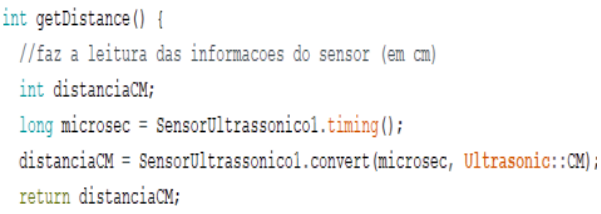

Figura 3

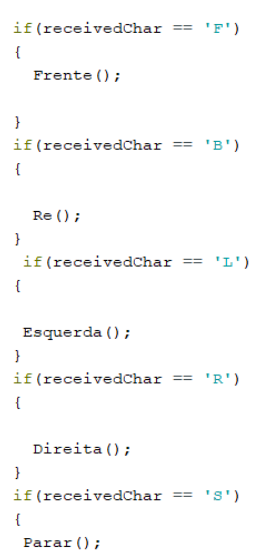

Figura 1. Parte do código que desvia de obstáculos, caso o robô detecte um obstáculo ele irá parar, dar uma ré, virar a direita e caso não haja nenhum outro obstáculo ele seguirá em frente

Figura 2. Parte do código segue, caso o sensor detecte a linha ele se corrigirá sozinho

Figura 3. Parte do código responsável por receber uma variável que o aplicativo* de celular enviará por Bluetooth que irá definir pra qual direção o robô se movimentará.

*O aplicativo pode ser baixado na playstore e se chama RC CONTROLL CAR

\subsection{MECÂNICA}

Os métodos utilizados nessa área, foram modelagem, impressão 3D e corte de acrílico em CNC.

\subsubsection{MODELAGEM}

O robô foi pensado para parecer com um jacaré, já que tinha que ser inspirado em um animal da amazônica, portanto, foi necessária uma estrutura que conseguisse acoplar os componentes e um design que desse o mínimo de semelhança com o animal. Assim foi utilizado o software SolidWorks para a modelagem. 


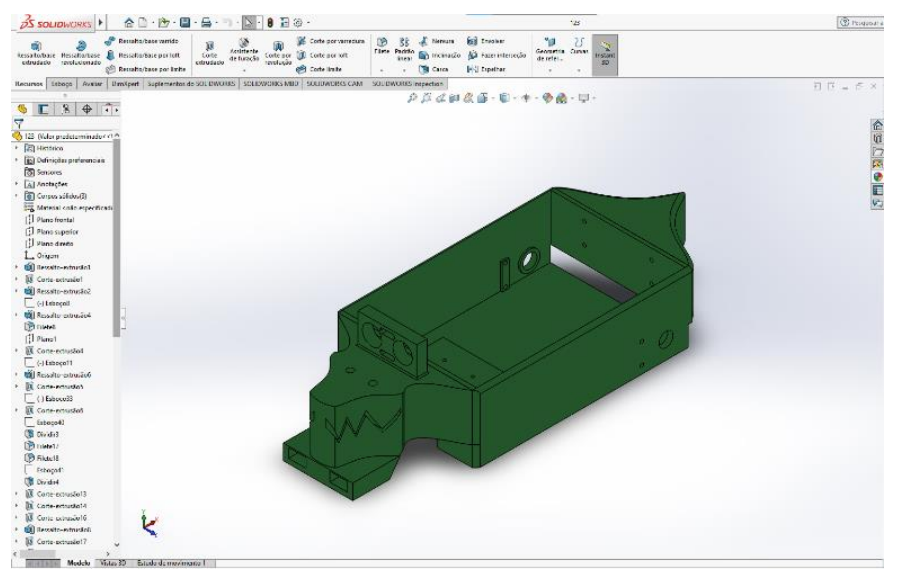

Figura 4. Modelagem 3D no SolidWorks

\subsubsection{IMPRESSÃO $3 D$}

Nesse processo, houve muito aprendizado, já que foi necessário, fazer algumas reimpressões, pois as medidas não dependem só do software de modelagem e também dependem do software CAM, assim para uma impressão melhor, sempre é bom fazer uns testes de medidas. Com isso, depois do término da modelagem em 3D, o arquivo foi passado para um software CAM para o início da impressão que no nosso caso foi o "Simplify3D". Neste processo, a impressora usada foi a "SETH3DS4X", o material escolhido para a impressão foi o PLA, pois era o mais acessível, o preenchimento das peças foi de 5\%, com uma resolução de 0.3 camadas, sendo gasto um total de cerca de $250 \mathrm{~g}$ de material, dando um total de mais ou menos $\mathrm{R} \$ 75$.

\subsubsection{ACRÍLICO}

Para tampar e proteger a parte de elétrica, além de deixar com um design mais sofisticado e para mostrar o interior, foi usado um acrílico.

O processo de fabricação foi feito a partir do software VCarve, sendo ele feito quase tudo em 2D, sendo a profundidade uma variável independente das outras, ou seja, ela será ajustada no final.

Foi usada uma broca com topo reto de $3 \mathrm{~mm}$ de diâmetro para fresagem, feita justamente para cortes verticais, também foi utilizado $266 \mathrm{rpm}$ de frequência para rotação da broca. A máquina utilizada foi a "CNC SHOPBOT". 


\subsection{ELÉTRICA}

\subsubsection{PLAMEJAMENTO}

Tendo em vista nossas necessidades o ESP-WROOM - 32 atendeu à todas, devido a sua conectividade a outros dispositivos utilizando tecnologia bluetooth e também oferece suporte a sensores que serão utilizados nesse projeto.

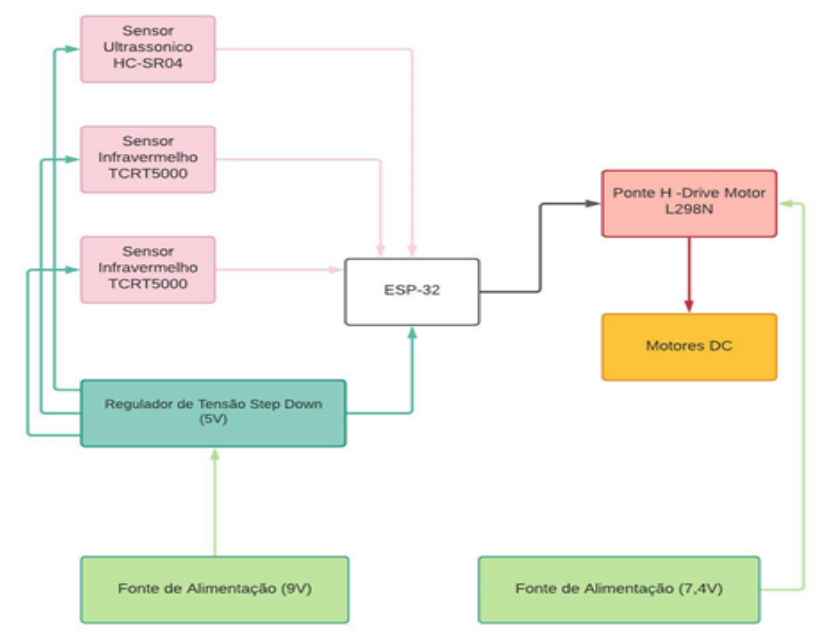

Figura 5. Diagrama de Blocos do Circuito Elétrico

Para as acomodações e conexões foi desenvolvido uma placa PCB criada e desenvolvida exclusivamente para este projeto, responsável para as conexões dos sensores, ESP e energia do circuito evitando contratempos que comprometam a integridade do projeto. O projeto elétrico conta com o Drive 1298n como ponte H para direção dos motores, 2 sensores infravermelhos TCRT5000 para a função seguidor de linha e um sensor ultrassônico HC-SR04 para detecção de Obstáculos. Para alimentar o circuito, utilizamos 2 baterias de Lítio de 3,7 V para alimentação dos motores e 01 bateria de $9 \mathrm{~V}$ para o regulador de tensão ajustar a $5 \mathrm{v}$ para alimentar somente o ESP e os sensores.

\subsubsection{DESENVOL VIMENTO DA PCB}

No software desenhamos o esquemático e desenhamos o Layout da Placa PCB que acomodará o ESP, as conexões dos Módulos e Sensores. 


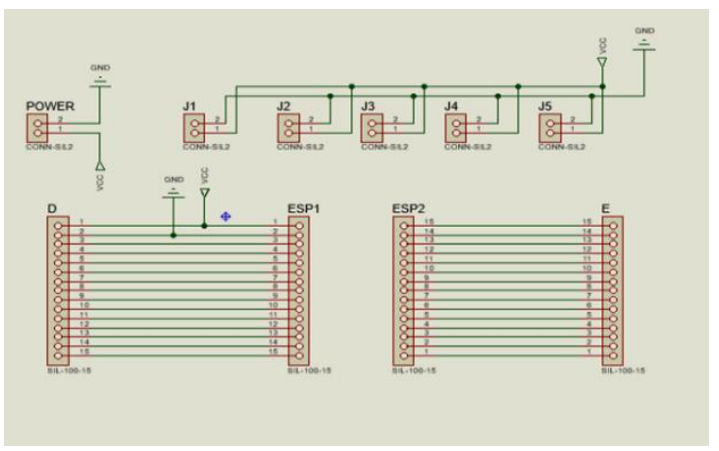

Figura 6. Esquemático da PCB

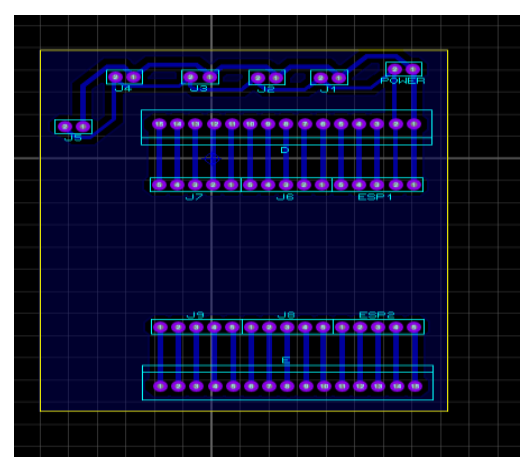

Figura 7. Design da PCB

Finalizado o esquemático do circuito, iremos desenhar a placa, obedecendo às dimensões de onde ela será inserida no robô. E após utilizamos a CNC Monofab SRM-20 para fresar as trilhas e logo após soldar os conectores para acomodar os componentes.

\section{RESULTADOS}

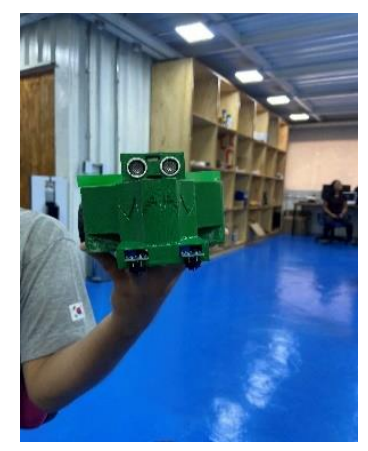

Figura 8. Parte frontal do robô 


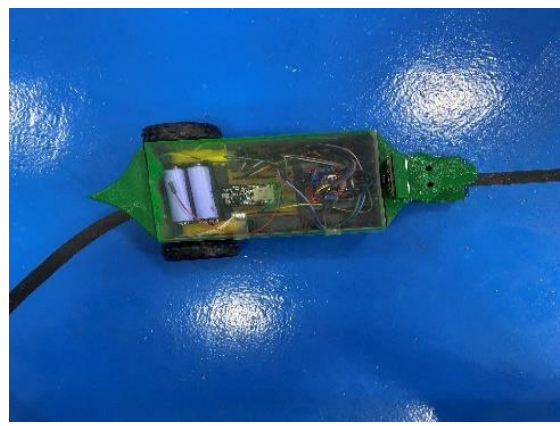

Figura 9. Robô visto por cima

O robô conseguiu concluir com êxito e obter bons resultados em todos os testes.

\section{CONCLUSÃO}

Com o fim desse projeto, conseguimos ganhar noções muito boas sobre microcontroladores, sensores e motores. Conseguimos com êxito concluir os objetivos iniciais do projeto utilizando todas as ferramentas disponíveis ao nosso redor.

Também ganhamos noções de elétrica básica que nos ajudaram muito no projeto e noções de programação necessárias para criar o sistema de troca de modos.

\section{REFERÊNCIAS BIBLIOGRÁFICAS}

K, Fernando. Controle de velocidade de motor DC com ESP32. Disponível em: $<$ Controle de velocidade de Motor DC com ESP32 - Fernando K Tecnologia>. Acesso em 24/08/2021

SOLIDWORKS, Dassault Systèmes. SolidWorks®. Version Solidworks, 2005. Adaptado do artigo Terminologia dos circuitos, de Willy McAllister, licenciado sob CC $\quad$ BY-NC-SA 4.0 .4 Disponível em:< https://pt.khanacademy.org/science/8-ano/utilizando-a-energiaeletrica/elementos-de-circuitos-eletricos/a/elementos-de-circuitoseletricos.> Acesso em: 18/08/2021 


\title{
CAPÍTULO XLI
}

\section{ANÁLISE DE PUBLICAÇÕES NACIONAIS E INTERNACIONAIS COM FOCO DO ROBÔ HUMANOIDE NAO PARA APLICAÇÕES EM INTELIGÊNCIA ARTIFICIAL}

\author{
Emanuelle Lima e Lima' \\ Williams de Lima Cavalcante ${ }^{1}$ \\ Paulo Fernanda Freitas Bastos' \\ Marlene Araúja de Faria'
}

1Escola Superior de Tecnologia (EST) - Universidade do Estado do Amazonas (UEA) CEP 69050-020 - Manaus - AM - Brasil ell.eai18@uea.edu.br,wdlc.ele20@uea.edu.br, pffb.eai18@uea.edu.br,mafaria@uea.edu.br

\section{INTRODUÇÃO}

O ensino atual e do futuro passa necessariamente pelo uso da cibernética contextualizada. É fundamental que os alunos aprendam a conviver com esta tecnologia e que a associem em suas concepções de novos sistemas de ensino. É neste contexto que surge a tecnologia educacional, utilizada para identificar todo o arsenal de recursos e serviços que contribuem para proporcionar ou ampliar habilidades dos estudantes de engenharia, em especial engenharia de controle e automação. O robô entra como um instrumento lúdico de aprendizagem em experimento realizado em Núcleo de Tecnologia Assistiva da UEA que vem desenvolvendo pesquisas com o Robô Humanoide NAO no município de Manaus/Amazonas. O robô humanoide NAO apresenta inúmeros recursos de inteligência artificial sendo utilizado nas melhores universidades nacionais e internacionais, o projeto irá realizar uma revisão na literatura de artigos científicos publicados com foco em inteligência artificial e sua aplicação nos dois exemplares de robôs humanoides do Núcleo de Tecnologia Assistiva da UEA.

\section{OBJETIVOS}

Para esse artigo a interação proporcionada pelo robô será através de um jogo de memória. A criança terá as cartas dispostas em uma mesa, viradas para baixo, ao escolher uma e apresentá-la ao NAO, ele irá identificar a vogal ou sílaba que a carta 
representa, e a criança deverá embaralhá-las novamente e encontrar a carta identificada.

\section{MATERIAIS E MÉTODOS}

É comprovado que o processo de alfabetização comum é dado por etapas, o método de encaminhamento, relação entre fala e escrita e a estimulação desenvolvida. No Brasil a aplicação do método global é a mais difundida, ela trabalha com a assimilação de palavras e seu significado, estimulando a leitura desde o primeiro contato com a linguagem. Deficiências e transtornos, como o TEA (transtorno do espectro autista), geralmente comprometem o processo que antecede a alfabetização, por isso existem muitos estudos que buscam metodologias de ensino eficientes para esses grupos, já que esse é o ponto de partida para interações comunicativas e, portanto, a integração social do indivíduo. Um método eficaz é o uso do som e de brincadeiras, mas com cuidado quanto a fonética de algumas palavras que podem gerar equívocos no aprendizado da criança.

O projeto irá utilizar Métodos Teóricos, Computacionais, Experimentais e Dedutivos, com revisão de artigos nacionais e internacionais.

02 exemplares do Robô Humanoide NAO, duas Licenças do software Choregraphe.

\section{RESULTADOS}

Os primeiros resultados foram obtidos através da materialização das cartas do jogo. Criadas e editadas através de softwares de edição de imagem online, foram impressas e então inseridas no banco de dados do robô NAO.

O tamanho escolhido foi baseado em cartas pré-existentes de alfabetização, no tamanho ideal para crianças conseguirem segurar com uma mão, e suficiente para a leitura das palavras e observação das imagens. Impressas em papel fotográfico, para maior qualidade das imagens e durabilidade das cartas. 

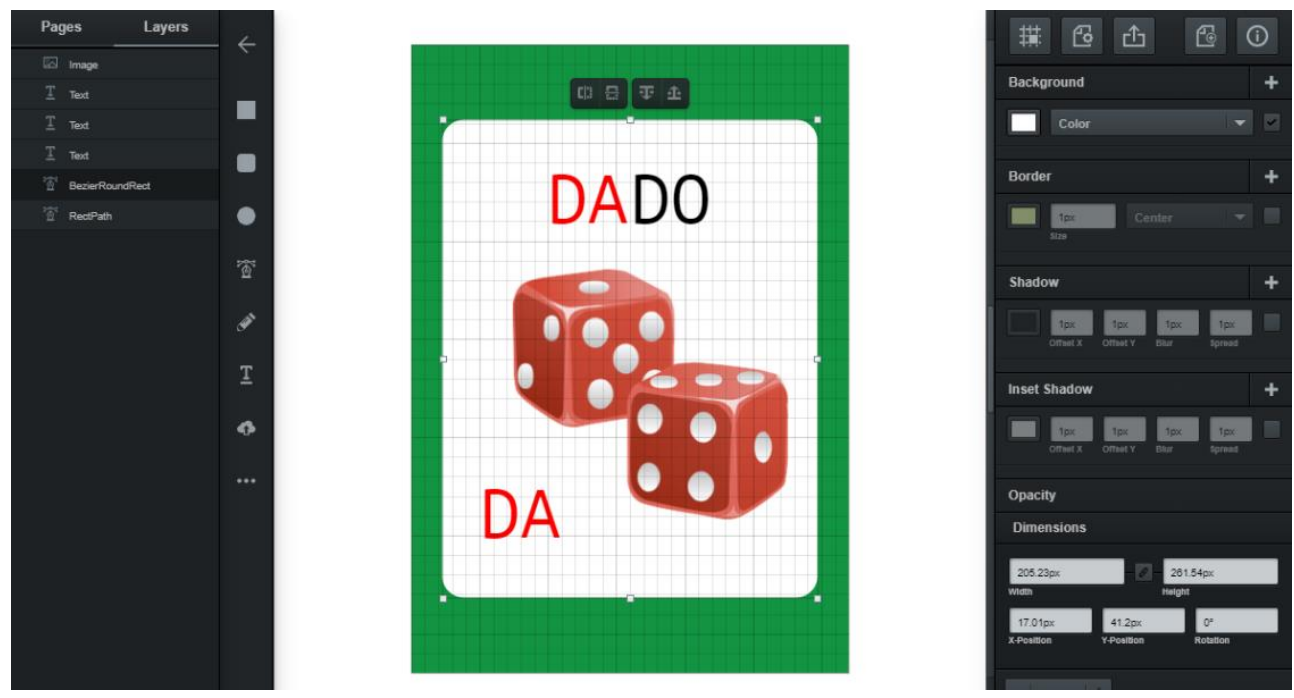

Figura 1. Criação das cartas

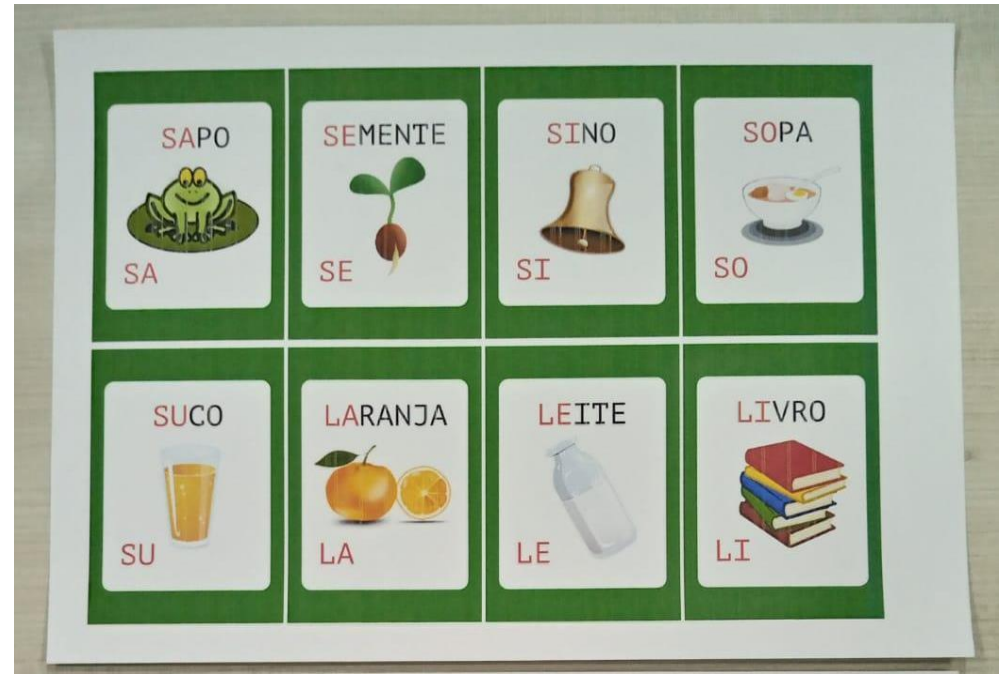

Figura 2. Algumas cartas impressas

Através do software Choregraphe e com as cartas prontas, criamos um banco de dados utilizando o reconhecimento visual do robô NAO para a execução do projeto. Com esses processos realizamos a identificação de cada carta e, atribuída a elas, designamos uma fala ao robô, para que ele expressasse a identificação da sílaba apresentada. Também pelo Choregraphe, utilizamos do reconhecimento de fala, para que ocorresse uma maior interação entre usuário e máquina.

Podemos observar nas figuras como ocorre tal processo, desde a interação, passando pela transformação de imagem em string até a fala reproduzida pelo robô NAO. 


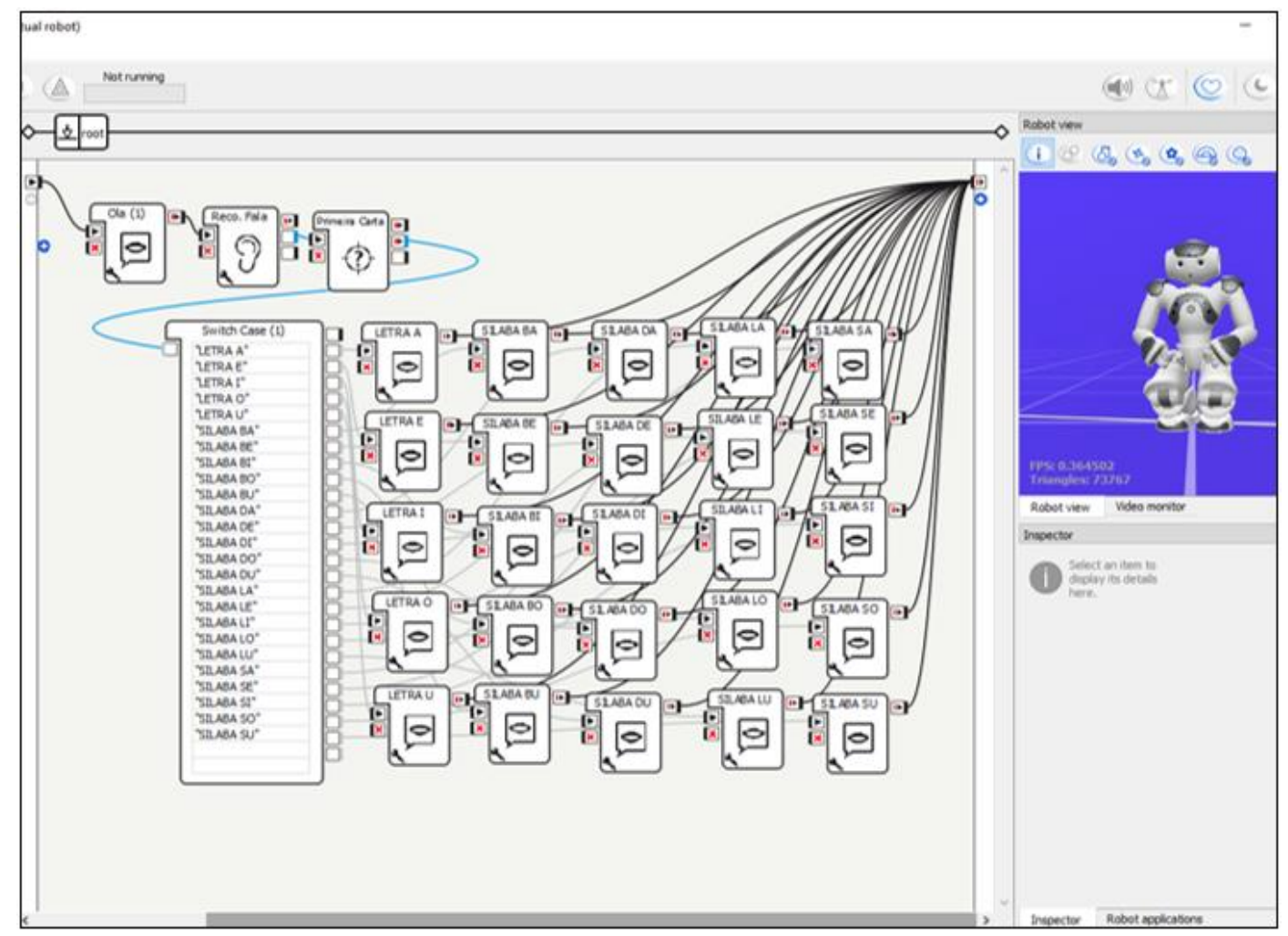

Figura 3. Programação no Choregraphe

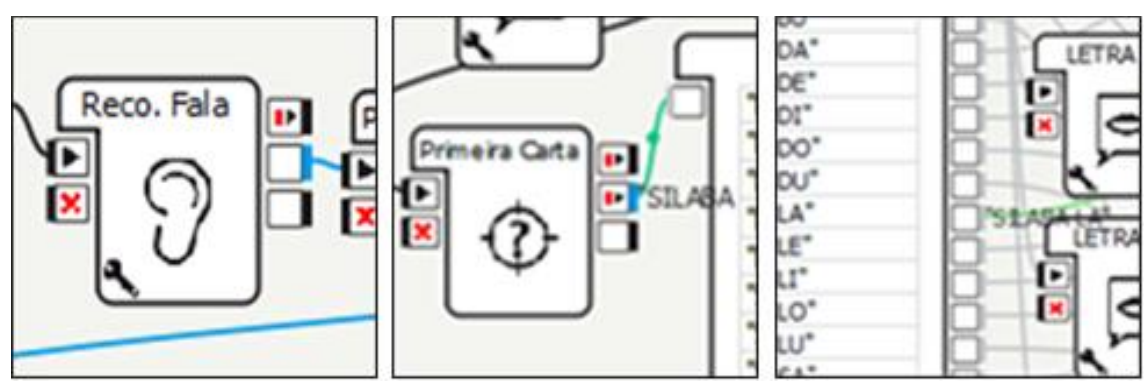

Figura 4. Processo de execução do programa

Com todos os processos realizados, foram realizados diversos testes para a validação da funcionalidade do programa. Apresentado a diversos professores, o jogo de memória com as cartas passou por aprovações, profissionais e educacionais, além da colaboração do autor Williams Cavalcante, também estudante da Escola Superior de Tecnologia (UEA), portador de transtorno do espectro autista, que contribuiu em práticas e melhorias do programa, tendo uma visão exclusiva da eficiência do projeto. 


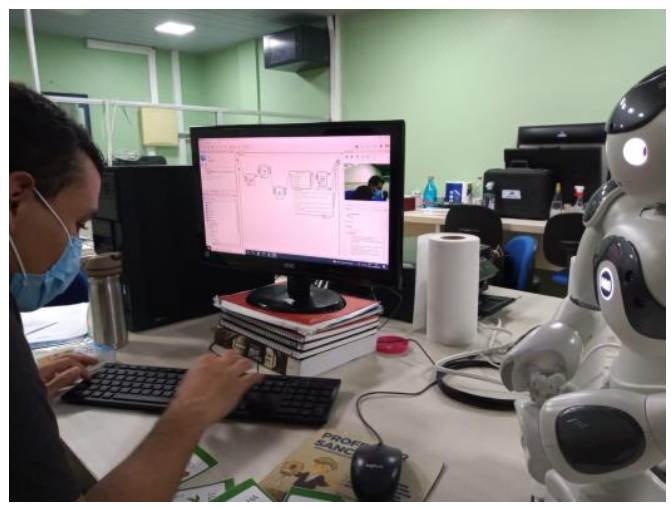

Figura 5. Programando o robô NAO

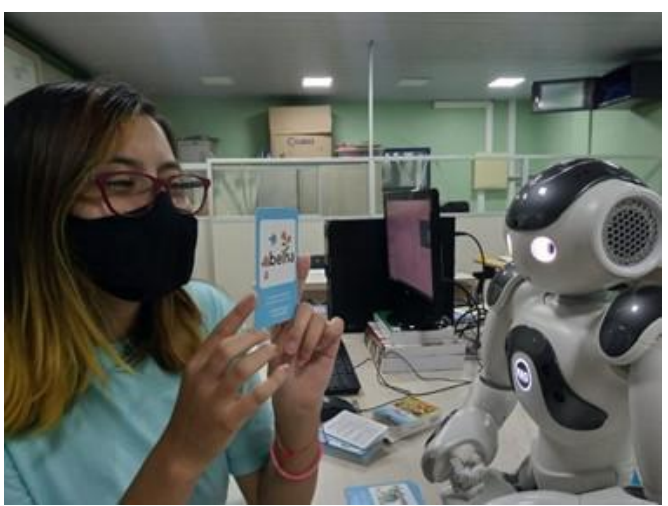

Figura 6. Primeiros testes realizados

\section{CONCLUSÃO}

A escolha de palavras foi definida para que as crianças entendam o que elas representam, e que possam ser associadas no seu cotidiano, como em desenhos infantis e objetos comuns. As cartas são apresentadas com desenhos para melhor identificação das palavras e trazem um tom divertido.

Nesse projeto, há interação do usuário com o robô, pois é necessária a fala de ativação do programa, isso permite que a criança tenha um contato verbal. Temos os estímulos de todas as habilidades sociais, já que a criança precisa falar com o robô, visualizar a carta, escutar a palavra e repetir, sendo agradável e benéfico para o processo de aprendizagem.

\section{REFERÊNCIAS BIBLIOGRÁFICAS}

S. Shamsuddin et al. (2012), "Initial response of autistic children in human-robot interaction therapy with humanoid robot NA0," 2012 IEEE 8th International Colloquium on Signal Processing and its Applications, 2012, pp. 188-193. 
Yordanka Karayaneva and Diana Hintea. (2018). Object recognition algorithms implemented on NAO robot for children's visual learning enhancement. In Proceedings of the 2018 2nd International Conference on Mechatronics Systems and Control Engineering (ICMSCE 2018). Association for Computing Machinery, New York, NY, USA, 86-92.

Miranda, Beatriz De Melo et al. (2019). Desafios no processo de ensino/aprendizagem na alfabetização de uma criança com tea. Anais VI CONEDU... Campina Grande: Realize Editora, 2019. https://www.editorarealize.com.br/index.php/artigo/visualizar/59825.

Sebra, Alessandra Gotuzo, \& Dias, Natália Martins. (2011). Métodos de alfabetização: delimitação de procedimentos e considerações para uma prática eficaz. Revista Psicopedagogia, 28(87), 306-320. Recuperado em 22 de setembro de 2021, http://pepsic.bvsalud.org/scielo.php?script=sci_arttext\&pid=S010384862011000300011\&lng=pt\&tlng=pt.

D. da Silva, A. Soares, A. Lundgren, E. Lima, and B. Bezerra. (2020). "NAO-Read: Empowering the Humanoid Robot NAO to Recognize Texts in Objects in Natural Scenes", in Anais Estendidos do XXXIII Conference on Graphics, Patterns and Images, Evento Online, 2020, pp. 151-154.

Bersch, R.; Tonolli, J. C. (2006). Introdução ao conceito de Tecnologia Assistiva e modelos de abordagem da deficiência. Bengala Legal, 2006. http://www.bengalalegal.com/tecnologia-assistiva.

H. Feng, A. Gutierrez, J. Zhang and M. H. Mahoor. (2013). "Can NAO Robot Improve Eye-Gaze Attention of Children with High Functioning Autism?," 2013 IEEE International Conference on Healthcare Informatics, 2013, pp. 484-484.

Goossens, C., \& Crain, S. S. (1992). Utilizing switch interfaces with children who are severely physically challenged: An emphasis on communication strategies. Austin, Tex: PRO-ED. 


\section{DESENVOLVIMENTO DE FIRMWARE PARA NAVEGAÇÃO INDOOR COM ROBÔS MÓVEIS}

Jhoendrio Gonçalves ${ }^{1}$

Laura Marques

Manuel Fabrício'

Marcus Eduarda'

Marivan Gomes'

Walfredo Kelvin'

${ }^{1}$ Escola Superior de Tecnologia (EST) - Universidade do Estado do Amazonas (UEA)

CEP 69050-020 - Manaus - AM - Brasil

\{jgm.eai20, lmdo.eai20, mflm.eai20, mens.eai20, msgomes, wksb.eai20\} @uea.edu.br

\section{INTRODUÇÃO}

A utilização dos robôs dentro da indústria traz grandes vantagens no aumento da produção, qualidade dos produtos e retorno econômico. Assim, é importante que as empresas se preparem para realizar a sua transição para a Indústria 4.0, de forma a se manterem competitivas frente ao mercado (KHAN, Ateeq; TUROWSKI, Klaus. (2016).

Nesse projeto buscou-se de forma resumida expor os alunos ao desenvolvimento metodológico de um robô móvel seguidor de linha, a motivação de tal projeto é a usabilidade na indústria em tarefas que envolvem logística básica. Além disso, esse projeto tem uma base em automação e controle bem estruturada, visto a necessidade dos alunos de compreenderem melhor sobre o que se trata, realmente, Controle e Automação.

\section{OBJETIVOS}

O principal objetivo do trabalho foi o desenvolvimento de Robôs seguidores de Linha, assim como ensinamento de métodos científicos e outras técnicas mais profissionais em bem aceitas na Indústria. 


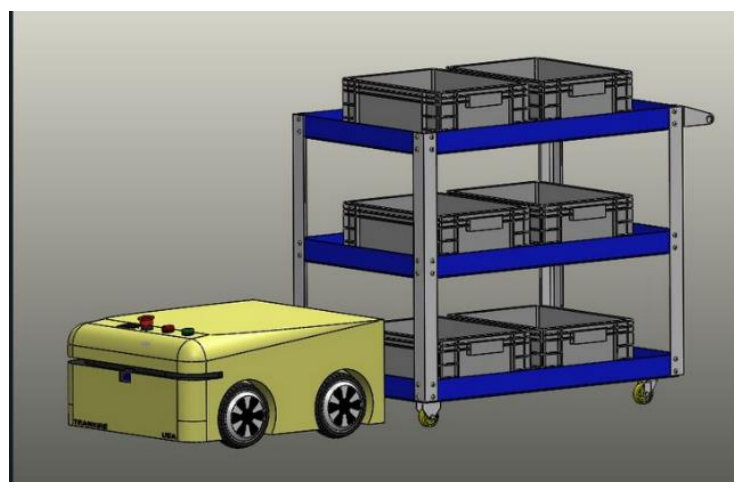

Figura 1. Exemplo de aplicação dos conceitos e técnicas aplicados no projeto

\section{MATERIAIS E MÉTODOS}

\subsection{MATERIAIS}

- Arduino NANO

- Acelerômetro e giroscópio de 3 eixos MPU 6050

- Display OLED I2C azul

- Protoboard de 400 pontos

- Kit chassi 2WD (2 rodas)

- Leory 4 Stots caixa bateria

- Driver Motor ponte H L298N

- Modulo seguidor de linha 5 canais TCRT5000

- Conector Flat Macho Macho

\subsection{MÉTODOS}

\subsubsection{VSCODE + PLATAFORMIO}

Utilizado para realizar a parte da programação do robô, esse método foi escolhido tendo em vista o seu grau de profissionalismo e a possibilidade de fazer upload do código para Github de forma automática. 0 código foi desenvolvido em Linguagem C para posteriormente ser inserido no Arduino Nano pela extensão PlataformIO.

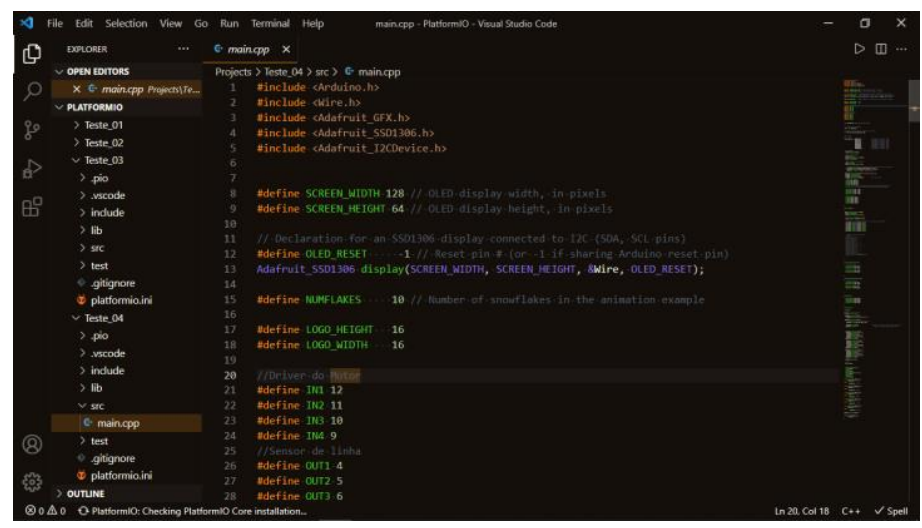

Figura 2. Desenvolvimento do Código no VSCode 


\subsubsection{PROTEUS:}

Utilizado para fazer testes e ter uma noção de como seria a parte elétrica do robô, verificação sobre a lógica de atuação antes da montagem do robô em si. Além disso, algumas bibliotecas como a Liquid Crystal foram instaladas para poder simular o LCD. Essa parte do processo foi essencial a nível de testes da parte elétrica do robô

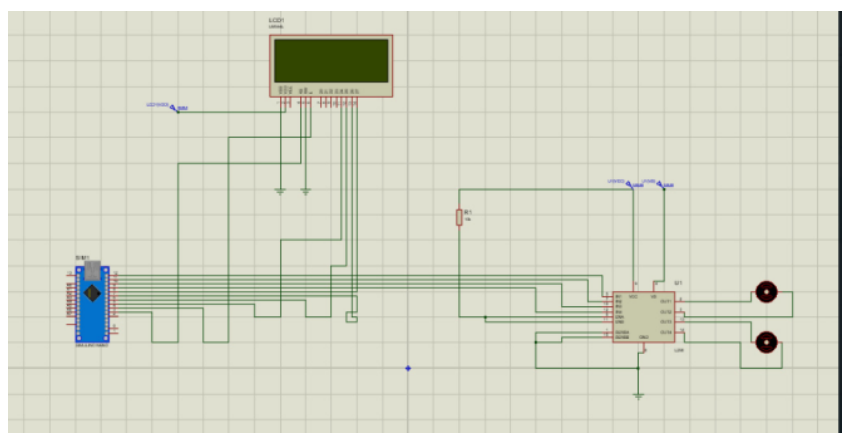

Figura 3. Analisando a base do sistema elétrico utilizando Proteus

\subsubsection{SLETCHUP:}

Utilizado para dar aos alunos uma maior noção de funcionamento de um CAD em 3D para modelagem de futuros projetos, assim como uma leve explicação sobre impressão 3d. Essa parte foi importante para dar uma visão espacial aos alunos e visar construção de robôs em futuros projetos.

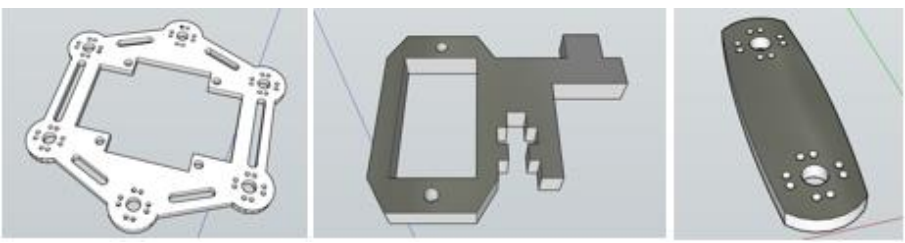

Figura 4. Testes em Modelagem com SketchUp

\subsubsection{ENCONTROS:}

Esses ocorreram de forma presencial ou remota, via Zoom ou Discord e comunicação via Whatsapp. Nesses encontros forma passados alguns conceitos teóricos em diversos tópicos que ampliaram o conhecimento dos alunos e forneceram uma base mais sólida para o desenvolvimento do robô seguidor de linha ou discussão sobre a implementação do hardware do robô.

A)Com o Professor: teoria e prática sobre partes eletrônicas, conceitos e métodos científicos, um pouco sobre a teoria de controle como PID e outros. 


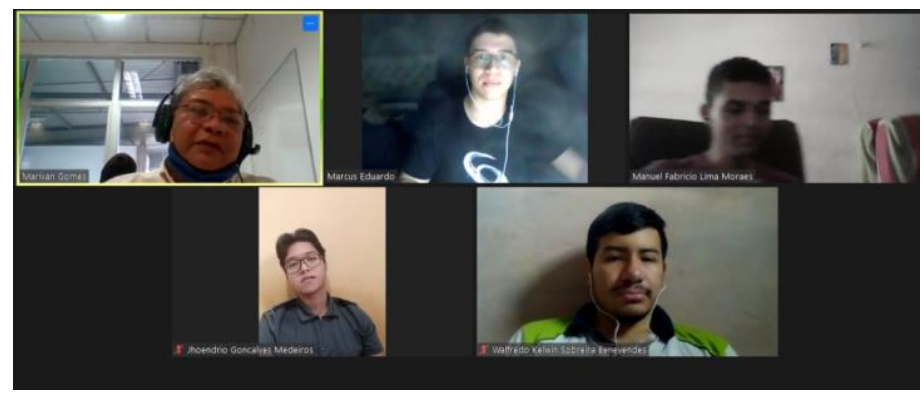

Figura 5. Encontro com o Prof. Marivan via Zoom

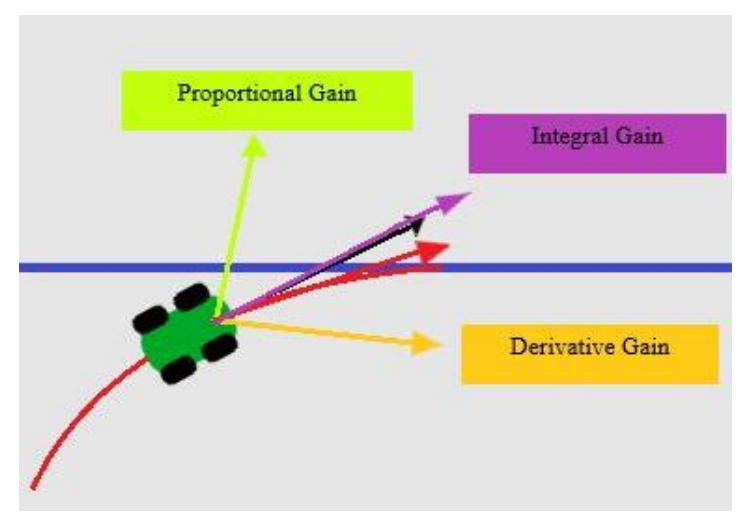

Figura 6. Explicação de Controle PID

B) Sem Professor: definição de metas e encontros a serem realizados.

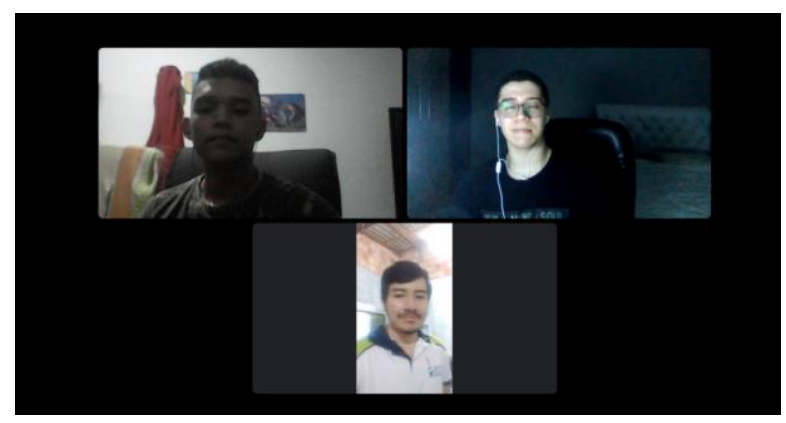

Figura 7. Encontro entre os Bolsistas via Discord

\subsubsection{MONTAGEME TESTE:}

Realizado de forma presencial, não necessariamente com vistoria do professor, para montagem e teste dos robôs seguidores de linha, isso envolve: design dos materiais no robô, arrumar a parte elétrica e achar soluções de materiais que façam sentido para a construção do robô. Nessa parte tivemos que utilizar a lógica aprendida nas simulações e encontros virtuais para implementar os robôs de forma coerente, nessa parte tivemos que utilizar ferramentas como: multímetro, 
ferro de solda, alicates, chaves de diversos tamanhos, fita isolante, fita dupla face e outros.

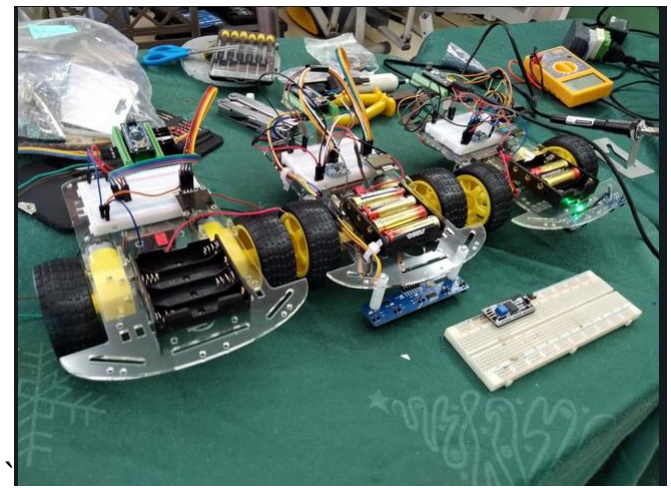

Figura 8. Montagem dos Robôs

\section{RESULTADOS}

0 assunto foi ministrado de forma esporádica de forma a valorizar o melhor aprendizado dos alunos, dessa forma houveram bons resultados quanto ao aprendizado de metodologias como PlataformIO e Proteus. Além disso, houve um bom desenvolvimento dos alunos quanto a montagem de robôs: eletrônica, programação, organização e outros fatores.

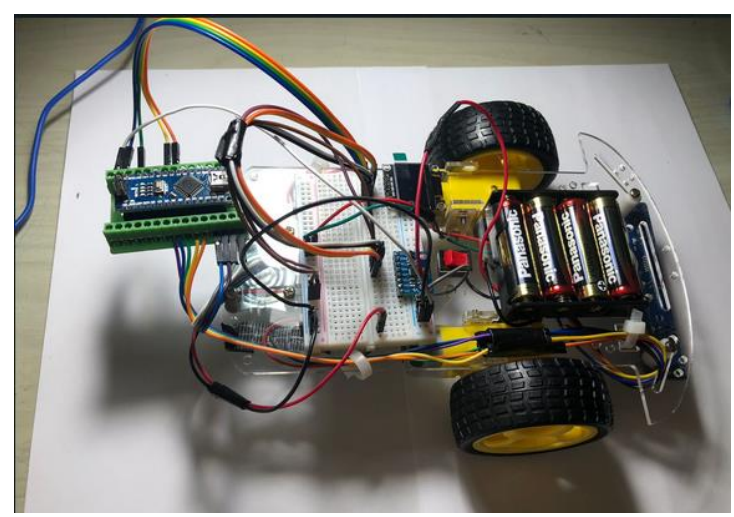

Figura 9. Primeiro Robô Seguidor de Linha funcional Desenvolvido

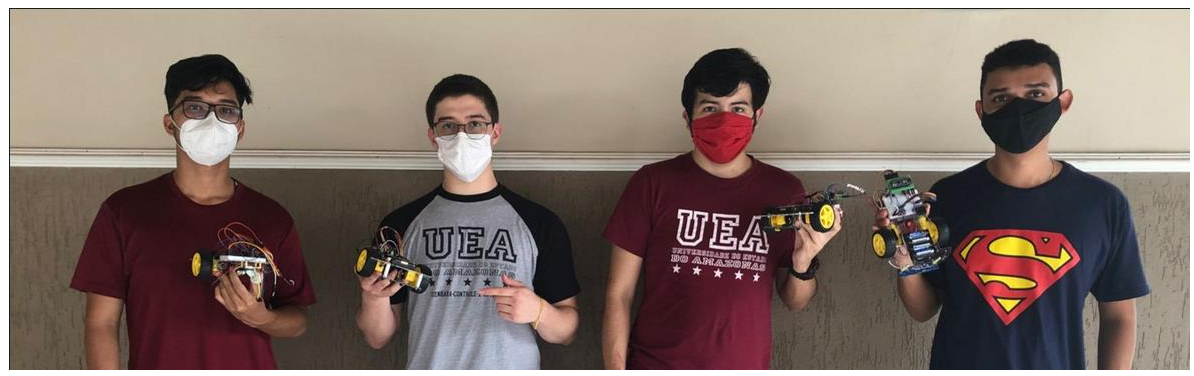

Figura 10. Desenvolvimento do Robô seguidor de linha para todos os integrantes 


\section{CONCLUSÃO}

Em suma, apesar de o resultado desejado não ter sido alcançado por falta de experiência dos alunos quanto a certos conceitos mais avançados de Controle e Automação, houve um bom aproveitamento dos alunos quanto ao material ministrado e materiais entregues para prática. Dessa forma, um total de 4 robores seguidores de linha foram desenvolvidos pelos alunos AcadStem.

Resultado Desejado: https://youtu.be/4F70VMLbuHk

\section{REFERÊNCIAS BIBLIOGRÁFICAS}

ANWAR, Md et al. Performance Enhancement of Solar Energy using PID controller based DC-DC boost converter. 2017. Tese de Doutorado. Department of Electrical and Electronic Engineering, Islamic University of Technology. IEEE/RSJ International Conference on Intelligent Robots and Systems. IEEE, 2011. p. 2014-2019.

KHAN, Ateeq; TUROWSKI, Klaus. A survey of current challenges in manufacturing industry and preparation for industry 4.0. In: Proceedings of the First International Scientific Conference "Intelligent Information Technologies for Industry”(IITI'16). Springer, Cham, 2016. p. 15-26.

MESSINA, Elena; JACOFF, A.; SCOTT, H. Performance Evaluation of Autonomous Mobile Robots. Intelligent Vehicle Systems: A D, v. 4, p. 247-282, 2006. 


\title{
DESENVOLVIMENTO DE COREOGRAFIAS PARA O ROBÔ HUMANOIDE NAO
}

\author{
Alberto Postigo \\ Amanda Costa \\ Edgard Freitas \\ Gabriel do Valle \\ Marlene Araujode Faria
}

Escola Superior de Tecnologia (EST) - Universidade do Estado do Amazonas (UEA) CEP 69050-020 - Manaus - AM - Brasil acbp.eai20@uea.edu.br, afc.eai20@uea.edu.br, ehnmdf.eai20@uea.edu.br, gpdv.eai20@uea.edu.br, mafaria@uea.edu.br

\section{INTRODUÇÃO}

Com a globalização diversos problemas sociais foram evidenciados, um exemplo que se tornou notório são as dificuldades de aprendizado em relação pessoas com deficiências (PCD), isso se torna ainda mais preocupante com as crianças pcd's, que por conta de suas condições diversas, como por exemplo autismo, TDH e doenças físicas.

Neste artigo, queremos mostrar que por meio da tecnologia podemos romper essas barreiras, utilizando a plataforma humanoide NAO com suasótimas habilidades motorase de fala para auxiliar o desenvolvimento da psicomotricidade.

\section{OBJETIVOS}

Este artigo visa mostrar como o uso do robô humanoide NAO pode ajudar,por meio de música e coreografia, no desenvolvimento social e psicológico de crianças que apresentam doenças psicomotoras, influenciando-as a interagirem e se identificar com o robô.

\section{MATERIAIS E MÉTODOS}

O projeto é focado na utilização do Robô humanoide NAO como peça utilizando músicas e coreografias feitas no software Choreographe versão2.8.5.10. 


\subsection{CHOREOGRAPHE}

O Choreographe, versão 2.8.5.10, é um software que utiliza um sistema intuitivocom um banco de dados próprio de movimentos pré-programados para o Robô humanoideNAO.

Os movimentos são divididos em pastas com outras subdivisões mais específicas paraum conjuntos de ações e sons que podem ir desde movimentos genéricos, por exemplo, mover o braço para frente, mover a cabeça de um lado para o outro, ou até expressões mais complexas como medo, afeto e frustração, todos esses gestos são divididos em blocos que podem ser arrastados para uma timeline e conectados em sequência para formar a coreografia desejada, épossível editar os blocos selecionados em quesitos de sons que eles possam ter ou em relação ao acionamento das luzes LED, também há o recurso para adiçãode sons externos para serem reproduzidos simultaneamente ao proceder das ações.

\subsection{ROBÔ HUMANOIDE NÃO}

O Robô Humanoide NAO é a parte essencial para o desenvolvimento do projeto, o mesmo é a ferramenta que serve como agente comunicativo utilizandode todas suas capacidades para este serviço.

Tem 57 centímetros de altura, cerca de 4,5 quilogramas, 25 graus de mobilidade, equipado também com X(59) sensores, incluindo duas câmera que pode captar 30 framespor segundo (FPS), dois giroscópios, três acelerômetros, 34 Encoders magnéticos rotativos (EMR), oito resistores sensíveis à força, dois sensores infravermelhos (emissores e receptores), dois sensores ultrassônicos, dois alto falantes, um microfone, eLEDs localizados nos olhos, nas áreas lateraisda cabeça, no botão central, onde o mesmoliga e desliga, e nos pés, incluindo umaparticular fluidez em seus movimentos também podendo ser rápidos devido a sua leveza.

\section{RESULTADOS}

Com base nos resultados ... 


\subsection{COREOGRAFIA AULD LANG SYNE}

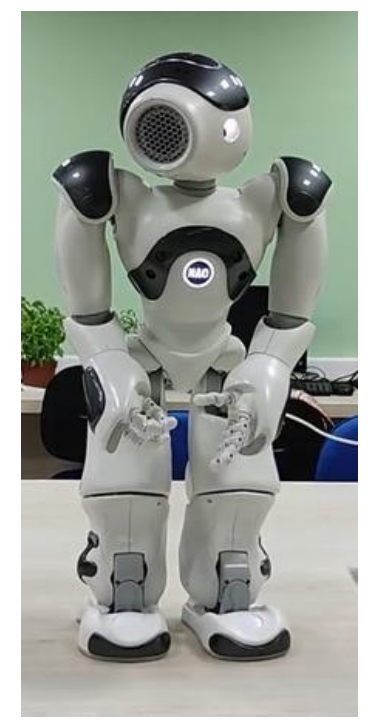

Figura 1. Robô NAO realizando o movimento ‘Golf'(utilizado no desenvolvimentoda coreografia)

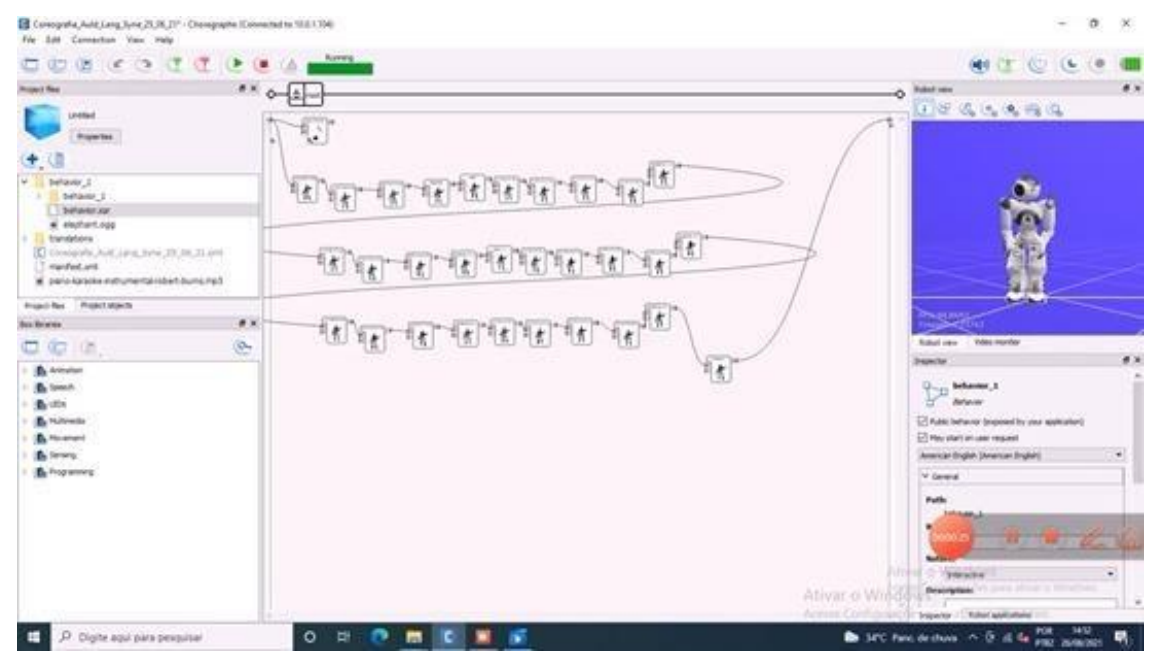

Figura 2. Imagem do Choreographe (software utilizado no projeto) da coreografia 'Auld Lang Syne'

\subsection{DANÇA DA FADA AÇUCARADA}

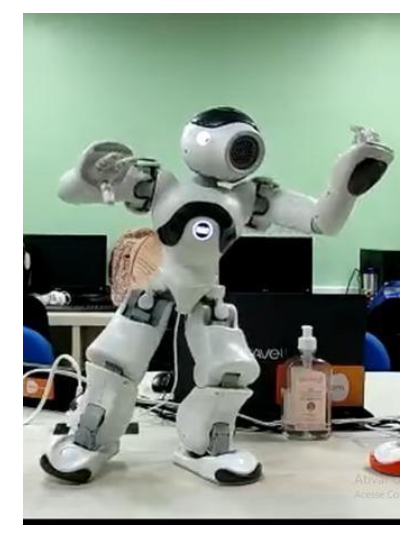

Figura 3. Robô NÃO realizando o movimento'Football'(utilizado no desenvolvimento da coreografia) 


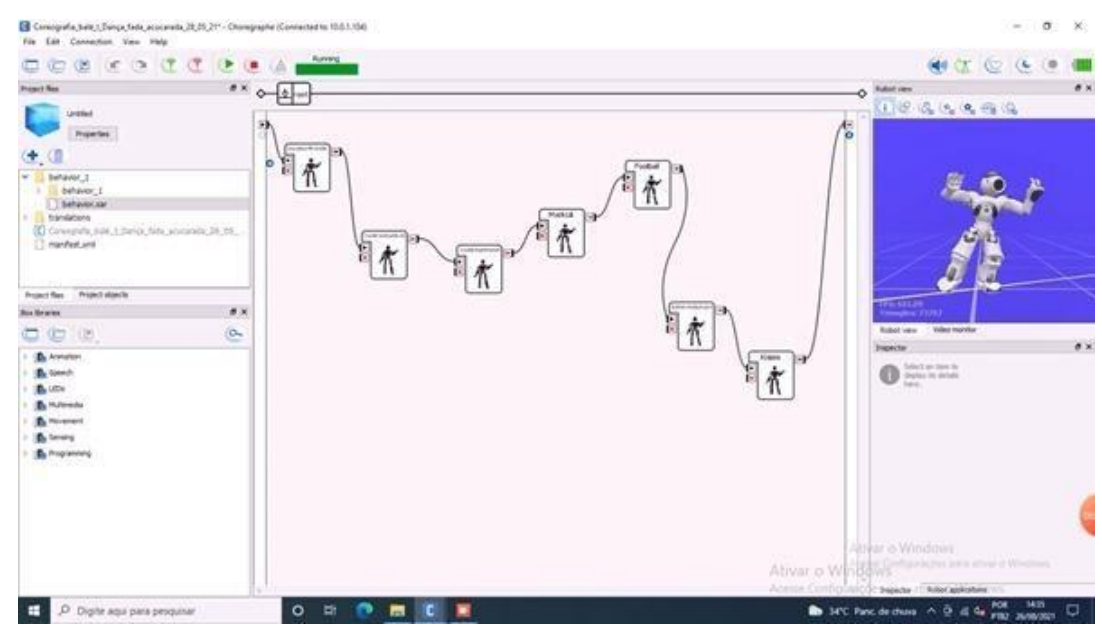

Figura 4. Imagem do Choreographe (softwareutilizado noprojeto) da coreografia 'Dança da Fada Açucarada'

\subsection{COREOGRAFIA NO MEU CORAÇÃO}

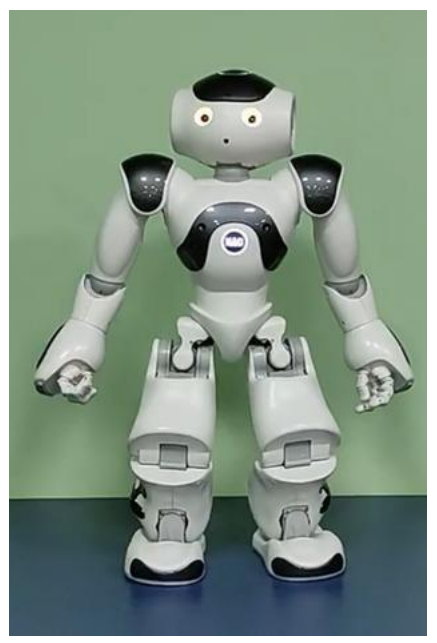

Figura 4. Imagem do Choreographe (software utilizado noprojeto) dacoreografia 'No Meu Coração'

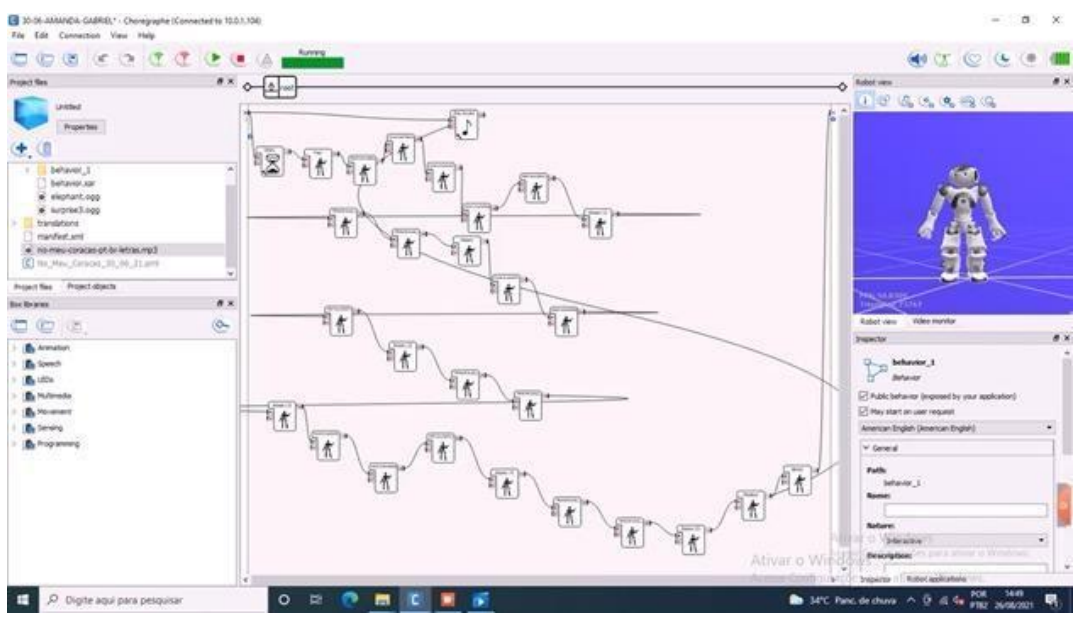

Figura 5. Robô NAO realizando o movimento'Fear' (utilizado no desenvolvimento da coreografia) 


\section{CONCLUSÃO}

Com base nos estudos, juntamente com as capacidades no robô NAO, foi possível por meio do software Choreographe desenvolver coreografias com intuito de ajudar na educação de crianças especiais, para que as mesmas venham a interagir e desenvolver seus aspectos sociais. Ao longo do projeto foram desenvolvidas 3 coreografias com músicas: Auld Lang Syne, Dança da Fada Açucarada e No Meu Coração, as aplicações dessascoreografias serão diversas no âmbito escolar, onde as crianças poderão ver de perto o que o robô é capaz de fazer e assim desenvolver todo seu interesse.

\section{REFERÊNCIAS BIBLIOGRÁFICAS}

Boulic, R. and Renault, O. (1991) "3D Hierarchies for Animation”, In: NewTrends inAnimation and Visualization, Edited by Nadia Magnenat-Thalmann and Daniel Thalmann,John Wiley \& Sons ltd., England.

Dyer, S., Martin, J. and Zulauf, J. (1995) "Motion Capture White Paper", http://reality.sgi.com/employees/jam_sb/mocap/MoCapWP_v2.0.html, December.

Holton, M. and Alexander, S. (1995) "Soft Cellular Modeling: A Techniquefor the Simulation of Non-rigid Materials", Computer Graphics: Developments in Virtual Environments, R. A. Earnshaw and J. A. Vince, England, Academic Press Ltd., p. 449-460.

Knuth, D. E. (1984), The TeXbook, Addison Wesley, $15^{\text {th }}$ edition.

Lemos Filho, L. C. A. Análise espaço-temporal da evapotranspiração de referênciapara o estado de Minas Gerais. 2005. 76p. Dissertação (Mestrado em Engenharia Agrícola) - Universidade Federal de Lavras, Lavras, MG, 2005.

Smith, A. and Jones, B. (1999).On the complexity of computing. In Advances inComputer Science, pages 555-566. Publishing Press. 


\title{
ESTUDO DO SISTEMA DE PROPULSÃO MANUAL DE CADEIRA DE RODAS
}

\author{
Airton Silva Monteiro' \\ Huga Gabriel Souza de Dliveira' \\ Muriel Kiane Guimaraes Jacob' \\ Mateus Mamede Da Silva Marques' \\ Joan Milton Do Carmo Ribeiro Saraiva' \\ Marlene Araújo de Faria'
}

\begin{abstract}
1Escola Superior de Tecnologia (EST) - Universidade do Estado do Amazonas (UEA)
CEP 69050-020 - Manaus - AM - Brasil asm.eai20@uea.edu.br, hgsdo.eai20@uea.edu.br, mkgj.eai20@uea.edu.br, mmdsm.eai20@uea.edu.br, jmdcrs.eai20@uea.edu.br,mafaria@uea.edu.br
\end{abstract}

\section{INTRODUÇÃO}

O presente projeto tem como objeto de estudo, proposta de estudo e pesquisa do sistema de propulsão manual para adaptação em cadeiras de rodas convencionais, com intuito de favorecer cadeirantes em geral, principalmente aqueles com baixa renda, domínio dos membros superiores e diminua os esforços físicos realizados nos trajetos do dia a dia. Com isso, reduzir os riscos de lesões nos membros superiores e exposição às intempéries climáticas, seguindo a Norma Regimental NBR9050 e Norma Ergonômica de Acessibilidade NBR6040, sendo possível utilizar alguns materiais do segmento automotivo e metalúrgico na sua fabricação. Obedecendo como referencial teórico, trabalhos acadêmicos e artigos existentes que alcançaram êxito na propulsão manual da cadeira de rodas, obtendo a partir desses estudos, valores comparativos para uma melhora das condições adequadas para uma cadeira de rodas.

\section{OBJETIVOS}

O projeto tem como objeto de estudo a cadeira de rodas por propulsão manual, com objetivo de analisar o sistema de propulsão e obter quais variáveis influenciam no desenvolvimento desse sistema, já que as cadeiras de rodas mais utilizadas não possuem o melhor sistema de propulsão manual. 0 estudo deste projeto se baseou na análise das variáveis mais importantes para o sistema, sendo 
possível localizar meios para que o usuário tenha um melhor aproveitamento da cadeira, diminuindo os danos causados pelos movimentos repetitivos. Além da parte mecânica da cadeira, um dos objetivos é compreender as dificuldades que um usuário de cadeira de rodas passa com a falta de uma boa cadeira de rodas para se locomover, com a falta de acessibilidade, sem uma boa infraestrutura urbana, entre outros inúmeros problemas.

\section{MATERIAIS E MÉTODOS}

Foi utilizado teoria como forma de desenvolvimento, a principal atividade foi a leitura de artigos e teses científicas, nesses textos foi obtido informações sobre como a utilização da cadeira de rodas ainda está bem longe de ser apropriada para quem precisa, uma observação que foi observado foi como a movimentação do sistema usuário e cadeira de rodas ainda não é algo natural e integro, existem muitas barreiras que dificultam esse sistema.

Além das leituras em artigos foi realizado reuniões via Google Meet e após um tempo presencialmente no Laboratório da UEA, visando debater mais ideias e o que foi absorvido dos textos lidos, sob orientação foi direcionado a buscar quais são as variáveis que afetam a movimentação de usuários de cadeira de rodas? Foi objeto de estudo as principais variáveis que podem ser mensuradas, como exemplo, tamanho do aro da roda, tamanho dos assentos e encostos, angulação da roda em relação aos assentos, todas essas variáveis são extremamente importantes para manter uma boa ergonomia e utilização a longo prazo de cadeira de rodas, possibilitando que o sistema homem e cadeira de rodas seja mais fluido.

Outra forma de pesquisa utilizada foi sobre a relação do esporte com a cadeira de rodas, foi pesquisado sobre atletas de diferentes modalidades, atletismo, basquete, crossfit, entre outros, foi buscado entender como funciona o sistema de propulsão dessas cadeiras de rodas e o porquê de serem mais efetivas e melhores ergonomicamente falando em relação as cadeira de rodas que são utilizadas no diaa-dia, uma metodologia que utilizamos foi a de aplicar medidas do sistema de propulsão das cadeiras de rodas utilizadas em esportes nas cadeiras de rodas normais e imaginar como isso impactaria na movimentação de pessoas que possuem deficiência de mobilidade. 
A pesquisa também se baseou em informações estatísticas, regulamentações e como é a indústria de fabricação de cadeira de rodas, foi orientado a buscar qual é o número de pessoas que necessitam da cadeira de rodas para se movimentar em todo Brasil e também na região Norte. Existem regulamentações muitas vezes não seguidas pela sociedade sobre a adequação de espaços públicos para a movimentação de cadeira de rodas, o problema é que por não serem seguidas só se tornam mais uma dificuldade para quem depende desse tipo de acessibilidade, fora essa dificuldade, foi verificado que o custo para se ter uma cadeira de rodas no Brasil é extremamente elevado, por isso, a maioria dos usuários de cadeira de rodas utilizam cadeira mais acessíveis porém muitas das vezes não adequadas para o seu tipo de corpo, acarretando em outras doenças físicas, principalmente lesões musculares por tamanho esforço a se fazer somente para se movimentar.

\section{RESULTADOS}

Com as variáveis estudadas durante todo o processo de pesquisa que podem afetar diretamente no rendimento da cadeira e no bom conforto do cadeirante onde na maioria das vezes as cadeiras podem ser adequadas ao corpo do paciente em questão, com isso o resultado obtido foi que as variáveis são de suma importância para uma boa ergonomia onde vários fatores podem alterar esses resultados como a construção de um aro ergonômico de acordo com a antropometria da mão e que com essas variáveis poderá ser feito uma cadeira ergonômica e de acordo com a estatura e deficiência do paciente colocando ele num maior conforto conforme suas medidas.

Uma das variáveis seria a medida do aro ergonômico responsável pela propulsão manual onde o metálico causa dores no membro superiores além de lesão nos mesmos, o tipo de pneu que influencia bastante na locomoção da cadeira, como o formato do encosto do assento e seu preenchimento onde ele tem que estar a um determinado ângulo do ombro da pessoa, a cambagem das rodas que melhora na locomoção da mesma.

Dimensões recomendáveis para uma melhor propulsão e ergonomia em uma cadeira de rodas em centímetros $(\mathrm{cm})$ : 


\begin{tabular}{|l|l|l|l|}
\hline COTA & DESCRIÇÃO & \multicolumn{1}{|c|}{ DIMENSÕES } & $\begin{array}{c}\text { DIMENSÕES } \\
\text { ATÉ }\end{array}$ \\
\hline A & Altura dos Pegadores & 92,5 & - \\
\hline B & Comprimento dos Pegadores & - & 25,0 \\
\hline C & Altura dos Apoios de Braço & 71,0 & 72,5 \\
\hline D & Altura do Assento & 49,0 & 53,0 \\
\hline E & Largura do Assento & 40,0 & 46,0 \\
\hline F & Profundidade do Assento & 42,0 & 45,0 \\
\hline G & Largura Total & 60,0 & 70,0 \\
\hline H & Comprimento Total & 95,0 & 11,5 \\
\hline I & Comprimento do Apoio de Pés & 30,0 & 40,0 \\
\hline J & Altura do Apoio dos Pés & 0,7 & - \\
\hline K & Largura da Roda & 1,5 & - \\
\hline L & Largura da Cadeira Dobrada & 33,0 & - \\
\hline
\end{tabular}

Figura 1. Tabela com as medidas em centímetros $(\mathrm{cm})$ dos componentes de uma cadeira de rodas

Diâmetro do Tubo = $19 \mathrm{~mm}$, aro de $530 \mathrm{~mm}$ a uma distância de 12 a $19 \mathrm{~mm}$ da roda. A Roda possui $610 \mathrm{~mm}$ o aro da roda possui diâmetro externo de $555 \mathrm{~mm}$ e diâmetro interno de 525 mm.

\section{CONCLUSÃO}

A Cadeira de Rodas por Manual é considerada uma das cadeiras de rodas mais usual. Ela pode ser impulsionada pelo próprio usuário ou movimentada pelo cuidador através de manoplas no encosto do equipamento. A cadeira de rodas manual somente se movimenta com a força humana e sua velocidade depende da força aplicada às argolas de propulsão. 0 direcionamento dela é feito pela diferença de velocidade empregada nas rodas traseiras.

Essas cadeiras de rodas se aplicam a situações em que o usuário possui nenhum ou pouco comprometimento dos membros superiores e consegue uma boa independência com o modelo, ou à pessoas que não tem coordenação ou capacidade para dirigir uma cadeira de rodas motorizada e precisam de ajuda de um cuidador para se locomover.

Como já foi dito antes, o projeto tem a finalidade de estudar as cadeiras de rodas, através de suas variáveis a fim de melhorar o desempenho desses sistemas, trazendo melhor conforto, mobilidade, fácil manuseio, resistência e claro melhor acessibilidade para pessoas que sofrem a ausência de sensibilidade nas pernas. Mesmo com problemas enfrentados para a obtenção de melhores matérias e auxílio 
externo, a UEA e todos os envolvidos no projeto P04 se sensibilizam para ajudar esse público que possui uma tremenda importância para a sociedade.

Ainda assim, apesar dos esforços em pesquisas e desenvolvimento, foi possível observar que existem muitas divergências com relação ao assunto e ainda não há um consenso nos métodos de avaliação adotados e treinamentos que poderiam ser prescritos para possíveis ajustes para as cadeiras de rodas manuais. Fatores estes que ajudariam a minimização das disfunções musculoesquelético e para o aumento do bem-estar de seus usuários. No entanto com o avanço científico e um forte avanço nas pesquisas espera-se que no futuro que possam ser instaurados vários protocolos que auxiliariam no melhor posicionamento dessas cadeiras de rodas e um maior empenho no treinamento de propulsão diminuindo assim os índices de lesão, ajudando no melhor direcionamento de políticas sociais de mudanças de infraestrutura na comunidade.

\section{REFERÊNCIAS BIBLIOGRÁFICAS}

Análise da propulsão em cadeira de rodas manual: revisão de literatura, Wheelchairs propulsion analysis: review, [Yoshimasa Sagawa Júnior, Alessandro Haupenthal, Noé Gomes Borges Junior, Daniela Pacheco dos Santos e Eric Watelain, 2012.], SciELO - Scientific Electronic Library Online;

Influência do design de cadeira de rodas manual nos aspectos biomecânicos, perceptivos e de desempenho na mobilidade de usuários e não usuários, [Sara Raquel Martins da Silva e Prof. Dr. Fausto Orsi Medola, 2018], Dissertação de mestrado, Pós-graduação, Design - FAAC;

[CARRIEL, Ivan Ricardo Rodrigues]. Recomendações tecnológicas de projeto para o desenvolvimento de cadeira de rodas de propulsão manual: uma proposta para ampliar o grau de mobilidade dos cadeirantes a partir do design. 2014. Tese (Doutorado em Design e Arquitetura) - Faculdade de Arquitetura e Urbanismo, Universidade de São Paulo, São Paulo, 2014. doi:10.11606/T.16.2014.tde-17102014-095909. Acesso em: 2021-09-15.

[KLEIN, Adriana Nathalie]. Plataforma eletrônica de apoio à prescrição de cadeira de rodas e dispositivos de adequação postural. 2020. Tese (Doutorado em Sistemas Eletrônicos) Escola Politécnica, Universidade de São Paulo, São Paulo, 2020. doi:10.11606/T.3.2020.tde17092020-112047. Acesso em: 2021-09-15.

[MEDOLA, Fausto Orsi]. Projeto conceitual e protótipo de uma cadeira de rodas servo-assistida. 2013. Tese (Doutorado em Bioengenharia) - Bioengenharia, Universidade de São Paulo, São Carlos, 2013. doi:10.11606/T.82.2013.tde-07102013-155234. Acesso em: 2021-09-15.

KOMINO, Caio Sadao Medeiros. Análise eletromiográfica da fase inicial da autopropulsão de cadeira de rodas manual. 2017. Dissertação (Mestrado em Bioengenharia) Bioengenharia, Universidade de São Paulo, São Carlos, 2017. doi:10.11606/D.82.2018.tde20082018-144932. Acesso em: 2021-09-15. 


\section{ANTI WIND-UP. COMPENSAÇÃO DE UM FENÔMENO REAL}

lúna Cardoso Mota'

Paulo Victor Sila'

Ruan Eleutério Rodrigues'

1Escola Superior de Tecnologia (EST) - Universidade do Estado do Amazonas (UEA) CEP 69050-020 - Manaus - AM - Brasil icm.eai20@uea.edu.br, pvsa.eng17@uea.edu.br, rergm.eai20@uea.edu.br

\section{INTRODUÇÃO}

De início é necessário responder a seguinte pergunta: 0 que é Wind-Up e quais suas consequências?. O fenômeno wind-up se caracteriza como à saturação dos atuadores por causa da acumulação de erro na componente integral, com isso a malha de realimentação é de certa forma quebrada, pois o atuador permanecerá no seu limite máximo (ou mínimo) independentemente da saída do processo. Como consequência a resposta transitória do sistema tenderá a ficar lenta e oscilatória, o que é algo completamente indesejável a qualquer processo industrial, já que o atraso ou erro em uma componente do sistema afetará o resultado.

Contudo existem formas de impedir o wind-up utilizando controladores PID, dentro delas, e : a técnica de Back Calculation and Tracking assim como a técnica de Integração Condicional, que serão abordadas no decorrer deste artigo.

\section{OBJETIVOS}

O presente trabalho tem por objetivo estudar o fenômeno Wind-Up, produzido nos reguladores com ação integral, na presencia da saturação dos atuadores, assim como técnicas Anti Wind-Up para sua compensação.

\section{MATERIAIS E MÉTODOS}

\subsection{CONTROLADOR PID}

Controlador proporcional integral derivativo, controlador PID ou simplesmente PID, é uma técnica de controle de processos que une as ações 
derivativa, integral e proporcional, fazendo assim com que o sinal de erro seja minimizado pela ação proporcional, zerado pela ação integral e obtido com uma velocidade antecipativa pela ação derivativa [1].

\subsubsection{AÇÃO PROPORCIONAL}

A ação proporcional produz um sinal de saída que é proporcional à amplitude do erro $e(t)$,

$$
u(t)=K_{p} e(t)
$$

sendo $K p$ a constante de proporcionalidade.

Comparado com a ação liga-desliga, esse método possui a vantagem de eliminar as oscilações do sinal de saída. Para tal, o sistema permanece sempre ligado e o sinal de saída é diferente de zero. Tendo em vista que o sinal de saída é proporcional ao erro, um erro não-nulo (conhecido por erro de off-set) é gerado. 0 valor do erro off-set é inversamente proporcional ao ganho $K p$ e pode ser compensado adicionando-se um termo ao valor de referência ou pelo controle integral. Um ganho proporcional muito alto gera um alto sinal de saída, o que pode desestabilizar o sistema. Porém, se o ganho proporcional é muito baixo, o sistema falha em aplicar a ação necessária para corrigir os distúrbios.

A figura a seguir mostra o comportamento dinâmico da variável controlada para um valor desejado constante (degrau) e um controlador com ação Proporcional $(\mathrm{P})$

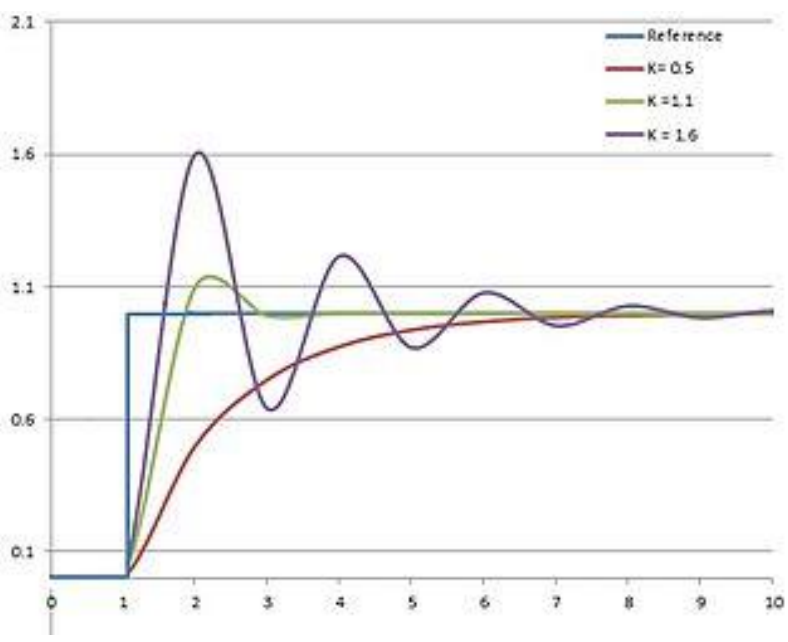

Figura 1. Variável Controlada vs tempo para diferentes valores de $\mathrm{K}_{\mathrm{p}}$. 


\subsubsection{AÇÃO INTEGRAL}

A ação integral produz um sinal de saída que é proporcional à magnitude e à duração do erro, ou seja, ao erro acumulado. Isso fornece uma alternativa para corrigir o erro de off-set gerado pela ação proporcional e acelera a resposta do sistema, permitindo-o chegar ao valor de referência mais rapidamente. 0 sinal de saída do controlador PI pode ser descrito por:

$$
u(t)=K_{p} e(t)+K_{i} \int_{0}^{t} e(t) d(t)
$$

onde $K i$ é o ganho integral.

A ação integral corrige o valor da variável manipulada em intervalos regulares, chamado tempo integral. Esse tempo integral é definido como o inverso do ganho integral. Se o ganho integral é baixo, o sistema pode levar muito tempo para atingir o valor de referência. No entanto, se o ganho integral for muito alto, o sistema pode tornar-se instável.

A figura a seguir mostra o comportamento dinâmico da variável controlada para um valor desejado constante (degrau) e um controlador com ação Proporcional Integral (PI).

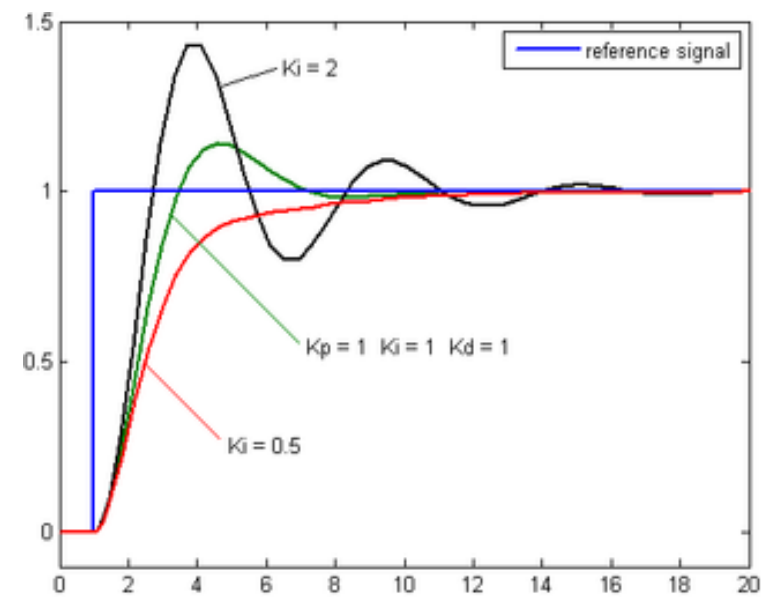

Figura 2. Variável Controlada vs tempo para diferentes valores de $\mathrm{K}_{\mathrm{i}}$.

\subsubsection{AÇÃO DERIVATIVA}

A ação derivativa produz um sinal de saída que é proporcional à velocidade de variação do erro. Visto num regulador PID,

$$
u(t)=K_{p} e(t)+K_{i} \int_{0}^{t} e(t) d(t)+K_{d} \frac{d e}{d t}
$$

onde $K d$ é o ganho derivativo. 
A ação derivativa fornece uma correção antecipada do erro, diminuindo o tempo de resposta e melhorando a estabilidade do sistema. [1][2][3] A ação derivativa atua em intervalos regulares, chamado tempo derivativo. Esse parâmetro é inversamente proporcional à velocidade de variação da variável controlada. Isso indica que a ação derivativa não deve ser utilizada em processos nos quais o sistema deve responder rapidamente a uma perturbação, nem em processos que apresentem muito ruído no sinal de medido, pois levaria o processo à instabilidade.

A figura a seguir mostra o comportamento dinâmico da variável controlada para um valor desejado constante (degrau) e um controlador com ação Proporcional Derivativo (PD).

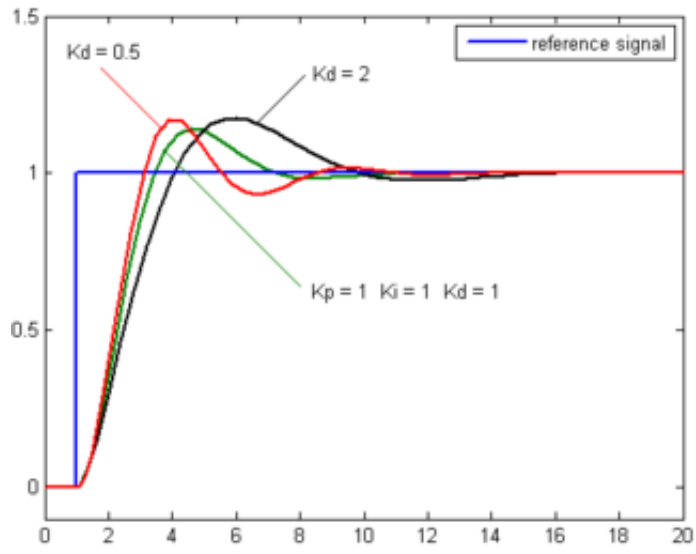

Figura 3. Variável Controlada vs tempo para diferentes valores de $\mathrm{K}_{\mathrm{d}}$.

\subsection{A SATURAÇÃO}

A saturação em uma malha de controle acontece quando o valor de entrada ou saída de qualquer elemento for menor que o limite mínimo ou maior que o limite máximo estabelecido. Isto provoca a abertura da malha de controle, impossibilitando a reação a certas variações da saída ou variável controlada medida $[2]$.

Importante ressaltar que essa não linearidade está presente em praticamente todos os dispositivos de controle reais. A seguir mostrasse uma representação gráfica dessa não linearidade: 


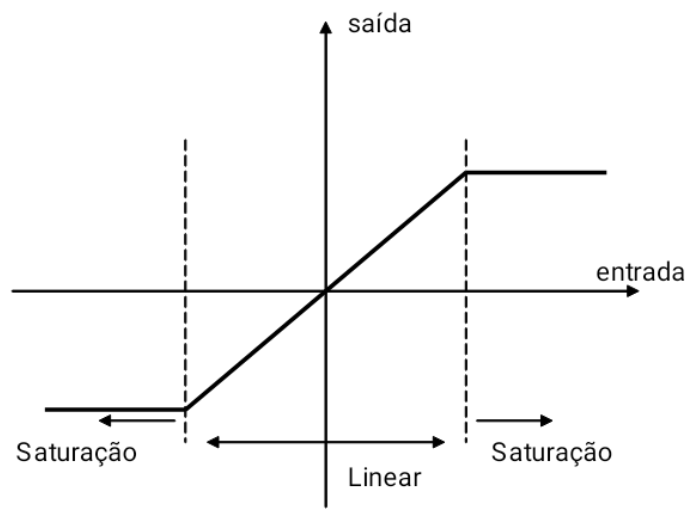

Figura 4. A não linearidade saturação.

Um exemplo frequente em controle é o torque de saída de um servo-motor o qual não pode crescer indefinidamente, independentemente da tensão de alimentação, e tende a saturar devido às propriedades dos materiais magnéticos.

\subsection{O FENÔMENO WIND-UP DA AÇÃO INTEGRAL}

Conforme discutido anteriormente [4], na prática todos os atuadores apresentam limites. Quando o valor da variável de controle atinge o limite máximo (ou mínimo) do atuador ocorre a saturação do sinal de controle. Este fato faz com que a malha de realimentação seja de certa forma quebrada, pois o atuador permanecerá no seu limite máximo (ou mínimo) independentemente da saída do processo. Entretanto, se um controlador com ação integral é utilizado, o erro continuará a ser integrado e o termo integral tende a se tornar muito grande, ou seja, tende a "carregar-se" demasiadamente. Do inglês, diz-se que o termo integral "winds-up" [2]. Neste caso, para que o controlador volte a trabalhar na região linear (saia da saturação) é necessário que o termo integral se "descarregue". Para tanto dever-se-á esperar que o sinal de erro troque de sinal e, por um longo período tempo, aplicar na entrada do controlador, um sinal de erro de sinal oposto. A consequência disto é que a resposta transitória do sistema tenderá a ficar lenta e oscilatória, característica esta extremamente indesejável em um processo industrial.

\section{RESULTADOS}

Existem várias maneiras de se evitar o wind-up da ação integral. A seguir apresentaremos duas técnicas de anti wind-up. A idéia básica dos métodos é impedir que o integrador continue a se carregar quando a saturação ocorre. 


\subsection{BACK-CALCULATION AND TRACKING}

A back-calculation [2][4] funciona da maneira seguinte: quando a saída do atuador satura, o termo integral é re-calculado de forma que seu valor permaneça no valor limite do atuador. É vantajoso fazer esta correção não instantaneamente, mas dinamicamente com uma constante de tempo $\mathrm{Tt}$.

A figura (5) mostra o diagrama em blocos de um controlador PID com anti wind-up do tipo back calculation. 0 sistema apresenta um laço de realimentação adicional. A diferença entre o valor da entrada e da saída do atuador constituem um erro e_s que é realimentado à entrada do integrador com um ganho $1 /$ Tt. Note que quando não há saturação o erro e_s é igual a zero e, portanto, este laço não tem nenhum efeito quando o controlador está operando linearmente, ou seja, quando sua saída não está saturada. Quando ocorre a saturação e_s será diferente de zero e o sinal aplicado na entrada do integrador não mais será eK/Ti, mas

$$
\frac{1}{T_{t}} e_{s}+\frac{K}{T_{i}} e
$$

sendo que, em regime permanente, teremos que:

$$
e_{s}=-\frac{K T_{t}}{T_{i}} e
$$

ou seja, a entrada do integrador será igual a zero prevenindo assim que o mesmo se carregue demasiadamente. 0 tempo para que a entrada do integrador chegue a zero é determinado pelo ganho $1 / \mathrm{Tt}$, onde $\mathrm{Tt}$ pode ser interpretado como a constante de tempo que determina o quão rápido a entrada do integrador será levada a zero. Assim, a escolha de valores bem pequenos para Tt pode parecer vantajosa à primeira vista. Entretanto, deve-se ter cuidado na escolha de $\mathrm{Tt}$ especialmente em sistemas com ação derivativa. 0 que pode acontecer é que ruídos espúrios podem levar a saída do controlador a saturação provocando a atuação muito rápida da malha de anti wind-up e levando a entrada do integrador indesejavelmente a zero.

Na prática deve-se ter Tt maior que Td e menor que Ti. Uma regra empírica sugerida é a escolha de

$$
T_{t}=\sqrt{T_{i} T_{d}}
$$




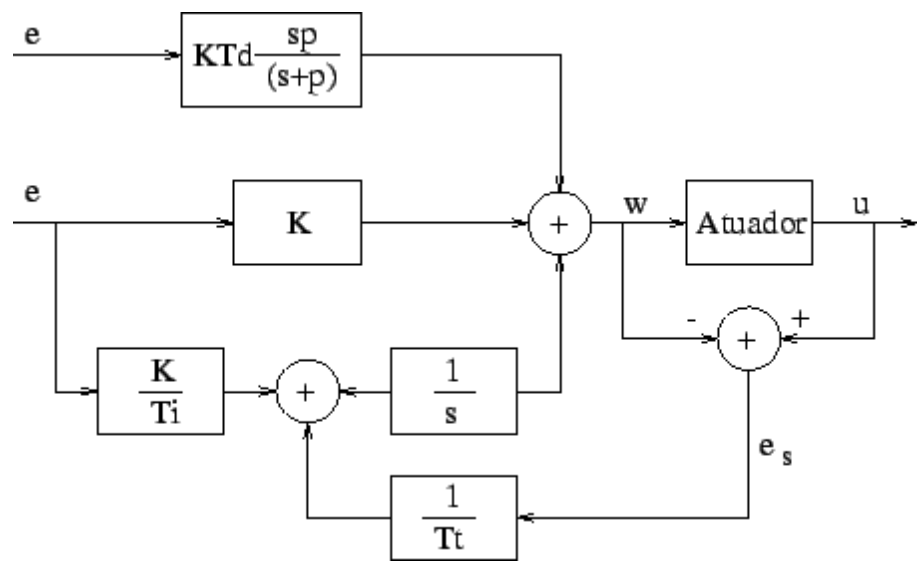

Figura 5. Anti wind-up: back calculation and tracking

$\mathrm{Na}$ figura (6) mostra-se a resposta ao degrau unitário de um sistema controlado por um controlador PI sem e com a compensação de wind-up. Note que o sistema sem o esquema de anti-wind up apresenta um maior sobrepasso e um maior tempo de estabilização.
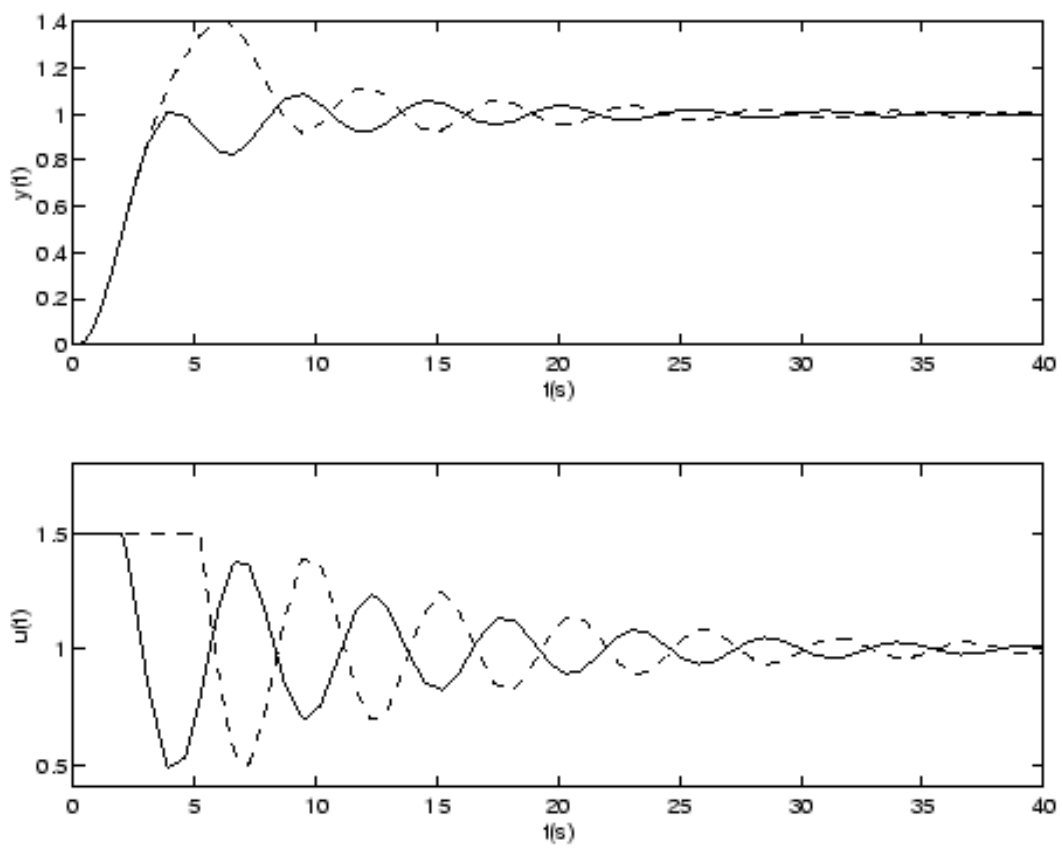

Figura 6. Anti-windup: sem (tracejado); com (linha contínua)

\subsection{INTEGRAÇÃO CONDICIONAL}

Este método de anti wind-up consiste em desligar a ação integral quando o controle está longe do regime permanente. A ação integral é assim ativada apenas quando certas condições pré-estabelecidas são satisfeitas, caso contrário o termo integral é mantido constante, ou seja, a entrada do integrador é mantida em zero. 
As condições para a integração ser inibida podem ser definidas de várias maneiras. Uma forma é desligar o integrador enquanto o sinal de erro $\boldsymbol{e}(\boldsymbol{t})$ for grande. Outra maneira é desligar o integrador somente durante a saturação. A desvantagem destas duas estratégias é que o valor do termo integral poderá ficar bloqueado em um valor muito alto enquanto o integrador permanecer desligado.

Para evitarmos este tipo de problema uma terceira estratégia pode ser implementada. A ideia consiste em desligar o integrador somente quando o controlador está saturado e o erro $\boldsymbol{e}(\boldsymbol{t})$ é tal que provocaria um aumento da carga do integrador fazendo com que o sinal de controle ficasse mais saturado. Assim, por exemplo, se o controlador está saturado no limite máximo a ação seria desligada somente enquanto $\boldsymbol{e}(\boldsymbol{t})$ fosse positivo. Entretanto, quando o sinal de erro se tornasse negativo a ação integral voltaria a ser ligada com o intuito de descarregar o integrador.

\section{CONCLUSÃO}

A partir do estudo realizado conclui-se que:

1. O fenômeno Wind-Up está presente sempre que seja usada a ação integral nos sistemas de controle real, motivado pela saturação dos dispositivos de controle reis.

2. Ao usar a ação integral nos reguladores industriais, devera incluir-se alguma técnica anti wind-up para garantir o bom funcionamento da malha de controle.

\section{REFERÊNCIAS BIBLIOGRÁFICAS}

DORF, R.C.; BISHOP, R. H., (2018) “Sistemas de Controle Modernos”. 13ª edição. Rio de Janeiro: LTC

GOOWIN, GRAEBER\& SALGADO, (2001). “Control Systems Design”. Prentice Hall.

CHEN, C. T, (1999). "Linear system theory and design", 3rd ed. New York. Oxford University Press, 1999.Wind-up da ação integral (ufrgs.br). 


\title{
DESENVOLVIMENTO DE UMA METODOLOGIA DE
} ENSINO DE LINGUAGEM DE PROGRAMAÇÃO APLICADA À AUTOMAÇÃO

\author{
Fabricio Filho' \\ Luan Barata' \\ Nículas Costa'
}

${ }^{1}$ Escola Superior de Tecnologia (EST) - Universidade do Estado do Amazonas (UEA) CEP 69050-020 - Manaus - AM - Brasil fllf.eai20@uea.edu.br, lcbb.eai19@uea.edu.br, nbsc.eai20@ue.edu.br

\section{INTRODUÇÃO}

Um dos principais motivos dos estudantes não se aproximarem na área da programação é a sua linguagem e o quão complexa ela pode ser, pois programar tem a complexidade de uma segunda língua. Contudo, vários métodos foram elaborados no intuito de facilitar essa aproximação e chamar a atenção de entusiastas a dar o seu primeiro passo. E por esses motivos introduzimos a Linguagem de Blocos [Silotto 2021], por meio do Tinkercad, onde cada função pode "encaixar-se" na outra (dependendo do propósito de cada função), construindo um grande bloco ditando todos os seus respectivos comandos, podendo haver diferentes cores diferenciando cada módulo.

\section{OBJETIVOS}

Lidar com o problema de ensino de linguagem de programação aplicada à automação. 0 público-alvo são alunos de ensino médio da rede de ensino estadual, os quais possivelmente não possuem nenhum conhecimento prévio sobre o tema. Dessa forma, propõe-se criar uma metodologia simples e didática para que o aluno possa desenvolver pequenos projetos de automação com Arduino sem a necessidade de um maior aprofundamento no assunto. 


\section{MATERIAIS E MÉTODOS}

Para o desenvolvimento do projeto, foi estudado o funcionamento da linguagem de blocos. A seguir, são apresentados alguns elementos da linguagem de blocos que são disponíveis no site [Autodesk Tinkercad 2021].

\subsection{FUNÇÕES EM BLOCOS}

$\mathrm{Na}$ criação dos experimentos foram utilizadas e explicadas as funções de entrada, saída, de controle e operações lógicas.

\subsection{BLOCOS DE FUNÇÕES DE ENTRADA}

Blocos onde os comandos serão reconhecidos, e quais são os caminhos da placa que serão usados nos seus projetos, além dos instrumentos utilizados. Seu formato é arredondado, Figura 1, encaixando-se dentro de outros blocos que possuem caixas de texto.

\section{ler pino digital $0 \varnothing$}

Figura 1. Bloco de entrada que lê o comando dado por um pino.

Fonte: [Autodesk Tinkercad 2021].

\subsubsection{BLOCOS DE FUNÇÕES DE SAÍDA}

A função de cada instrumento e seus respectivos comandos serão executados nestes blocos. Por estes blocos possuírem um encaixe em formato de "dentes", Figura 2, eles podem ser empilhados em cima de outros, como também podem estar indentados nos Blocos de Controle.

\section{definir pino $0 \triangleright$ como ALTO $\succ$}

Figura 2. Bloco de saída que envia um comando para um pino executar.

Fonte: [Autodesk Tinkercad 2021].

\subsubsection{BLOCOS DE FUNÇÔES DE CONTROLE}

Neste módulo de blocos uma de suas principais características é a de realizar ações padronizadas, sendo estes por condições, repetições ou adicionar períodos entre cada ação. 0 formato de encaixe dentro de suas indentações permitem o encaixe de blocos de entrada e de comentários, veja a Figura 3. 


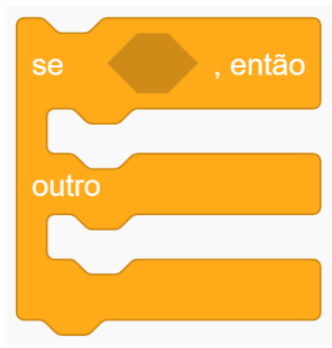

Figura 3. Bloco de controle de condição e exceção para uma ação ou comando.

Fonte: [Autodesk Tinkercad 2021].

\subsubsection{BLOCOS DE OPERADORES LÓGICOS}

Os operadores lógicos, Figura 4, são termos que modificam os resultados esperados dependendo de qual operador venha a ser utilizado. Normalmente são usados em conjunto com os blocos de controle.

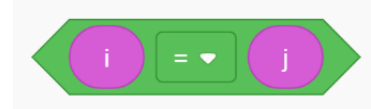

Figura 4. Bloco de operador lógico de igualde.

Fonte: [Autodesk Tinkercad 2021].

\subsection{FERRAMENTAS}

Foram utilizados ferramentas e hardwares, sendo elas ferramentas elétricas simples, como: lâmpada, LED, piezo, resistor, transistor; sensores eletrônicos como: sensor PIR, sensor de distância ultrassônico, sensor de gás Winsen, micro servo, e placas para a recepção dos comandos, sendo elas a placa de ensaio e a placa de Arduino UNO R3, ilustrada na Figura 5.

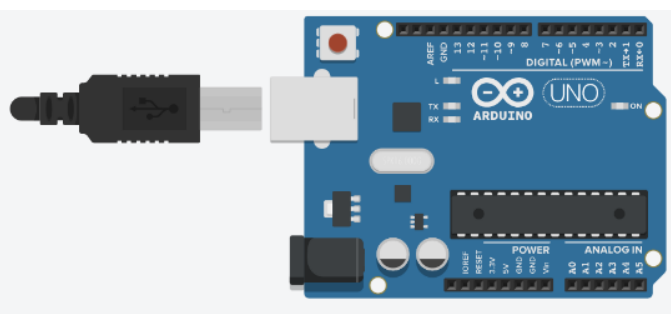

Figura 5. Arduino Uno R3.

Fonte: [Autodesk Tinkercad 2021]. 


\section{RESULTADOS}

Os experimentos realizados em uma placa Arduino usando uma linguagem de blocos facilita a compreensão de como os algoritmos de qualquer código são operados, como acender uma luz de LED, usar sensores de aproximação e emitir sons através de amplificadores. Todos os módulos e experimentos estão descritos no Tinkercad para simular o Arduino.

\subsection{LUZ ACIONADA POR MOVIMENTO}

O experimento permite que uma lâmpada comum seja acionada pela presença de movimento em determinada área, detectada pelo sensor de movimento PIR. 0 circuito eletrônico é mostrado na Figura 6 e o código criado a partir da linguagem de blocos é disponibilizado na Figura 7. (Link para o projeto: https://www.tinkercad.com/things/a5UcHzv1SFC)

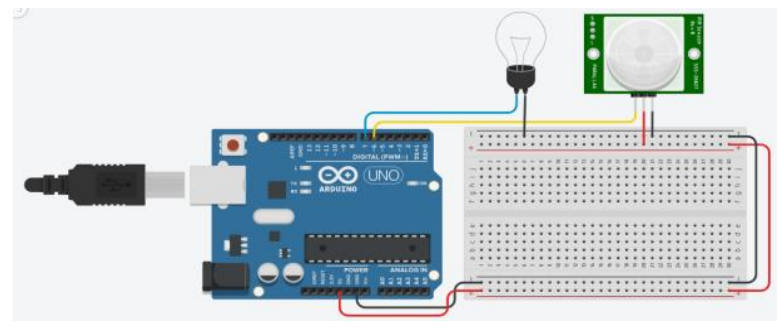

Figura 6. Circuito do experimento da luz acionada por movimento.

Fonte: [Autodesk Tinkercad 2021].

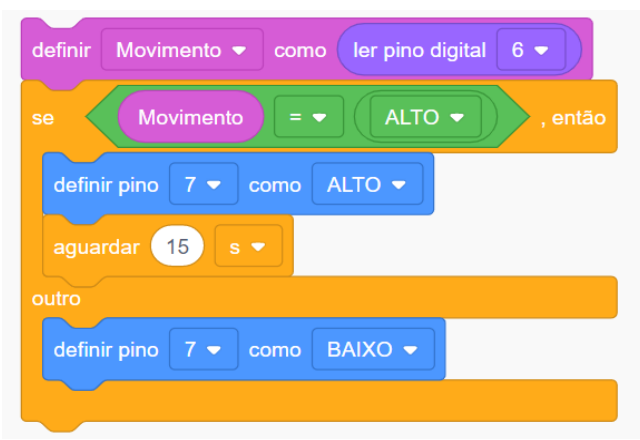

Figura 7. Código em bloco do experimento de luz acionada por movimento.

Fonte: [Autodesk Tinkercad 2021].

\subsection{SENSOR DE ESTACIONAMENTO}

O experimento apresenta uma forma de criar um sensor que avisa a distância entre objetos em um estacionamento, utilizando-se de um sensor de distância ultrassônico, em que caso a distância fique muito perto, um aviso de luz e sonoro é 
acionado. 0 circuito eletrônico é mostrado na Figura 8 e o código criado a partir da linguagem de blocos é disponibilizado na Figura 9. (Link para o projeto: https://www.tinkercad.com/things/6UlgzV4Ml4y)

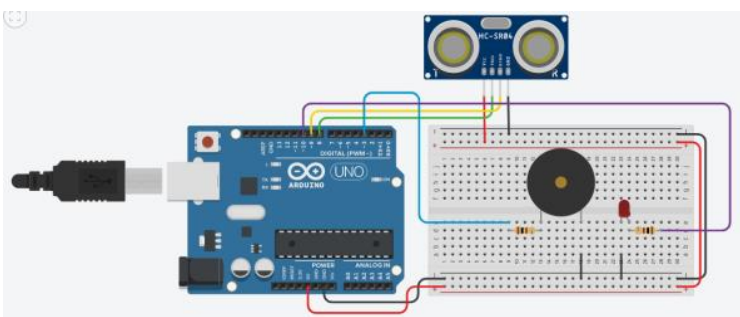

Figura 8. Circuito do experimento Sensor de Estacionamento.

Fonte: [Autodesk Tinkercad 2021].

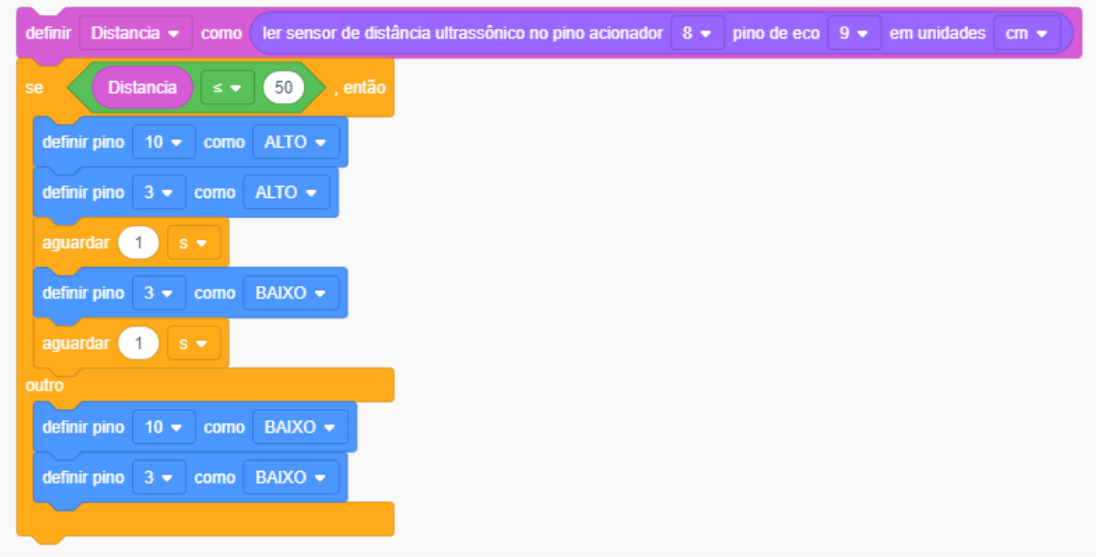

Figura 9. Código em bloco do Experimento Sensor de Estacionamento.

Fonte: [Autodesk Tinkercad 2021].

\subsection{DETECTOR DE INCÊNDIO}

0 experimento do detector de incêndio ensina como fazer um circuito que aciona um aviso de luz e sonoro quando gás é detectado pelo sensor Winsen. 0 circuito eletrônico é mostrado na Figura 10 e o código criado a partir da linguagem de blocos é disponibilizado na Figura 11. (Link para o projeto: https://www.tinkercad.com/things/6gVTxdRGcRD)

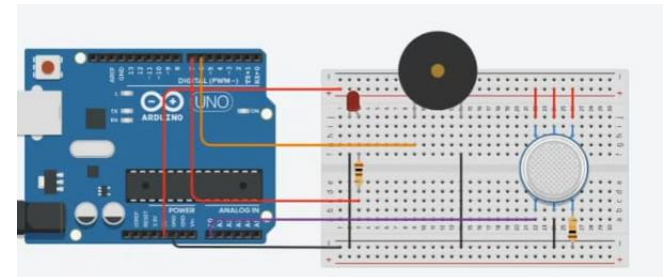

Figura 10. Circuito do experimento Detector de Incêndio.

Fonte: [Autodesk Tinkercad 2021]. 


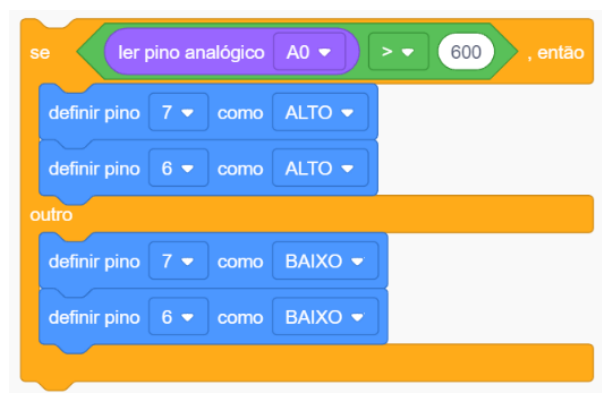

Figura 11. Código em bloco do experimento detector de Incêndio.

Fonte: [Autodesk Tinkercad 2021].

\subsection{LIXEIRA INTELIGENTE}

O experimento da Lixeira Inteligente ensina como fazer um circuito que movimenta o micro servo detectado pelo sensor ultrassônico. 0 circuito eletrônico é mostrado na Figura 12 e o código criado a partir da linguagem de blocos é disponibilizado na Figura 13. (Link para o projeto: https://www.tinkercad.com/things/4TH2gTPqDq6)

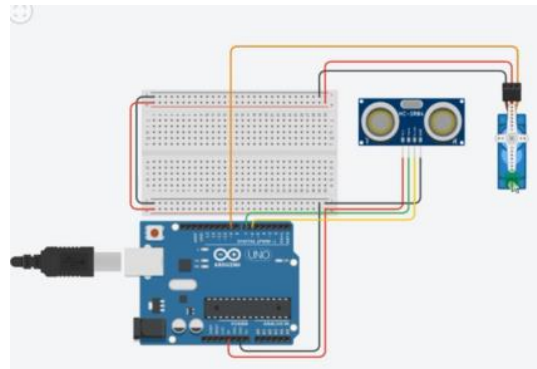

Figura 12. Circuito do experimento Lixeira Inteligente.

Fonte: [Autodesk Tinkercad 2021].

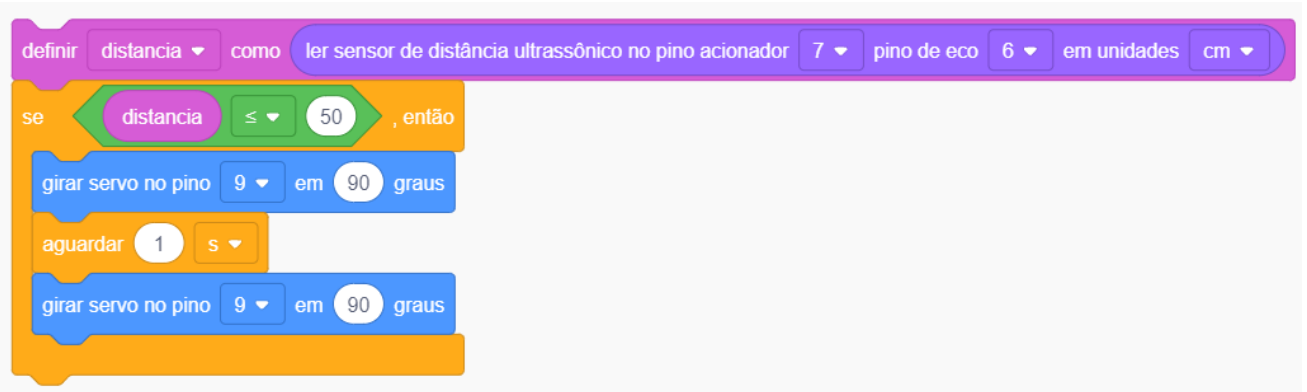

Figura 13. Código em blocos do experimento Lixeira Inteligente.

Fonte: [Autodesk Tinkercad 2021]. 


\section{CONCLUSÃO}

Foi notório que o ensino da linguagem de programação aplicada à automação é simplificado por meio da programação em blocos. Além disso, é perceptível que o resultado do projeto mostrou o quanto a programação em blocos pode influenciar nos interesses dos estudantes pela linguagem de programação, assim facilitando o seu aprendizado aplicado à automação.

A introdução de conceitos básicos em códigos tem o potencial de despertar o interesse de jovens estudantes na hora de escolherem suas carreiras antes de entrar em uma universidade, para que não se arrependam de suas escolhas e se sintam mais seguros de suas decisões.

\section{REFERÊNCIAS BIBLIOGRÁFICAS}

Autodesk Tinkercad (2021), https://www.tinkercad.com. Acesso em março de 2021.

Silotto, R.. Programação baseada em blocos pode ser considerada linguagem de programação? iMasters, 2 de outubro de 2017. Disponível em: $<$ https://imasters.com.br/desenvolvimento/programacao-baseada-emblocos-pode-ser-considerada-linguagem-de-programacao-2>. Acesso em março de 2021. 
